UNIVERSIDADE DE BRASÍLIA

FACULDADE DE TECNOLOGIA

DEPARTAMENTO DE ENGENHARIA CIVIL E AMBIENTAL

ESTIMATIVA DA CAPACIDADE DE CARGA E RECALQUE DE FUNDAÇÕES TIPO ALLUVIAL ANKER NO SOLO DO DISTRITO FEDERAL

FELIPE ALVAREZ ZULUAGA

ORIENTADOR: RENATO PINTO DA CUNHA, Ph. D.

DISSERTAÇÃO DE MESTRADO EM GEOTECNIA

PUBLICAÇÃO: G.DM-249/2015

BRASÍLIA/DF, MARÇO/2015 


\author{
UNIVERSIDADE DE BRASÍLIA \\ FACULDADE DE TECNOLOGIA \\ DEPARTAMENTO DE ENGENHARIA CIVIL E AMBIENTAL
}

\title{
ESTIMATIVA DA CAPACIDADE DE CARGA E RECALQUE DE FUNDAÇÕES TIPO ALLUVIAL ANKER NO SOLO DO DISTRITO FEDERAL
}

FELIPE ALVAREZ ZULUAGA

DISSERTAÇÃO DE MESTRADO SUBMETIDA AO DEPARTAMENTO DE ENGENHARIA CIVIL E AMBIENTAL DA UNIVERSIDADE DE BRASILIA COMO PARTE DOS REQUISITOS NECESSÁRIOS PARA A OBTENÇÃO DO GRAU DE MESTRE EM GEOTECNIA.

APROVADA POR:

PROF. RENATO PINTO DA CUNHA, Ph.D. (UnB)

(ORIENTADOR)

PROF. JUAN FÉLIX RODRÍGUEZ REBOLLEDO, Ph.D. (UnB) (EXAMINADOR INTERNO)

PROF. OSVALDO DE FREITAS NETO, D.Sc. (UFS)

(EXAMINADOR EXTERNO)

DATA: BRASÍLIA/DF, 3 DE MARÇO DE 2015. 


\section{FICHA CATALOGRÁFICA}

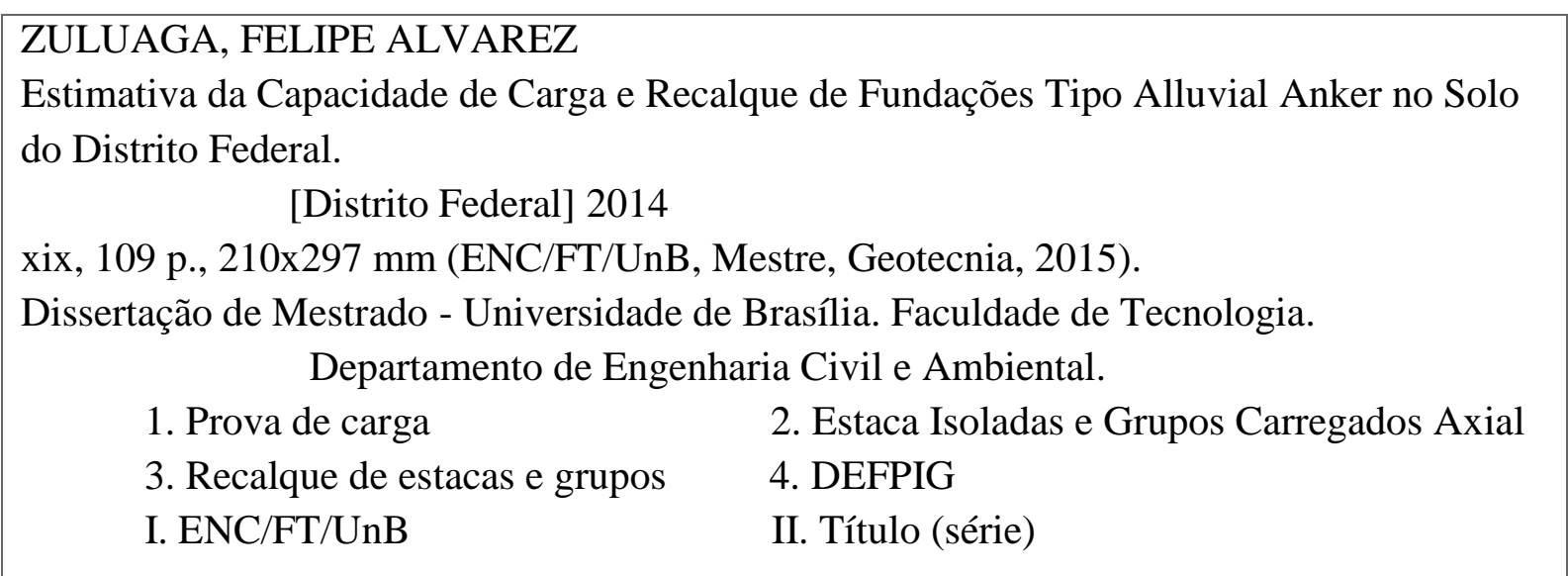

\section{REFERÊNCIA BIBLIOGRÁFICA}

ZULUAGA, F.A. (2015). Estimativa da Capacidade de Carga e Recalque de Fundações Tipo Alluvial Anker no Solo do Distrito Federal. Dissertação de Mestrado, Publicação G-DM249/2015, Departamento de Engenharia Civil e Ambiental, Universidade de Brasília, Brasília, DF, 109 p.

\section{CESSÃO DE DIREITOS}

NOME DO AUTOR: Felipe Alvarez Zuluaga

TITULO DA DISSERTAÇÃO DE MESTRADO: Estimativa da Capacidade de Carga e Recalque de Fundações Tipo Alluvial Anker no Solo do Distrito Federal.

É concedida à Universidade de Brasília a permissão para reproduzir cópias desta dissertação de mestrado e para emprestar ou vender tais cópias somente para propósitos acadêmicos e científicos. O autor reserva outros direitos de publicação e nenhuma parte desta dissertação de mestrado pode ser reproduzida sem a autorização por escrito do autor.

Felipe Alvarez Zuluaga

e-mail: felipealvarezzuluaga@gmail.com 
A mis padres Emma y Jhon Jairo:

Por su amor y apoyo incondicionales en cada decisión que he tomado, gracias por tener el corazón dispuesto para forjar en mi las herramientas necesarias para enfrentar los desafíos día a día.

A mi Hermana Nataly:

Por ser esa hermana, que trae integrada a tu mejor amiga. Es grande mi admiración por ti. 


\section{AGRADECIMENTO}

Agradezco primeramente a Dios por permitirme vivir está oportunidad de alcanzar un escalón más en mi formación integral e ir convirtiéndome cada día en la persona e ingeniero que sueño ser.

Aprendí que hasta en el país del futbol y la samba los goles no entran solos, donde este trabajo nunca habría sido posible sin el apoyo moral y económico de ustedes, mis más sinceros agradecimientos a:

Al Profesor Renato Pinto da Cunha, por su dedicación, esfuerzo, objetividad y estimulo constante para alcanzar los objetivos de este trabajo.

Agradezco a la Universidad de Brasilia y al programa de Post-Graduación en Geotecnia por el acogimiento, convirtiéndose en mi segundo hogar a lo largo de estos dos años.

Agradezco a los profesores que conforman el programa de Post-Graduación en Geotecnia, por sus enseñanzas técnicas, académicas y de vida, en esa difícil tarea de enseñar.

A Max Barbosa y el personal técnico-administrativo de la empresa SOLOTRAT Ltda., por su apoyo económico en la ejecución de las pilas y prueba de carga, parte fundamental en el desarrollo de esta disertación.

A mis niñas Carolina López, Johana Pabón y Elizabeth Agudelo, por convertirse en más que amigas, formando una familia a lo largo de este viaje.

A mis amigos del alma, David Tabares, Anderson Sierra, Alejandra Diez, Nataly Vasco y Julián Restrepo, por su apoyo infaltable y constante motivación.

A Victoria Meza por creer en mí, brindándome todo su apoyo cuando esto era solo un proyecto.

Agradezco a todos mis amigos e colegas que conocí en esta gran experiencia de vida, Alex Wilk, Isadora y Julia Vasconcelos, Francisco Alva, Raydel Lorenzo, Tamara Gregol, Jorge de la Rosa, Karen Fabara, Julián Buritica, Oisy Hernández, Edel Martínez, Ewerton Fonseca, Estefanía Muñoz, Gabriela Duboc, Dasiel Hernandez, Andressa Mesias, Yuri Paz, Erich Wolf Jairo Caicedo, Yina Muñoz, Geovanni Bahía, Jaime Obando, Serguey Figueredo, David Bernal y Mayra Montoya, que sin duda hicieron que este tiempo en Brasil fuera más agradable.

Agradezco muy especialmente a mi familia, mi mamá, mi papá, mi hermana, mis primos, mis tíos, por ser esa energía e inspiración interminable, aun cuando las oportunidades nos llevan a estar separados, donde los sacrificios del presente son el éxito del mañana.

Agradezco a CNPq y CAPES, por todo el apoyo logístico y económico durante estos dos años. 


\section{RESUMO}

A estaca Alluvial Anker é um tipo novo de fundação de pequeno diâmetro caracterizada pela rapidez de execução, com vantagens técnicas e econômicas. Neste trabalho, apresenta-se uma avaliação carga-recalque em estacas deste tipo executadas na Argila Porosa de Brasília, aplicando métodos analíticos e semi-empíricos para o cálculo da capacidade de carga axial e recalque para estaca isolada e em grupo. Para tanto, foi executada uma prova de carga estática em uma estaca isolada sem instrumentação e utilizou-se dos resultados de provas de carga estática em grupos sem contato com solo realizadas por Mendoza (2013) em configurações lineares ( 2 estacas e 3 estacas) e retangulares (4 estacas, 5 estacas e 6 estacas) com diâmetro de $0,20 \mathrm{~m}$ e comprimento igual a $8,0 \mathrm{~m}$ para todas as estacas, incluindo a isolada.

A prova de carga executada na estaca isolada forneceu a curva carga-recalque característica de um comportamento de estaca escavada e foi analisada por diferentes metodologias para-se estimar a carga última definida em $424 \mathrm{kN}$. Além disso, tentou-se separar as contribuições de atrito lateral e de ponta com metodologias como Décourt (2008) e Valencia \& Camapum (2011), tendo sido estimados valores de $92 \%$ para o atrito lateral e $8 \%$ para ponta, em média.

Os parâmetros geotécnicos utilizados foram obtidos a partir de ensaios in-situ (SPT, SPT-T, DMT e triaxiais), realizados no Campo Experimental da SOLOTRAT Engenharia Geotécnica Ltda., detalhado no trabalho de Mendoza (2013).

Os resultados da eficiência experimental foram agrupados de acordo com o tipo de configuração, tendo sido constatada uma eficiência média de 0,87 em configurações lineares, e 0,99 nas configurações retangulares.

Verificou-se uma alta dispersão dos resultados na estimativa da capacidade de carga com os métodos semi-empíricos e observa-se a necessidade de se obter fatores empíricos mais apropriados para estimar a capacidade de carga em estacas escavadas do tipo Alluvial Anker, já que as melhores estimativas foram com fatores equivalente à estaca "Raiz", que levaram a resultados dentro da faixa admissível adotada de $\pm 20 \%$.

A análise de deslocabilidade (recalque) para a estaca isolada e para os grupos foi realizada com metodologias baseadas na teoria da elasticidade e utilizando o software de elementos de contorno DEFPIG “Deformation Analysis of Piles Groups”.

Palavras chaves: Prova de carga, capacidade de carga, recalque, eficiência de grupo, Alluvial Anker, fundações profundas 


\begin{abstract}
The Alluvial Anker pile is a new type of small diameter bored and injected foundation characterized by the speed of execution, which presents technical and economic advantages. In this work, it will be presented a load-settlement review on piles of this type performed at The Porous Clay of Brasília, where it was applied analytical and semi-empirical methods in order to calculate the axial load capacity and the settlement for single pile and piles groups. To do so, it was performed a static load test in a single pile without instrumentation and it was used the results of static load tests in groups without contact with soil made by Mendoza (2013) in a linear configuration ( 2 piles and 3 piles) and rectangular ( 4 piles, 5 piles and 6 piles) with a diameter of $0.20 \mathrm{~m}$ and a length of $8.0 \mathrm{~m}$ for all piles, including the single pile. The load test performed on the single pile provided a load-settlement curve characteristic of an excavated behavior, which was analyzed through different methods to estimate the ultimate load defined as $424 \mathrm{kN}$. In addition, there was an attempt to separate the contributions of shaft resistance and the tip with methodologies such as Décourt (2008) \& Camapum Valencia (2011). Those have an estimated value of $92 \%$ for the shaft resistance and $8 \%$ for the tip, on average. The geotechnical parameters used in the research were obtained from in-situ tests (SPT SPT-T, DMT and triaxial), performed in the Experimental Field of SOLOTRAT Geotechnical
\end{abstract} Engineering Ltda., detailed in the work of Mendoza (2013). The efficiency of the experimental results is grouped according to the type of configuration that has been noted on an average efficiency of 0.87 in linear configurations and 0.99 in rectangular configurations.

There was a high dispersion of the estimated results in terms of the bearing capacity when the semi-empirical methods were used and it is paramount the need of a more appropriate empirical factor to estimate the bearing capacity of Alluvial Anker bored type piles. This occurs because the best estimative were performed by the factors equivalent to a injected type pile, which leads to results within the permissible range adopted of $\pm 20 \%$.

The displaceability analysis (settlement) for the single pile and the groups were performed using methodologies based on the Theory of Elasticity and the boundary elements software DEFPIG (Deformation Analysis of Piles Groups).

Keywords: load test, bearing capacity, settlement, group efficiency, Alluvial Anker, deep foundations 


\section{ÍNDICE}

1. INTRODUÇÃO ........................................................................................................... 1

1.1. MOTIVAÇÃ

1.2. OBJETIVO GERAL ........................................................................................................... 2

1.3. OBJETIVOS ESPECÍFICOS................................................................................ 2

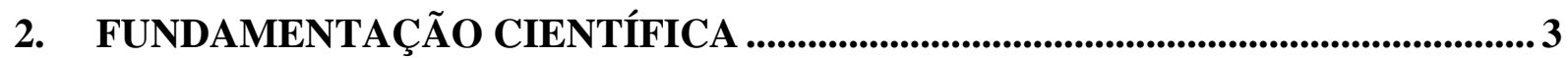

2.1. GEOLOGIA DO DISTRITO FEDERAL _........................................................ 3

2.2. CLIMA DO DISTRITO FEDERAL ............................................................................... 4

2.3. SOLOS LATERÍTICOS COLAPSÍVEIS .......................................................... 4

2.4. ARGILA POROSA DE BRASÍLIA.......................................................................... 4

2.5. ESTACA TIPO ALLUVIAL ANKER ..................................................................5

2.6. CONCEITO DA ESTACA ALLUVIAL ANKER ................................................. 6

2.7. ESTACAS HELICOIDAIS “SCREW PILES” '........................................................... 7

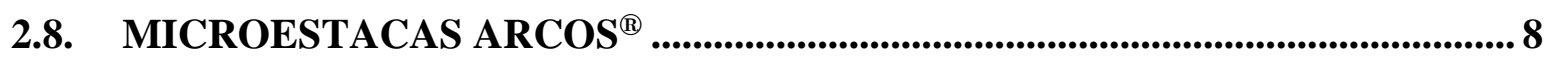

2.9. ESTACAS CARREGADAS AXIALMENTE .......................................................9

2.9.1. MÉTODOS DE ESTIMATIVA DE CARGA COM O SPT................................ 12

2.9.2. MÉTODOS DE ESTIMATIVA DE CARGA COM O SPT-T ............................. 18

2.9.3. MÉTODOS DE ESTIMATIVA DE CARGA COM O DMT..............................2 21

2.9.4. PRESSIÔMETRO DE MÉNARD PMT .............................................................. 23

2.10. ANÁLISE DE DESLOCABILIDADE SOB CARGA AXIAL .............................23

2.10.1. MÉTODO DE POULOS \& DAVIS (1980) .................................................. 24

2.10.2. MÉTODO DE RANDOLPH \& WROTH (1978 e 1979) ................................ 27

2.11. GRUPOS DE ESTACAS CARREGADOS AXIALMENTE................................29

2.12. EFICIÊNCIA DE GRUPO DE ESTACAS ............................................................30

2.13. MODELAGEM DE BLOCOS DE ESTACAS COM O PROGRAMA DEFPIG 32 
3. MATERIAIS E MÉTODOS................................................................................... 33

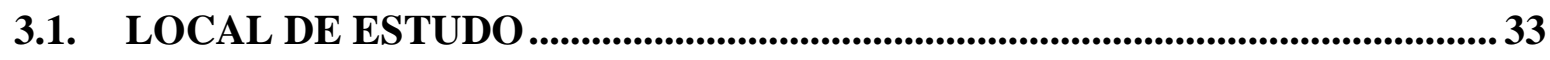

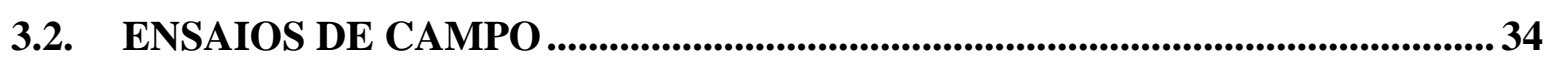

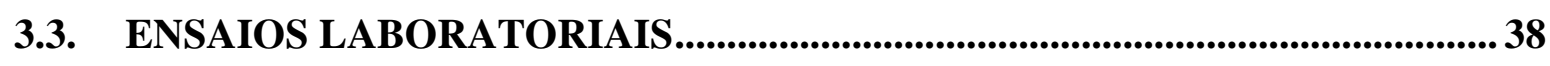

3.3.1. CARACTERIZAÇÃO DO SOLO ESTUDADO ............................................. 38

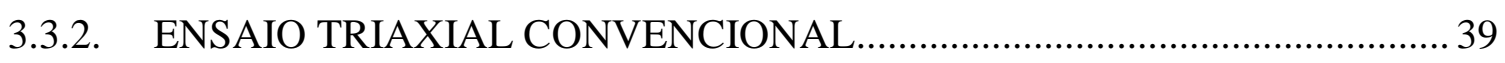

3.4. PARÂMETROS DO SOLO OBTIDOS DE ENSAIOS LABORATORIAIS E DE

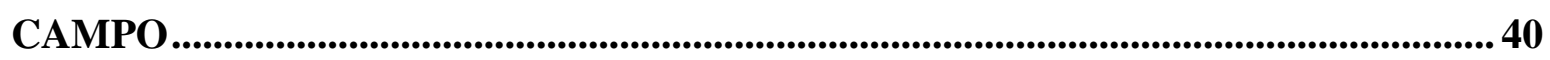

3.5. PROVAS DE CARGA ESTÁTICAS EM GRUPOS ALLUVIAL ANKER ...... 41

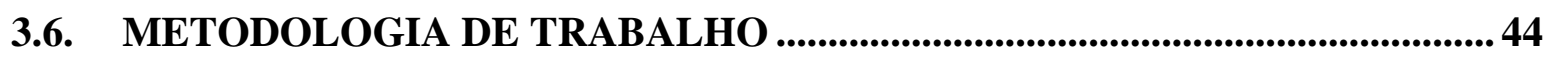

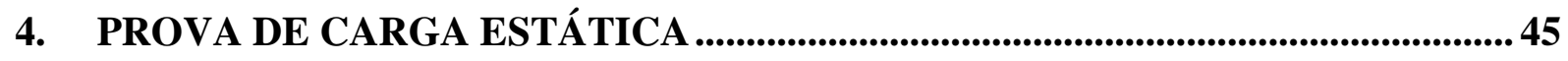

4.1. EXECUÇÃO DE ESTACAS ALLUVIAL ANKER ......................................45

4.2. MONTAGEM DA PROVA DE CARGA ........................................................ 46

4.3. RESULTADO DA PROVA DE CARGA ............................................................ 49

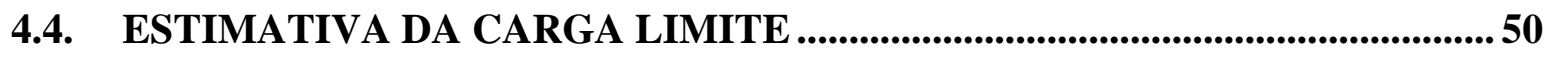

4.5. ANÁLISE DA PROVA DE CARGA ESTÁTICA ................................................. 56

4.6. DETERMINAÇÃO DA PARCELA DE ATRITO LATERAL E PONTA ........ 60

4.7. PROVAS DE CARGA DE GRUPOS DE ESTACAS ALLUVIAL ANKER..... 65

4.8. EFICIÊNCIA DE GRUPOS DE ESTACAS ALLUVIAL ANKER ................... 65

4.9. SUMÁRIO DOS PRINCIPAIS RESULTADOS DA PROVA DE CARGA ...... 68

5. ESTIMATIVA DA CAPACIDADE DE CARGA E RECALQUE DE ESTACAS ALLUVIAL ANKER 69

5.1. ESTIMATIVA DE CARGA AXIAL PARA ESTACA ISOLADA ALLUVIAL ANKER 69

5.1.1. CAPACIDADE DE CARGA COM METODOLOGIAS SEMI-EMPÍRICAS. 69

5.1.2 CAPACIDADE DE CARGA COM MÉTODOS RACIONAIS..... 80

5.2 ESTIMATIVA DE CAPACIDADE DE CARGA DE GRUPOS DE ESTACAS ALLUVIAL ANKER 82 
5.2.1. ESTIMATIVA DA CAPACIDADE DE CARGA COM METODOLOGIAS ANALÍTICAS

5.2.2. ESTIMATIVA DA CAPACIDADE DE CARGA NO MÉTODO EMPÍRICO COM EFICIÊNCIA DE GRUPO

5.3. ANÁLISE DE DESLOCABILIDADE DE ESTACAS ISOLADAS E EM GRUPOS DE ESTACAS TIPO ALLUVIAL ANKER ...................................................... 87

5.4. ANÁLISE DE DESLOCABILIDADE COM DEFPIG .....................................93

5.4.1. DEFINIÇÃO DOS PRINCIPAIS PARÂMETROS ......................................... 93

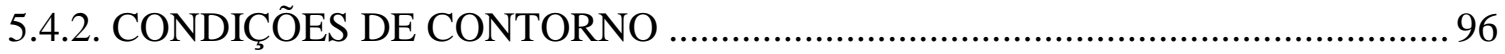

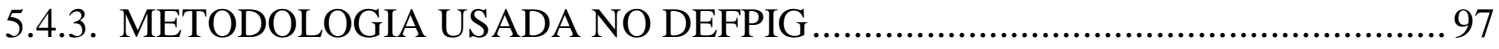

5.5. SUMÁRIO DOS PRINCIPAIS RESULTADOS .................................................. 98

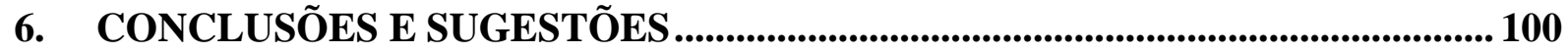

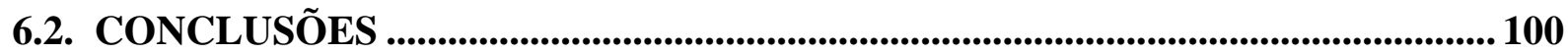

6.3. SUGESTÕES PARA PESQUISAS FUTURAS .................................................... 102

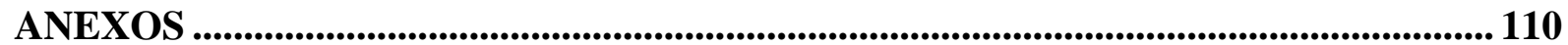

I. DADOS DE ENSAIOS SPT, SPT-T E DMT …....................................................... 111

II. PARÂMETROS PARA METODOGIAS SEMI-EMPÍRICAS DE CAPACIDADE

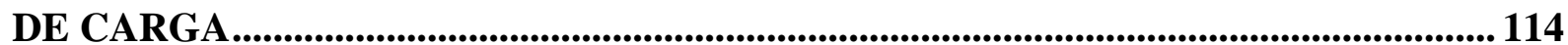




\section{LISTA DE TABELAS}

Tabela 2.1. Fatores de correção F1 e F2 Atualizados Velloso e Lopes (2010)........................ 13

Tabela 2.2. Coeficiente K e razão de atrito $\alpha$ Velloso e Lopes (2010) .................................... 14

Tabela 2.3. Valores de $\alpha$ e $\beta$ (Décourt e Quaresma-estendido) Aoki e Cintra (2010).............. 15

Tabela 2.4. Parâmetro $\alpha_{\text {tex }}$ (Teixeira, 1996 e Aoki e Cintra, 2010) ......................................... 16

Tabela 2.5. Parâmetro $\beta_{\text {tex }}$ (Teixeira, 1996 e Aoki e Cintra, 2010)......................................... 16

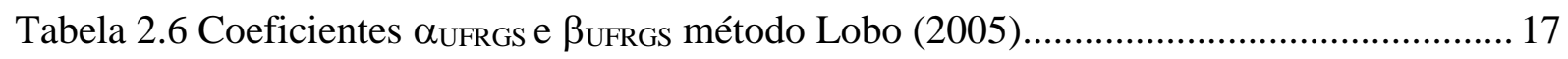

Tabela 2.7. Expressões para prever adesão de diferentes tipos de estacas obtido do SPT-T

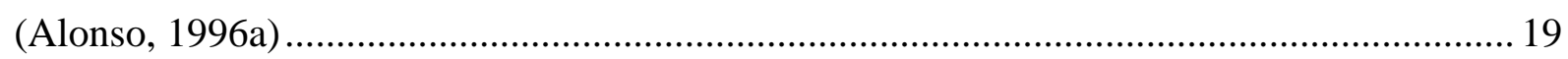

Tabela 2.8. Valores dos coeficientes $S_{\rtimes}$ e $F_{\lambda}$ Peixoto (2001)............................................. 20

Tabela 3.1. Classificação do tipo de solo com o parâmetro Tmax/ $\mathrm{N}_{\mathrm{SPT}}$ (Decourt \& Filho, 1994)

Tabela 3.2. Valores de índice de torque (Tmax/ $\mathrm{N}_{\text {SPT }}$ ) no campo experimental Solotrat .......... 37

Tabela 3.3. Caracterização básica do material (Mendoza, 2013)........................................... 38

Tabela 3.4. Parâmetros obtidos no campo experimental da Solotrat Ldta (Mendoza, 2013) .. 41

Tabela 3.5. Resumo dos resultados das provas de carga verticais (sem suporte de placa) no campo experimental Solotrat (Mendoza, 2013) .................................................................. 44

Tabela 4.1. Estágios de carregamento da prova de carga estática sob a estaca Alluvial Anker 49

Tabela 4.2. Valores de carga limite obtidos da análise curva carga-recalque..........................56

Tabela 4.3. Valores de carga limite em relação ao valor da prova de carga estática ...............56

Tabela 4.4. Carga máxima aplicada $(\mathrm{kN})$ na estaca em cada estágio a assumindo o final do

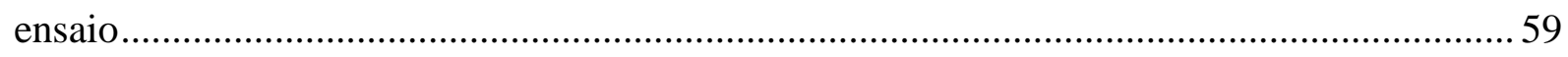

Tabela 4.5. Carga limite $(\mathrm{kN})$ com o avanço da prova de carga estática ...............................59

Tabela 4.6. Variação da carga limite em relação ao estágio anterior ......................................5 59

Tabela 4.7. Erro na carga limite em cada estágio em relação ao valor de carga limite adotado

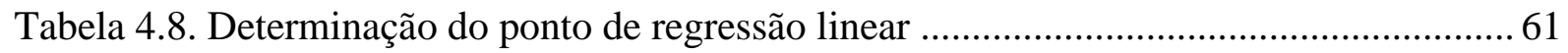

Tabela 4.9 Resultados das diferentes metodologias para o cálculo de eficiência .................... 66

Tabela 5.1 Valores de $\mathrm{N}_{\text {SPT }}$ considerados para cada metodologia......................................... 70

Tabela 5.2 Parâmetros de estaca escavada método Aoki-Velloso (1975)................................ 71 
Tabela 5.3 Parâmetros de estaca escavada método Décourt-Quaresma (1978-1996).............. 71

Tabela 5.4 Parâmetros de estaca escavada método Teixeira (1996) ………............................ 71

Tabela 5.5 Parâmetros de estaca escavada método UFRGS (2005) ........................................ 71

Tabela 5.6 Parâmetros de estaca escavada método Alonso (1996) .......................................... 71

Tabela 5.7 Parâmetros de estaca escavada método Décourt (1998) ......................................... 71

Tabela 5.8 Parâmetros de estaca escavada método Peixoto (2001) ....................................... 71

Tabela 5.9 Resultados Rp, Rl, Rcal dos diferentes métodos semi empíricos ......................... 72

Tabela 5.10 Parâmetros para metodologia analítica................................................................ 81

Tabela 5.11 Parâmetros empregados na metodologia Terzaghi \& Peck (1948) ....................... 84

Tabela 5.12 Capacidade de carga método Terzaghi \& Peck (1948) ......................................... 84

Tabela 5.13 Capacidade de carga método Poulos \& Davis (1980) .......................................... 84

Tabela 5.14 Resultados da capacidade de carga dos grupos com eficiência............................ 86

Tabela 5.15 Carga e recalque de trabalho obtidos de provas de carga estáticas ..................... 87

Tabela 5.16 Relações de acréscimos $\Delta \mathrm{h}$ para definir o parâmetro $(\mathrm{H})$ de espessura total ....... 89

Tabela 5.17 Parâmetros método Poulos \& Davis (1980) ....................................................... 89

Tabela 5.18 Fatores de correção método Poulos \& Davis (1980) ........................................... 90

Tabela 5.19 Resultados dos recalques para cada configuração de estaca Alluvial Anker ....... 90

Tabela 5.20 Parâmetros Método de Randolph \& Wroth (1978) para estaca isolada ............... 91

Tabela 5.21 Parâmetros Método Randolph \& Wroth (1979-1994) para grupos de estacas ..... 91

Tabela 5.22 Resultado de recalque pelo método Randolph \& Wroth ..................................... 92

Tabela 5.23 Módulos de elasticidade empregados nas análise de recalque com DEFPIG ...... 95

Tabela 5.24 Parâmetros inseridos no DEFPIG para o cálculo de recalque.............................. 96

Tabela 5.25 Resultados de recalque obtidos com DEFPIG ................................................. 97

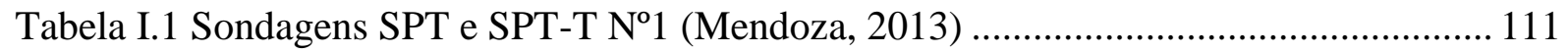

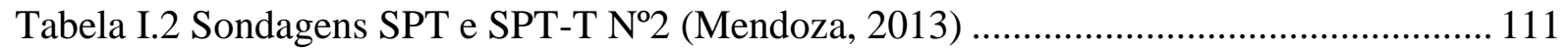

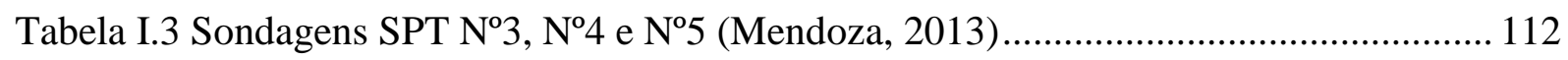

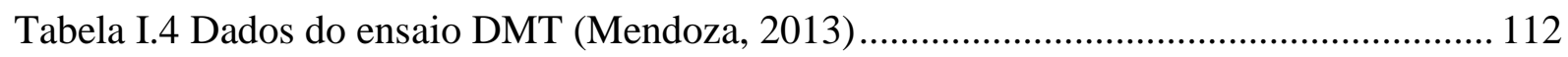

Tabela II.1 Parâmetros Aoki \&Velloso Modificado Laprovitera (1988) ............................... 114

Tabela II.2 Parâmetros Aoki \& Velloso Modificado Alonso (1981) ..................................... 114

Tabela II.3 Parâmetros Aoki \& Velloso (1975) com coeficientes empíricos de estaca escavada

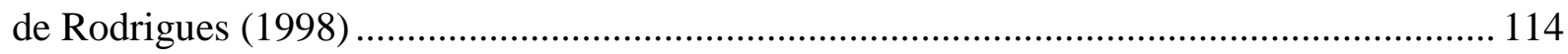

Tabela II.4 Parâmetros Décourt \& Quaresma (1978) com coeficientes empíricos de estaca

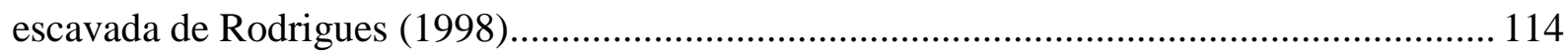


Tabela II.5 Parâmetros Aoki \& Velloso (1975) com fator empírico de estaca raíz ................ 114 Tabela II.6 Parâmetros Aoki \& Velloso (1975) com fator de estaca Raiz e coeficientes para o

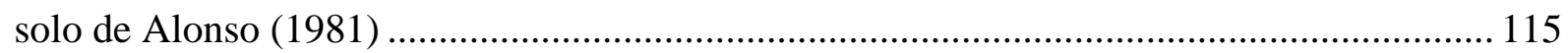

Tabela II.7 Parâmetros Décourt \& Quaresma (1978) com fator empírico de estaca raiz ...... 115

Tabela II.8 Parâmetros Teixeira (1996) com fator empírico de estaca raiz .......................... 115

Tabela II.9 Parâmetros para Décourt (1998) para estaca raiz ............................................... 115

Tabela II.10 Parâmetros Alonso (1996) para estaca raiz ...................................................... 115

Tabela II.11 Parâmetros Peixoto (2001) para estaca raiz ..................................................... 115

Tabela II.12 Parâmetros Camapum (1998) para estaca escavada .......................................... 116

Tabela II.13Parâmetros Peixoto (2001) para estaca injetada .................................................. 116 


\section{LISTA DE FIGURAS}

Figura 2.1. Mapa geológico do Distrito Federal das áreas de referência (Modificado-Freitas-

Silva \& Campos, 1998) 3

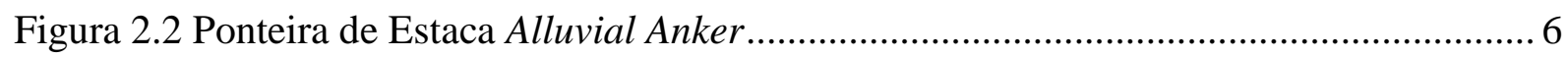

Figura 2.3. Processo executivo da estaca Alluvial Anker Modificado (Barbosa, 2009) ........... 7

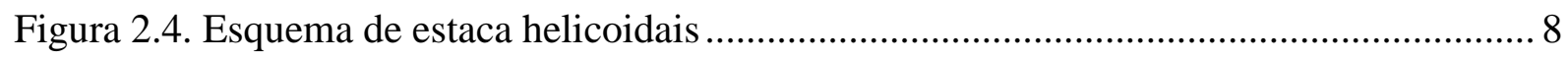

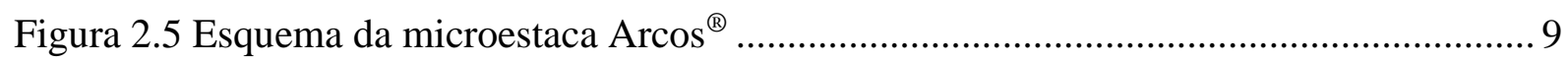

Figura 2.6. Esquema para obtenção dos parâmetros utilizados no cálculo (Magalhães, 2005)24

Figura 2.7. Fatores para o cálculo de recalque de estacas (Poulos \& Davis, 1980)................ 26

Figura 2.8. Variação do módulo cisalhante (Gs) do solo com a profundidade (Z) .................. 28

Figura 2.9. Diferentes distribuições de estacas (Bowles, 1997)............................................ 29

Figura 2.10. Interação de bulbos de tensão entre estacas de fundação (Bowles, 1997)........... 30

Figura 3.1. Locação do campo experimental da SOLOTRAT Modificado (Mendoza, 2013) 33

Figura 3.2. Localização dos grupos de estacas e sondagens no campo experimental (Mendoza,

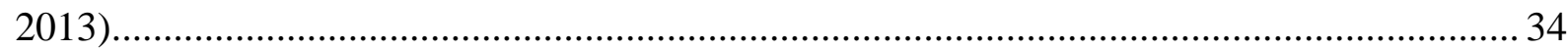

Figura 3.3. Resultados de ensaios SPT e SPT-T (Mendoza, 2013) ….................................... 35

Figura 3.4. Perfil típico de solo do campo experimental (Mendoza, 2013) ............................. 36

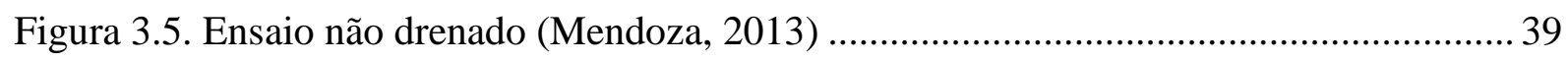

Figura 3.6. Trajetórias drenadas e não drenadas no ensaio triaxial (Mendoza, 2013) ............. 40

Figura 3.7. Localização dos grupos de estacas e dimensões dos blocos no campo experimental (Mendoza, 2013) 42

Figura 3.8. Provas de carga com contribuição da placa (Radier Estaqueado) e sem contribuição da placa (grupo convencional de fundação) Alluvial Anker (Mendoza, 2013) ....................... 43

Figura 3.9. Local da estaca isolada Alluvial Anker AA-01 Modificado (Mendoza, 2013) ..... 47

Figura 3.10 Prova de carga na estaca Alluvial Anker AA-01 .............................................. 48

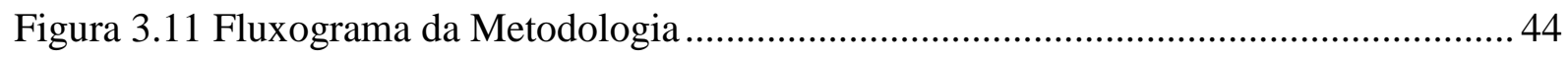

Figura 4.1. Montagem do tubo Schedule na perfuratriz.................................................... 45

Figura 4.2. Estacas de reação para montagem da prova de carga estática ............................... 46

Figura 4.3 Esquema da montagem da prova de carga estática.............................................. 46

Figura 4.4. Montagem da prova de carga estática.................................................................... 47

Figura 4.5. Extensômetros em estaca testada e de reação ...................................................... 47

Figura 4.6. Leituras de extensômetros na prova de carga estaca isolada ................................ 48 
Figura 4.7. Resultado da prova de carga estática (Curva Carga-Recalque) ............................ 50

Figura 4.8. Critérios que aplicam uma regra geométrica ..................................................... 51

Figura 4.9. Curva carga-recalque método conceito de rigidez de Decourt (2006-2008) ......... 52

Figura 4.10. Gráficos obtidos no método de rigidez de Decourt (1996)................................. 52

Figura 4.11. Cálculo da carga limite método de Van der Veen (1953).................................... 53

Figura 4.12. Extrapolação curva carga-recalque para estaca isolada Van der Veen $(1953,1976)$

Figura 4.13. Extrapolação da curva carga-recalque para estaca isolada Chin-Kondner (1971)

Figura 4.14. Obtenção da carga limite (Terzaghi (1943), Davisson (1972), NBR 6122/2010)55

Figura 4.15 Curva carga recalque estaca escavada Alluvial Anker segundo (Hirany e Kulhawy, 1989) .57

Figura 4.16 Cargas limites no gráfico de regiões da curva carga-recalque............................. 58

Figura 4.17 Cargas de Trabalho no gráfico de regiões da curva carga-recalque 58

Figura 4.18. Evolução da curva de extrapolação nas diferentes regiões da curva carga-recalque 60

Figura 4.19 Relação carga-recalque Estaca AA-01 62

Figura 4.20 Identificação das parcelas de ponta e atrito lateral Estaca AA-01 ........................63

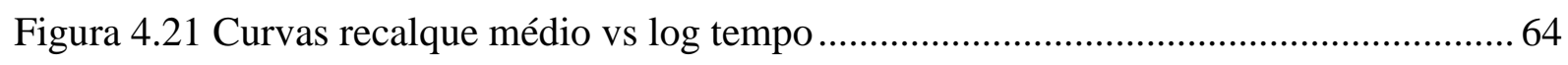

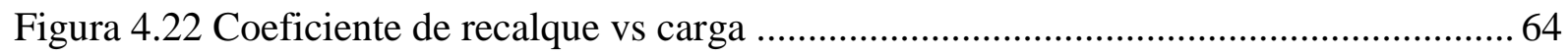

Figura 4.23 Provas de carga estática isolada e em grupos Alluvial Anker ............................. 65

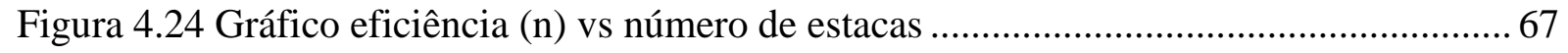

Figura 5.1 Resultado comparativo de capacidade de carga última das metodologias empregadas .75

Figura 5.2 Contribuições de resistência de ponta e atrito lateral para cada metodologia ........ 76

Figura 5.3 Resultado comparativo de capacidade de carga última das metodologias empregadas $(8 \% \mathrm{RP})$ .77

Figura 5.4 Contribuições de resistência de ponta e atrito lateral para cada metodologia ( $\%$ Rp) .78

Figura 5.5 Resultado comparativo de capacidade de carga última das metodologias empregadas $(0 \% \mathrm{Rp})$ .79

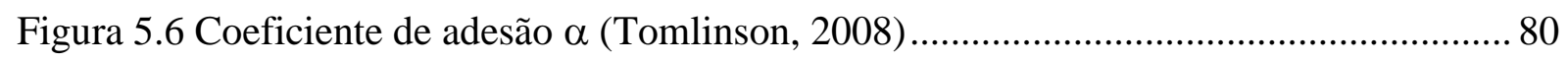

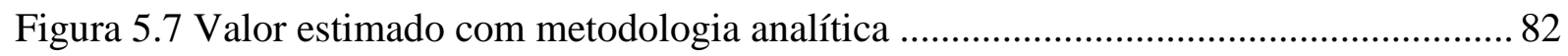

Figura 5.8 Contorno da área efetiva para cálculo de capacidade de carga .............................. 83 
Figura 5.9. Carga calculada vs Carga experimentais para cada configuração de estacas .85

Figura 5.10 Comparação entre o valor calculado e o valor experimental contemplado a eficiência .87

Figura 5.11 Solução de Poulos \& Davis (1980) para o módulo do solo equivalente. .88

Figura 5.12 Resultados de recalque por metodologias baseadas na teoria da elasticidade ...... 92 Figura 5.13 Comparação dos métodos elásticos de recalque para cada configuração de estacas Alluvial Anker 93

Figura 5.14 Parâmetros de entrada para o software DEFPIG .94

Figura 5.15 Condições do bloco adotadas no software DEFPIG .96

Figura 5.16 Interface de entrada de dados software DEFPIG 97

Figura 5.17 Comparação dos resultados de recalques calculados com DEFPIG .98

Figura 5.18 Resultado comparativo da estimativa de recalque. 99 


\section{LISTA DE ABREVIAÇÕES E NOMENCLATURAS}

\section{ABREVIAÇÕES}

AA Alluvial Anker

AAR Alluvial Anker de reação

AAMV Argila arenosa de consistência mole de cor vermelha

ABNT Associação Brasileira de Normas Técnicas

ASMMO Argila siltosa de consistência média e cor marrom escuro

ASTM Associação Americana para ensaios e materiais

A\&V Aoki-Velloso

API American Petroleum Institute

CPT Cone Penetration Test

CD Ensaio triaxial drenado

$\mathrm{CH}$ Argila de alta compressibilidade

CEUnB Campo Experimental da Universidade de Brasília

CESolotrat Campo Experimental da SOLOTRAT

DEFPIG Deformation Analysis of Piles Groups

DF Distrito Federal

D\&Q Décourt-Quaresma

DMT Dilatometer Test

DER Departamento de Estradas de Rodagem

E Estagio de carga

EPTG Estrada Parque Taguatinga

FS Fator de segurança global

Fig Figura

LOG Logaritmo natural

Ltda Limitada

MDF Método das Diferenças Finitas

MEC Método dos Elementos de Contorno

MEF Método dos Elementos Finitos

NBR Norma Brasileira

OCR Over Consolidation Ratio (Taxa de Sobreadensamento)

PCE Prova de Carga Estática

SAAM Silte arenoso, consistência média, aderência ligeiramente de cor marrom

SADB Silte arenoso de consistência dura e cor branca

SARA Silte arenoso de consistência rija e cor amarela

SMAS Setor de Múltiplas Atividades Sul

SPT Standard Penetration Test

SPT-T Standard Penetration Test com Torque

TSBSP Bacia sedimentaria terciaria de São Paulo

UFRGS Universidade Federal de Rio Grande do Sul

USP Universidade de São Paulo

UnB Universidade de Brasília 
UNICAMP Universidade Estadual de Campinas

\section{NOMENCLATURA}

\section{$\underline{\text { Relativas ao solo }}$}

$\mathrm{N}_{\mathrm{c}}, \mathrm{N}_{\mathrm{q}}$ Fatores de capacidade de carga por ponta consideram a contribuição da coesão e o atrito respectivamente

p Tensão de confinamento isotrópico

q Tensão de desvio isotrópico

$\varepsilon_{\mathrm{a}}$ Deformação axial

$\mu_{0}$ Poropressão inicial

$\Delta \mu$ Poropressão

$\mathrm{K}_{\mathrm{s}}$ Coeficiente de empuxo

$\mathrm{K}_{0}$ Coeficiente de empuxo em repouso

$\mathrm{E}_{\mathrm{s}}$ Módulo de elasticidade

$\nu, \mu$ Coeficiente de Poisson

$\sigma_{\mathrm{v}}^{\prime}$ Tensão vertical efetiva

c Coesão drenada

$\varphi$ Ângulo de atrito

$\psi$ Ângulo de dilatância

$\gamma \quad$ Peso específico

$\mathrm{S}_{\mathrm{u}} \quad$ Resistência não drenada

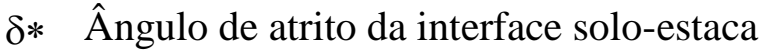

$\Delta_{1}$ Espessura da camada

MEDO Módulo de compressão unidimensional

$\eta$ Eficiência de grupo

\section{$\underline{\text { Relativas às estacas }}$}

$\mathrm{r}_{1}$ Resistência unitária de atrito lateral

$\mathrm{R}_{1}$ Capacidade de carga por atrito lateral

$r_{p}$ Resistência unitária por ponta

$\mathrm{R}_{\mathrm{p}}$ Capacidade de carga por ponta

$\mathrm{R}_{\mathrm{A}-\mathrm{V}}$ Capacidade de carga calculada por Aoki \& Velloso

$\mathrm{R}_{\mathrm{D}-\mathrm{Q}}$ Capacidade de carga calculada por Décourt \& Quaresma

$\mathrm{R}_{\mathrm{TEX}}$ Capacidade de carga calculada por Teixeira

$\mathrm{R}_{\mathrm{u}}, \mathrm{P}_{\mathrm{ult}} \quad$ Resistência última

$P_{\text {trab }}$ Carga de trabalho

$\mathrm{R}_{\mathrm{CAL}}$ Resistência calculada

$\mathrm{R}_{\mathrm{PCE}}$ Resistência limite experimental

CL Carga limite

$\mathrm{N}_{\text {SPT }}$ Número de golpes do ensaio SPT 


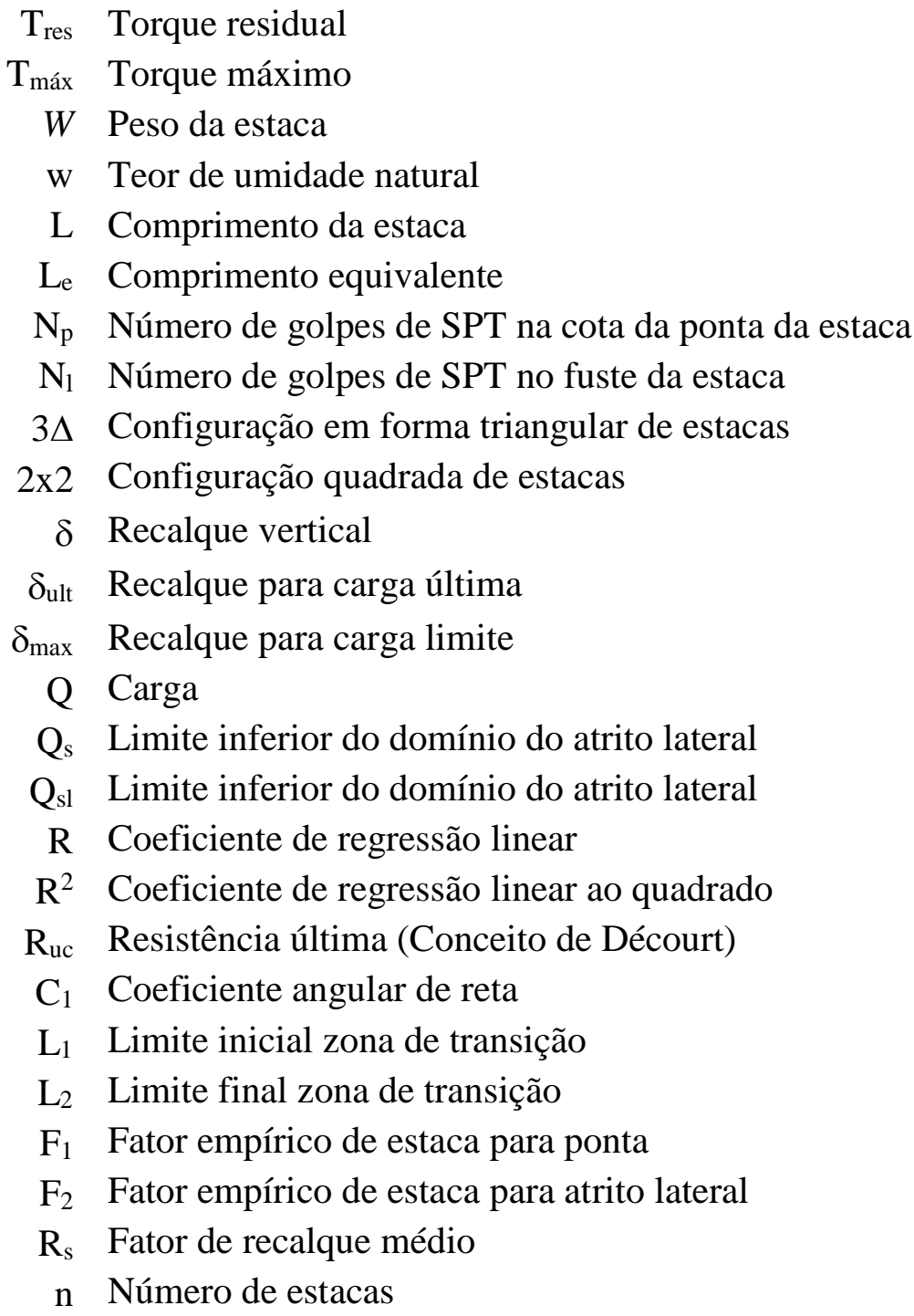




\section{INTRODUÇÃO}

As propriedades do solo de Brasília-DF são resultado do alto grau de intemperismo e lixiviação, e estes solos são chamados de "argila porosa" por engenheiros geotécnicos locais (Guimarães e Camapum de Carvalho, 2003). Estes solos apresentam alto índice de vazios e consequentemente baixos pesos específicos, além de uma estrutura bastante porosa, baixa resistência à penetração (SPT < 4) e são instáveis quando submetidos a variações no estado de tensões, apresentando, em consequência, um comportamento colapsível (Araki, 1997). Por isto a maioria das estruturas geotécnicas construídas em Brasília pode se estender até $30 \mathrm{~m}$ de profundidade, onde o nível d'água em geral se encontra a $5 \mathrm{~m}$ de profundidade, salvo as regiões próximas da borda do lago. (Camapum de Carvalho et al., 1993).

A estaca Alluvial Anker é um tipo novo de fundação utilizada na engenharia geotécnica, sendo uma estaca de pequeno diâmetro moldada in loco e inserida ao solo por perfuração rotativa e injeção simultânea. Estas estacas são ideais para fundações em solos argilosos moles como o solo de Brasília. Esta estaca foi usada com sucesso em uma obra do DER para reforço de base de aterro construído na nova passarela do viaduto da EPTG (estrada parque Taguatinga), em frente à entrada de Águas Claras (Barbosa et al.,2009) mostrando-se como uma solução interessante em solos moles, com vantagens técnicas, econômicas e ambientais em relação às estacas pré-moldadas, tendo como grande diferencial a velocidade de execução e o custo (Barbosa, 2009).

\subsection{MOTIVAÇÃO}

Dadas as condições especiais que caracterizam o solo de Brasília, surge a necessidade de entender o comportamento de fundações profundas. Atualmente os projetos de fundações precisam adequar-se melhor a seu entorno, e para dar solução destas características, são usadas pela comunidade geotécnica em geral fundações que trabalham principalmente pelo atrito lateral (micro-estacas, estacas pré-moldadas, estaca raiz), as quais resolvem os problemas geotécnico como tal, mas levam a um alto custo de execução, alto consumo de cimento, uso de equipamento especial, isto impulsiona pesquisas para se encontrar diferentes tipos de fundações alternativas, as quais tentam novas técnicas que ajudem a uma execução mais rápida, segura, limpa, durável e econômica, que obviamente garante um bom critério de capacidade de carga e minimiza os recalques.

Não há norma específica para a estaca tipo Alluvial Anker, por ser está um novo tipo de fundação, havendo muito por estudar e definir acerca da mesma, como por exemplo o seu 
comportamento em termos de capacidade de carga vertical e horizontal, o estudo do seu reforço, do solo ou a influência do seu processo executivo e geometria.

\subsection{OBJETIVO GERAL}

Avaliar o comportamento mecânico à compressão de estacas Alluvial Anker isoladas e em grupo, por meio da curva carga-recalque, comparando os resultados de métodos analíticos e semi-empíricos de capacidade de carga e de recalque, e considerando sua interação com a Argila Porosa de Brasília.

\subsection{OBJETIVOS ESPECÍFICOS}

- Avaliar o comportamento de estacas Alluvial Anker com análises de provas de carga estática.

- Fornecer informações adicionais para projeto, extraídas das provas de carga como a carga limite; níveis de carga para mobilizar o atrito e ponta e o início de deformações plásticas importantes no contato solo-estaca.

- Comparar resultados dos métodos tradicionais de estimativa da capacidade de carga baseados nos ensaios de campo tipo SPT, SPT-T e DMT com os valores de carga limite obtidos nas provas de carga.

- Analisar os valores de recalque para carga de trabalho comparando com resultados das provas de carga;

- Análise dos resultados de eficiência experimental de grupos de estacas Alluvial Anker. 


\section{FUNDAMENTAÇÃO CIENTÍFICA}

Este capítulo foi dividido em três tópicos principais onde mostra-se a revisão bibliográfica para o desenvolvimento desta pesquisa.

- Geologia Regional

- Carregamento axial de estaca isolada e em grupo

- Recalque de estaca isolada e em grupo

\subsection{GEOLOGIA DO DISTRITO FEDERAL}

A geomorfologia do Planalto Central do Brasil apresenta características específicas em virtude, principalmente, dos condicionantes climáticos, geológicos e antrópicos da região. Segundo (Cardoso, 2002 citado por Campos, 2004) a geologia do Distrito Federal é basicamente composta por rochas dos grupos Paranoá, Canastra, Araxá e Bambuí. A litologia regional é caracterizada pela presença de ardósias, metarritmitos, metassiltitos e quartzitos geralmente muito intemperizados em sua porção superior (Mota, 2003).

No mapa apresentado na Fig. 2.1, mostra a localização dos campos experimentais do programa de Pós-Graduação em Geotécnia da Universidade de Brasília e da Solotrat Ltda., onde predominam as rochas do grupo Paranoá com um grau de metamorfismo menor. Apresentam uma alternância de estratos de quartzitos com granulometria fina a média, metassiltitos argilosos, metarritmitos arenosos, metarritmitos argilosos e ardósias (Mota, 2003).

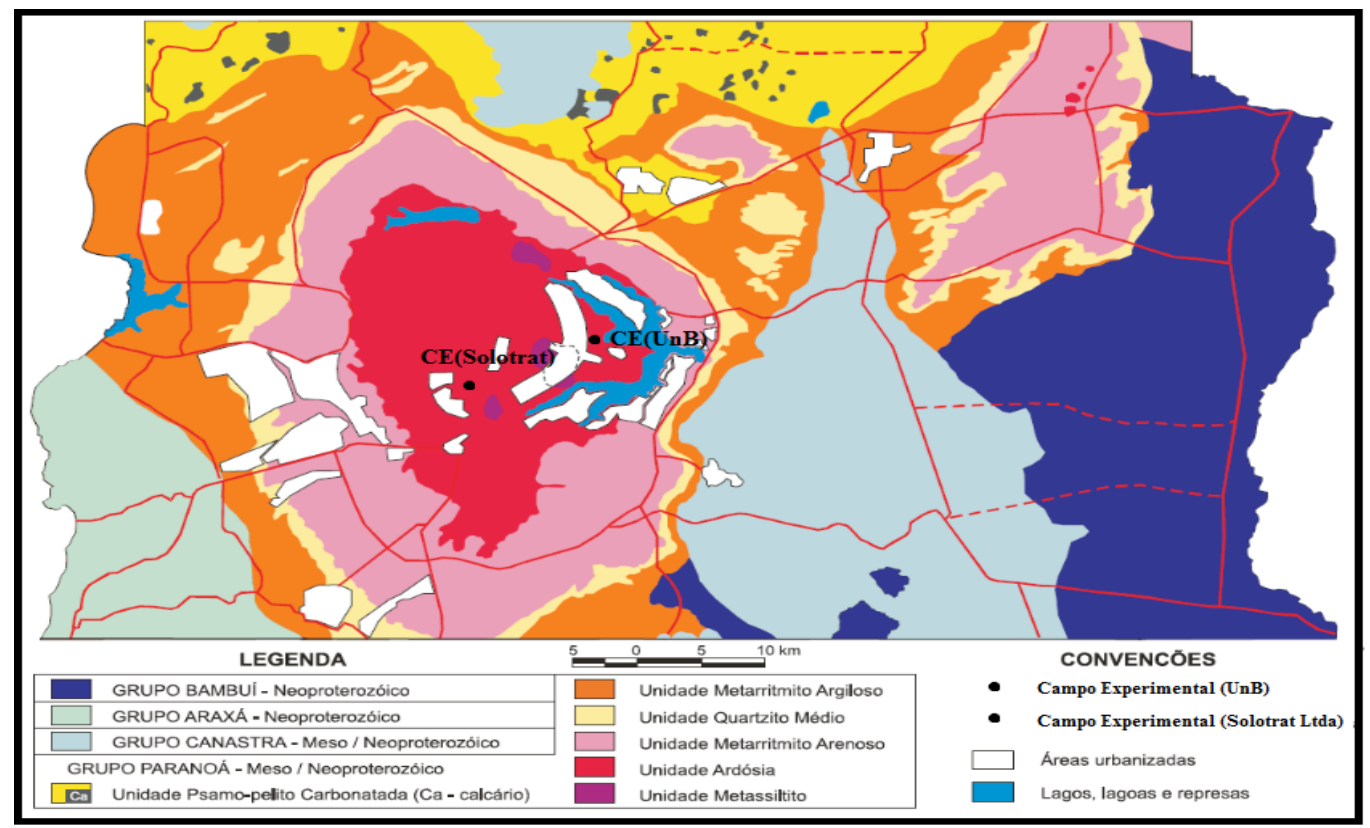

Figura 2.1. Mapa geológico do Distrito Federal das áreas de referência (Modificado-Freitas-Silva \& Campos, 1998) 
Referente a fundamentação científica realizada em trabalhos como (Cardoso, 1995; Araki, 1997; Guimarães, 2002; Mota, 2003), encontrou-se por Mendoza (2013) características geológicas, geotécnicas, pedológico e climatológicas muito similares entre o campo experimental da Universidade de Brasília e o campo experimental da Solotrat Ltda., os quais estão localizados na mesma região e formação geológica.

\subsection{CLIMA DO DISTRITO FEDERAL}

Segundo a classificação de Köppen-Geiger o clima do Distrito Federal é típico do cerrado Brasileiro $(A w / A s)$ tropical de savana e temperado chuvoso de inverno seco, com altas temperaturas durante todo o ano, chuvas concentração da precipitação pluviométrica no período de verão (Outubro-Abril) e estação seca e fria (Maio-Setembro).

Estes aspectos climatológicos do Distrito Federal tornam-se relevantes em virtude da influência que eles têm na contribuição do intemperismo do solo dada a distribuição bastante irregular da precipitação ao longo do ano.

\subsection{SOLOS LATERÍTICOS COLAPSÍVEIS}

Os solos tropicais são o resultado de processos geológicos e/ou pedológicos típicos de regiões de clima quente, com regime de chuvas moderadas a intensas apresentando propriedades e comportamento diferentes daqueles de clima temperado (Vargas, 1985)

O solo laterítico é constituído por argilas com elevadas concentrações de ferro e alumínio, o que atribui a coloração avermelhada ou amarelada ao solo.

A laterização é um processo de migração das partículas submetidas a ação de infiltração e evaporação, dando origem ao horizonte superficial poroso e permanecendo na estrutura do solo apenas os minerais mais estáveis como: quartzo, magnetita, ílmelita e caulinita (Miguel \& Albuquerque, 2006)

Existe na estrutura do solo laterítico a presença de uma agregação intensa de grãos finos no horizonte mais profundo, que confere ao solo a característica porosa e permeável.

\subsection{ARGILA POROSA DE BRASÍLIA}

O solo do Distrito Federal é coberto por um manto de solo resultante de intemperismo, principalmente químico, associado a processos de lixiviação e laterização de idade Terciária/Quaternária (Mendonça et al., 1994 citado por Cardoso, 1995; Araki, 1997; Mascarenha, 2003). A espessura das camadas é bastante variável e depende de vários fatores 
como topografia, cobertura vegetal e rocha de origem. A profundidade média estimada em todo D.F. está na ordem de 15,0 a 30,0 m (Cardoso, 1995) apresenta-se como um material muito mole a mole, com um baixo índice de resistência a penetração em algumas partes com (SPT< 6 golpes) e com níveis do lençol freático em média à $5 \mathrm{~m}$, salvo as áreas perto da borda do lago. (Blanco, 1995; Guimarães, 2002).

Produto das duas estações que predominam na região uma estação fria e seca e outra quente e chuvosas (Anjos, 2006), os processos anteriores geram microagregados unidos uns aos outros através de cimentantes de argila, sustentando uma estrutura bastante porosa (Araki, 1997) segundo estimativas de Coimbra (1987), aproximadamente $12 \%$ da precipitação total infiltra na zona vadosa e alcançam efetivamente a zona saturada do aquífero, devido a este que é um dos fatores que influenciam a formação da estrutura porosa na argila, a qual apresenta normalmente agregações em grãos (argila floculada) de textura arenosa e com permeabilidade de solos granulares finos (a aumento $10^{-3}$ a 10 $0^{-4} \mathrm{~cm} / \mathrm{s}$ ) (Blanco, 1995; Araki, 1997; Guimarães, 2002; Mascarenha, 2003). Isto dá lugar a estrutura metaestável quando apresenta mudanças na energia, que pode ser interna (reações químicas) ou externas (umidade e/ou a alteração do estado de tensões), gerando variação de volume, denominado colapso.

A característica laterítica do solo deve ser considerada nos métodos semi-empíricos, já que apresentam comportamento mecânico diferente de um solo não-laterítico de mesma granulometria (Schulze, 2013). Segundo Nogami \& Villibor (1995) os argilo-minerais cimentantes presentes no solo laterítico proporcionam maiores resistências e rigidez quando comparado ao solo não-laterítico.

O programa de pós-graduação em Geotecnia da Universidade de Brasília tem contribuído com trabalhos na área de engenharia de fundações sobretudo escavadas interagindo com solos tropicais colapsíveis como é o solo de Brasília em frentes tanto numéricos como experimentais citam-se Guimarães (2002); Mota (2003); Magalhães (2005); Anjos (2006); Hortegal (2011); Mendoza (2013).

\subsection{ESTACA TIPO ALLUVIAL ANKER}

A aplicação deste recente tipo de estacas Alluvial Anker (nome comercial). Na realidade trata-se de uma estaca escavada com simultâneo processo de injeção da calda de cimento de formação do fuste, encontra-se na fronteira entre estacas clássicas escavadas e injetadas. É usada para solucionar problemas de fundação gerados antes, durante e após o termino de uma construção civil. 


\subsection{CONCEITO DA ESTACA ALLUVIAL ANKER}

Trate-se de uma estaca de pequeno diâmetro que trabalha principalmente por atrito lateral, moldada no local e armada com tubo de aço sem costura, com comprimento de cerca de 10 metros e com diâmetro de $2^{1 / 2}$, os tubos são adaptados com uma ponta perfurante na parte inferior da haste e são introduzidos ao solo, através de altíssima rotação até o comprimento definido, com ajuda de uma perfuratriz de cabeçote especial Fig. 2.2, isto gera alta produtividade pois a haste de perfuração é a própria armação da estaca. Assim a estaca é feita à medida que a perfuração está sendo executada.

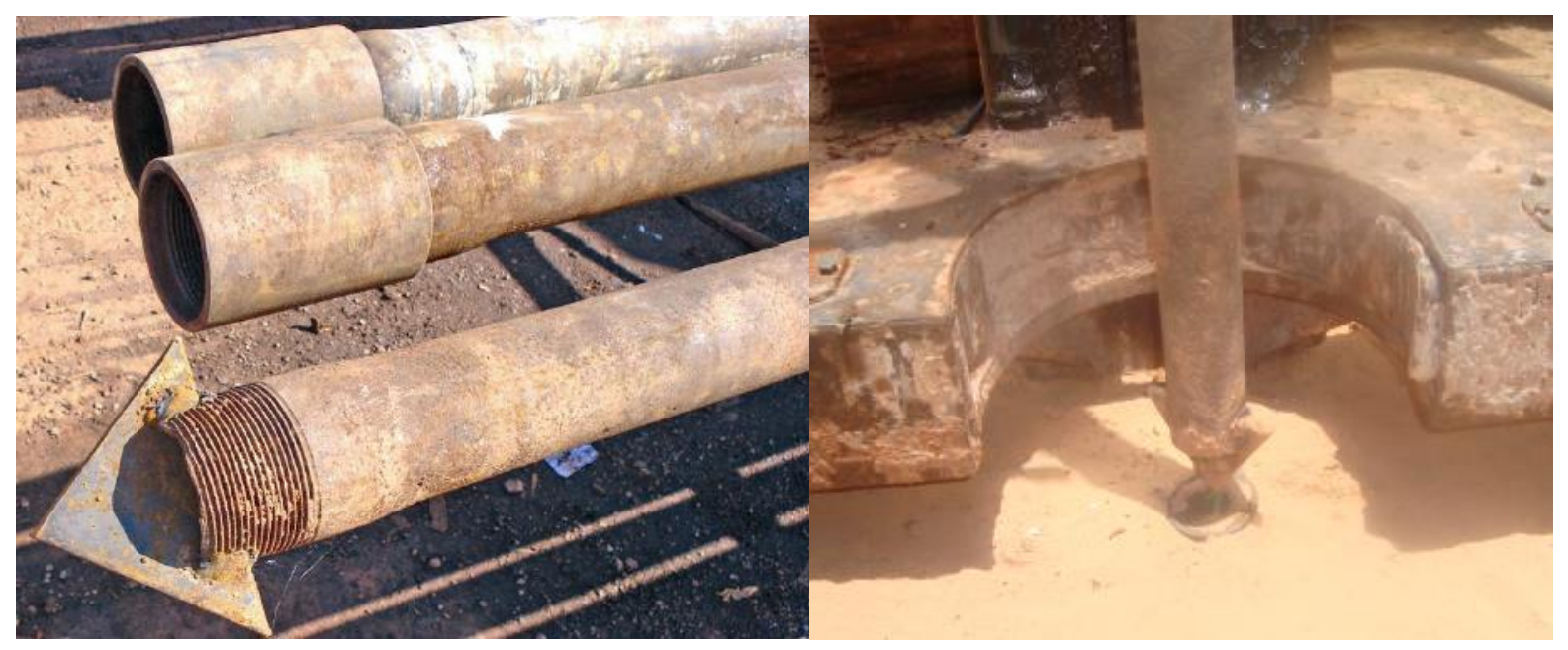

Figura 2.2 Ponteira de Estaca Alluvial Anker

Durante a instalação (perfuração) é feita a injeção do fluido cimentante, que funciona como elemento de refrigeração da haste, além disso com pressão suficiente que permita a mistura com o solo perfurado a grande profundidade. Para garantir a formação de um bulbo de maior diâmetro, nos últimos três metros a injeção da calda de cimento deve ser mais demorada. A quantidade estimada de cimento absorvido é de $100 \mathrm{~kg}$ por metro linear de estaca, depois de executada as estacas, é instalado um bloco de coroamento de concreto armado pré-moldado ou uma placa de aço para melhorar a transferência das cargas para estaca. Para um melhor entendimento do processo construtivo veja a Fig. 2.3. 

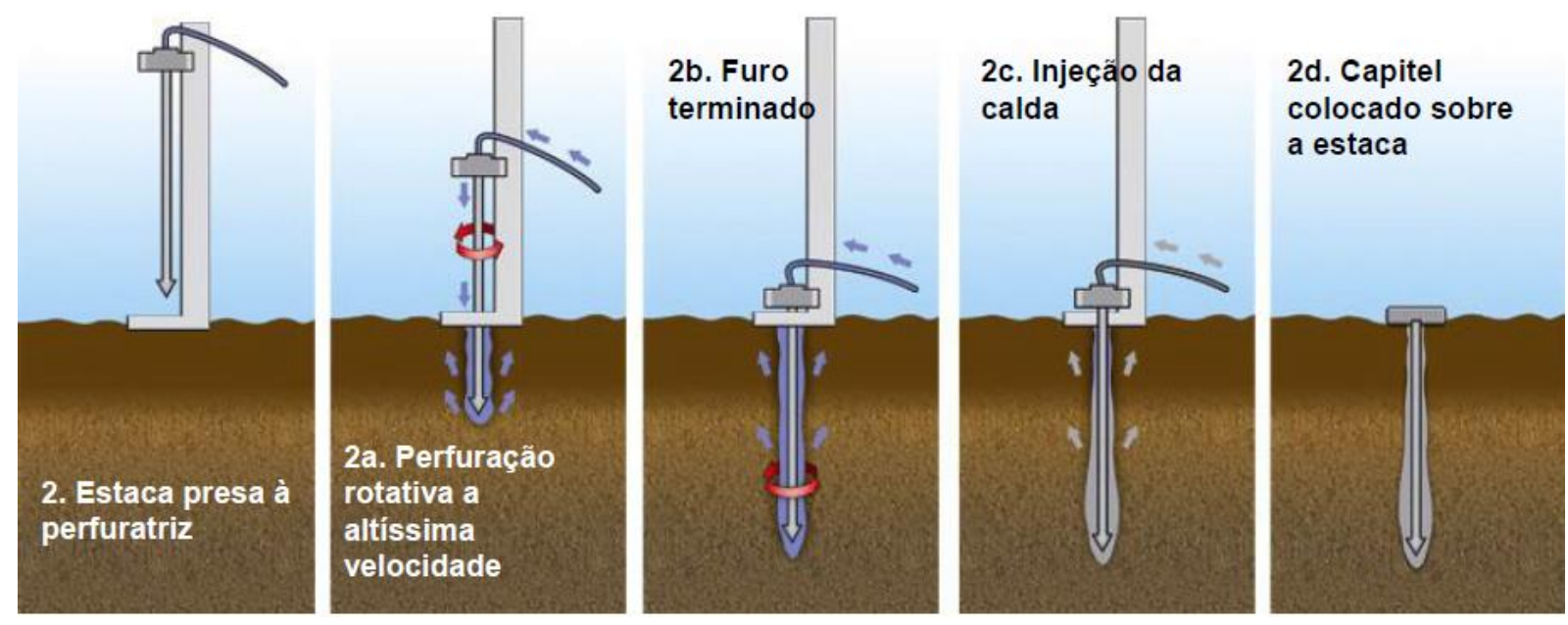

Figura 2.3. Processo executivo da estaca Alluvial Anker Modificado (Barbosa, 2009)

A estaca Alluvial Anker foi utilizada com sucesso como fundação do aterro de acesso ao viaduto situado na interseção da DF-079 com a DF-085 (Aguas Claras, DF) propriedade do DER/DF (Departamento de Estradas de Rodagem do Distrito Federal) onde se apresentou como a melhor técnica a ser utilizada, em análises preliminares, que tinham como objetivo definir a melhor técnica a ser utilizada, aliada ao menor preço de execução, entre quatro soluções possíveis: por pré-carregamento; por troca de solo de fundação; por estaqueamento; e pela utilização de drenos verticais e geossintéticos.

Estas análises preliminares foram realizadas pelo Laboratório de Geotecnia do Departamento de Engenharia Civil e Ambiental da Universidade de Brasília e pela Fundação de Empreendimentos Científicos e Tecnológicos (Finatec).

\subsection{ESTACAS HELICOIDAIS "SCREW PILES"}

Este tipo de fundação profunda foi desenvolvido pelo engenheiro civil Tomas Mitchell in 1833. O primeiro uso registrado de estacas helicoidais foram utilizadas para amarrar barcos no portos em 1836, além disso, são utilizadas como fundações para faróis, pontes, ancoragem de dutos, torres autoportantes, reforço e aerogeradores.

As estacas helicoidais são instaladas de forma rápida no solo como um parafuso na madeira, as estacas são feitas de perfis de aço ocos circulares com diâmetros que vão desde 15 $\mathrm{cm}$ até $61 \mathrm{~cm}$ com uma o mais hélices unidas ao perfil tubular com diâmetros entre 7,3 cm a 14,5 cm (Fig. 2.4), uma vez a estaca atinge a profundidade desejada ela pode ser com ou sem concretagem dependendo do uso.

O torque de instalação está na ordem de 6 kN.m a 100 kN.m, entre suas vantagens estão a facilidade de instalação, com ou sem concretagem, carregamento imediato, mínima 
perturbação (vidração, barulho e limpeza), utilizadas em tração e compressão e é possível seu reaproveitamento em obras temporárias.

Sua limitante apresenta-se durante a instalação, o torque aplicado na estaca não pode comprometer a integridade estrutural da mesma, impossibilitando sua utilização em solos muito resistentes.
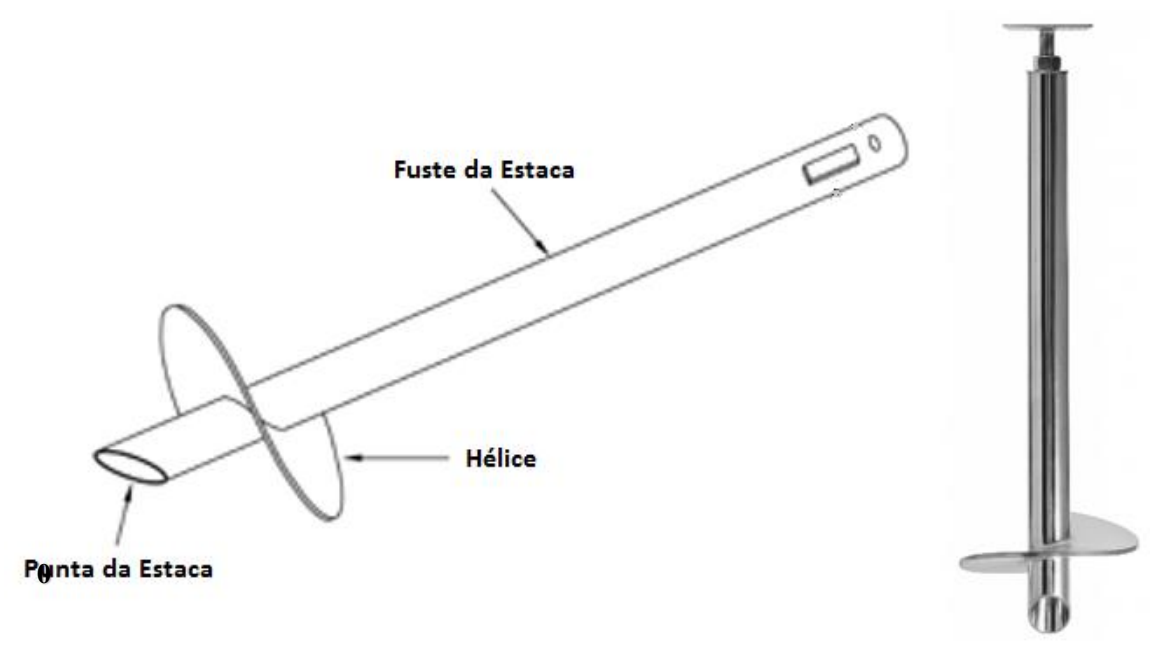

Figura 2.4. Esquema de estaca helicoidais

A perfuração é feita usualmente em solos moles. Estas estacas trabalham principalmente por fuste e se utilizam correlações empíricas de resistência a partir dos dados do ensaio CPT, PMT, DMT e metodologias analíticas com parâmetros de solo como $\left(S_{u}, \alpha, \phi, \gamma\right)$.

\subsection{MICROESTACAS ARCOS ${ }^{\circledR}$}

Desenvolvida na década de 80, pelo engenheiro civil Pedro Elísio da Silva, a partir das dificuldades encontradas na execução de reforços de fundação num prédio na cidade de Belo Horizonte.

A microestaca $\operatorname{Arcos}^{\circledR}$ é um tipo de fundação moldada in loco caracterizada pela cravação à percussão de tubos especiais de aço de $2 \frac{1}{2}$ ”" ou 3 ” (Schedulle 40), com o auxílio de um micro bate-estacas elétrico e posterior injeção de calda de cimento sob pressão mostrado na Fig. 2.5.

Após da cravação dos tubos inicia o processo interno que o preenche com calda de cimento com fator água-cimento entre 0,6 e 0,8, de baixo para cima, ao mesmo tempo que realiza o recobrimento externo da mesma, visando criar uma aderência solo-estaca e ao mesmo tempo proteger o elemento de fundação contra corrosões. O diâmetro final varia entre 12 a $15 \mathrm{~cm}$. 
A microestaca $\operatorname{Arcos}{ }^{\circledR}$ possui uma capacidade de carga de até $350 \mathrm{kN}$ para um diâmetro acabado de $15 \mathrm{~cm}$.

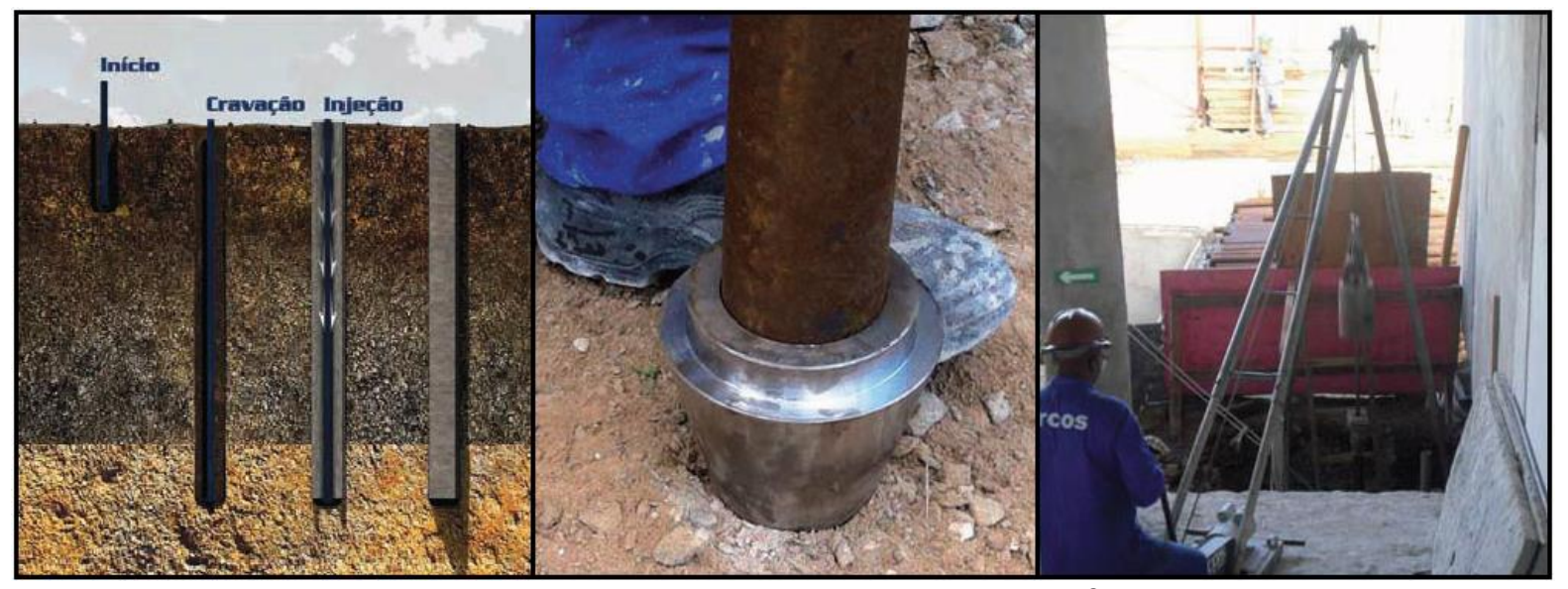

Figura 2.5 Esquema da microestaca $\operatorname{Arcos}^{\circledR}$

\subsection{ESTACAS CARREGADAS AXIALMENTE}

As estacas são utilizadas para realizar uma transferência adequada e progressiva da carga estrutural ao solo. A capacidade última de carga $\left(R_{u}\right)$ de uma estaca sob carregamento vertical está determinada como a soma da capacidade de carga por ponta $\left(R_{p}\right)$ e a resistência por atrito lateral ou longo do fuste da estaca $\left(R_{l}\right)$ gerado na interface solo-estaca como é mostrado na Eq. 2.1 (Poulos \& Davis, 1980; Fleming, 1992).

$$
R_{u}=R_{p}+R_{l}-W
$$

Usualmente o termo $(W)$ que é o peso da estaca é menor em relação ao $\left(R_{p}\right)$ na literatura e em geral este termo é ignorado, entretanto, é necessário prever $(W)$ em situações onde as estacas faz parte de estruturas marinhas em águas profundas em que o comprimento estende-se acima do nível do mar (Tomlinson \& Woodward, 2008).

A resistência por atrito lateral $\left(R_{l}\right)$ pode ser definida como a integral da resistência ao cisalhamento de Mohr-Coulomb do sistema solo-estaca $\left(q_{s}\right)$ na área do fuste da estaca Eq. 2.2.

$$
R_{l}=\int_{0}^{l} C f_{s} d z \quad \rightarrow \quad q_{s}=c_{a}+k_{s} \sigma_{v} \tan \delta
$$

Onde:

$c_{a}$ : fator de aderência;

$k_{s} \sigma_{v}=\sigma_{n}$ : tensão normal entre o solo e estaca;

$\tan \delta$ : ângulo de atrito entre o solo e estaca; 
Segundo Poulos \& Davis (1980), a tensão normal entre a estaca e o solo, é função do coeficiente de empuxo de terra $\left(K_{s}\right)$ e da tensão vertical do solo $\left(\sigma_{v}\right)$.

A resistência lateral (em termos de tensões) aumenta linearmente com a profundidade e a profundidade crítica para a qual a tensão vertical efetiva permanece constante, normalmente é entre 10-20 vezes o diâmetro da estaca, medida por Poulos \& Davis, 1980 e Braja, 2001.

A resistência por ponta $\left(R_{p}\right)$ pode ser obtida pelas equações clássicas para o cálculo de capacidade de carga (Eq. 2.3), como Terzaghi (1943) Skemton (1951), Hansen (1961), Vesic (1973), Meyerhof (1976), Jambu (1976), Bowles (1997), Braja (2001) e Randolph (2003).

$$
R_{p}=A_{b} q_{b} \quad \rightarrow \quad q_{b}=c N_{c}+\sigma_{v b} N_{q}+0.5 \gamma D N_{\gamma}
$$

Onde

$A_{b}:$ Área na ponta da estaca.

c: Coesão do solo.

$\sigma_{v b}:$ Tensão vertical na ponta da estaca.

$\gamma$ : Peso unitário do solo.

$N_{c}, N_{q}, N_{\gamma}:$ Fatores de capacidade de carga, que depende só do ângulo de atrito do solo.

D: Diâmetro da estaca.

Fazendo as derivadas substituindo-se nas equações anteriores é obtida a Eq. 2.4 geral de capacidade última de carga vertical.

$$
R_{u}=\int_{0}^{l} C\left(C_{a}+\sigma_{n} \tan \delta\right) d z+A_{b}\left(C N_{c}+\sigma_{v} b N_{q}+0.5 \gamma d N_{\gamma}\right)-W
$$

A capacidade de carga última do sistema solo-estaca é a máxima carga que este pode suportar, sem ocorrer a ruptura do solo, e em muitos casos quem governa o dimensionamento do sistema solo-estaca é a superestrutura já que não pode sofrer recalques excessivos. A capacidade de carga depende basicamente do tipo de solo onde a estaca vai ser executada, da tecnologia executiva, da geometria e de seu comprimento.

A análise de capacidade de carga pode ser determinada por diversas metodologias:

- Métodos empíricos e semi-empíricos (processo diretos e indiretos)

- Métodos analíticos

- Provas de carga

- Métodos numéricos (MDF, MEF, MEC) 
Os métodos empíricos, semi-empíricos e analíticos, os quais são desenvolvidos por processos diretos e indiretos respectivamente. Los processos diretos são determinados através de correlações com o apoio de algum tipo de ensaio in loco, os processos indiretos determinam as principais características como a resistência ao cisalhamento e rigidez, com ensaios laboratoriais e/ou no local, com o qual é determinada sua capacidade de carga através da formulação teórica ou experimental.

As provas de carga são a melhor forma de obter a capacidade de carga de estacas, sendo um ensaio realizado a escala real, dada a dificuldade de conhecer as propriedades do solo após da execução das estacas, e criam a necessidade de utilizar este tipo de ensaio para verificar a capacidade de carga, porém não para projetar o que na lógica deveria ser ao contrário. Este ensaio é de alto custo e leva tempo em preparação e execução.

Os métodos analíticos são baseados em soluções teóricas derivadas de estudos em fundações superficiais, envolvendo propriedades do solo que a maioria das vezes obtidas de ensaios de laboratório, que consideram o estado de tensões ao redor da estaca e a forma de distribuição do esforço cisalhante na ruptura (González, 2014).

A literatura oferece três métodos analíticos clássicos desenvolvidos pela American Petroleum Institute (API) para determinar a capacidade de carga.

O método alpha $(\alpha)$ para solos coesivos ou sob condições não drenadas, determina a resistência por atrito lateral Eq. 2.5 definindo um coeficiente chamado alpha como a parcela da resistência não drenada correspondente à adesão que vai ter o solo com a estaca.

$$
r_{l}=\propto * S_{u}
$$

Onde:

$S_{u}$ : resistência não drenada

O método beta $(\beta)$ para solos arenosos ou não coesivos sob condições drenadas, determina a resistência do atrito lateral Eq. 2.6 entre o solo e a estaca, relativo ao ângulo de atrito do solo e a profundidade crítica para a qual a tensão vertical efetiva permanece constante Eq. 2.7, normalmente adota-se um critério entre 10 a 20 vezes o diâmetro da estaca, medida por Vesic (1967); Poulos \& Davis (1980); Braja (2001).

$$
\begin{aligned}
& r_{l}=\beta \sigma_{v}^{\prime} \\
& \beta=K_{s} \tan \delta \\
& \sigma_{v}^{\prime}=\gamma^{\prime} z_{\text {crit }}
\end{aligned}
$$


Onde:

$\sigma_{v}^{\prime}$ : tensão efetiva vertical

$K_{S}$ : coeficiente de empuxo passivo

$\delta$ : ângulo de atrito da interface

$z_{\text {crit }}:$ profundidade crítica adotando o critério de 10 a 20 vezes o diâmetro da estaca

O método Lambda $(\lambda)$ para estacas de aço considerando solo coesivo-friccional, nesse caso a resistência e determinada com a seguinte Eq. 2.8. (Braja, 2001).

$$
r_{l}=\lambda\left(\sigma_{v}^{\prime}+2 S_{u}\right)
$$

Onde:

$\varphi^{\prime}$ : ângulo de atrito efetivo do solo

Nesse caso a maior dispersão é dada pelos próprios coeficientes correspondente a cada método $(\alpha),(\beta)$ ou $(\lambda)$, e principalmente devido ao coeficiente de empuxo do solo $\left(\mathrm{k}_{0}\right)$, para o qual existem diversas propostas Eq. 2.9 e Eq. 2.10, aproximando-se na maioria dos casos ao valor do empuxo de repouso. $\mathrm{O}$ valor adotado para o ângulo de atrito da interface solo-estaca está entre 0,5 a $2 / 3$ do valor do ângulo de atrito do solo, o coeficiente de empuxo passivo variando entre uma e duas vezes o coeficiente de empuxo em repouso (Bowles, 1997; Tomlinson \& Woodward, 2008).

$$
\begin{aligned}
& k_{0}=(1-\sin \varphi) O C R^{0,5} \\
& k_{0}=(1-\sin \varphi)
\end{aligned}
$$

Onde:

OCR: relação de sobreadensamento

Existem na literatura geotécnica outros métodos para determinar as parcelas de resistência tanto de ponta como por atrito lateral como as teorias semi-empíricas baseadas em ensaios de campo como o SPT e SPT-T.

\subsubsection{MÉTODOS DE ESTIMATIVA DE CARGA COM O SPT}

No Distrito Federal o ensaio mais utilizado para o dimensionamento e estimativa da carga última de estacas é o SPT (Standard Penetration Test), dada sua simplicidade de execução, economia e vantagens executivas. Em geral são adotados métodos semi-empíricos baseados nestes resultados para o cálculo da capacidade de carga, levando em consideração a tipologia da estaca, sua geometria e a tecnologia construtiva.

Em solos lateríticos e saprolíticos, as características dos finos dificilmente são representadas nos ensaios SPT, sendo comum o erro de precisão em comprimento e de 
capacidade de carga admissível de estacas cravadas e escavadas. Em fundações profundas, as mudanças significativas de umidade podem resultar na alteração da capacidade de carga (Marchezini, 2013). Segundo Guimarães (2002) as metodologias semi-empíricas baseadas no SPT subdimensionam o carregamento, principalmente o lateral, mas quando se utilizam coeficientes regionais as estimativas melhoram com respeito ao valor experimental obtido.

O ensaio SPT é normalizado pela Associação Brasileira de Normas Técnicas ABNT através da (NBR 6484, 2001).

Na literatura apresenta-se várias metodologias semi-empíricas que usam o SPT como Meyerhof (1956-1976), Aoki \& Velloso (1975), Décourt \& Quaresma (1978-1996), Teixeira (1996) e Lobo (2005).

A seguir serão listados os métodos de estimativa de capacidade de carga que serão analisados e utilizados na presente dissertação.

\subsubsection{MÉTODO DE AOKI \& VELLOSO (1975)}

O método Aoki-Velloso (1975) leva em conta tanto a resistência de ponta $\left(\mathrm{R}_{\mathrm{P}}\right)$ quanto a lateral da estaca $\left(R_{L}\right)$, foi baseado inicialmente sob resultados de resistência do ensaio de penetração do cone (CPT).

A diferença de comportamento entre a estaca e o cone é corregida pelos fatores empíricos de estaca F1 e F2 mostrado na Tab. 2.1. Estes fatores empíricos são função das diferentes tecnologias executivas do fuste e seus valores foram determinados por comparações com resultados de provas de carga, o conhecimento dessas correlações permite a estimativa dos parâmetros correspondentes para uma estaca pelas Eq. 2.11 e 2.12.

$$
\begin{aligned}
& R_{p}=\frac{r_{p}}{F_{1}} \\
& R_{l}=\frac{r_{l}}{F_{2}}
\end{aligned}
$$

Tabela 2.1. Fatores de correção F1 e F2 Atualizados por Velloso e Lopes (2010)

\begin{tabular}{|c|c|c|}
\hline Tipo de estaca & F1 & F2 \\
\hline Franki & 2,50 & $2 \mathrm{~F} 1$ \\
\hline Metálica & 1,75 & $2 \mathrm{~F} 1$ \\
\hline Pré-moldada & $1+\mathrm{D} / 0,80$ & $2 \mathrm{~F} 1$ \\
\hline Escavada & 3,00 & $2 \mathrm{~F}_{1}$ \\
\hline Raíz, Hélice continua, Ômega & 2,00 & $2 \mathrm{~F}_{1}$ \\
\hline
\end{tabular}

O fato de ser pouco utilizado este tipo de ensaio (CPT) no Brasil levaram Aoki-Velloso a criar uma correlação linear entre o ensaio CPT e SPT, para obter valores da resistência de ponta $\left(r_{p}\right)$ e da resistência por atrito lateral $\left(r_{l}\right)$, conforme as Eq. 2.13 e 2.14. 


$$
\begin{aligned}
& r_{p}=K N_{S P T} \\
& r_{l}=\propto K \bar{N}_{l}
\end{aligned}
$$

Onde:

$N_{S P T}$ : índice de resistência à penetração na cota de apoio da estaca;

$\bar{N}_{l}$ : índice de resistência à penetração médio na camada de solo de espessura $\Delta_{L}$;

$K$ e $\alpha$ : Coeficientes que dependem do tipo de solo Tab. 2.2

A formulação geral para o cálculo da capacidade de carga é dada pela seguinte Eq. 2.15

$$
R_{A-V}=A_{p} \frac{K N_{S P T}}{F_{1}}+\sum_{c p}^{c a} U \Delta_{L} \frac{\alpha K \bar{N}_{l}}{F_{2}}
$$

Onde:

$A_{p}$ : área da ponta da estaca;

$U$ : perímetro da seção transversal da estaca;

$c p$ : cota da ponta;

$c a$ : cota de arrasamento;

Tabela 2.2. Coeficiente K e razão de atrito $\alpha$ (Velloso e Lopes, 2010)

\begin{tabular}{|c|c|c|}
\hline Solo & K (MPa) & $\boldsymbol{\alpha}(\boldsymbol{\%})$ \\
\hline Areia & 1,00 & 1,4 \\
\hline Areia siltosa & 0,80 & 2,0 \\
\hline Areia siltoargilosa & 0,70 & 2,4 \\
\hline Areia argilosa & 0,60 & 3,0 \\
\hline Areia argilossiltosa & 0,50 & 2,8 \\
\hline Silte & 0,40 & 3,0 \\
\hline Silte arenoso & 0,55 & 2,2 \\
\hline Silte arenoargiloso & 0,45 & 2,8 \\
\hline Silte argiloso & 0,23 & 3,4 \\
\hline Silte argiloarenoso & 0,25 & 3,0 \\
\hline Argila & 0,20 & 6,0 \\
\hline Argila arenosa & 0,35 & 2,4 \\
\hline Argila arenossiltosa & 0,30 & 2,8 \\
\hline Argila siltosa & 0,22 & 4,0 \\
\hline Argila siltoarenosa & 0,33 & 3,0 \\
\hline
\end{tabular}

\subsubsection{MÉTODO DÉCOURT \& QUARESMA (1978-1996)}

Em 1978 os Eng. Luciano Décourt e Arthur Quaresma apresentaram um método para a determinação da capacidade de carga de estacas o qual foi desenvolvido a partir de um estudo comparativo entre resultados de provas de carga e sondagens a percussão SPT.

A resistência por atrito lateral em kPa, é dada pela seguinte Eq. 2.16. 


$$
r_{l}=10\left(\frac{\bar{N}_{l}}{3}+1\right)
$$

Onde:

$\bar{N}_{l}$ : valor médio ao longo do fuste, tomando-se como limite inferior os valores do $N_{S P T}$ menores que 3, e como limite superior os valores de $N_{S P T}$ maiores que 50.

A capacidade de carga de ponta da estaca é estimada pela Eq. 2.17.

$$
r_{p}=C \bar{N}_{p}
$$

Onde:

$C$ : fator caraterístico do solo, $\left(\right.$ argilas $=100 \mathrm{kN} / \mathrm{m}^{2} ;$ siltes $=300 \mathrm{kN} / \mathrm{m}^{2} ;$ areias $=500 \mathrm{kN} / \mathrm{m}^{2}$ )

$\bar{N}_{p}$ : valor médio dos $N_{S P T}$, correspondentes ao nível da ponta da estaca, o imediatamente superior e o imediatamente inferior a este.

Em 1996 este método foi estendido para mais tipos de estaca também muito utilizadas, que não eram levadas em conta inicialmente, e introduziram coeficientes $\alpha$ e $\beta$ na fórmula de capacidade de carga (Eq. 2.18), para estacas escavas em geral. Estes valores são de majoração ou de minoração, respectivamente para a resistência de ponta e para a resistência lateral, os valores propostos são apresentados na Tab. 2.3

$$
R_{D-Q}=\propto C \bar{N}_{p} A_{p}+10 \beta\left(\frac{\bar{N}_{l}}{3}+1\right) A_{l}
$$

Tabela 2.3. Valores de $\alpha$ e $\beta$ Décourt e Quaresma-estendido (Aoki e Cintra, 2010)

\begin{tabular}{|c|c|c|c|c|c|c|c|c|c|c|c|c|c|}
\hline Estaca & \multicolumn{2}{|c|}{ Cravada } & \multicolumn{2}{c|}{$\begin{array}{c}\text { Escavada } \\
\text { (em geral) }\end{array}$} & \multicolumn{2}{c|}{$\begin{array}{c}\text { Escavada } \\
\text { (com } \\
\text { bentonita) }\end{array}$} & \multicolumn{2}{c|}{$\begin{array}{c}\text { Hélice } \\
\text { continua }\end{array}$} & \multicolumn{2}{|c|}{ Raíz } & \multicolumn{2}{c|}{$\begin{array}{c}\text { Injetada } \\
\text { (alta } \\
\text { pressão) }\end{array}$} \\
\hline SOLO & $\boldsymbol{\alpha}$ & $\boldsymbol{\beta}$ & $\boldsymbol{\alpha}$ & $\boldsymbol{\beta}$ & $\boldsymbol{\alpha}$ & $\boldsymbol{\beta}$ & $\boldsymbol{\alpha}$ & $\boldsymbol{\beta}$ & $\boldsymbol{\alpha}$ & $\boldsymbol{\beta}$ & $\boldsymbol{\alpha}$ & $\boldsymbol{\beta}$ \\
\hline Argilas & 1,00 & 1,00 & 0,85 & 0,80 & 0,85 & 0,90 & 0,30 & 1,00 & 0,85 & 1,50 & 1,00 & 3,00 \\
\hline $\begin{array}{c}\text { Arenas } \\
\text { argilosas }\end{array}$ & 1,00 & 1,00 & 0,60 & 0,65 & 0,60 & 0,75 & 0,30 & 1,00 & 0,60 & 1,50 & 1,00 & 3,00 \\
\hline Areias & 1,00 & 1,00 & 0,50 & 0,50 & 0,50 & 0,60 & 0,30 & 1,00 & 0,50 & 1,50 & 1,00 & 3,00 \\
\hline
\end{tabular}

\subsubsection{MÉTODO DE TEIXEIRA (1996)}

Teixeira (1996) desenvolveu um método com base nos métodos de Aoki-Velloso (1975) e Décourt e Quaremas (1978), adotando parâmetros $\alpha_{\text {tex }}$ e $\beta_{\text {tex }}$ para calcular a capacidade de carga de um sistema solo-estaca e com isso propôs uma espécie de equação unificada Eq. 2.19.

$$
R_{\text {tex }}=\propto_{\text {tex }} \bar{N}_{p} A_{p}+\beta_{\text {tex }} \bar{N}_{l} P L
$$


Onde:

$\alpha_{\text {tex }}$ : parâmetro em função da natureza do solo Tab. 2.4;

$\beta_{\text {tex: }}$ parâmetro em função da tecnologia executiva da estaca Tab. 2.5;

$\bar{N}_{p}$ : valor médio dos $N_{S P T}$, correspondentes ao nível onde vai ficar a ponta da estaca no intervalo

de 4 diâmetros acima da ponta da estaca até 1 diâmetro abaixo;

$P, L:$ perímetro e comprimento da estaca;

$\bar{N}_{l}:$ média dos valores de resistência à penetração ao longo do fuste da estaca;

Tabela 2.4. Parâmetro $\alpha_{\text {tex }}$ (Teixeira, 1996 e Aoki e Cintra, 2010)

\begin{tabular}{|c|c|c|c|c|}
\hline & \multicolumn{4}{|c|}{ Tipo de estaca $\boldsymbol{\alpha}_{\text {tex }}$} \\
\hline Tipo de Solo (4< N < 40) & $\begin{array}{c}\text { Pré-moldada e } \\
\text { perfil metálico }\end{array}$ & Franki & $\begin{array}{c}\text { Escavada a } \\
\text { céu aberto }\end{array}$ & Raiz \\
\hline Argila siltosa & 110 & 100 & 100 & 100 \\
\hline Silte argiloso & 160 & 120 & 110 & 110 \\
\hline Argila arenosa & 210 & 160 & 130 & 140 \\
\hline Silte arenoso & 260 & 210 & 160 & 160 \\
\hline Areia argilosa & 300 & 240 & 200 & 190 \\
\hline Areia siltosa & 360 & 300 & 240 & 220 \\
\hline Areia & 400 & 340 & 270 & 260 \\
\hline Areia com pedregulhos & 440 & 380 & 310 & 290 \\
\hline
\end{tabular}

Tabela 2.5. Parâmetro $\beta_{\text {tex }}$ (Teixeira, 1996 e Aoki e Cintra, 2010)

\begin{tabular}{|c|c|}
\hline Tipo de estaca & $\boldsymbol{\beta}_{\text {tex }}$ \\
\hline Pré-moldada e perfil metálico & 4 \\
\hline Franki & 5 \\
\hline Escavada a céu aberto & 4 \\
\hline Raíz & 6 \\
\hline
\end{tabular}

\subsubsection{MÉTODO DE LOBO (2005)}

O método também é chamado como o método da UFRGS, iniciou-se com a tese de doutorado de Odebrecht (2003) onde estudou-se os fatores que influenciam a penetração do amostrador SPT, nesse trabalho foi realizada uma serie de ensaios de campo instrumentados, onde utilizou-se quatro comprimentos de haste $(5,80 \mathrm{~m}, 11,80 \mathrm{~m}, 18,18 \mathrm{~m}$ e $35,80 \mathrm{~m})$ determinado os valores para os coeficientes $\left(\mathrm{n}_{1}, \mathrm{n}_{2}\right.$ e $\left.\mathrm{n}_{3}\right)$ representando todas as perdas de energia referente ao golpe, as perdas de energia ao longo das hastes e a eficiência do sistema respectivamente.

Com base nisto foi proposto o método de Lobo (2005), desenvolvido através de conceitos de conservação da energia estabelecendo uma relação entre a força de reação 
dinâmica do solo $\left(\mathrm{F}_{\mathrm{d}}\right)$ e a cravação do amostrador SPT, para-se estimar a capacidade de carga do sistema solo-estaca, relacionando os mecanismos de mobilização da resistência por ponta e atrito lateral do amostrador através da Eq. 2.20.

$$
R_{L O B O}=\left(\beta_{U F R G S} * 0,7 * F_{d} * \frac{A_{p}}{a_{p}}\right)+\left(\alpha_{U F R G S} \frac{0,2 * P}{a_{l}} \sum F_{d} \Delta_{l}\right)
$$

Onde:

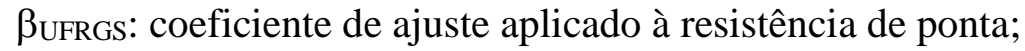

$\mathrm{F}_{\mathrm{d}}$ : variação da energia potencial $[\mathrm{N}]$;

$\mathrm{A}_{\mathrm{p}}$ : área da ponta da estaca $\left[\mathrm{m}^{2}\right]$;

$\mathrm{a}_{\mathrm{p}}$ : área da ponta do amostrador SPT $\left(20,4 \times 10^{-4}\right)\left[\mathrm{m}^{2}\right]$;

$\alpha_{\text {UFRGS: }}$ coeficiente de ajuste aplicado à resistência por fuste;

$\mathrm{P}:$ perímetro da estaca $[\mathrm{m}]$

$\mathrm{a}_{1}$ : área lateral total do amostrador SPT $\left(\right.$ externa + interna $\left.=810,5 \times 10^{-4}\right)\left[\mathrm{m}^{2}\right]$;

$\Delta_{\mathrm{l}}$ : espessura de cada camada de solo considerada [m].

Os coeficientes de ajuste mostrados na Tab. 2.6 foram estimados a partir da análise comparativa e da correlação estatística entre os resultados gerados pelo método da UFRGS (2005), 324 provas de carga à compressão e 43 provas de carga à tração (Nienov, 2006).

Tabela 2.6 Coeficientes $\alpha$ Ufrgs e $\beta$ Ufrgs (Lobo, 2005)

\begin{tabular}{|c|c|c|}
\hline Tipo de Estaca & $\boldsymbol{\alpha}_{\text {UFRGS }}$ & $\boldsymbol{\beta}_{\text {UFRGS }}$ \\
\hline Cravada Pré-moldada & 1,5 & 1,1 \\
\hline Estaca metálica & 1,0 & 1,0 \\
\hline Hélice Continua & 1,0 & 0,6 \\
\hline Escavada & 0,7 & 0,5 \\
\hline
\end{tabular}

Para o cálculo da força dinâmica de penetração do amostrador é utilizada a seguinte Eq. 2.21

$$
F_{d}=\frac{n_{3}\left[n_{1}\left(0,75+\Delta_{p}\right) * M_{m} * g+n_{2} \Delta_{p} M_{h} * g\right]}{\Delta_{p}}
$$

Onde:

$\mathrm{n}_{1}$ : eficiência do golpe $=0,764$;

$\mathrm{n}_{2}$ : eficiencia das hastes $=1$;

$\mathrm{n}_{3}$ : eficiência do sistema $=0,907-0,066 \mathrm{z}$;

$\mathrm{z}$ : comprimento da haste que penetrou no solo $[\mathrm{m}]$;

$\mathrm{M}_{\mathrm{m}}$ : massa do martelo [kg]; 
$\mathrm{M}_{\mathrm{h}}$ : massa da haste $[3,23 \mathrm{~kg} / \mathrm{m}]$;

$\mathrm{g}$ : gravidade $\left[\mathrm{m} / \mathrm{s}^{2}\right]$;

$\Delta_{\mathrm{p}}$ : penetração do golpe $=0,3 / \mathrm{N}_{\mathrm{SPT}}[\mathrm{m} /$ golpes $]$.

\subsubsection{MÉTODOS DE ESTIMATIVA DE CARGA COM O SPT-T}

A incorporação de medidas de torque no ensaio SPT foi inicialmente sugerida por Ranzini (1988), tendo contribuições nos anos 1994, 1999 e 2000, com a utilização dos valores de torque ou correlações entre $\mathrm{N}_{\mathrm{SPT}}$ e o torque medido no SPT-T. Este valor poderia ser utilizado, por exemplo, na avaliação da tensão lateral em estacas, através da adesão e o possível atrito lateral estimado, desenvolvido na interface solo-amostrador (Mascarenha, 2003). A literatura apresenta várias metodologias para estimar a capacidade de carga de estacas cita-se exemplos como: Alonso (1996), Décourt (1996), Camapum de Carvalho (1998) e Peixoto (2001).

\subsubsection{MÉTODO DE DÉCOURT (1996)}

Este método é uma modificação da metodologia proposta por Décourt e Quaresma (1978), descrito no item 2.5.1.2, substituindo-se o valor do $\mathrm{N}_{\mathrm{SPT}}$ diretamente pelo torque obtido no ensaio SPT-T. Assim, os valores de $\mathrm{N}_{\mathrm{SPT}}$ podem tanto corresponder ao $\mathrm{N}_{\mathrm{SPT}}$ tradicional, como $\mathrm{N}_{\text {eq }}$ obtido do ensaio SPT-T.

\subsubsection{MÉTODO DE ALONSO (1996)}

Este método foi originalmente desenvolvido para estacas hélice continua, a partir de correlações entre o atrito lateral medido como torque $\left(f_{s}\right)$ e a adesão média entre o solo e o fuste $\left(\mathrm{r}_{1}\right)$ dos diversos tipos de estacas. Devido à não existência de provas de carga em estacas instrumentadas em locais onde se realizaram ensaios SPT-T, as correlações foram obtidas de forma indireta, partindo das correlações entre $r_{l}$ e o índice de resistência à penetração $\mathrm{N}_{\mathrm{SPT}}$ (propostas realizadas pelos diversos autores das metodologias de estimativa de capacidade de carga) com correlações análogas, obtidas entre o atrito lateral e o torque máximo, e a resistência por ponta com $\mathrm{N}_{\mathrm{SPT}}$.

Foi obtida uma correlação entre $\mathrm{f}_{\mathrm{s}}$ e $\mathrm{N}_{\mathrm{SPT}}$ apresentada nas seguintes Eq. 2.22 e 2.23

$$
\begin{gathered}
f_{S}=15+5 N_{S P T} \\
f_{s}=6 N_{S P T}
\end{gathered}
$$

Para estabelecer as correlações entre $\mathrm{r}_{1}$ e $\mathrm{f}_{\mathrm{s}}$ foram utilizadas as diversas expressões dos vários métodos de capacidade de carga baseados no SPT-T mostrados na Tab. 2.7. 
Tabela 2.7. Expressões para prever adesão de diferentes tipos de estacas obtido do SPT-T (Alonso, 1996)

\begin{tabular}{|c|c|}
\hline Tipo de Estaca & Expressão \\
\hline Hélice continua & $\mathrm{r}_{1}=0,65 * \mathrm{f}_{\mathrm{s}} \leq 200 \mathrm{kPa}$ \\
\hline Raíz & $\mathrm{r}_{1}=1,15 * \mathrm{f}_{\mathrm{s}}$ \\
\hline Escavada com lama bentonítica & $\mathrm{r}_{1}=\mathrm{f}_{\mathrm{S}} / 1,7$ \\
\hline Pré-moldada & $\mathrm{r}_{1}=\mathrm{f}_{\mathrm{s}} / 1,5$ \\
\hline $\begin{array}{l}\mathrm{r}_{1}=\text { adesão da estaca } \\
\mathrm{f}_{\mathrm{s}}=\text { atrito lateral obtido do SPT-T }\end{array}$ \\
\hline
\end{tabular}

Para o cálculo de $r_{p}$ utilizou-se o modelo proposto por De Beer (1972) citado por (Peixoto, 2001), substituindo-se o valor de $\mathrm{N}_{\mathrm{SPT}}$ por $\mathrm{T}_{\text {res }}$ como é mostrado na Eq. 2.24

$$
r_{p}=\beta \frac{T_{r e s} 1+T_{r e s} 2}{2}
$$

Onde:

$\mathrm{r}_{\mathrm{p}}$ : capacidade de carga do solo na ponta da estaca

$\mathrm{T}_{\text {res1: }}$ média aritmética dos valores do torque mínimo no trecho $8 \mathrm{D}$ acima da ponta da estaca $\mathrm{T}_{\text {res2: }}$ média aritmética dos valores do torque mínimo no trecho 3D abaixo da ponta da estaca $D$ : diâmetro da estaca

$\beta: 200(\mathrm{kPa} / \mathrm{kgf})$ para areias; $150(\mathrm{kPa} / \mathrm{kgf})$ para os siltes e $100(\mathrm{kPa} / \mathrm{kgf})$ para argilas Os valores de $\mathrm{T}_{\text {res1 }}$ e $\mathrm{T}_{\text {res2 }}$ superiores a $40 \mathrm{kgf}$ devem ser adotados iguais a $40 \mathrm{kgf}$.

\subsubsection{MÉTODO DE PEIXOTO (2001)}

O método foi desenvolvido com a continuidade dos estudos feitos por Ranzini (2000), comparando os resultados das previsões de atritos laterais quando este utilizava o torque máximo ou o residual.

Peixoto (2001) sugeriu para o cálculo da parcela de atrito lateral de estacas através da adesão-atrito solo-amostrador a equação proposta por Ranzini (2000), porém com o fs máx multiplicado por um fator $\mathrm{F} \lambda$, função do comportamento do solo, que é representada pela relação $\mathrm{T}_{\text {máx }} / \mathrm{N}$

No estudo realizado por Peixoto (2001) a parcela de ponta apresentou uma grande variabilidade, justificada pelo autor com o fato de que as medidas de torque estavam em direção diferente ao carregamento da ponta da estaca. Então a metodologia proposta por Décourt (1996) foi utilizada para cálculo da parcela de ponta, utilizando os valores de $\mathrm{N}_{\mathrm{spt}}$ e não de $\mathrm{N}_{\mathrm{eq}}$, pois foram os que melhor aproximaram das provas de cargas instrumentadas realizadas por Peixoto (2001). 
Desta maneira, para cálculo da parcela de resistência da ponta é sugerida a metodologia de Decourt e Quaresma (1978) acrescida do coeficiente $\alpha$ sugerido por Decourt (1996). Então tem-se a Eq. 2.25 e Eq. 2.26:

$$
R_{l}=F_{\lambda} * S_{\lambda} * \overline{f S}_{m a ́ x} * A_{l}
$$

Onde:

$F_{\lambda}$ : fator de correção em função do tipo de estaca e da relação $\mathrm{T}_{\text {máx }} / \mathrm{N}$ (Tab. 2.8)

$S_{\lambda}$ : coeficiente em função do tipo de estaca

$$
\overline{f S}_{\text {máx }}=\frac{\sum L_{i} * f s_{m a ̂ x}}{\sum L_{i}}
$$

Onde:

$L_{i}$ : comprimento do trecho elementar de fuste do solo de ordem " $\mathrm{i}$ "

$f s_{\text {máx }}$ : tensão de atrito lateral medida pelo torquímetro na altura do trecho elementar de ordem "i"

$A_{l}$ : área da superfície lateral da estaca

$\mathrm{Na}$ procura de posicionar o ensaio SPT-T como uma boa ferramenta para obter parâmetros que permitam obter uma adequada estimativa na capacidade de carga de estacas, esta metodologia foi aplicada em estacas de seis campos experimentais e a outros dados de provas de carga obtidos na literatura. Os resultados mostram que a metodologia apresentada é adequada para os cálculos de capacidade de carga.

Segundo Guimarães (2002) o método de Peixoto (2001) oferece melhor previsão do atrito lateral das estacas assentes nos solos porosos do campo experimental da universidade de Brasília.

Tabela 2.8. Valores dos coeficientes $S_{\lambda}$ e $F_{\lambda}$ Peixoto (2001)

\begin{tabular}{|c|c|c|c|}
\hline Tipo de estaca & \multirow{2}{*}{$\mathbf{S}_{\lambda}$} & \multicolumn{2}{|c|}{$\mathbf{F}_{\lambda}$} \\
& & $\mathbf{T}_{\text {máx }} / \mathbf{N}<\mathbf{1}$ & $\mathbf{T}_{\text {máx }} / \mathbf{N}>\mathbf{1}$ \\
\hline Pré-moldada de pequeno diâmetro & 0,8 & & \\
\hline Ômega & 3,0 & \multicolumn{2}{|c}{1,0} \\
\hline Metálica & 0,3 & \multicolumn{2}{|}{} \\
\hline Injetada de pequeno diâmetro & 2,0 & \multicolumn{2}{|c}{} \\
\hline Raíz & 1,5 & & 0,7 \\
\hline Barrete & 0,7 & 1,3 & 0,5 \\
\hline Strauss & 0,8 & 0,7 & 0,5 \\
\hline Franki & 0,8 & 0,7 & 0,3 \\
\hline Apiloada & 3,5 & 1,0 & 0,7 \\
\hline Hélice contínua & 2,0 & 1,4 & \\
\hline Escavada e broca & 1,4 & & \\
\hline
\end{tabular}




\subsubsection{MÉTODO DE CAMAPUM DE CARVALHO et al. (1998)}

O método foi desenvolvido com a utilização de resultados de provas de carga em estacas executadas no solo poroso do Distrito Federal. Este método só fornece a equação para o cálculo da parcela de resistência por atrito lateral na interface solo-estaca. A resistência por ponta podese calcular através dos métodos anteriormente citados: Aoki-Velloso (1975) ou DecourtQuarema (1978).

O dimensionamento de estacas pode ser feito através de resultados dos ensaios SPT para calcular a parcela por ponta e com a extensão do ensaio deste, SPT-T é calculada a parcela correspondente ao atrito lateral utilizando os coeficientes propostos por Rodrigues et al. (1998).

\subsubsection{MÉTODOS DE ESTIMATIVA DE CARGA COM O DMT}

O dilatômetro de Marchetti (DMT) é uma ferramenta desenvolvida na Itália em 1975, usada para medir por meio de correlações propriedades do solo e caracterização in loco.

O ensaio DMT consiste em cravar verticalmente no terreno uma lâmina de aço com uma membrana de aço de $6.0 \mathrm{~cm}$ de diâmetro em um dos lados, após aplicar pressões ao solo através da mesma.

Os aspectos considerados no ensaio são: coleta de dados a cada $20 \mathrm{~cm}$, velocidade de penetração de $2 \mathrm{~cm} / \mathrm{s}$, obtenção das pressões $\left(\mathrm{P}_{\mathrm{A}}\right)$ pressão para uma separação de membrana de $0,05 \mathrm{~mm},\left(\mathrm{P}_{\mathrm{B}}\right)$ pressão de gás a uma deformação radial do diafragma de 1,1 mm e $\left(\mathrm{P}_{\mathrm{C}}\right)$ pressão interna do diafragma para voltar à posição $\mathrm{P}_{\mathrm{A}}$ (Mendoza, 2013).

Os três parâmetros do ensaio DMT, que são utilizados como dados para utilizar as correlações são o índice de material $\left(\mathrm{I}_{\mathrm{D}}\right)$, o indice de tensão horizontal $\left(\mathrm{K}_{\mathrm{D}}\right)$ e o módulo dilatométrico $\left(\mathrm{E}_{\mathrm{D}}\right)$.

\subsubsection{MÉTODO DE PFEIFFER E VAN IMPE (1991)}

O método de Pfeiffer \& Van Impe (1991) foi apresentado em um trabalho realizado pela Universidade do Estado de Ghent na Bélgica, em que os resultados da previsão da capacidade de carga através do DMT eram comparados aqueles obtidos de provas de carga realizadas em estacas escavadas com concreto injetado sob pressão com dimensões de $35 \mathrm{~cm}$ de diâmetro e 10 m de comprimento. (Bessa, 2005). 
Para a aplicação do método deve-se, calcular a tensão horizontal efetiva ( $\sigma^{\prime}$ hc) empregando os resultados da pressão $\mathrm{P}_{0}$ fornecido pelo ensaio DMT através da seguinte Eq. 2.27

$$
\sigma_{h c}^{\prime}=P_{0}+u_{o}
$$

Com a tensão horizontal efetiva calculada, pode-se calcular a resistência lateral da estaca com a Eq. 2.28 mostrada a seguir.

$$
R_{l}=A_{l} * p * \sigma_{h c}^{\prime}
$$

Onde:

$\mathrm{u}_{\mathrm{o}}$ : poropressão;

$\mathrm{P}_{\mathrm{A}}$ : pressão inicial aplicada para dilatar a membrana $0,05 \mathrm{~mm}$;

p: razão de atrito lateral (para estacas escavadas é igual a 0,20) Marchetti et al (1986) citado por Bessa (2005).

O método de Pfeiffer \& Van Impe (1991) só fornece as equações para calcular a parcela de resistência por atrito lateral. A parcela de resistência por ponta deve-se calcular através dos métodos disponíveis na literatura (Bessa, 2005).

\subsubsection{MÉTODO DE POWELL (2001)}

Powell (2001) propuseram duas metodologias diferentes para o cálculo da resistência por atrito lateral em argilas, a primeira foi desenvolvida para estacas submetidas à tração e compressão. A segunda somente é para estacas à compressão.

Os parâmetros utilizados no método para o cálculo da resistência por atrito lateral em argilas são mostrados nas Eq. 2.29, Eq. 2.30 e Eq. 2.31.

$$
\begin{array}{rcc}
I_{D} & <0,1 & r_{l} /\left(P_{B}-P_{0}\right)=0,5 \\
0,1<I_{D} & <0,65 & r_{l} /\left(P_{B}-P_{0}\right)=-0,73077 * I_{D}+0,575 \\
I_{D} & >0,65 & r_{l} /\left(P_{B}-P_{0}\right)=0,1
\end{array}
$$

Onde:

ID: índice de material

$\mathrm{P}_{\mathrm{B}}$ : pressão correspondente ao deslocamento de $1,1 \mathrm{~mm}$;

$\mathrm{P}_{0}$ : pressão inicial aplicada para dilatar a membrana;

$\mathrm{O}$ cálculo da resistência por atrito lateral unitária $\left(\mathrm{r}_{\mathrm{l}}\right)$, para o segundo método é apresentado nas seguintes Eq. 2.32 e Eq. 2.33.

$$
I_{D}<0,6 \quad r_{l} /\left(P_{B}-P_{0}\right)=-1,1111 I_{D}+0,775
$$




$$
I_{D}<0,6 \quad r_{l} /\left(P_{B}-P_{0}\right)=0,11
$$

Para estacas com relação L/raio > 50, deve-se multiplicar as equações de $\mathrm{r}_{1}$ por 0,85 para ambos métodos.

\subsubsection{PRESSIÔMETRO DE MÉNARD PMT}

O pressiômetro de Ménard é um equipamento de fácil locomoção e instalação que possibilita a determinação bastante confiável do módulo de deformabilidade do solo, que pode ser correlacionado com o recalque de uma fundação. Apesar de o ensaio de pressiometria realizado com o pressiômetro de Ménard ser pouco difundido no Brasil, pesquisas existentes indicam um grande potencial do ensaio, incentivando, assim sua utilização (Dourado, 2005).

Todo ensaio pressiométrico tem que ser calibrado para poder obter a verdadeira curva volumepressão do solo, para isto tem que se conhecer as perdas de volume e de pressão inerentes ao próprio aparelho. Deste modo, a calibração consiste em quantificar o valor dessas perdas, de modo que se conheça o real comportamento tensão-deformação do solo (Oliva, 2009).

\subsection{ANÁLISE DE DESLOCABILIDADE SOB CARGA AXIAL}

Os métodos de estimativa de recalque são classificados como:

- Métodos semi-empíricos;

- Métodos teóricos baseados na teoria da elasticidade;

- Métodos numéricos;

Os trabalhos sobre métodos teóricos são baseados na teoria da elasticidade linear e a maioria utiliza a equação de Mindlin, a qual oferece o deslocamento de um ponto no interior do maciço elástico ideal, além de estarem sujeitos às seguintes limitações:

- Admitem o solo como um meio elástico ideal de duas fases, homogêneo, semi-infinito e isotrópico além de apresentar múltiplas camadas;

- Os esforços de compressão e tração que o solo suporta são os mesmos;

- O módulo de elasticidade do solo $\left(\mathrm{E}_{\mathrm{s}}\right)$ e o coeficiente de Poisson $(v)$ permanecem iguais em presença da fundação;

- Aderência entre a estaca e o solo é perfeita.

Além de estas limitações em Poulos \& Davis (1968) e Poulos \& Mattes (1969) consideram que não há variação na continuidade do meio elástico pela presença das estacas. $\mathrm{O}$ caso mais frequente é que o terreno apresenta múltiplas camadas. Em relação a esta perspectiva, 
Palmer e Barber (1940) utilizam espessura e módulos equivalentes para assim, aplicar as equações de Mindlin ao solo então "homogeneizado".

Com tudo, as soluções obtidas com estas metodologias apresentam bons resultados se comparados com os registros em estacas instrumentadas e com análises a partir do método dos elementos finitos.

O comportamento de estacas carregadas axialmente com cargas de trabalho geralmente encontra-se no trecho elástico da curva carga-recalque já que possui fatores de segurança que variam entre 2 e 3 , o que permite que estas soluções sejam geralmente suficientes quando as cargas estejam no trecho elástico da resposta carga-recalque.

\subsubsection{MÉTODO DE POULOS \& DAVIS (1980)}

Para calcular a ação da estaca sobre o solo, o método de Poulos \& Davis (1980) considera que ao momento da aplicação de uma solicitação axial à estaca, o movimento entre a estaca e o solo adjacente são iguais (domínio elástico). Estes deslocamentos no solo, são obtidos por meio da equação de Mindlin.

Com a ilustração da Fig. 2.6 a geometria e as condições de contorno são definidos os parâmetros utilizados no cálculo do recalque de estacas da solução de Poulos \& Davis (1980).

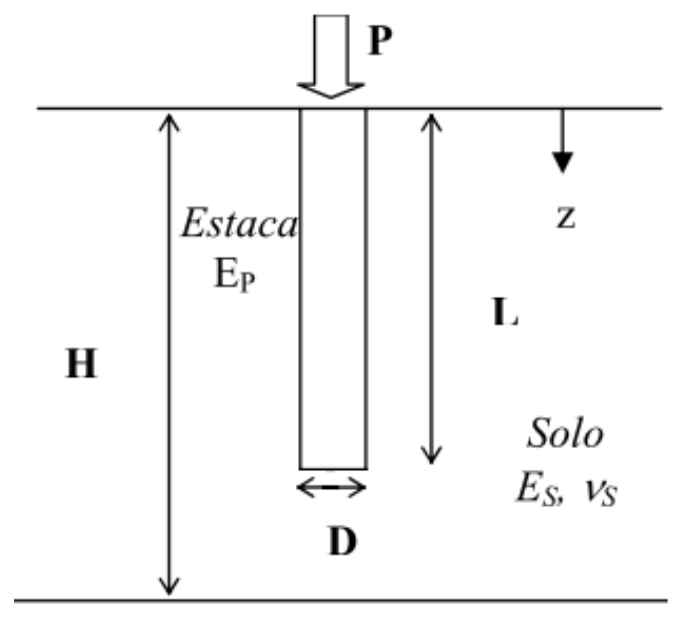

Camada resistente

$$
E_{b}, v_{b}
$$

Figura 2.6. Esquema para obtenção dos parâmetros utilizados no cálculo (Magalhães, 2005)

Onde:

P: carga aplicada

H: espessura da camada de solo

L: comprimento da estaca

D: diâmetro da estaca 
Ep: módulo de elasticidade do material da estaca

Es: módulo de elasticidade do solo

$\mathrm{E}_{\mathrm{b}}$ : módulo de elasticidade da camada resistente de solo

$v_{s}:$ coeficiente de Poisson do solo

$v_{b}:$ coeficiente de Poisson da camada resistente de solo

A solução da determinação do recalque de estacas é dada com o uso de gráficos e pela Eq. 2.34.

$$
\rho=\frac{P I}{E_{S} D}
$$

Onde:

P: carga admissível da estaca

$I$ : fator de influência

Nessa formulação é introduzido um parâmetro denominado coeficiente de rigidez (K), dado pela Eq. 2.35.

$$
K=\frac{E_{p}}{E_{S}} R_{A}
$$

Onde:

$R_{A}=A_{p} / \pi r^{2}, R_{A}=1:$ para estacas maciças

$A_{p}:$ área da seção transversal da estaca

Para aplicação desta metodologia, supõe-se que exista compatibilidade entre os deslocamentos da estaca e do solo adjacente. O recalque no topo da estaca pode ser expresso, com precisão suficiente, em termos do recalque de uma estaca incompressível no semi-espaço, com fatores de correção Eq. 2.36 para os efeitos da compressibilidade da estaca compressível (Poulos \& Davis, 1980; Citado por Magalhães, 2005).

$$
I=I_{0} R_{k} R_{h} R_{v}
$$

Onde:

$I_{0}$ : fator de influência do recalque para estaca incompressível na massa semi-infínita $R_{k}$ : fator de correção para compressibilidade da estaca $R_{h}$ : fator de correção para profundidade finita da camada sobre base rígida 
$R_{v}$ : correção para o coeficiente de Poisson do solo

Para obter os valores de $I_{0}, R_{k}, R_{h}$ e $R_{v}$ utilizaram-se a Fig. 2.7
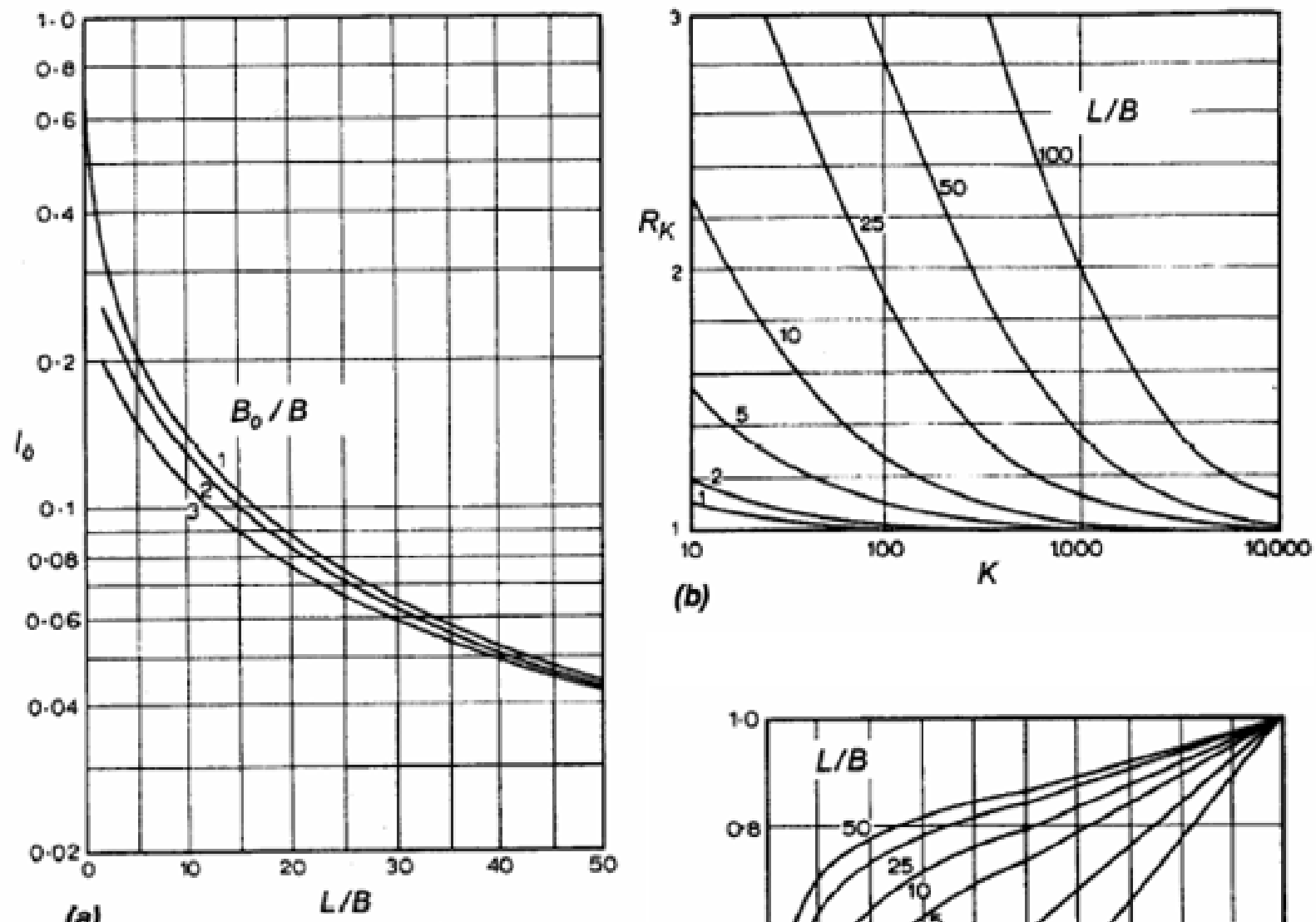

(b)

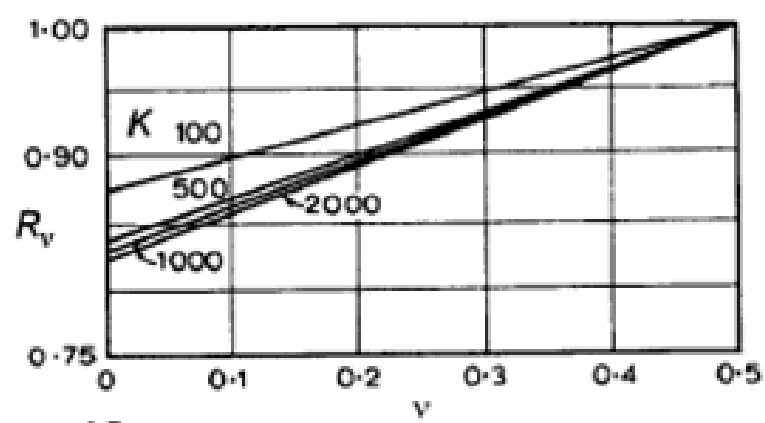

(d)

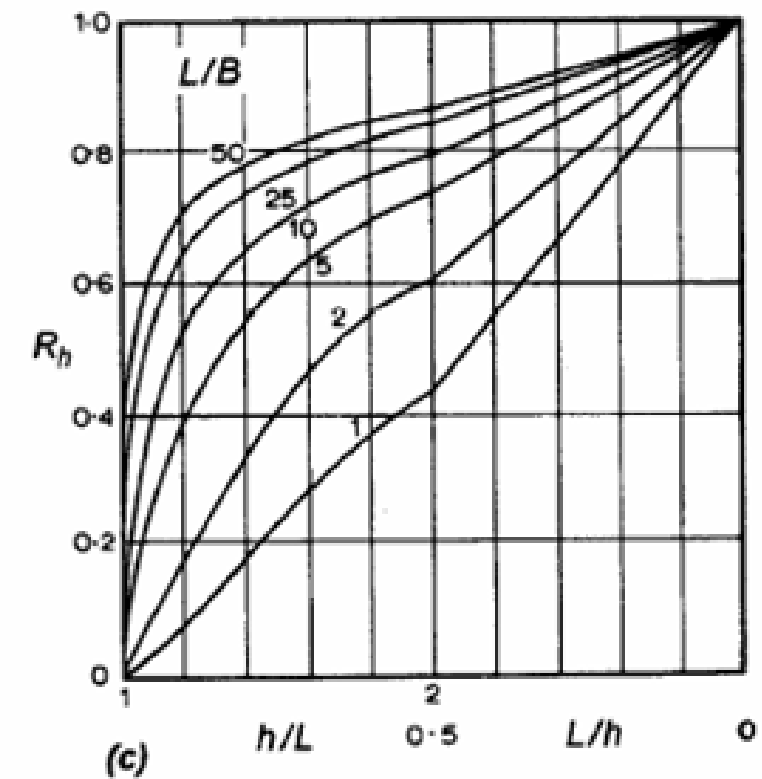

Figura 2.7. Fatores para o cálculo de recalque de estacas (Poulos \& Davis, 1980)

Poulos e Davis (1980) desenvolveram uma metodologia para o cálculo de recalque de grupos de estacas, consiste em transformar o grupo de estacas em uma estaca circular com área equivalente $\left(\mathrm{A}_{\mathrm{G}}\right)$. O método fornece fórmulas para achar o diâmetro desta estaca $\left(d_{e q}\right.$, Eq. 2.37) e terá um módulo de Young equivalente ( $E_{\text {eq }}$, Eq. 2.38).

$$
d_{e q}=1,27 \times \sqrt{A_{G}}
$$


Sendo, $\mathrm{A}_{\mathrm{G}}$ a área da figura plana circunscrita ao grupo de estacas

$$
E_{e q}=E_{S}+\left(E_{p}-E_{S}\right) *\left(\frac{A_{T}}{A_{G}}\right)
$$

Onde:

$A_{T}$ : somatório das áreas das seções das estacas do grupo

Após realizada a transformação da estaca equivalente é possível utilizar a teoria de Poulos e Davis para estaca isolada para determinar o recalque do grupo de estacas.

Para estimar o recalque de grupos tem-se um método empírico simplificado proposto por Randolph, em Fleming et al. (1985) mostrado na Eq. 2.39 e Eq. 2.40.

$$
\begin{array}{r}
R_{s}=n^{w} \\
\rho_{\text {grupo }}=\rho_{1} * R_{S}
\end{array}
$$

Onde:

n: número de estacas;

w: exponente geralmente entre 0,4 e 0,6 para a maioria dos grupos. $\mathrm{O}$ valor 0,5 vem sendo empregado por diversos autores, como Poulos (1993a) citado por Sales (2000);

$\rho_{1}$ : recalque para estaca isolada $[\mathrm{mm}]$.

Poulos \& Davis (1980) propuseram uma série de ábacos para a determinação do fator de recalque $R_{s}$ considerando fatores de interação entre estacas. Estes fatores foram calculados, pelo MEC (método de elementos de contorno), supondo válido o princípio da superposição dos campos de deformação para pontos próximos a várias estacas. Os fatores de interação, além das propriedades elásticas do solo e das estacas, dependem fundamentalmente do espaçamento entre os elementos envolvidos (Sales, 2000).

\subsubsection{MÉTODO DE RANDOLPH \& WROTH (1978 e 1979)}

O método estima a transferência de carga de uma estaca isolada ao solo, sendo baseado na solução de Boussineq para um semi-espaço elástico (Randolph \& Wroth, 1978) que separa inicialmente as cargas transferidas pela base e pelo fuste para calcular os recalques e em seguida juntam os dois efeitos.

Este método leva em conta a variação do módulo cisalhante do solo $\left(\mathrm{G}_{\mathrm{s}}\right)$ com a profundidade como mostra-se na Fig. 2.8, chegando à solução completa, fornecida pela Eq. 2.41 . 


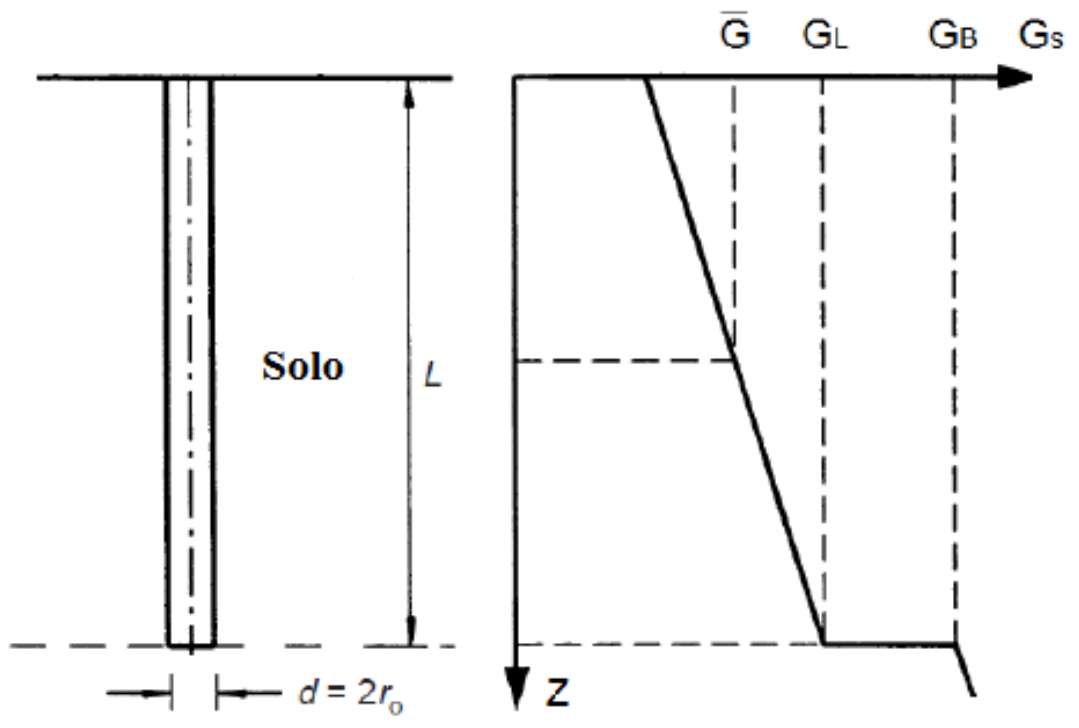

Figura 2.8. Variação do módulo cisalhante (Gs) do solo com a profundidade (Z)

$$
\frac{P_{t}}{G_{l} r_{0} W_{t}}=\frac{\frac{4 \eta}{(1-v) * \xi}+\frac{2 \pi * \operatorname{tgh}(\mu L) * L}{\zeta * \mu L * r_{0}}}{1+\frac{1}{\pi \lambda} * \frac{4 \eta}{(1-v) * \xi} * \frac{\operatorname{tgh}(\mu L)}{\mu L} * \frac{L}{r_{0}}}
$$

Onde:

$P_{t}$ : Carga no topo da estaca

$W_{t}$ : recalque no topo da estaca

$G_{l}$ : módulo cisalhante do solo a uma profundidade $\mathrm{Z}=\mathrm{L}$

$L:$ comprimento da estaca

$r_{0}$ : raio inicial da estaca

$\eta=r_{b} / r_{0}, r_{b}=$ raio da ponta da estaca

$\xi=G_{l} / G_{b}, G_{b}=$ módulo cisalhante abaixo da ponta da estaca

$\rho_{R}=G_{m} / G_{l}, G_{m}=$ módulo cisalhante médio do solo no trecho penetrado pela estaca

$\lambda=E_{p} / G_{l}, E_{p}=$ módulo de elasticidade do material da estaca

$\zeta=\ln \left(r_{m} / r_{0}\right)$

$r_{m}=L\left\{0,25+\xi\left[2,5 \rho_{R}(1-v)-0,25\right]\right\}$

$\mu L=\frac{L}{r_{0}} \sqrt{\frac{2}{\zeta \lambda}}, \mu L$ entra na equação em radianes 
Para o cálculo do grupo de estacas Randolph \& Wroth (1979) estenderam o método através da mudança dos parâmetros de transferência de carga ( $\zeta$, Eq. 2.42) e de rigidez da estaca ( $\xi$, Eq. 2.43).

$$
\begin{aligned}
\zeta^{*} & =n * \zeta-\sum_{i-2}^{n} \ln \left(\frac{S_{i}}{r_{0}}\right) \\
\xi^{*} & =\xi *\left[1+\frac{2}{\pi} \sum_{i-2}^{n} \frac{r_{b}}{S_{i}}\right]
\end{aligned}
$$

Onde:

$n:$ número de estacas

$S_{i}$ : espaçamento entre as estacas

\subsection{GRUPOS DE ESTACAS CARREGADOS AXIALMENTE}

Geralmente num projeto de fundação quando uma estaca é insuficiente para transmitir a carga proveniente da superestrutura ao solo, são utilizadas como mínimo duas ou três estacas sob um elemento de ligação bloco de fundação ou de coroamento (geralmente rígido). A quantidade de estacas no grupo é função da capacidade de carga vertical ou horizontal da estaca isolada quando esta se encontra em agrupamento Fig. 2.9.

O fato de utilizar mais de uma estaca complica a determinação da capacidade de carga de um grupo, e uma das razões para isso é que a sobreposição dos bulbos de tensão entre estacas o que produz o chamado efeito de grupo.

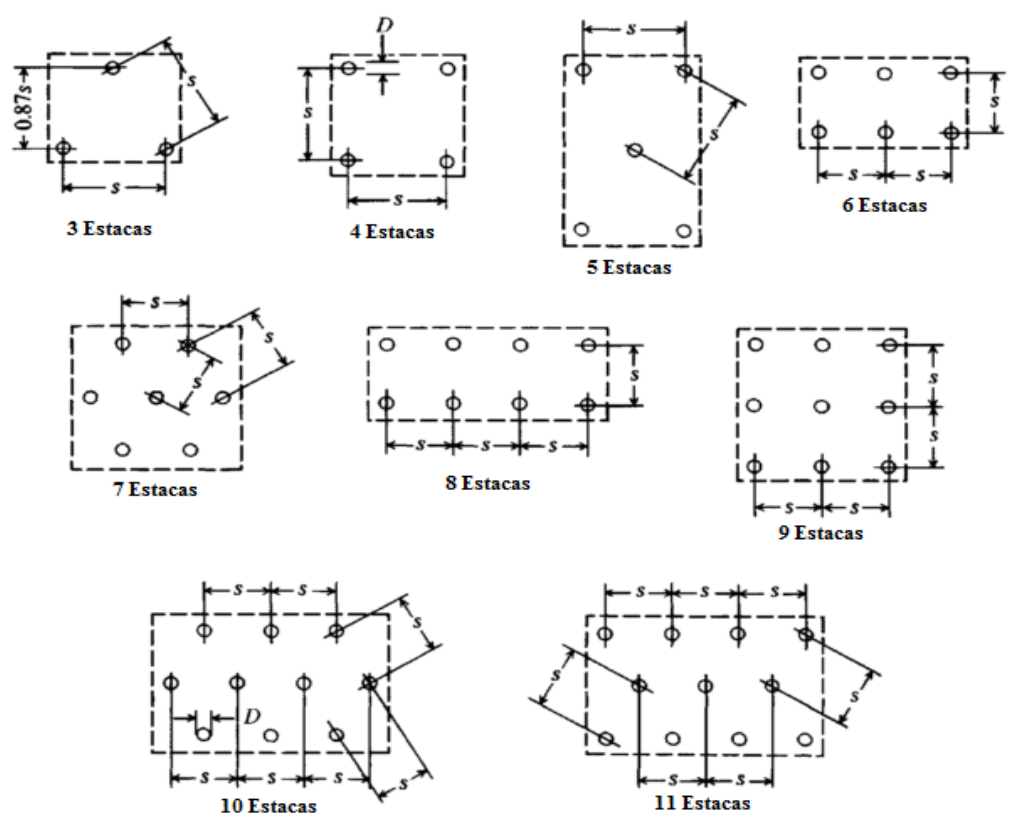

Figura 2.9. Diferentes distribuições de estacas (Bowles, 1997) 
A norma brasileira NBR 6122/10 descreve o efeito de grupo como o comportamento interativo entre estacas de fundação (Fig. 2.10), que ao transmitirem cargas ao solo. Esse comportamento faz que o recalque obtido por um grupo de estacas seja diferente do recalque de uma estaca isolada que recebe a mesma carga.
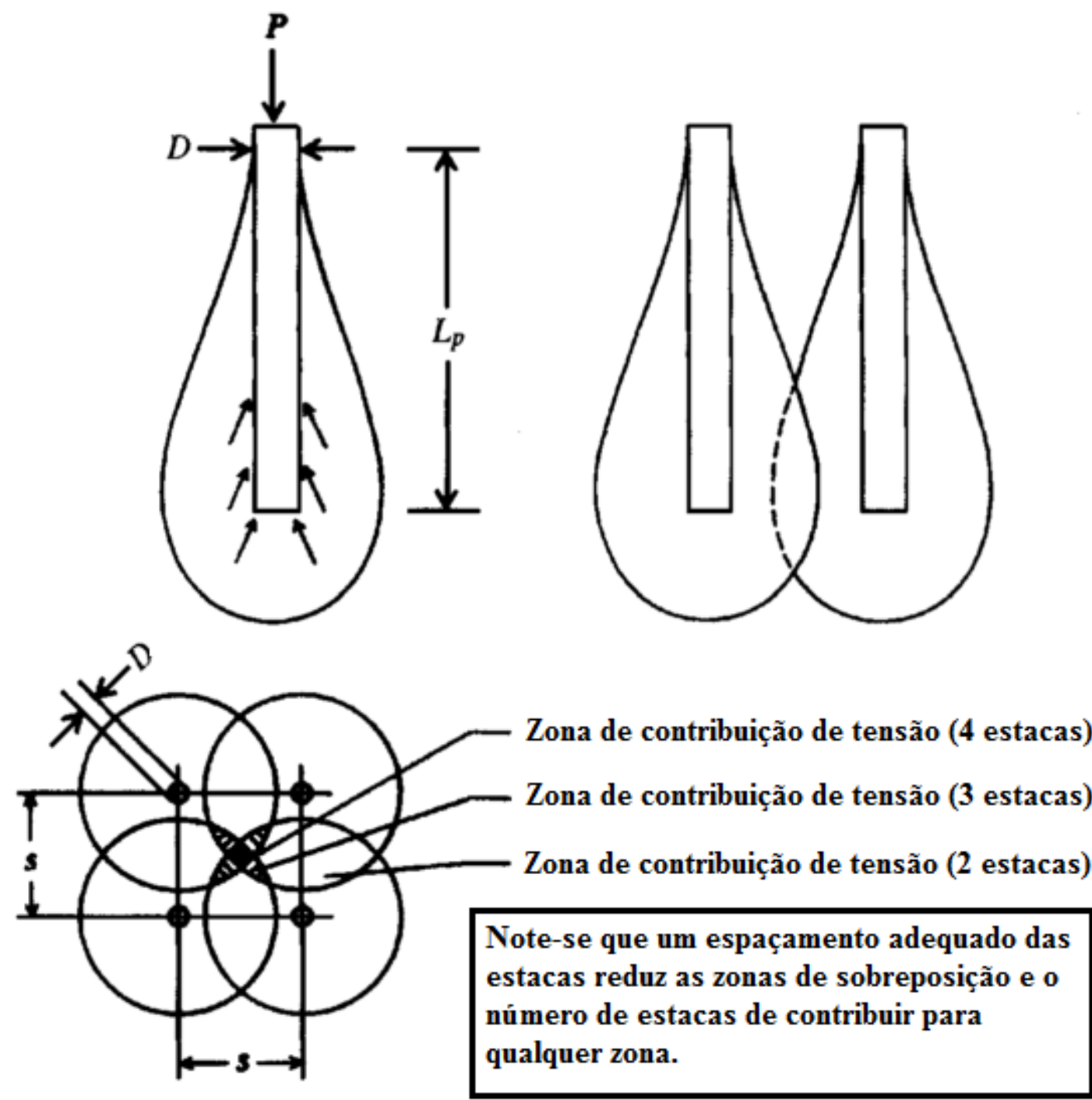

Figura 2.10. Interação de bulbos de tensão entre estacas de fundação (Bowles, 1997)

Para reduzir o efeito de grupo vários autores cita-se (Poulos \& Davis, 1980; Bowles, 1997; Braja, 2001) propõem um intervalo de espaçamento mínimo de centro a centro entre estacas de 2,5 a 3,5D (onde $\mathrm{D}$ é o diâmetro da estaca). Na prática e em situações usuais usa-se 3D, além de isso também deve ser respeitado o espaçamento entre estacas de blocos vizinhos.

\subsection{EFICIÊNCIA DE GRUPO DE ESTACAS}

A eficiência é definida como a relação entre a capacidade última de carga do grupo e a capacidade última da carga de cada estaca isolada sem o efeito de grupo (Braja, 2001), dada 
pela Eq. 2.44. Em princípio, a eficiência do grupo depende da forma e do tamanho, do espaçamento e tipo de estacas e, principalmente do tipo de solo.

$$
\eta=\frac{R_{g}}{\sum R_{i}}
$$

Onde:

$\eta$ : eficiência de grupo de estacas

$R_{g}$ : capacidade última de carga do grupo

$R_{i}$ : capacidade última de carga do elemento isolado

É necessário verificar a eficiência do grupo, devido à interação entre bulbos de tensões já que na maioria dos casos é desfavorável e produz reduções na resistência global do grupo. Vesic (1975) também comprovou que a eficiência de um grupo de estacas cresce com o afastamento entre elas, até um máximo de 3 diâmetros, sendo que a partir de tal valor a capacidade do conjunto começa a se estabilizar.

Segundo uma série de publicações do Comitê de fundações profundas apresentadas no ASCE (1984) citado por Bowles (1997) não se recomenda o uso da eficiência de grupo como uma descrição da ação do grupo. Este sugere que as estacas que trabalham principalmente por atrito lateral em solos friccionais não coesivos usando espaçamento $s=2$ até $3 \mathrm{D}$ apresentam eficiência de grupo $(n>1)$, e a razão dada é que o solo não coesivo as estacas cravadas aumentam a densidade do solo na zona vizinha das outras estacas.

Existem na literatura metodologias para estimar o coeficiente de eficiência de grupos de fundação.

Feld (1943) propôs um método simples aproximado e empírico, de cálculo da eficiência de grupos de fundação, que consiste em reduzir 1/16 da capacidade de carga de cada estaca, para cada estaca adjacente a ela. A regra de Feld não leva em consideração o espaçamento entre estacas, e pode ser equacionado da seguinte forma (Eq. 2.45):

$$
n_{\text {total }}=\frac{n_{1} e_{1}+n_{2} e_{2}+\cdots+n_{m} e_{m}}{n_{1}+n_{2}+\cdots+n_{m}}=\frac{\sum_{1}^{m} n_{i} e_{i}}{\sum_{1}^{m} n_{i}}
$$




\subsection{MODELAGEM DE BLOCOS DE ESTACAS COM O PROGRAMA DEFPIG}

O software numérico DEFPIG (Deformation Analysis of Piles Groups), utiliza os elementos de contorno desenvolvido na Universidade de Sydney por Poulos (1990). O programa determina as rigidezes e os fatores de interação de um grupo convencional de estacas submetidos a um carregamento generalizado (vertical, horizontal e momento).

O programa considera o grupo de estacas possuindo rigidez axial e lateral constante com a profundidade. As estacas são suportadas por um meio linear elástico, isotrópico e homogêneo, mas com a possibilidade de considerar o solo heterogêneo de forma simplificada, por meio da variação do módulo de elasticidade $\left(\mathrm{E}_{S}\right)$, além disso, permite calcular tanto assumindo homogeneidade lateral do solo, quanto para perfis heterogêneos.

As propriedades dos materiais que formam esses elementos foram definidas em termos dos respectivos módulos de elasticidade e coeficientes de Poisson, admitindo-se como elásticolinear para as estacas e o bloco e, além disso, isotrópico para o solo.

Cada caso analisado é definido pela variação no módulo de elasticidade do solo $\left(\mathrm{E}_{\mathrm{s}}\right)$ obtido por diferentes correlações oriundas dos ensaios de campo (SPT e DMT), além da carga para cada grupo de estacas analisado, mantendo os demais parâmetros constantes como a geometria e parâmetros mecânicos da estaca, coeficiente de Poisson do solo $\left(v_{\mathrm{s}}\right)$.

Os parâmetros mecânicos como a coesão (c') e o ângulo de atrito ( $\left.\phi^{\prime}\right)$ de cada camada foram utilizados para o cálculo da adesão entre a estaca e o solo.

As distribuições de tensões são calculados a partir da solução de Mindlin (1936) para um meio elástico, linear isotrópico, homogêneo, porém a não homogeneidade do solo ao longo do comprimento da estaca pode ser considerado de forma aproximada. As estacas são assumidas rígidas engastadas no bloco de coroamento, o limite máximo do grupo é de 36 estacas.

Os parâmetros de entrada para este programa são geometria geral do grupo de estacas (diâmetro, comprimento, espaçamento e configuração), o módulo de elasticidade da camada de solo, espessura da camada de solo, coeficiente de Poisson, módulo de elasticidade do material da estaca e o momento de inércia da seção da estaca. As demais considerações que vão ser levadas em conta nesta dissertação com o software numérico DEFPIG pode-se ver no capitulo 5. 


\section{MATERIAIS E MÉTODOS}

Neste capítulo serão descritas a localização geográfica do campo experimental SOLOTRAT Ltda., bem como, as características geotécnicas da argila porosa de Brasília. Visando conhecer mais sobre o comportamento mecânico de fundações do tipo Alluvial Anker executadas neste tipo de perfil geotécnico foi dada continuação nesta dissertação do trabalho realizado por Mendoza (2013). Este trabalho forneceu os procedimentos e resultados da investigação geotécnica e dos ensaios laboratoriais e de campo, obtidos por meio de sondagem geotécnica SPT, SPT-T, DMT, Triaxiais e provas de carga estática de carregamento lento.

Com os materiais definidos, este capítulo também apresenta a metodologia proposta empregada para avaliação da capacidade de carga axial e recalque de estacas Alluvial Anker isoladas e em grupo, executadas no campo experimental da SOLOTRAT Engenharia Geotécnica Ltda.

\subsection{LOCAL DE ESTUDO}

A empresa SOLOTRAT Engenharia Geotécnica Ltda., executora deste tipo de fundação no DF, criou um campo experimental de fundações novo em seu terreno, localizado no SAI SMAS - Conj. A1 - Lote 06 - Guará-DF, (Latitude: 1548' 59.38” S, Longitude 47 58' 0.50” O) com cota de elevação de $1084 \mathrm{~m}$. A área possui topografia suave e vegetação do cerrado, cujo perfil geotécnico é composto pelo silte argiloso poroso mole típico da região, conforme características do planalto central do Brasil (Mendoza, 2013), como mostrado na Fig. 3.1.

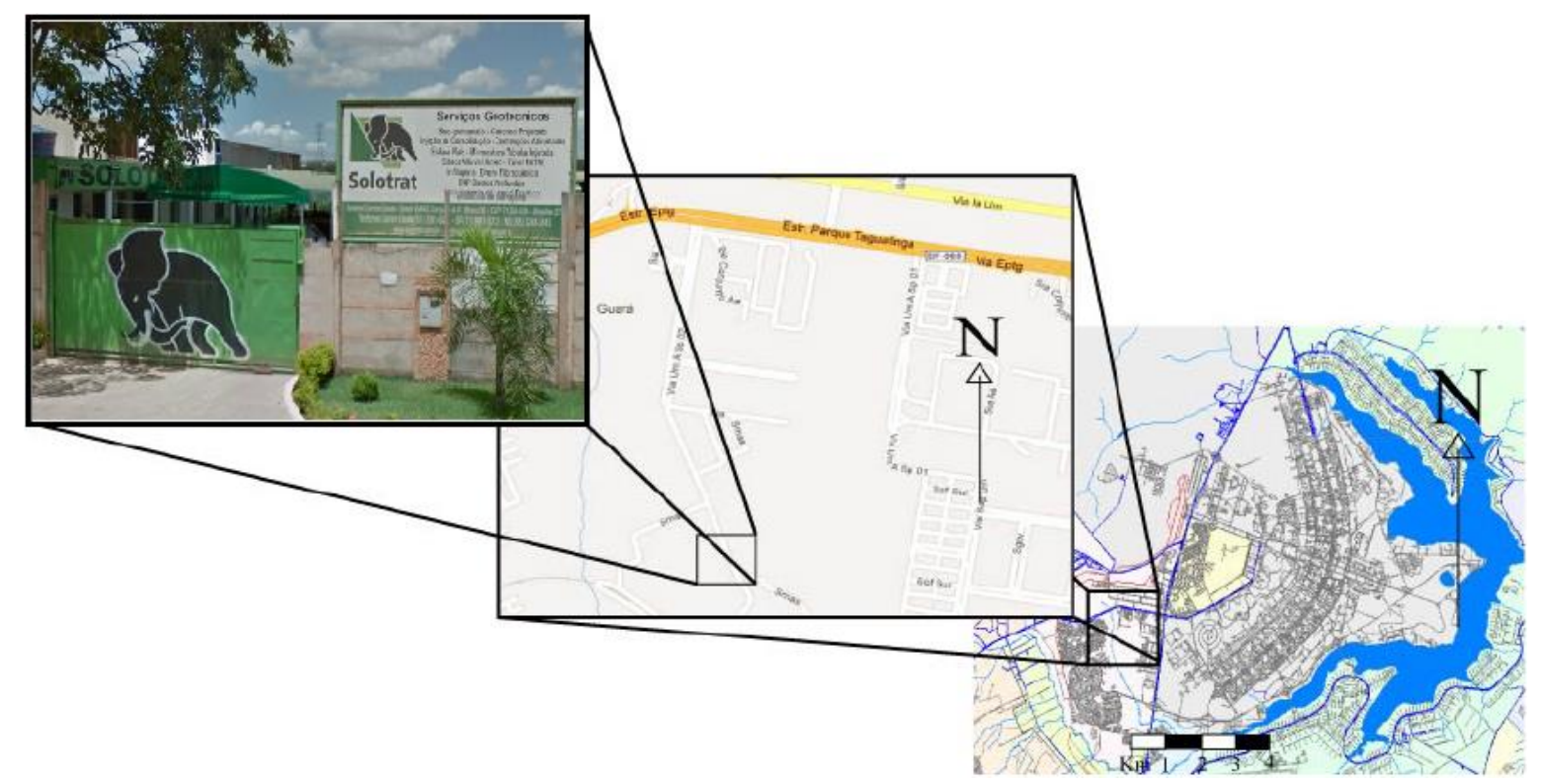

Figura 3.1. Locação do campo experimental da SOLOTRAT Modificado (Mendoza, 2013) 
$\mathrm{Na}$ área referente ao campo experimental da SOLOTRAT Ltda., se encontram camadas de solo laterítico vermelho argiloso, denominado pela comunidade geotécnica como "Argila porosa de Brasília”, a qual geralmente apresenta baixa capacidade de suporte nas camadas mais superficiais. A Argila porosa de Brasília apresenta camadas colapsíveis até os primeiros $10 \mathrm{~m}$ metros, e este tipo de comportamento foi apresentado por Guimarães (2002) por meio de ensaios de adensamento em que foi observado um comportamento colapsível a profundidades de 2, 4, e $8 \mathrm{~m}$, comportamento que desaparece a partir dos $10 \mathrm{~m}$, definindo a tensão de colapso em $100 \mathrm{kPa}$ para o campo experimental da UnB. Dadas as características similares desta formação geológica com o campo experimental da Solotrat Ltda., é apropriado usar este parâmetro como referência ao mesmo. Este comportamento também foi observado nos trabalhos apresentados por Araki, 1997; Mota, 2003 e Anjos, 2006.

\subsection{ENSAIOS DE CAMPO}

Para a obtenção da caracterização do solo, foram feitas seis perfurações espaçadas de 2,40 m, com profundidades de 8 a 15 m, cuja distribuição é apresentada na Fig. 3.2. Cinco perfurações são por meio de cravação vertical contínua no solo por meio de um cilindro amostrador padrão de diâmetro externo de 50,8 mm e $700 \mathrm{~mm}$ de comprimento, através da queda livre de um martelo com massa padronizada de $65 \mathrm{~kg}$, solto de uma altura de $75 \mathrm{~cm}$. Simultaneamente à penetração do amostrador, foram feitas medidas do $\mathrm{N}_{\mathrm{SPT}}$ e do torque (SPTT). Para a obtenção do NSPT determina-se o número de golpes necessários para a penetração de $45 \mathrm{~cm}$ do amostrador no solo, dividido em três trechos consecutivos de $15 \mathrm{~cm}$. O N $\mathrm{N}_{\mathrm{SPT}}$ é o número de golpes dos últimos $30 \mathrm{~cm}$ (sem nenhuma correção).

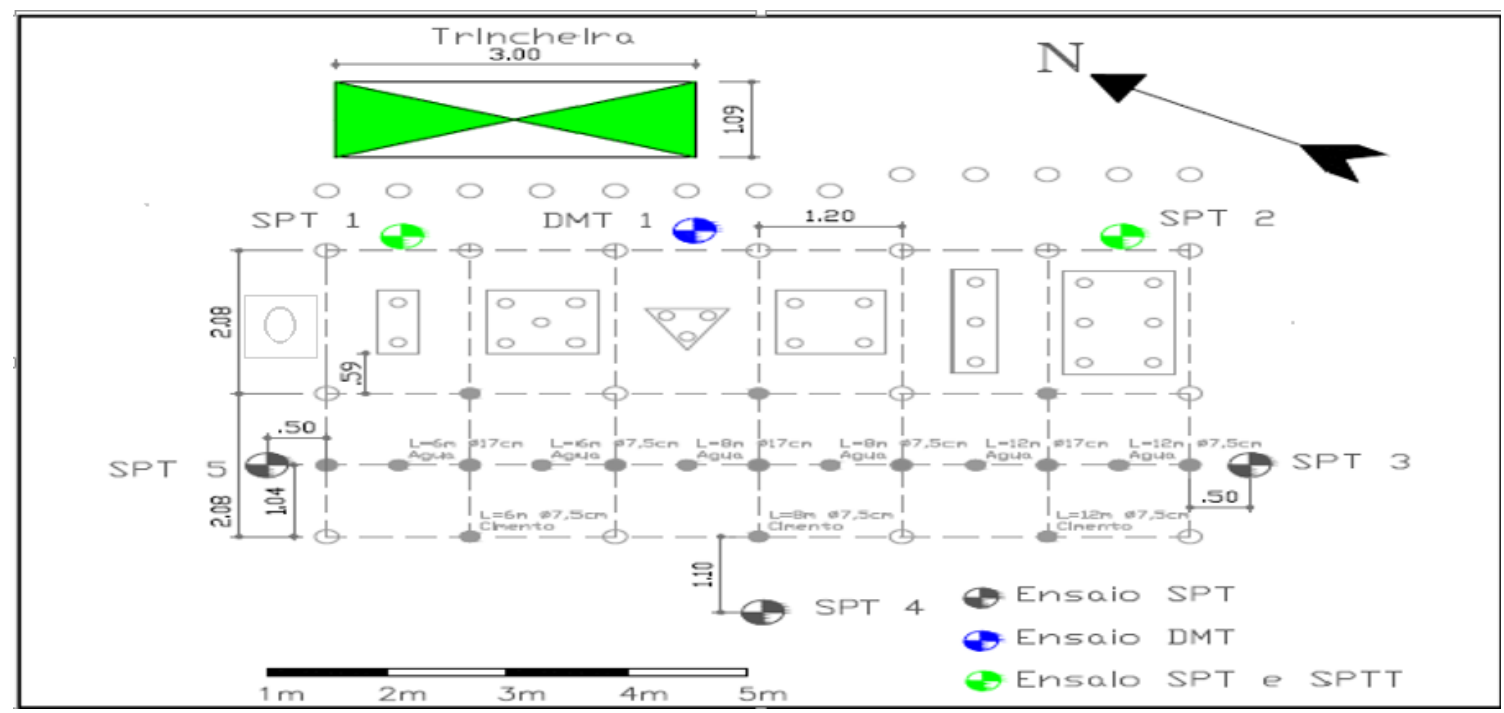

Figura 3.2. Localização dos grupos de estacas e sondagens no campo experimental (Mendoza, 2013) 
Os resultados dos ensaios como: número de golpes do ensaio SPT vs profundidade; torque máximo vs profundidade; torque residual vs profundidade; média do número de golpes do ensaio SPT e desvio padrão dos dados, são apresentados nos gráficos da Fig. 3.3.

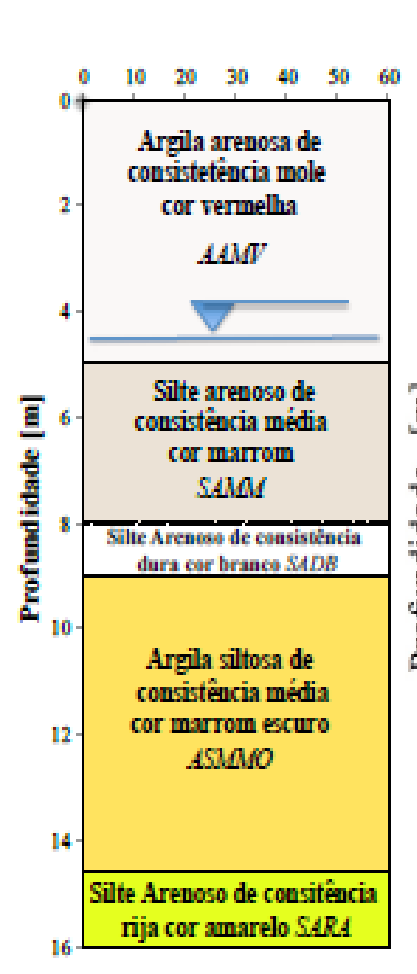

(a)

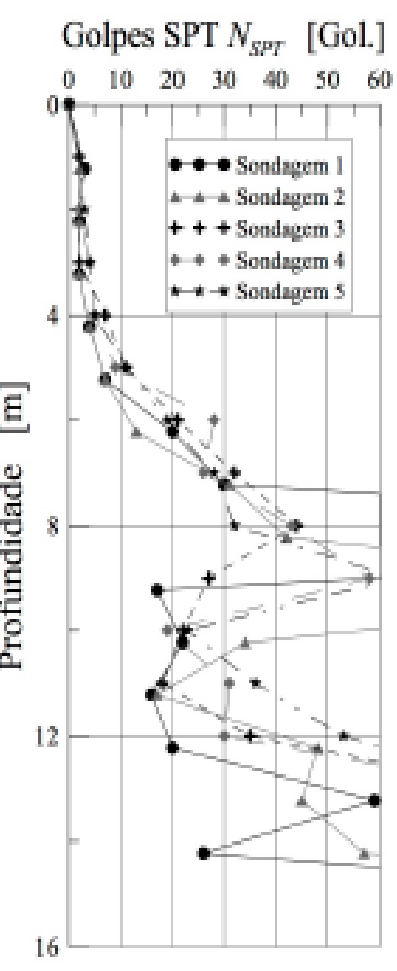

(b)

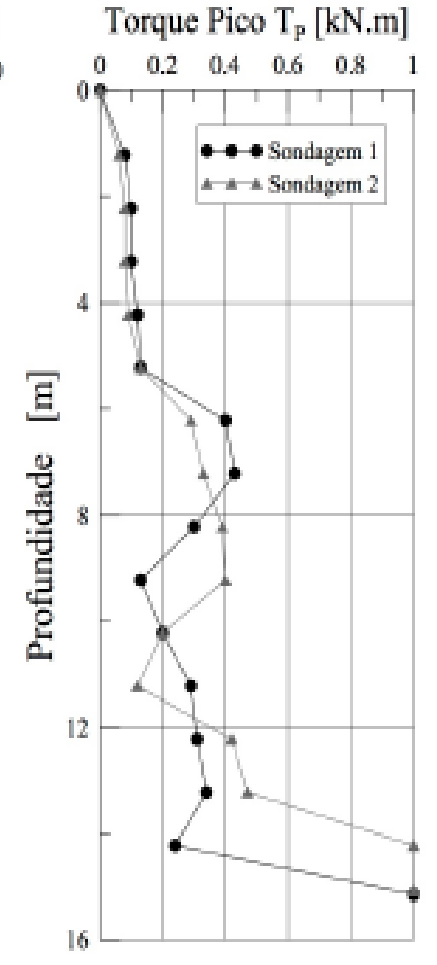

(c)

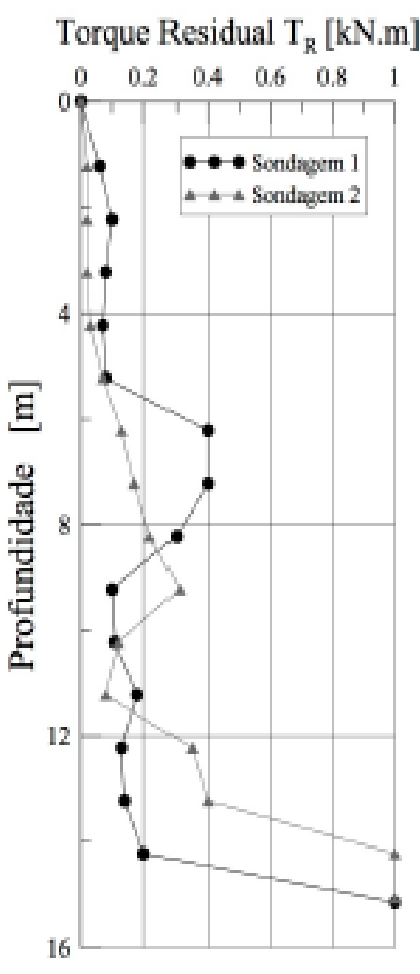

(d)

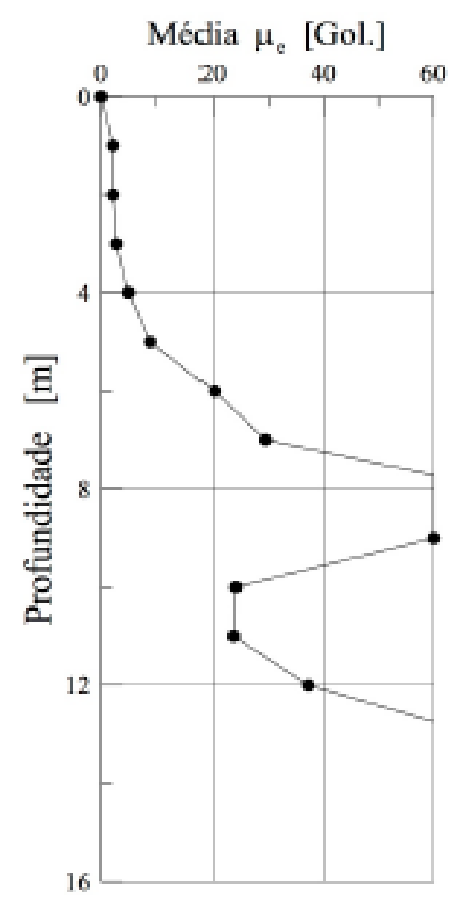

(e)

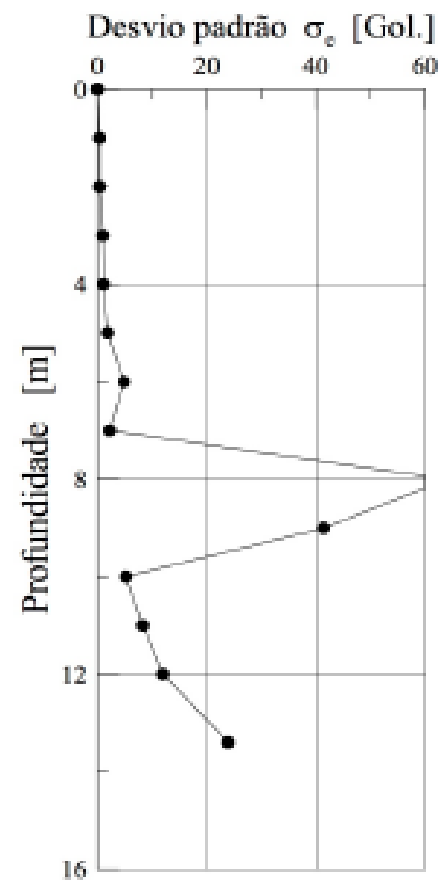

(f)

Figura 3.3. Resultados de ensaios SPT e SPT-T (Mendoza, 2013) 
Com os resultados destes ensaios, SPT e SPT-T, foram reconhecidas cinco camadas de solo. O perfil geotécnico foi definido por Mendoza (2013) da seguinte maneira: a primeira camada de 0 a 5,0 m, argila arenosa de cor vermelha com consistência mole; a segunda camada foi até $8,0 \mathrm{~m}$, composta por silte arenoso de cor marrom e consistência média; a terceira camada de 8,0 m a 9,0, silte arenoso de cor branca e consistência dura; após os 9,0 m encontra-se uma argila siltosa de consistência média de cor marrom escura; a partir dos 14,5 m até o final da perfuração, encontrou-se um silte arenoso de cor amarela e consistência rija. As camadas foram denominadas por Mendoza (2013) como: AAMV, SAAM, SADB, ASMMO e SARA, respectivamente. O lençol freático encontrou-se a 4,5 m de profundidade Fig. 3.4.

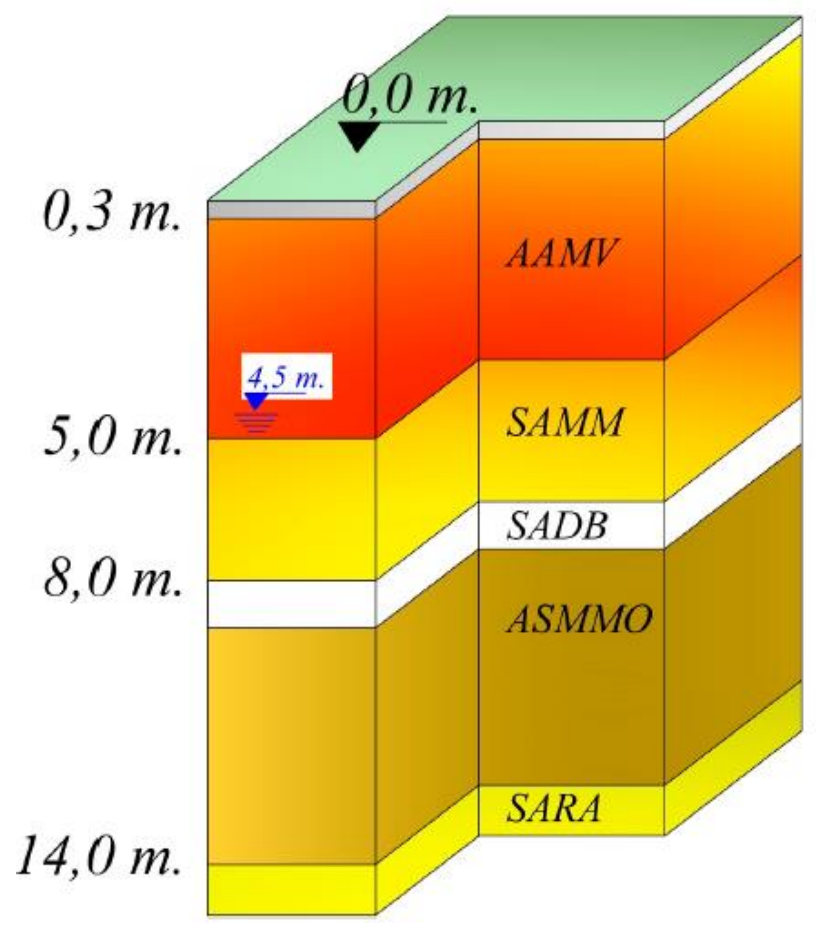

Figura 3.4. Perfil típico de solo do campo experimental (Mendoza, 2013)

No processo de identificação das camadas utilizou-se do trabalho apresentado por Decourt \& Filho (1994), integrando aos ensaios realizados (SPT, SPT-T e DMT). Para obter a confirmação do perfil geotécnico identificado, empregou-se a relação Tmax/ $\mathrm{N}_{\text {SPT }}$ também chamada de índice de torque. A primeira camada apresenta valores na faixa Tmax/ $\mathrm{N}_{\text {SPT }}$ entre 25 a 50, sendo classificada como argila porosa colapsível, conforme Tab. 3.1, com um ângulo de atrito igual a 29 graus e módulo de elasticidade do solo igual a $9 \mathrm{MPa}$, quase constante até os $5 \mathrm{~m}$, conforme a Fig 3.3. Para a segunda camada o valor de Tmax/ $\mathrm{N}_{\mathrm{SPT}}$ apresentou-se na faixa entre 15 e 25 e foi classificado como um solo saprolítico, validando a correlação para um solo de São Paulo; na terceira camada os valores de Tmax/N $\mathrm{N}_{\mathrm{SPT}}$ foram menores que 10 e o solo 
foi classificado como areia sedimentar. Nessa camada observou-se um aumento na rigidez, com valores de $\mathrm{N}_{\mathrm{SPT}}$ maiores que 60, levando a um ângulo de atrito de 45 graus, densidade relativa de $80 \%$, módulo de elasticidade do solo maior do que $60 \mathrm{MPa}$. Na quarta camada têm-se valores aproximados Tmax/ $\mathrm{N}_{\text {SPT }}$ iguais a 1, classificada como areia sedimentar, apresentando queda nos parâmetros do solo. O ensaio SPT apresenta um número de golpes de 20 a 40, densidade relativa de 20 a 40\%, com ângulo de atrito médio de 38 graus e módulo de elasticidade do solo médio de $40 \mathrm{MPa}$. Os valores do índice de torque nas diferentes camadas do campo experimental da Solotrat são mostrados na Tab. 3.2.

Tabela 3.1. Classificação do tipo de solo com o parâmetro Tmax/N

\begin{tabular}{|c|c|}
\hline Relação T/NSPT & Classificação parcial dos solos analisados \\
$10 \leq \mathrm{T} / \mathrm{N} \leq 12$ & Areias sedimentares, camadas inferiores \\
Solos Típicos da TSBSP
\end{tabular}

Tabela 3.2. Valores de índice de torque (Tmax/NSPT) no campo experimental Solotrat

\begin{tabular}{|c|c|c|}
\hline \multirow{4}{*}{ Perfil } & $\begin{array}{c}\text { Profundidade } \\
(\mathbf{m})\end{array}$ & Tmax/Nspt \\
\hline \multirow{4}{*}{ AAMV } & 1 & 0,0 \\
\cline { 2 - 3 } & 2 & 27,5 \\
\cline { 2 - 3 } & 3 & 44,1 \\
\cline { 2 - 3 } & 4 & 44,1 \\
\hline \multirow{3}{*}{ SAMM } & 5 & 25,7 \\
\cline { 2 - 3 } & 6 & 18,2 \\
\hline \multirow{2}{*}{ SADB } & 7 & 20,5 \\
\hline \multirow{3}{*}{ ASMMO } & 8 & 12,2 \\
\cline { 2 - 3 } & 10 & 2,8 \\
\cline { 2 - 3 } & 11 & 3,4 \\
\cline { 2 - 3 } & 13 & 7,0 \\
\hline \multirow{2}{*}{ SARA } & 14 & 12,2 \\
\cline { 2 - 3 } & 15 & 10 \\
\hline
\end{tabular}




\subsection{ENSAIOS LABORATORIAIS}

Mendoza (2013) caracterizou mecanicamente o solo do campo experimental da Solotrat Ltda. com dois blocos de solo inalterados de dimensões $30 \mathrm{~cm}$ x $30 \mathrm{~cm}$ x $30 \mathrm{~cm}$, a $3 \mathrm{~m}$ de profundidade, e as amostras foram coletadas de uma trincheira localizada no campo experimental, (Fig. 3.2). Para obter os parâmetros elasto-plásticos para alimentar os modelos constitutivos, foram realizados ensaios de caracterização e comportamento mecânico, como ensaio triaxial convencional CD e ensaios de adensamento. Com estes parâmetros alimentamse as diferentes metodologias analíticas de capacidade de carga e recalque de estacas isoladas e grupo utilizadas nesta dissertação.

\subsubsection{CARACTERIZAÇÃO DO SOLO ESTUDADO}

A identificação e descrição do solo foi realizada seguindo a norma ASTM-D2488, 2000. A partir do reconhecimento de características intrínsecas do material como cor, textura, odor, forma, consistência, cimentação, angularidade dos grãos, umidade natural, dilatância, dureza, plasticidade e granulometria volumétrica. Segundo Mendoza (2013) o solo foi classificado como uma argila, amparado em outros trabalhos como Araki, 1997; Guimarães, 2002; Mota, 2003, já que os métodos utilizados em seu trabalho a classificava como uma argila CH (alta compressibilidade), enquanto os ensaios de LL e IP a descrevia como um silte ML (silte de baixa compressibilidade). Dessa forma, com base nos trabalhos antes mencionados, conclui-se que o solo apresenta características de argila.

Além disso, foram feitos ensaios de caracterização do material como ensaios de umidade natural w, limite de liquidez LL, limite plástico LP, peso específico $\gamma$, peso especifico de sólidos $\gamma \mathrm{s}$, peso especifico seco $\gamma \mathrm{d}$, granulometria por sedimentação e índice plástico, conforme apresentados na Tab. 3.3.

Tabela 3.3. Caracterização básica do material (Mendoza, 2013)

\begin{tabular}{|c|c|c|c|c|c|c|c|c|c|c|}
\hline Camada & Prof. (m) & Descrição & $\begin{array}{c}\mathrm{W} \\
(\%)\end{array}$ & $\begin{array}{c}\mathrm{LL} \\
(\%)\end{array}$ & $\begin{array}{c}\mathrm{LP} \\
(\%)\end{array}$ & $\begin{array}{c}\mathrm{IP} \\
(\%)\end{array}$ & $\gamma\left(\mathrm{kN} / \mathrm{m}^{3}\right)$ & $\begin{array}{c}\text { Areia } \\
(\%)\end{array}$ & $\begin{array}{c}\text { Silte } \\
(\%)\end{array}$ & $\begin{array}{c}\text { Argila } \\
(\%)\end{array}$ \\
\hline $\begin{array}{c}\text { AAMV } \\
(\mathrm{CH})\end{array}$ & $0-5$ & $\begin{array}{c}\text { Argila } \\
\text { arenosa } \\
\text { vermelha }\end{array}$ & 32,4 & 42 & 30 & 12 & 14,85 & 16,4 & 11,3 & 72,3 \\
\hline
\end{tabular}




\subsubsection{ENSAIO TRIAXIAL CONVENCIONAL}

Os ensaios foram realizados sob condições drenadas e não drenadas, e com estes ensaios foi obtido o comportamento para condições de cisalhamento, parâmetros do solo em estado crítico e a rigidez do solo.

Foram realizados seis ensaios dos quais três ensaios adensados isotropicamente a pressões confinantes iguais a 110, 200 e $300 \mathrm{kPa}$, observando-se segundo Mendoza (2013) uma maior tensão desviadora quanto maior a pressão confinante, e com excesso de poropressão devido ao aumento da tensão confinante. Na Fig. 3.5. (a), pode-se ver um ganho na resistência a medida que o solo é deformado, comportamento não comum em argilas notado por Mendoza (2013) fato este citado no trabalho de Roscoe et al., (1963) que demostra tal comportamento.

Além disso, o autor da presente dissertação concorda com esta análise, mas quer agregar que este comportamento de ganho de resistência está fundamentado na estrutura do solo, a qual tem pontos que colapsam a diferentes energias com o aumento da tensão confinante, principalmente durante o adensamento do ensaio, no qual o solo vai apresentando colapso parcial, aumentando os níveis de contato entre as agregações de argila (dano na estrutura). Consequentemente o solo aumenta a força cisalhante, e como a área do ensaio é "constante" o mesmo apresenta um aumento artificial na resistência enquanto está sendo deformado.

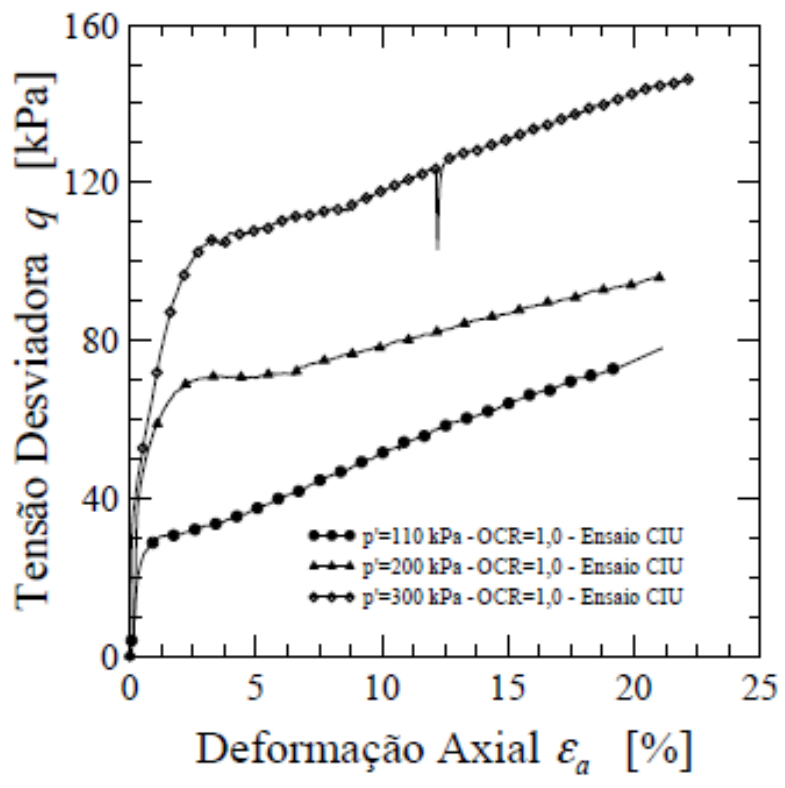

(a)

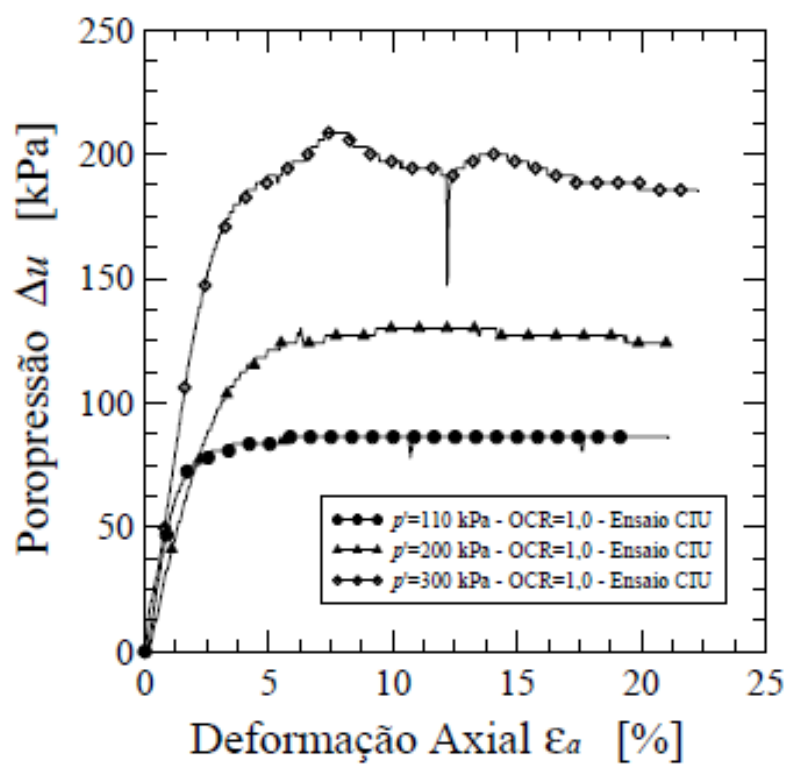

(b)

Figura 3.5. Ensaio não drenado (Mendoza, 2013)

Os outros três ensaios adensados a tensões efetivas de 110, 200 e $300 \mathrm{kPa}$ geraram uma tensão desviadora em condições drenadas (CD), cujas trajetórias de tensões são apresentadas na Fig. 3.6, em que se observa que estas chegam quase à mesma linha do estado crítico. 


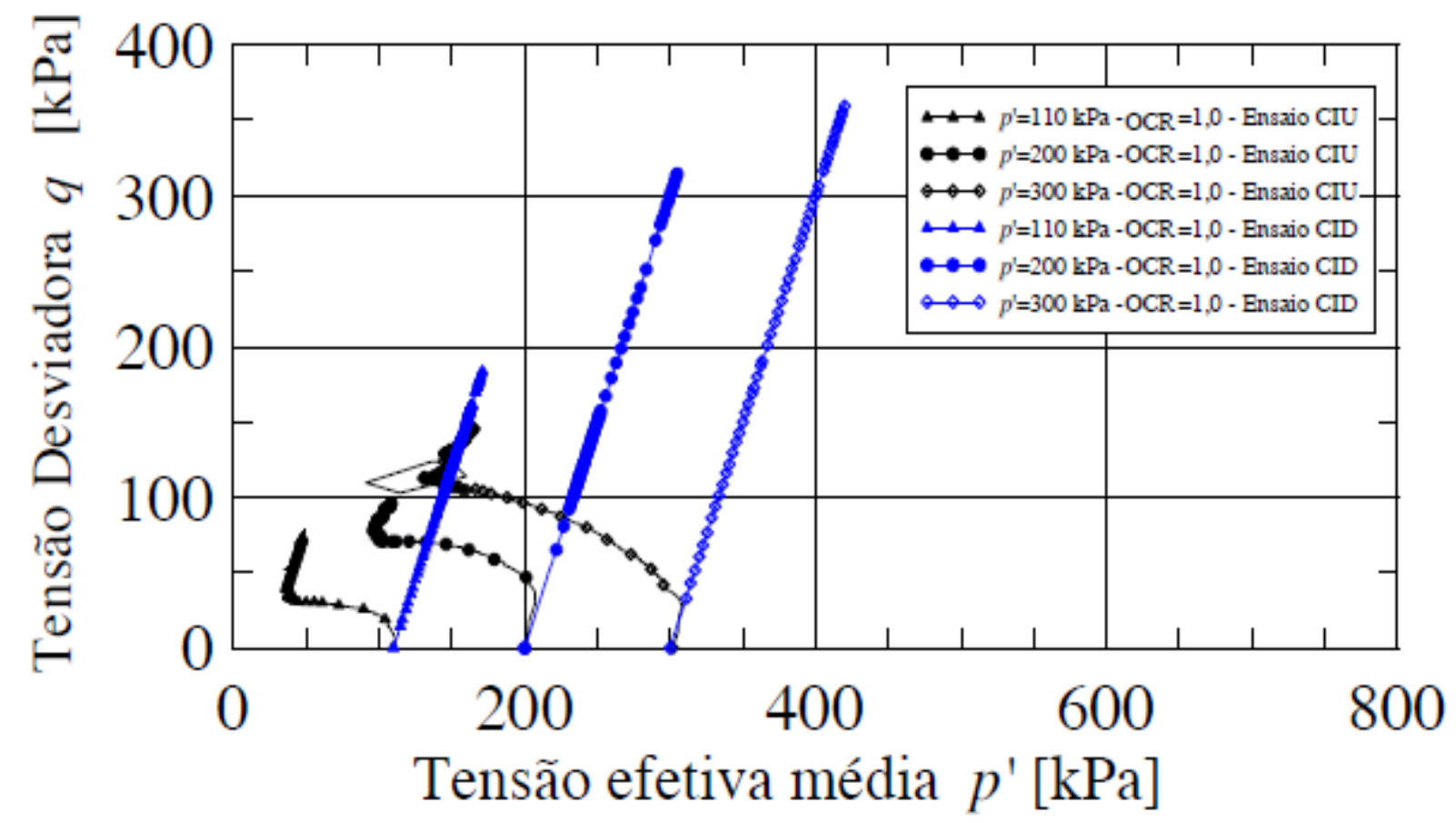

Figura 3.6. Trajetórias drenadas e não drenadas no ensaio triaxial (Mendoza, 2013)

\subsection{PARÂMETROS DO SOLO OBTIDOS DE ENSAIOS LABORATORIAIS E DE CAMPO}

A obtenção dos parâmetros aproximados do perfil de solo existente no campo experimental da SOLOTRAT, foi alcançada com ensaios de campo e laboratorio resumidamente descritos anteriormente, que se encontram explicados no trabalho de Mendoza (2013). Estes resultados foram complementados com dados do campo experimental da universidade de Brasília, já que ambos apresentam características geológicas e geotécnicas similares; neste último caso podem ser citados alguns trabalhos como Araki, 1997; Guimarães, 2002; Mascarenha, 2003; Mota, 2003; Anjos, 2006; Hortegal, 2011 de acordo com a revisão bibliográfica realizada.

Na Tab. 3.4 Mendoza (2013) agrupou os parâmetros do solo obtidos por meio de ensaios laboratoriais e de campo, os quais vão ser utilizados para o desenvolvimento desta dissertação, quando aplicados a metodologias analíticas de capacidade de carga vertical e deslocabilidade. 
Tabela 3.4. Parâmetros obtidos no campo experimental da Solotrat Ldta (Mendoza, 2013)

\begin{tabular}{|c|c|c|c|c|c|}
\hline Camada & Parâmetro & Símbolo & Valor médio & Intervalo & Origem \\
\hline \multirow{4}{*}{ AAMV } & Ângulo de atrito & $\phi^{\prime}$ & 29 & $26-34$ & Ensaio de campo e triaxial \\
\hline & Módulo de elasticidade & $\mathrm{E}(\mathrm{Mpa})$ & 9 & $2,3-14$ & Ensaio de campo e triaxial \\
\hline & Coesão & $\mathrm{c}^{\prime}(\mathrm{kPa})$ & 14 & 9 - 19 (Araki, 97) & triaxial \\
\hline & Coeficiente de Poisson & $v$ & 0,35 & $0,38-0,33$ & Ensaio de campo \\
\hline \multirow{4}{*}{ SAMM } & Ângulo de atrito & $\phi^{\prime}$ & 35 & $29-41$ & Ensaio de campo e triaxial \\
\hline & Módulo de elasticidade & $\mathrm{E}(\mathrm{Mpa})$ & 38 & $7,4-96$ & Ensaio de campo \\
\hline & Coesão & $\mathrm{c}^{\prime}(\mathrm{kPa})$ & 20 & 16 - 24 (Perez, 97) & triaxial \\
\hline & Coeficiente de Poisson & $v$ & 0,29 & $0,27-0,33$ & Ensaio de campo \\
\hline \multirow{4}{*}{ SADB } & Ângulo de atrito & $\phi^{\prime}$ & 39 & $33-45$ & Ensaio de campo e triaxial \\
\hline & Módulo de elasticidade & $\mathrm{E}(\mathrm{Mpa})$ & 60 & $20-120$ & Ensaio de campo e triaxial \\
\hline & Coesão & $\mathrm{c}^{\prime}(\mathrm{kPa})$ & 50 & $40-60$ (Mota, 03) & triaxial \\
\hline & Coeficiente de Poisson & $v$ & 0,27 & $0,22-0,32$ & Ensaio de campo \\
\hline \multirow{4}{*}{ ASMMO } & Ângulo de atrito & $\phi^{\prime}$ & 35 & $33-40$ & Ensaio de campo e triaxial \\
\hline & Módulo de elasticidade & $\mathrm{E}(\mathrm{Mpa})$ & 43 & $19-100$ & Ensaio de campo e triaxial \\
\hline & Coesão & $\mathrm{c}^{\prime}(\mathrm{kPa})$ & 28 & $22-34$ (Mota, 03) & triaxial \\
\hline & Coeficiente de Poisson & $v$ & 0,29 & $0,26-0,31$ & Ensaio de campo \\
\hline
\end{tabular}

\subsection{PROVAS DE CARGA ESTÁTICAS EM GRUPOS ALLUVIAL ANKER}

Para avaliar o comportamento mecânico das estacas Alluvial Anker no campo experimental da SOLOTRAT Ltda. foram executadas por Mendoza (2013) um total de 50 estacas, 23 de $13 \mathrm{~cm}$ de diâmetro nominal com $8 \mathrm{~m}$ de comprimento, para conformar os 6 grupos de fundação, e 27 estacas de $17 \mathrm{~cm}$ de diâmetro nominal com $12 \mathrm{~m}$ de comprimento, que serviram como reação das provas de carga estática. As estacas foram locadas a uma distância igual a três vezes o seu diâmetro para se minimizar o efeito de grupo entre as estacas de reação e as testadas. A distribuição e localização dos grupos é apresentada na Fig. 3.7. Além disso, a figura também apresenta as dimensões dos blocos de coroamento, os quais foram dimensionados para garantir rigidez infinita a fim de não se ter efeitos de deflexões entre o bloco de coroamento e o solo. 


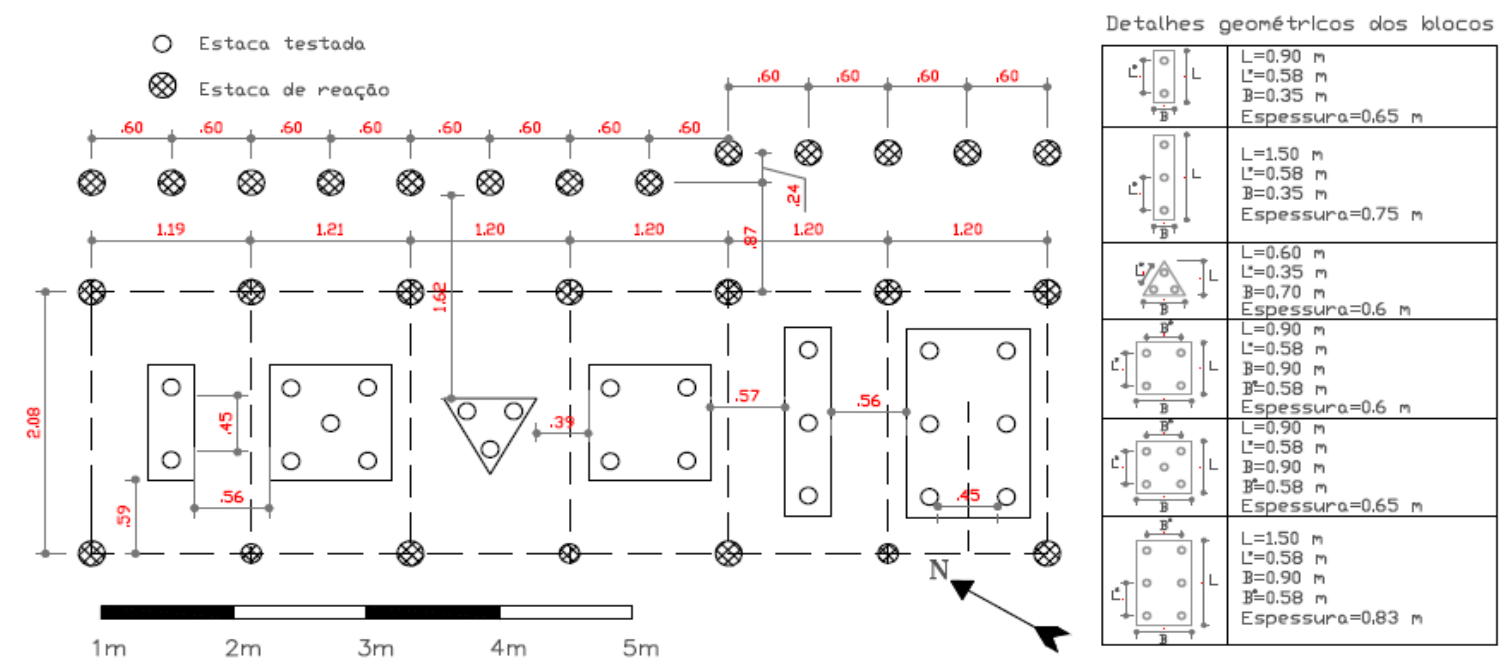

Figura 3.7. Localização dos grupos de estacas e dimensões dos blocos no campo experimental (Mendoza,

2013)

Os grupos de estacas foram testados com provas de carga carregadas lentamente segundo a norma Brasileira NBR 12131-06. Foram feitas com o objetivo de validar seu comportamento com os seguintes aspectos de: prazo mínimo de dez dias entre a execução da estaca e a prova de carga; incrementos iguais de carga não superiores a $20 \%$ da carga de trabalho da estaca; carga estabilizada por no mínimo de 30 minutos, com leituras de recalque a 2, 4, 8, 15 e 30 minutos; e repetição do processo com intervalos de 30 minutos até que as leituras de recalque estabilizassem.

A carga máxima aplicada para as provas de carga verticais foi de $1800 \mathrm{kN}$ porque a capacidade máxima do macaco hidráulico e da célula de carga era de 2000kN. Cada ensaio foi realizado em duas etapas:

- Oito incrementos de carga com uma força de $196,2 \mathrm{kN}$ no grupo de estacas até 1765,8 $\mathrm{kN}$. As leituras finais de recalque foram feitas após a estabilização.

- Descarga por meio de quatro estágios de 392,4 kN no bloco testado. Após cada estágio de descarga, as medidas nos extensômetros foram lidas até, no mínimo, 15 minutos.

Foram executadas doze (12) provas de carga estáticas verticais de carregamento lento com as curvas carga-recalque para cada configuração de estaca, fornecendo a carga limite para cada grupo e o nível de recalque para cada carregamento, como apresentado na Fig. 3.8.

Além disso, as provas de carga verticais executadas por Mendoza (2013) foram feitas com o contato solo-placa (Radier Estaqueado), e posteriormente foi realizada uma escavação de 10 centímetros embaixo do bloco de coroamento para executar as provas de carga sem o suporte da placa, e neste caso obter as curvas carga-recalque de um grupo de fundação "convencional" para cada configuração estudada. 

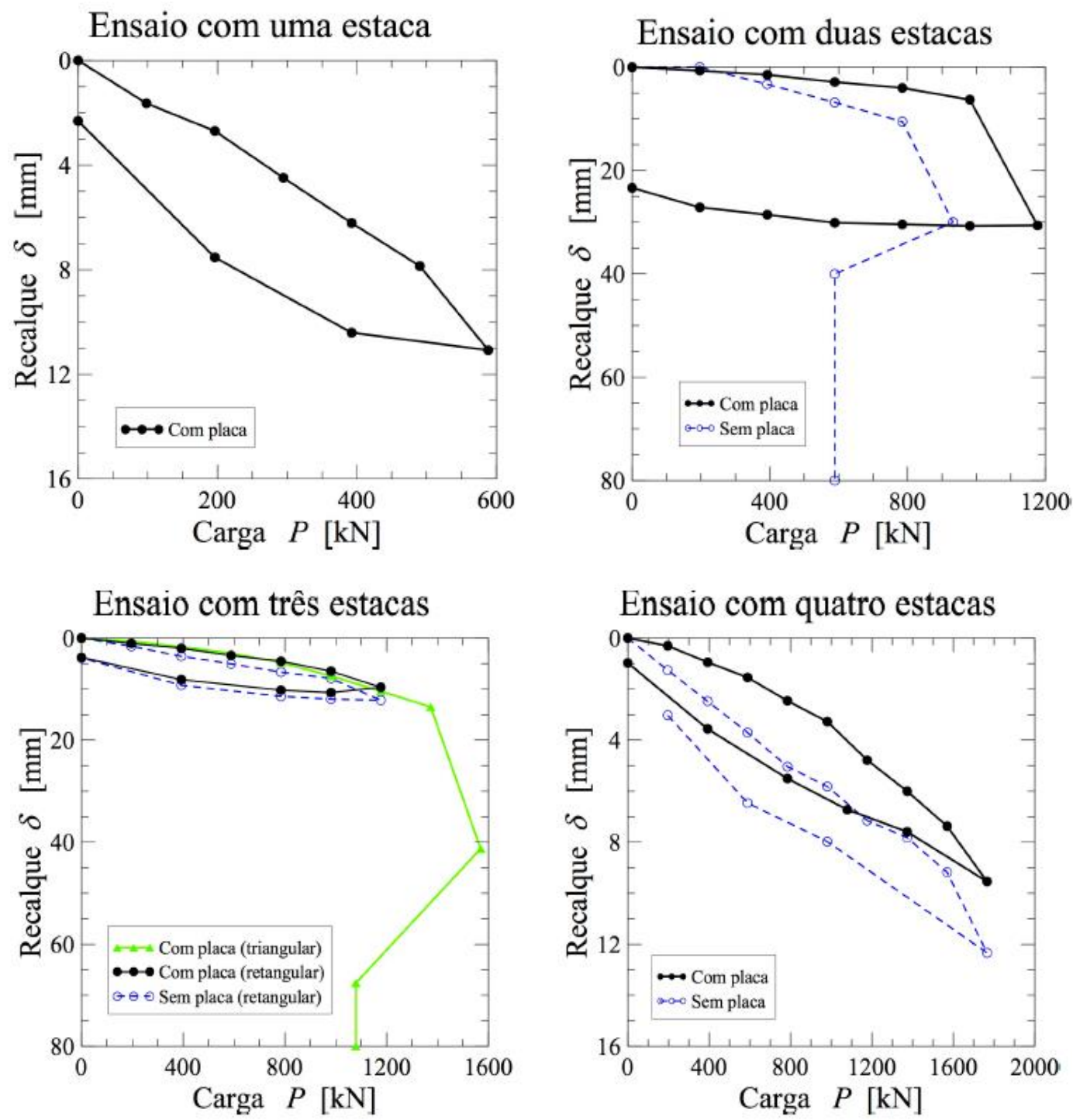

Ensaio com cinco estacas

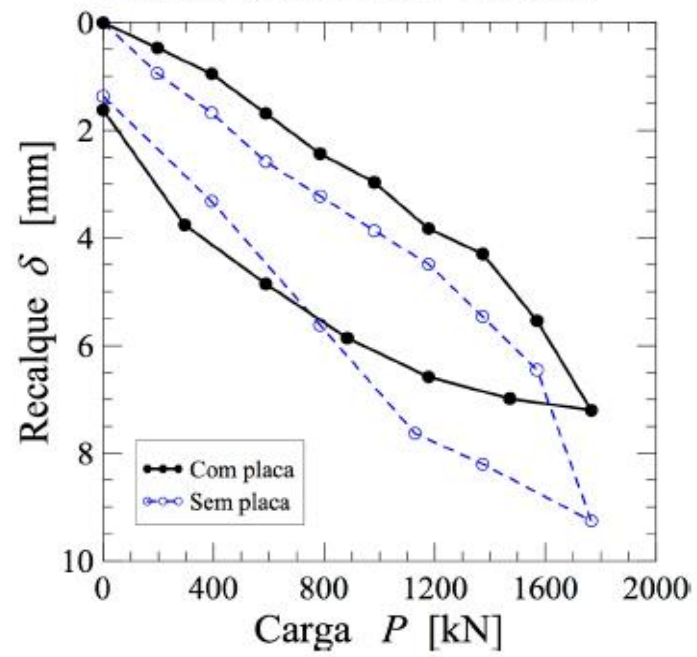

Ensaio com seis estacas

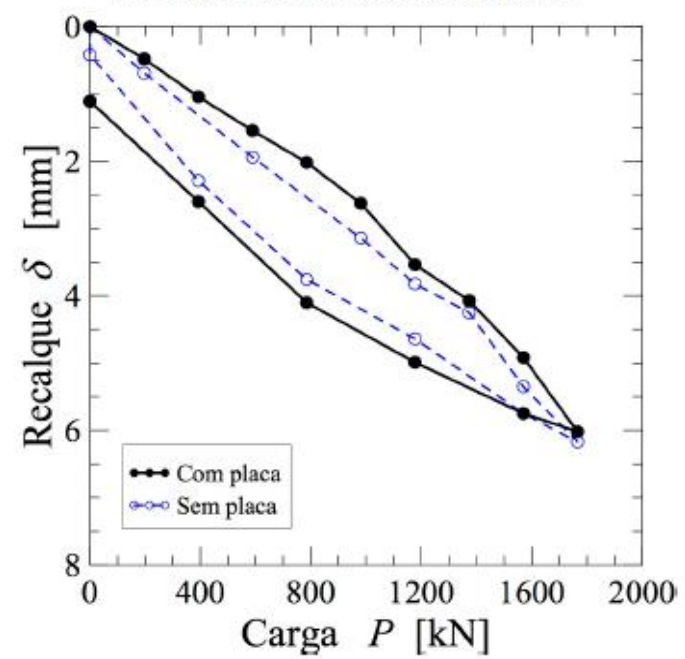

Figura 3.8. Provas de carga com contribuição da placa (Radier Estaqueado) e sem contribuição da placa (grupo convencional de fundação) Alluvial Anker (Mendoza, 2013) 
A estimativa da capacidade limite de cada configuração de estacas, segundo Mendoza (2013), foi obtida utilizando duas metodologias consagradas na engenharia de fundações; ou seja o critério usado pela norma brasileira de fundações NBR 6122-2010, e outro baseado em extrapolação da curva carga-recalque por Van der Veen, modificado por Aoki (1976).

Na Tab. 3.5 são apresentados os resultados das provas de carga estáticas verticais realizadas no campo experimental da SOLOTRAT Ltda., a carga limite, a carga de trabalho e o deslocamento para cada configuração de estacas obtidas para cada metodologia de estimativa de carga limite.

No trabalho de Mendoza (2013) foram medidos os tempos de construção da estaca Alluvial Anker com média dos tempos para ambos diâmetros (13 e $17 \mathrm{~cm})$ foi de 8 min na perfuração, enchimento em 6 min e um tempo total médio de 13 min, concluindo que a este tipo de estaca é uma alternativa rápida como solução em fundações profundas, além disso, observouse que a carga máxima aplicada nas provas dos grupos de quatro, cinco e seis é menor que a carga última calculada. Isso ocorreu devido à limitação de carga máxima permitida pelo macaco hidráulico de 2000 kN.

Tabela 3.5. Resumo dos resultados das provas de carga verticais (sem suporte de placa) no campo experimental Solotrat (Mendoza, 2013)

\begin{tabular}{|c|c|c|c|c|c|c|c|c|}
\hline $\begin{array}{c}\text { Prova de } \\
\text { Carga }\end{array}$ & $\begin{array}{c}\mathbf{P}_{\text {MAX }} \\
(\mathbf{k N})\end{array}$ & $\begin{array}{c}\boldsymbol{\delta}_{\text {máx }} \\
(\mathbf{m m})\end{array}$ & $\begin{array}{c}\mathbf{P}_{\text {ult }} \\
(\mathbf{k N})^{\mathbf{1}}\end{array}$ & $\begin{array}{c}\mathbf{P}_{\text {ult }} \\
(\mathbf{k N})^{\mathbf{2}}\end{array}$ & $\begin{array}{c}\boldsymbol{\delta}_{\text {ult }} \\
(\mathbf{m m})^{\mathbf{2}}\end{array}$ & $\begin{array}{c}\mathbf{P}_{\text {trab }} \\
(\mathbf{k N})^{\mathbf{1}}\end{array}$ & $\begin{array}{c}\mathbf{P}_{\text {trab }} \\
(\mathbf{k N})^{\mathbf{2}}\end{array}$ & Data \\
\hline Grupo 2 & 950 & --- & 833 & 650 & 8 & 416 & 325 & $22 / 03 / 2011$ \\
\hline Grupo 3 & 1200 & 12,2 & 1220 & 1100 & 10,8 & 610 & 550 & $08 / 06 / 2011$ \\
\hline Grupo 4 & 1800 & 12,33 & 1991 & 1780 & 14,1 & 996 & 890 & $11 / 04 / 2011$ \\
\hline Grupo 5 & 1800 & 9,25 & 2050 & 1950 & 15,1 & 1025 & 975 & $04 / 04 / 2011$ \\
\hline Grupo 6 & 1800 & 6,17 & 2766 & 2520 & 18,2 & 1383 & 1260 & $17 / 06 / 2011$ \\
\hline $\begin{array}{l}\text { 1 Obtido pelo método de Van Der Veen de 1953 } \\
\text { 2 Obtido pelo método da NBR 6122-2010 }\end{array}$
\end{tabular}

\subsection{METODOLOGIA DE TRABALHO}

Para avaliar o comportamento de estacas Alluvial Anker no solo poroso característico do Distrito Federal, foi portanto utilizado parte dos dados de uma tese de Doutorado desenvolvida no campo experimental da SOLOTRAT (Mendoza, 2013) intitulada "Estudo do comportamento mecânico e numérico de grupo de estacas do tipo Alluvial Anker em solo poroso do Distrito Federal". Este trabalho forneceu os resultados de ensaios laboratoriais e de campo (SPT, SPT-T, DMT), a caracterização do solo que conforma o perfil de estudo, os ensaios triaxiais e curvas carga-recalque de grupos Alluvial Anker para os grupos de 2,3,4,5 e 6 
estacas. Destaca-se que só foram utilizadas as provas de carga sem contato com solo (grupos convencionais), e além disso, na presente dissertação trabalhou-se com as mesmas condições executivas e dimensões de diâmetro e comprimento das estacas utilizadas no trabalho de Mendoza (2013).

Com a informação à disposição passou-se a identificar as linhas de trabalho da presente Dissertação que foram conformadas pela análise da informação fornecida, identificação de informação indisponível e o cumprimento dos objetivos traçados tanto analíticos e semiempíricos, como experimentais.

Para definir as metodologias analíticas e semi-empíricas utilizadas na estimativa da capacidade de carga axial de estacas Alluvial Anker correntemente usadas na engenharia de fundações, foram levados em conta a geometria da estaca, os dados de ensaios SPT, SPT-T, DMT e Triaxiais, a tecnologia executiva empregada para execução, e o local/solo de estudo (Argila porosa de Brasília), conforme descrição no Capítulo 2.

As metodologias a serem analisadas baseadas no ensaio SPT são as seguintes: Aoki \& Velloso (1975); Decourt \& Quaresma (1978), Teixeira (1996) e Lobo (2005), baseadas no ensaio SPT-T: Alonso (1996); Decourt (1996); Camapum de Carvalho (1998) e Peixoto (2001) e baseadas no DMT: Pfeiffer \& Van Impe (1991) e Powell (2001).

O processo executivo de estacas Alluvial Anker foi considerado inicialmente pelo autor da presente Dissertação como misto (escavada e injetada), e com isto, foi calculada a capacidade de carga axial da estaca considerado metodologias semi-empíricas baseadas no SPT e SPT-T e diferentes fatores de estaca (fatores empíricos de correlação) como: escavada, injetada de pequeno diâmetro e raiz. Ou seja, foi calculada a capacidade de carga axial assumindo-se diferentes processos executivos como raiz, injetada ou escavada e assim foi identificado qual desses é o mais apropriado para estimar a capacidade de carga axial em estacas Alluvial Anker no solo regional do D.F.

As metodologias analíticas levam em conta apenas as propriedades geotécnicas do local onde a estaca foi executada e a geometria da mesma. Foram utilizadas metodologias teóricas clássicas formuladas para solos puramente argilosos ou arenosos como são o método "alfa" e "beta", dado que o solo estudado pode apresentar as duas condições de drenagem. Neste caso considerou-se no cálculo a soma das duas equações propostas para cada tipo de solo, sendo que a mesma foi feita com base no exposto por Cintra e Aoki (1999) e Décourt (1996). Estas são metodologias consagradas na prática de fundações, em que os parâmetros são obtidos de ensaios laboratoriais para calcular a resistência por atrito lateral. 
A análise de deslocabilidade é composta por metodologias de estimativa de recalque baseadas na teoria da elasticidade e em metodologias empíricas como: Poulos \& Davis (1980) e Randolph \& Wroth, (1978, 1979) modificado por Randolph (1994) e método empírico simplificado Randolph, em Fleming et al. (1985) para estacas isoladas e para grupo de estacas.

Para complementar a análise de estimativa de recalque em estacas Alluvial Anker, foi empregado o software DEFPIG, o qual é alimentado com parâmetros elásticos como o módulo de elasticidade do solo e o coeficiente de Poisson para cada camada do perfil estudado.

Os valores adotados para o módulo de elasticidade (Es) e o coeficiente de Poisson ( $v_{\mathrm{s}}$ ) das diferentes camadas que conformam o perfil de estudo foram fornecidas por ensaios de campo e laboratoriais como os ensaios SPT, DMT e triaxiais inicialmente conforme a Tab 3.4.

Utilizando o programa DEFPIG para complementar a análise de deslocabilidade em grupos de estacas Alluvial Anker, foi calculado o valor de recalque para o módulo de elasticidade do solo (Es) obtido com SPT pelos métodos de Clayton (1993) e Poulos (1998), e com o ensaio DMT pelo método de Marchetti (2001). Não foi calculado o recalque utilizando o módulo de elasticidade obtido com o ensaio triaxial, dado que só se tinha o ensaio para uma única profundidade, e com um só dado não se consegue construir o gráfico do módulo do solo ao longo da profundidade.

Com tudo isto, passou-se à parte experimental da realização de uma prova de carga estática adicional em estaca isolada complementando assim as informações previamente obtidas a partir da tese de doutorado de Mendoza (2013). A prova de carga foi realizada numa estaca isolada Alluvial Anker de 8,0m de comprimento e 0,20m de diâmetro final denominada como AA-01, executada no campo experimental da SOLOTRAT, com as mesmas características construtivas das estacas executadas no trabalho de Mendoza (2013) porém em época posterior (2014) (Ver Fig. 3.9). 


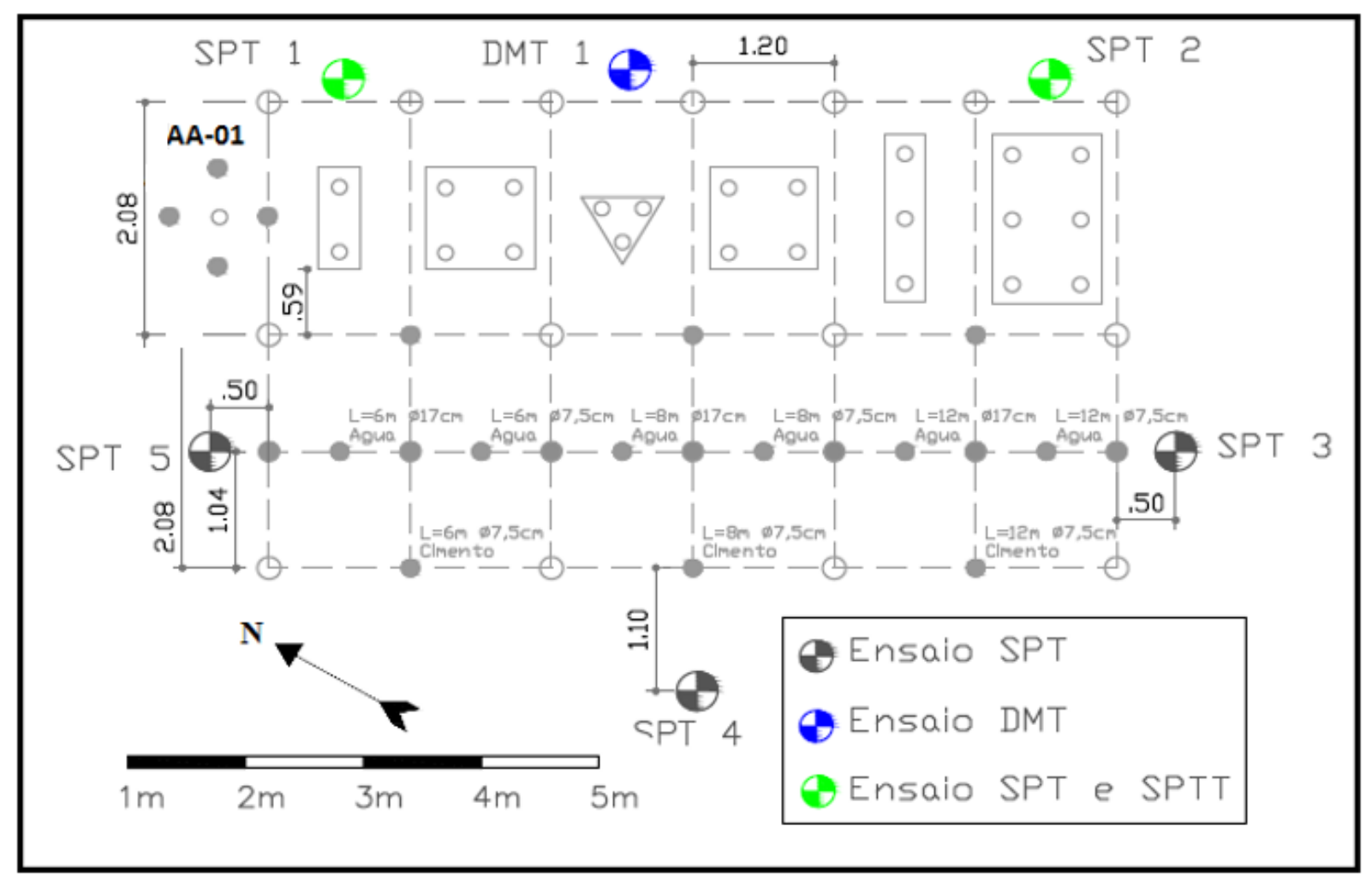

Figura 3.9. Local da estaca isolada Alluvial Anker AA-01 Modificado (Mendoza, 2013)

O sistema de reação empregado constou de 4 (quatro) estacas Alluvial Anker de $12 \mathrm{~m}$ de comprimento e 0,17 m de diâmetro nominal, conectadas em cruz por duas vigas de seção transversal $0,50 \mathrm{~m} \times 0,50 \mathrm{~m}$. Abaixo da interseção das vigas foram colocados o macaco hidráulico de 2000 kN e a célula de caga de 1000 kN com precisão de 0,1kN.

Como não foi executado nenhum bloco de coroamento, visto que não é o alcance da pesquisa estudar a contribuição do bloco, deixou-se um segmento da tubulação de reforço exposta por cima do terreno para facilitar a união do topo da estaca com a placa metálica implementada de $0,40 \mathrm{~m}$ x 0,40 m, e 0,05 $\mathrm{m}$ de espessura, também para facilitar a montagem do macaco hidráulico, bem como evitar excentricidades na hora da aplicação da carga, já que a estaca é de pequeno diâmetro e pode sofrer facilmente rotação como é mostrado na Fig. 3.10. 


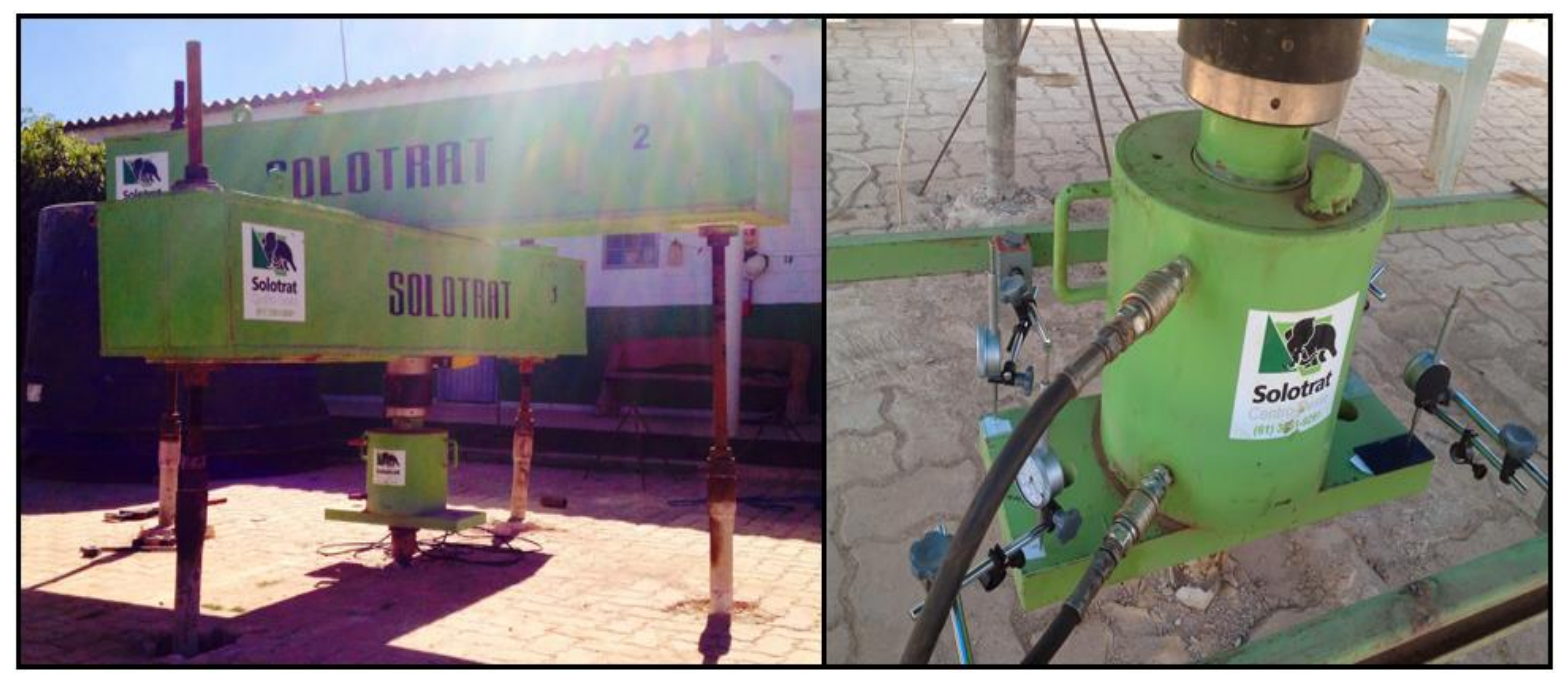

Figura 3.10 Prova de carga na estaca Alluvial Anker AA-01

Foi realizada a prova de carga estática carregada lentamente segundo NBR 12131 (ABNT, 2006). Os incrementos de carga não ultrapassaram $20 \%$ da carga de trabalho calculada $(150 \mathrm{kN})$, sendo os carregamentos realizados de 30, 60, 90, 120, 150, 180, 210, 240, 270, 300, 330, 360, 390, $420 \mathrm{kN}$. Para paralisar a prova de carga foram adotados dois critérios, ou seja, deslocamento superior à 20\% do diâmetro, que segundo Décourt (2008) é determinada a "ruptura" convencional em estacas escavadas, dado que as estacas escavadas não apresentam ruptura "física", e o critério o qual a carga na estaca não estabiliza e os recalques são incessantes. Desta forma ao serem atingidos ambos critérios, a prova de carga nesta estaca isolada foi paralisada.

A curva carga-recalque obtida do ensaio foi avaliada com diferentes metodologias encontradas na literatura, tais como a utilização de métodos gráficos, métodos baseados em rigidez e métodos de extrapolação da curva carga-recalque (Terzaghi 1943; Van der Veen 1953; Mansur-Kaufman 1956; De Beer 1967; Chin 1971; Davisson 1973; Van der Veen Modificado por Aoki 1976; Décourt 1996; Décourt 2006-2008; Valencia \& Camapum 2011; NBR 6122 2010).

Na presente Dissertação foi adotado o termo de "carga limite" para se referir à carga de ruptura, uma vez que carga limite é o termo mais apropriado para referir-se à "ruptura" em estacas escavadas.

Para definir a carga limite da estaca isolada Alluvial Anker AA-01 aqui testada foram escolhidas três metodologias de extrapolação da curva carga-recalque, ou seja, Van der Veen, 1953; Van der Veen Modificado por Aoki, 1976 e Décourt, 2006-2008, que representaram melhor os fatos que aconteceram na prova de carga, ou seja, a carga limite foi o valor da média aritmética entre essas três metodologias empregadas. A carga final de trabalho foi definida com 
um fator de segurança global $(\mathrm{FS}=2)$ da norma brasileira para fundações profundas (NBR 6122/2010).

Este critério é diferente ao adotado por Mendoza (2013) (Só Van der Veen Modificado por Aoki (1976)), porém na realidade o valor da carga limite entre adotar só uma metodologia e as três consideradas não difere muito no resultado $2 \mathrm{kN}$, entretanto tem-se um ganho de confiança na hora de definir a mesma, ou seja, tem mais respaldo.

A estaca Alluvial Anker testada AA-01 não possui instrumentação para se obter informação da contribuição de resistência por fuste e ponta ao serem solicitados pelo carregamento, então foram utilizadas extensões das metodologias de Decourt (2006-2008) e Valencia \& Camapum (2011), para se obter as parcelas de ponta e fuste em estacas não instrumentadas.

Para estimar a capacidade de carga de grupos Alluvial Anker foram utilizadas metodologias analíticas e semi-empiricas como a de Terzaghi \& Peck (1948) e Poulos \& Davis (1980). Considerando o critério de ruptura generalizada, e se trabalhou com os parâmetros obtidos dos ensaios laboratoriais para coesão e ângulo de atrito do solo.

Com a carga limite obtida por meio da prova de carga estática na estaca isolada, e os resultados de carga limite nas provas de carga dos grupos de 2,3,4,5 e 6 estacas fornecidos no trabalho de Mendoza (2013) passou-se a calcular a eficiência experimental para um espaçamento igual a três (3) vezes o diâmetro da estaca nas diferentes configurações dos grupo de estacas Alluvial Anker, comparando estes resultados com os valores de eficiência obtidos por Mendoza (2013) com uma estaca isolada simulada numericamente no programa Abaqus. Além disso, os valores de eficiência experimental foram comparados com metodologias empíricas como as de Feld 1943; Converse-Labarre e do Grupo de los Angeles.

Então, já com os valores experimentais definidos como a capacidade de carga final de trabalho e carga limite, além dos valores de recalque para carga de trabalho fornecidos das curvas cargarecalque de cada configuração estudada (isolada, 2 estacas, 3 estacas, 4 estacas, 5 estacas e 6 estacas), passou-se a comparar estes valores experimentais com os obtidos por metodologias analíticas, semi-empiricas e numéricas de capacidade de carga e recalque, para uma posterior validação de qual ou quais métodos representam melhor o comportamento de fundações do tipo Alluvial Anker.

A metodologia proposta para o desenvolvimento desta Dissertação de mestrado, descrita anteriormente, pode ser visualizada de uma forma melhor para complementar a compressão do leitor com o fluxograma apresentado na Fig. 3.11. 


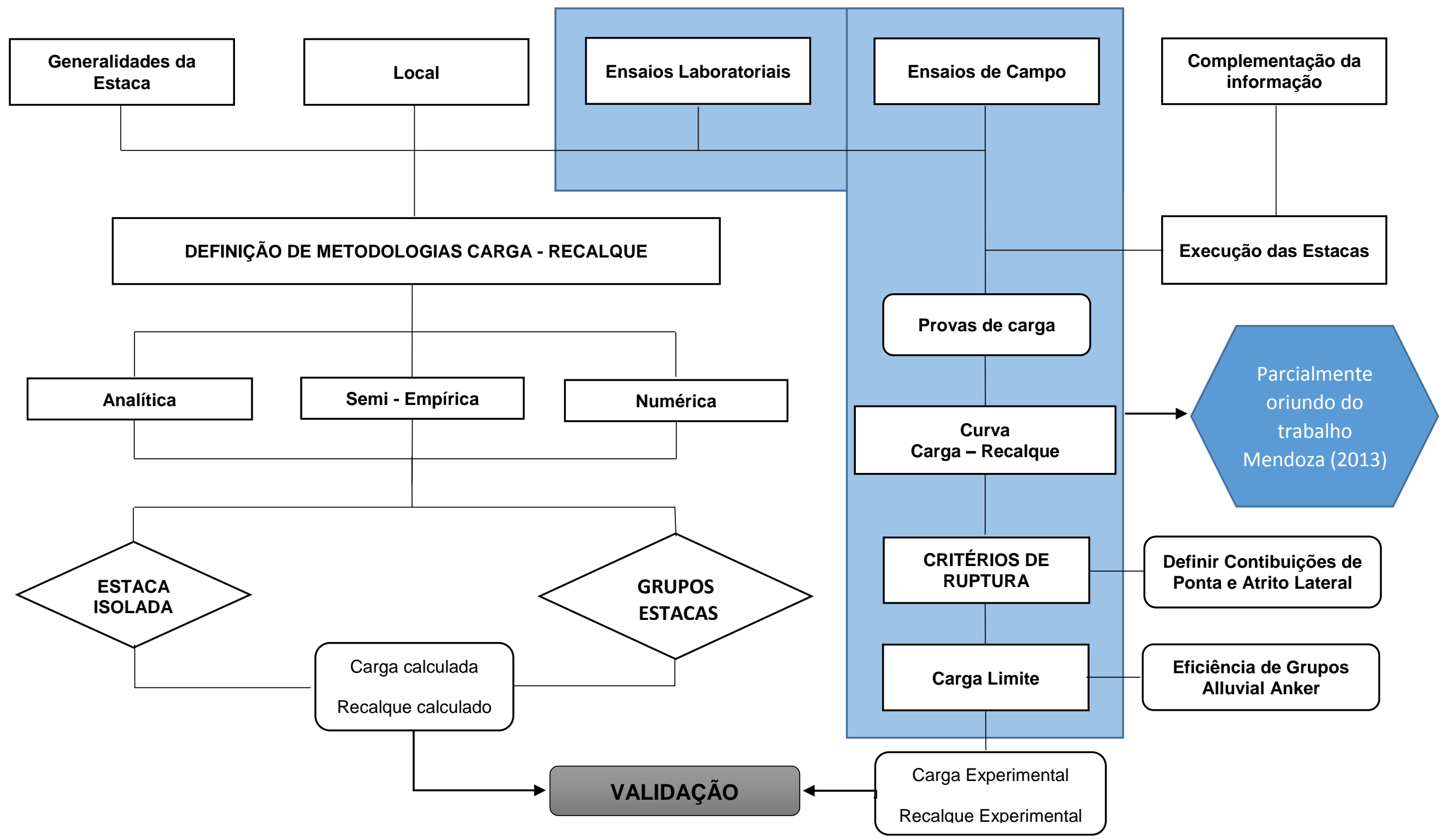

Figura 3.11 Fluxograma da Metodologia 


\section{PROVA DE CARGA ESTÁTICA}

Para a validação do comportamento de estacas Alluvial Anker nesta dissertação de mestrado, foi executada uma prova de carga estática, conforme ABNT NBR 12131/2006 (estacas - prova de carga estática), realizada em uma estaca isolada de diâmetro de $0,20 \mathrm{~m}$ e comprimento igual a 8m, sendo executada no Campo Experimental da SOLOTRAT Engenharia Geotécnica Ltda. As características do local como locação, geologia, propriedades mecânicas foram apresentadas no item 3.1.

\subsection{EXECUÇÃO DE ESTACAS ALLUVIAL ANKER}

A estaca, denominada como AA-01, para ser testada foi executada com um tubo schedule liso de $63 \mathrm{~mm}$ de diâmetro com uma ponteira de $13 \mathrm{~cm}$ soldada no começo da haste. O tubo é acoplado a uma perfuratriz, compondo o sistema de perfuração mecânica, e após essa montagem é feita a injeção de calda de cimento até o furo ficar preenchido pela mesma (Fig. 4.1). O tubo schedule é utilizado como reforço armado da estaca existente em todo o seu comprimento. A calda de cimento utilizada na estaca possuía $25 \mathrm{Mpa}$. O processo executivo da estaca Alluvial Anker é apresentado em mais detalhe no item 2.4.1.

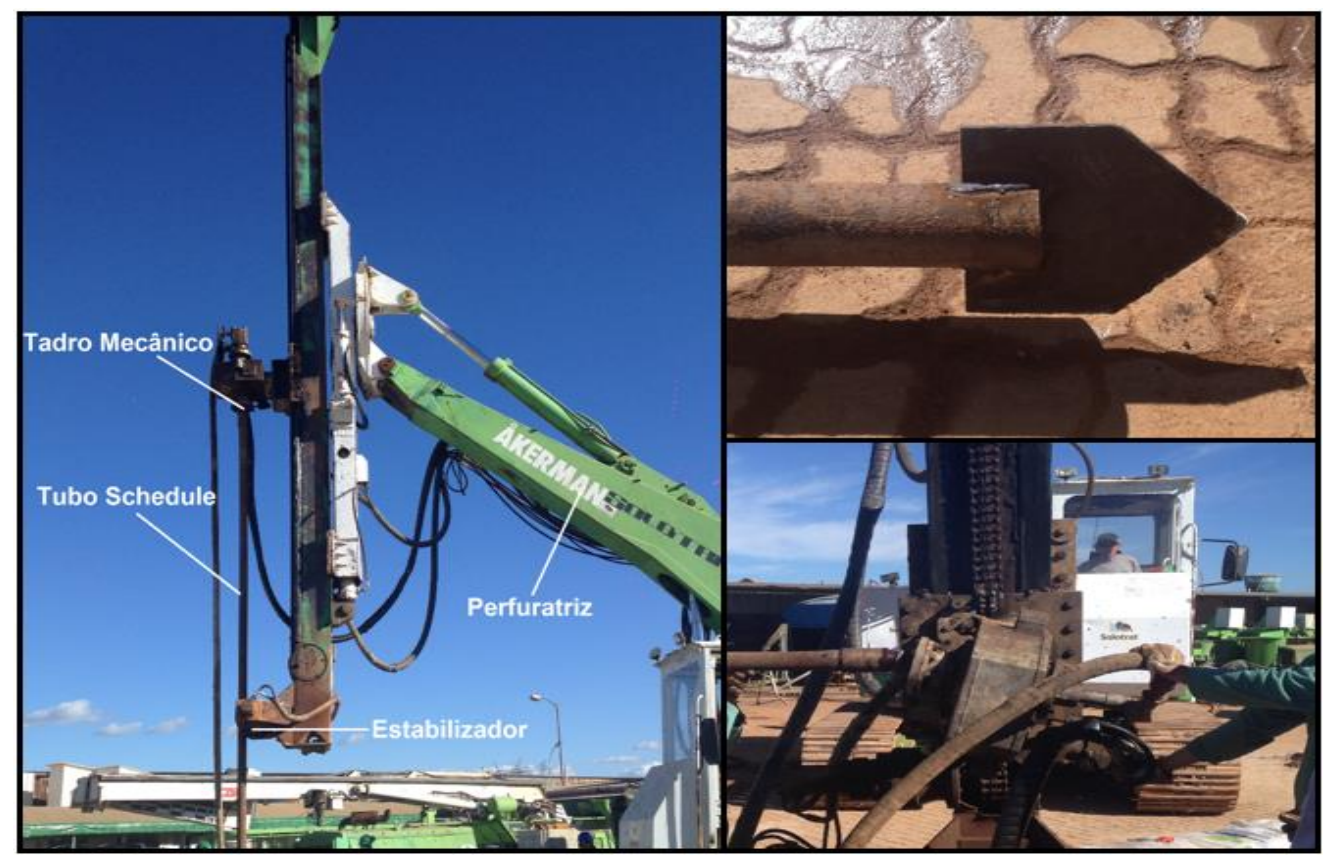

Figura 4.1. Montagem do tubo Schedule na perfuratriz

O sistema de reação foi composto por 4 estacas escavadas do tipo Alluvial Anker chamadas como AAR-01, AAR-02, AAR-03 e AAR-04 com 0,17m de diâmetro nominal e 12m de comprimento, também armada com o tubo schedule em todo o seu comprimento, Fig. 4.2. 
Além dessas estacas serem projetadas para resistir aos esforços de tração provocados pelo empuxo do macaco hidráulico, também se obtêm maior estabilidade e uma melhor distribuição da carga aplicada evitando a excentricidade da carga.

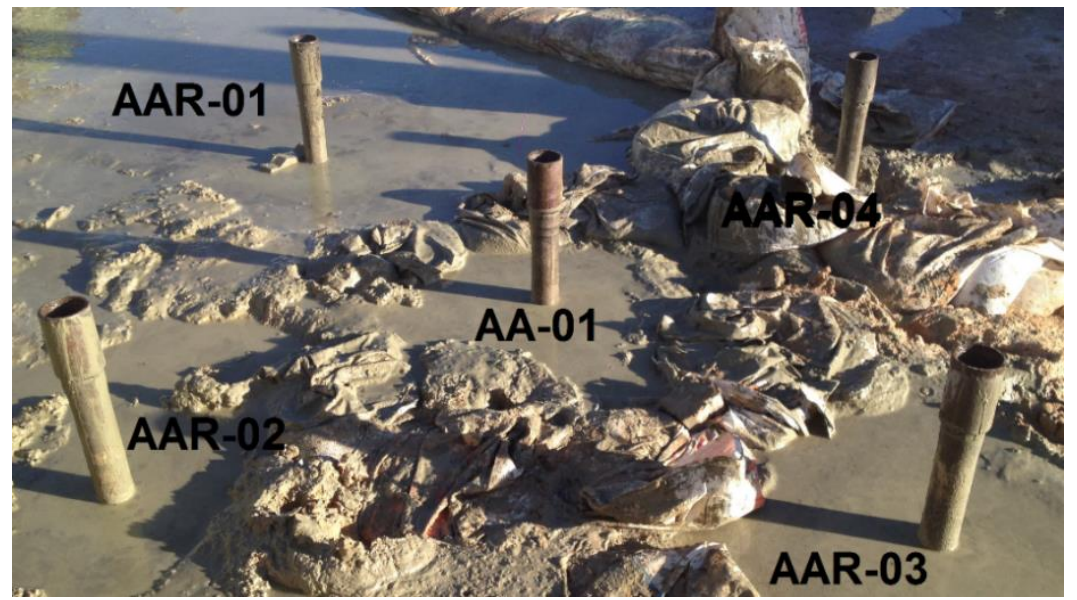

Figura 4.2. Estacas de reação para montagem da prova de carga estática

Destaca-se que as estacas de reação localizam-se a uma distância maior do que três vezes o diâmetro da estaca teste, para evitar a interferência entre os bulbos de tensões entre a mesma e as de reação (Poulos \& Davis, 1980).

\subsection{MONTAGEM DA PROVA DE CARGA}

Para conformar o sistema de reação, estas estacas foram conectadas por vigas de aço colocadas em cruz AAR-01, AAR-03 e AAR-02, AAR-04, servindo como suporte ao macaco hidráulico de 2000 kN. O esquema da Fig. 4.3, mostra a montagem do sistema no momento da execução da prova de carga estática em campo, como também se vê na Fig. 4.4.

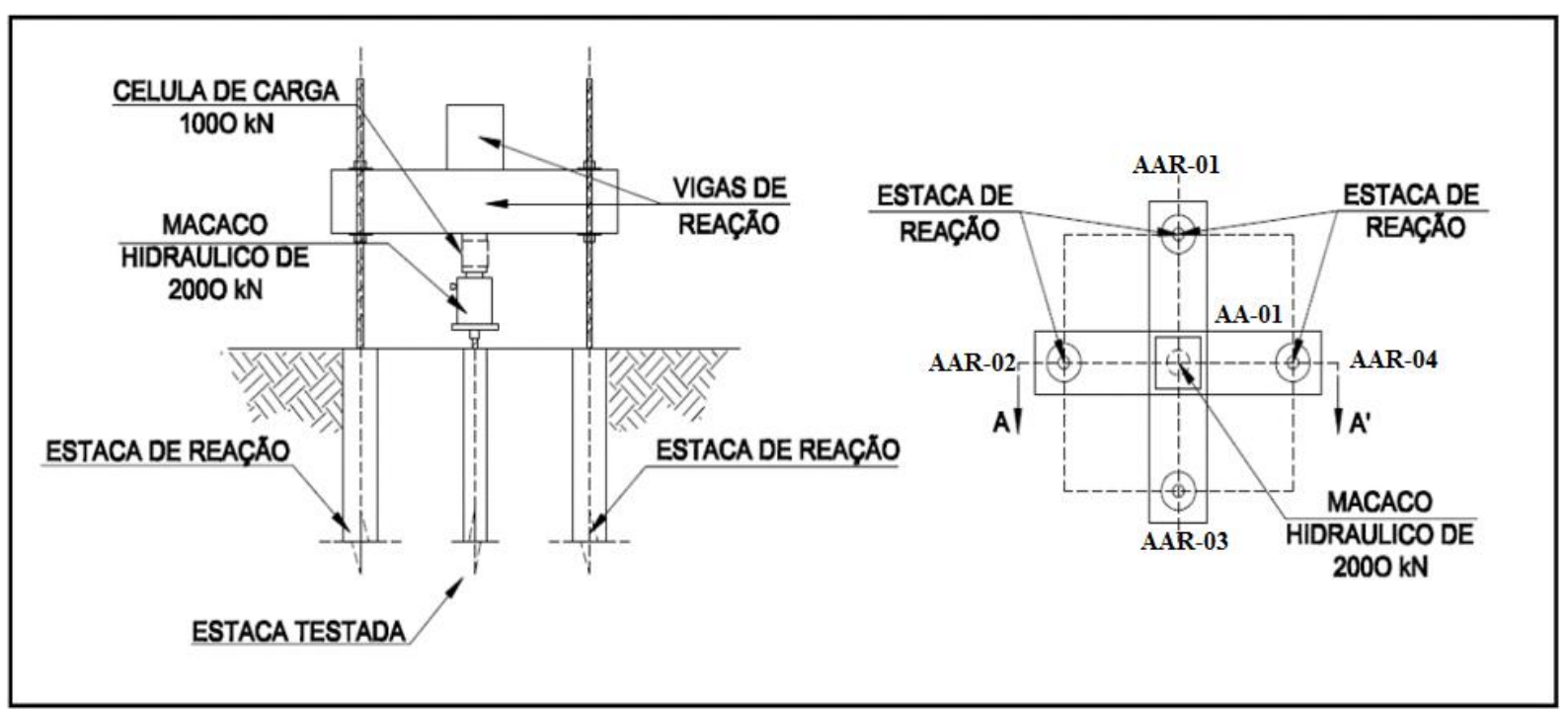

Figura 4.3 Esquema da montagem da prova de carga estática 


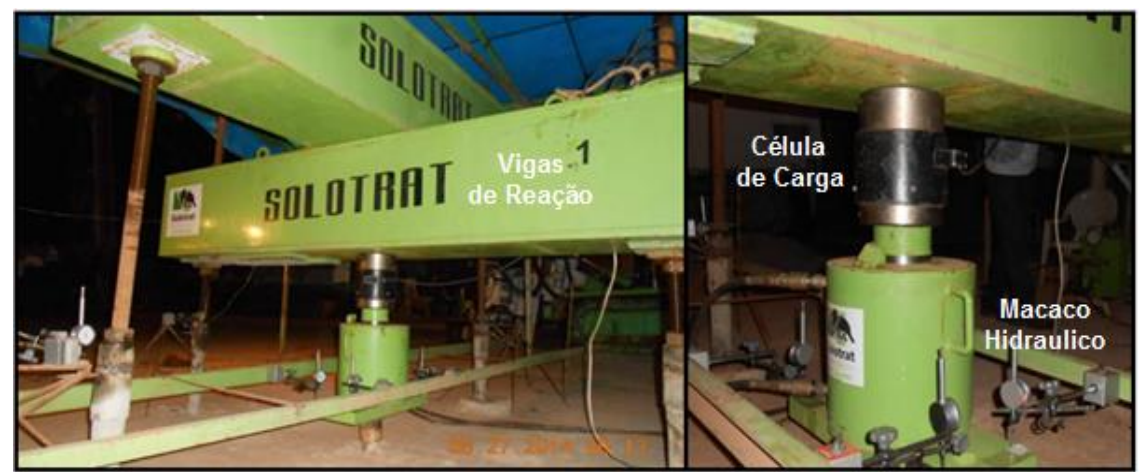

Figura 4.4. Montagem da prova de carga estática

Entre a execução das estacas e a realização da prova de carga se passaram 30 dias. Vale ressaltar que a norma NBR 12131/2010 exige que seja cumprido um prazo mínimo dez (10) dias, no caso de solos com comportamento coesivo, além de garantir um prazo mínimo para que a resistência do elemento estrutural seja compatível com a carga máxima do ensaio.

A estaca testada foi projetada por diferentes metodologias para uma carga média de trabalho de 150 kN e 300 kN para carga limite. Segundo a ABNT NBR 12131/2006, a estaca deverá ser carregada até a ruptura, ou ao menos até duas vezes o valor estimado para sua carga de trabalho.

No topo da estaca testada foi soldada uma placa de aço de $5 \mathrm{~cm}$ de espessura, onde foram colocados um macaco hidráulico e quatro (4) extensômetros, e em cada estaca de reação foram colocados um (1) extensômetros, como se apresenta na Fig. 4.5.

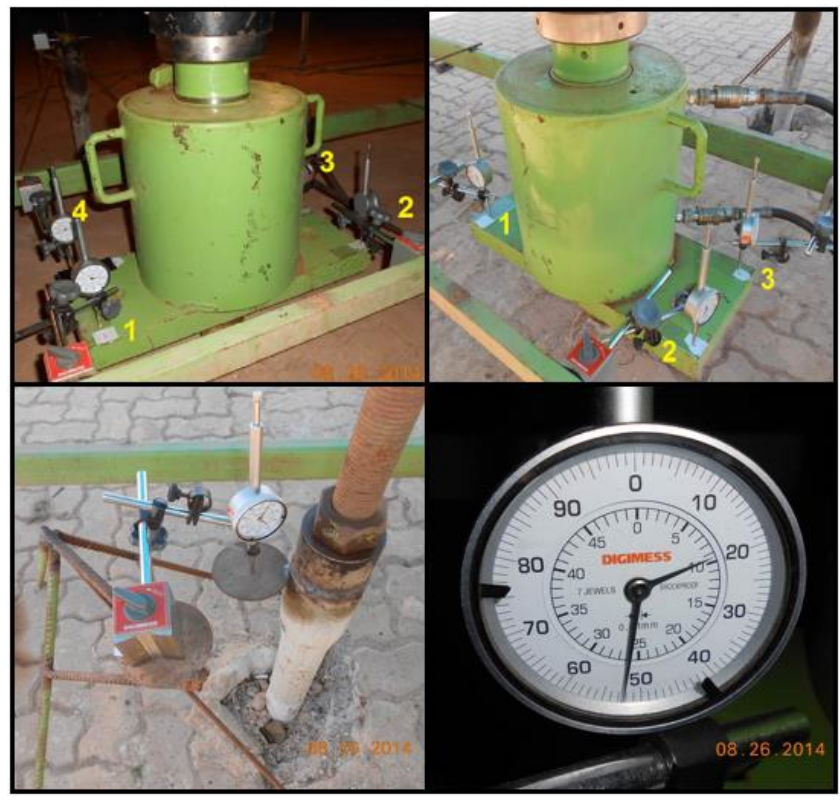

Figura 4.5. Extensômetros em estaca testada e de reação

Na estaca AA-01 foi aplicado um carregamento do tipo lento, composto por estágios iguais e sucessivos de $30 \mathrm{kN}$ até atingir a ruptura do sistema solo-estaca, onde os acréscimos de carga não ultrapassaram os $20 \%$ da carga de trabalho. Em cada estágio a carga deve ser mantida até a estabilização dos deslocamentos e, por no mínimo, 30 minutos. 
A medição dos acréscimos de carga foi realizada com uma célula de carga com capacidade de $1000 \mathrm{kN}$ com sensibilidade de $1 \mathrm{kN}$, colocada entre a vigas de conexão das estacas de reação e o macaco hidráulico.

Em cada estágio de carregamento foram lidos os deslocamentos após a aplicação da carga correspondente, seguindo-se leituras a 2, 4, 8, 15 e 30 minutos contados a partir do início do estágio e posteriormente a cada 30 minutos, até se atingir a estabilização. Na Fig. 4.6 são apresentadas algumas estabilizações para determinados carregamentos.

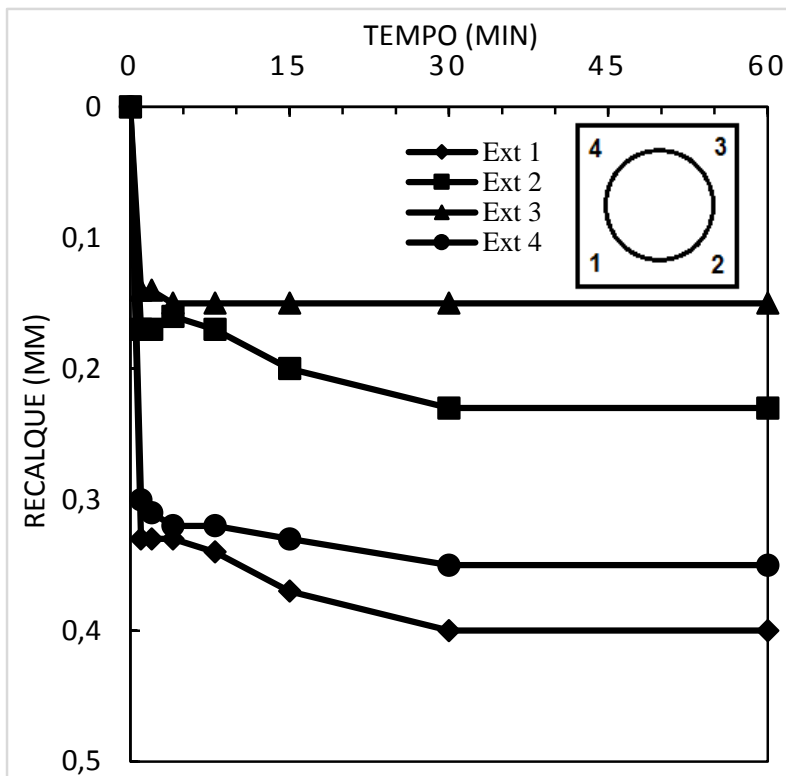

(a) Leitura dos extensômetros carga de $30 \mathrm{kN}$

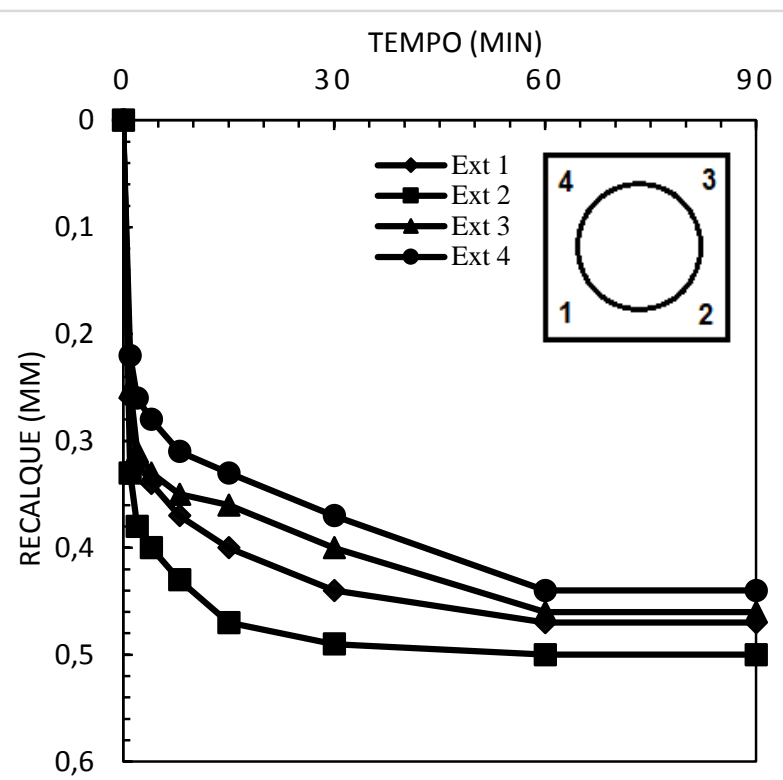

(b) Leitura dos extensômetros carga de $150 \mathrm{kN}$

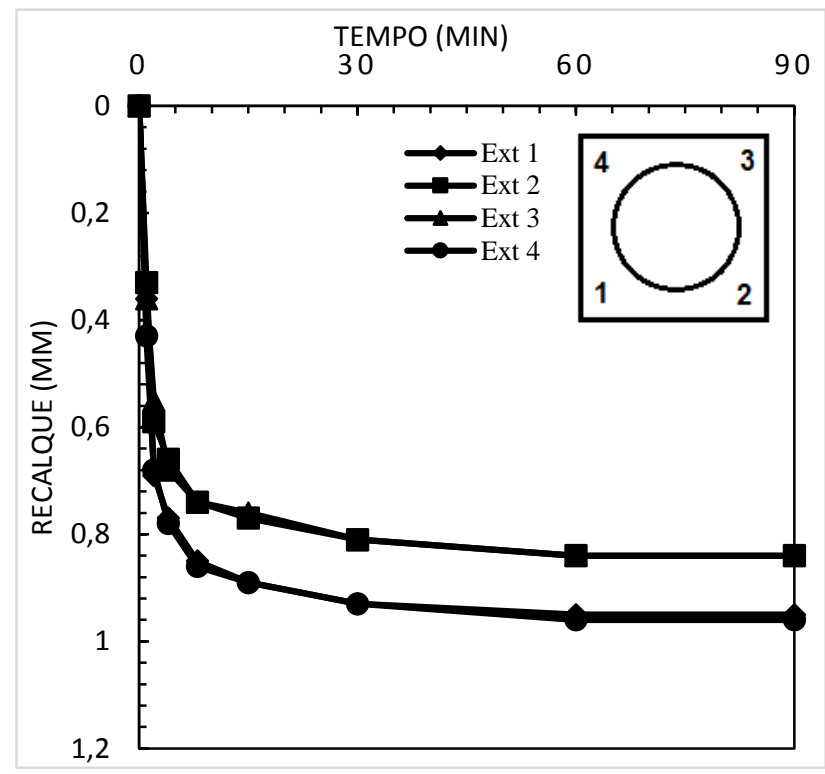

(c) Leitura dos extensômetros carga de 300 kN

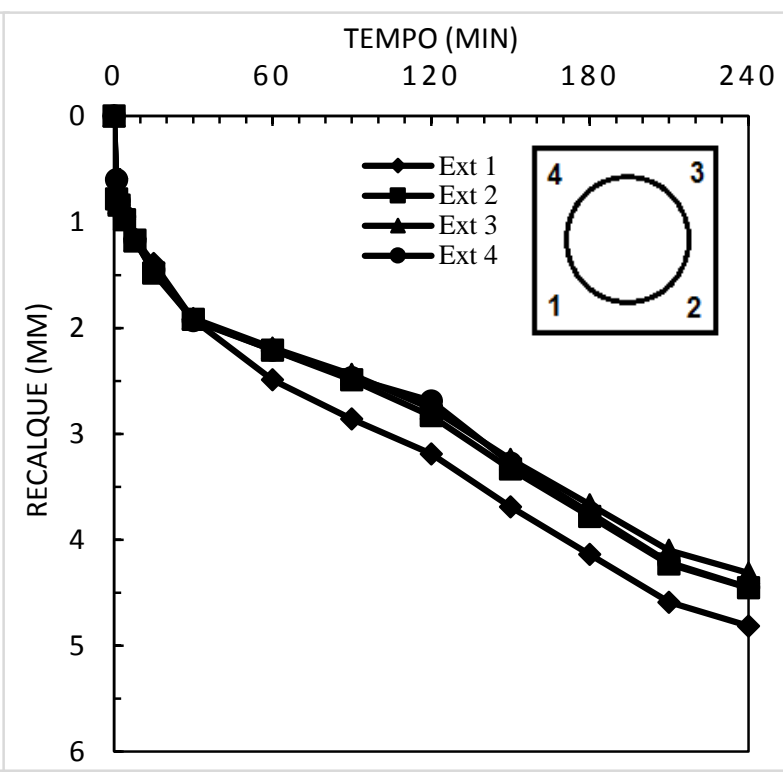

(d) Leitura dos extensômetros carga de $390 \mathrm{kN}$

Figura 4.6. Leituras de extensômetros na prova de carga estaca isolada 
Considerou-se que a estabilização das leituras foi atingida quando a diferença entre o recalque do tempo t e t/2 foi inferior à $5 \%$ do recalque total do estágio carregado, como é definido pela norma brasileira NBR 12131/2006.

\subsection{RESULTADO DA PROVA DE CARGA}

Com a ideia de se levar a estaca até sua carga limite, conseguiu-se aplicar 13 carregamentos estabilizados apresentados na Tab. 4.1. Terminada a estabilização do último estágio de 390 kN, incrementou-se para 420 kN, onde não se conseguiu mais manter a carga aplicada estabilizada, apresentando neste momento recalques excessivos para um mesmo nível de carregamento.

Tabela 4.1. Estágios de carregamento da prova de carga estática sob a estaca Alluvial Anker

\begin{tabular}{|c|c|c|}
\hline \multicolumn{3}{|c|}{ Prova de Carga Estática na Estaca $(\mathbf{A A - 0 1})$} \\
\hline Estágio & Carga $(\mathbf{k N})$ & $\boldsymbol{\Delta}(\mathbf{m m})$ \\
\hline 1 & 30 & 0,28 \\
\hline 2 & 61,12 & 0,53 \\
\hline 3 & 90,68 & 0,90 \\
\hline 4 & 121,18 & 1,27 \\
\hline 5 & 150,77 & 1,74 \\
\hline 6 & 181,05 & 2,16 \\
\hline 7 & 210,51 & 2,59 \\
\hline 8 & 240,51 & 3,07 \\
\hline 9 & 270,31 & 4,00 \\
\hline 10 & 300,26 & 4,92 \\
\hline 11 & 330,4 & 5,90 \\
\hline 12 & 360,26 & 7,77 \\
\hline 13 & 390,2 & 12,34 \\
\hline 14 & 420,1 & 20,50 \\
\hline
\end{tabular}

A curva carga-recalque é apresentada na Fig. 4.7. O carregamento máximo aplicado no topo da estaca foi de $421,23 \mathrm{kN}$ e a leitura do recalque máximo correspondente foi de $20,5 \mathrm{~mm}$. Não foi efetuado o descarregamento porque ao se atingir a carga de 421,23 kN, a estaca não conseguiu suportar por 60 min a carga, sendo muito difícil manter as leituras da célula de carga em $420 \mathrm{kN}$ com o macaco hidráulico, e dessa forma, só foram tomadas leituras até $60 \mathrm{~min}$. A estaca apresentou deslocamentos excessivos na tentativa de manter a carga estabilizada em 420 $\mathrm{kN}$, como já relatado, até que os extensômetro perderem o contato com o topo da placa metálica.

Segundo Décourt (2008 e 2014) as estacas escavadas submetidas a provas de carga nunca rompem nem apresentam ruptura nítida, e dessa forma ele muda o termo de carga de ruptura para carga "limite". 


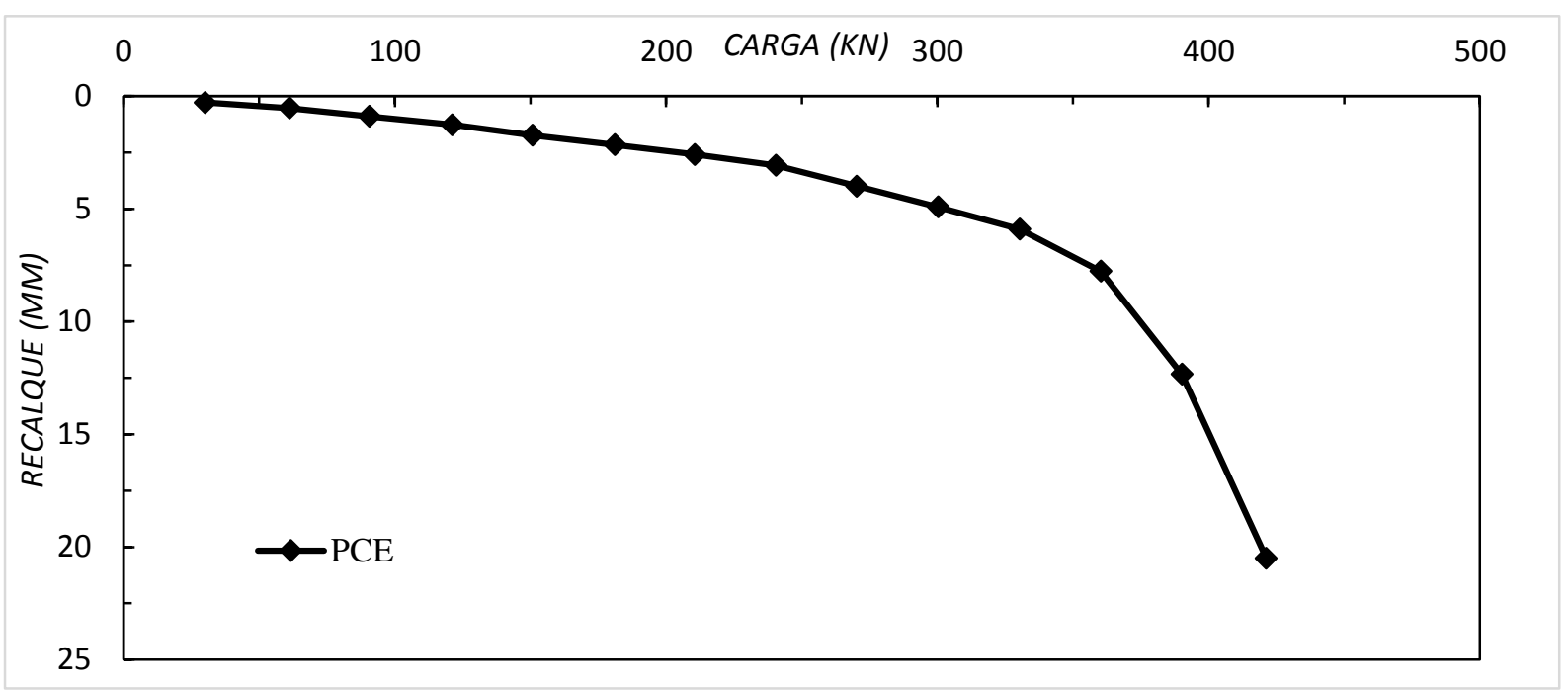

Figura 4.7. Resultado da prova de carga estática (Curva Carga-Recalque)

\subsection{ESTIMATIVA DA CARGA LIMITE}

Na estimativa da carga limite usaram-se metodologias e critérios consagrados na literatura técnica de engenharia de fundações como o método de Terzaghi (1943), Davisson (1973), norma brasileira NBR 6122/2010 e também metodologias de extrapolação da curva carga-recalque: Van der Veen (1953), Chin-Kondner (1971), Van der Veen Modificado por Aoki (1976), e métodos baseados em deslocabilidade como o de Décourt (1996) e Décourt (2006-2008), além de critérios que aplicam uma regra geométrica à curva carga-recalque como o de De Beer (1967-1968), Mansur-Kaufman (1956) e Valencia \& Camapum (2011).

O diâmetro usado para os cálculos da carga limite é de $20 \mathrm{~cm}$, verificado com a exumação realizada em estacas Alluvial Anker no trabalho de Mendoza (2013), ou seja, o diâmetro "verdadeiro" médio da estaca é 1,5 vezes maior que o diâmetro teórico nominal das mesmas $(13 \mathrm{~cm})$. No módulo de elasticidade da estaca usou-se os valores reportados no trabalho de Pando et.al. (2002) citado por Mendoza (2013) para seções compostas de tubo de aço com concreto igual a 23,8 GPa.

Inicialmente utilizou-se os critérios que aplicam uma regra geométrica à curva cargarecalque como De Beer (1967-1968) definindo a carga limite pelo ponto de inflexão no gráfico Log Q-Log $\delta$, e o critério de Mansur-Kaufman (1956) conhecido como de interseção de tangentes, onde a carga limite é definida pela interseção das tangentes aos trechos lineares inicial e final da curva carga-recalque, além do método de Valencia \& Camapum (2011) que 
define a carga limite no ponto de inflexão no gráfico Log Q vs $\delta$, como são todos apresentados ao longo da Fig. 4.8.

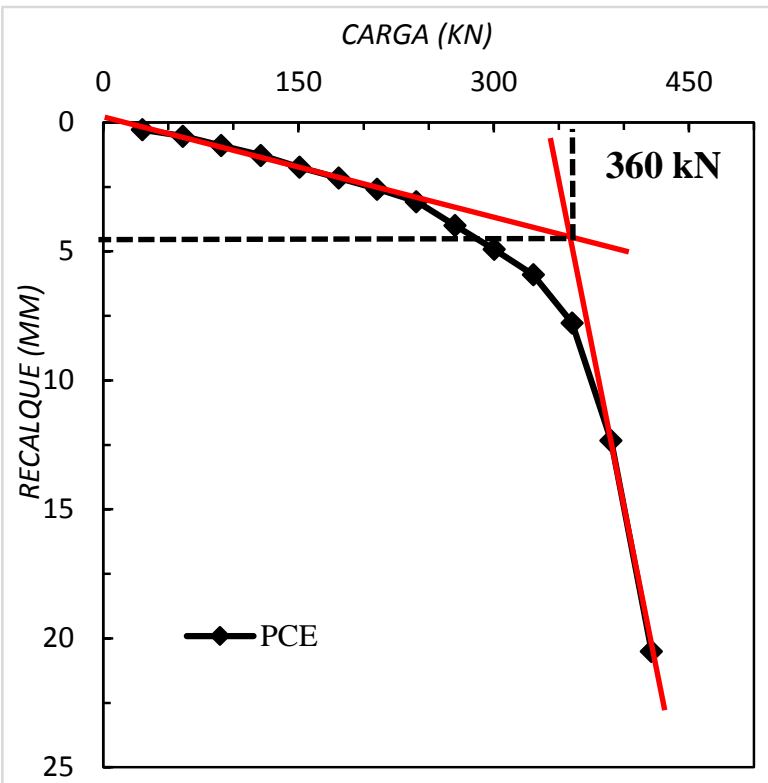

(a) Critério Mansur-Kaufman (1956)

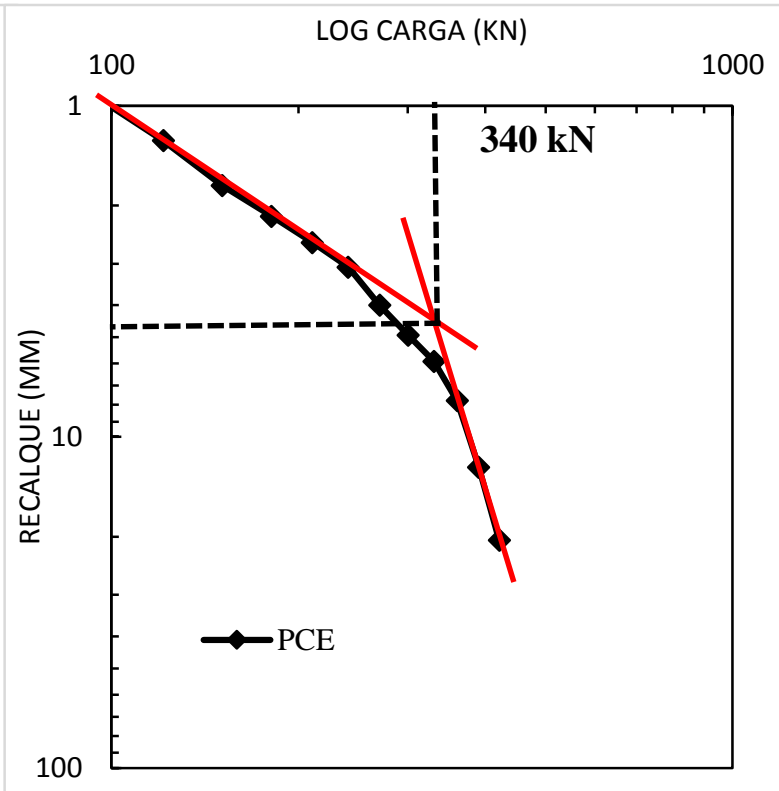

(b) Critério de De Beer (1967-1968)

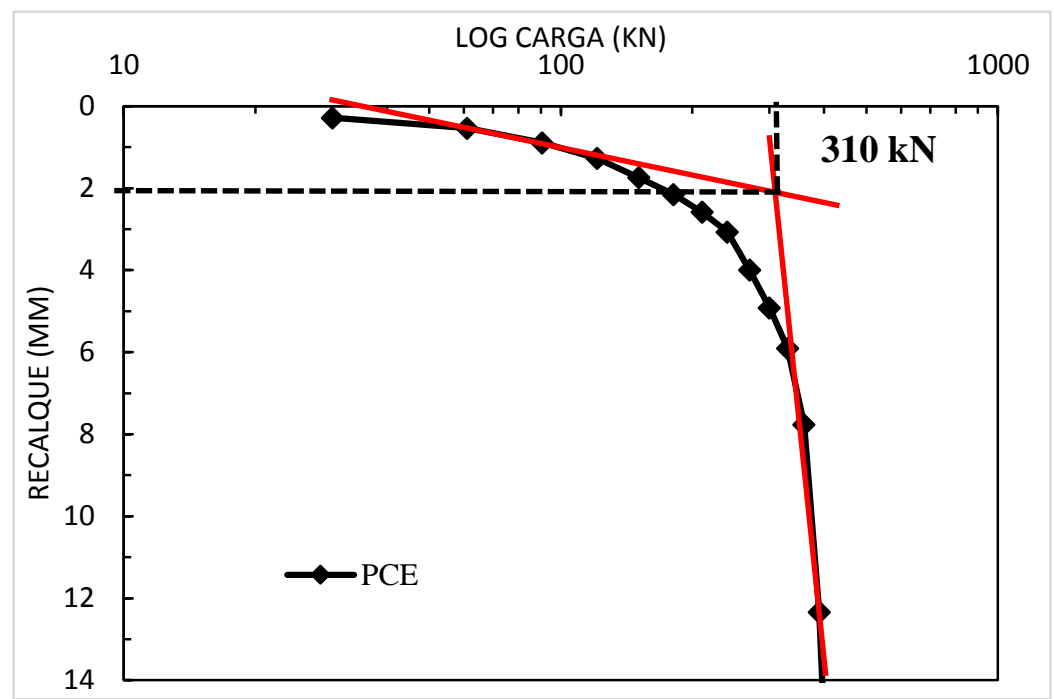

(c) Critério de Camapum de Carvalho (2011)

Figura 4.8. Critérios que aplicam uma regra geométrica

A estimativa da carga limite com base no conceito de rigidez proposto por Décourt (2006-2008), foi realizado através dos gráficos fornecidos por um programa computacional feito pelo próprio Engenheiro Luciano Décourt (2008).

Com os dados obtidos da prova de carga estática, e determinado o ponto de regressão da curva estabelecendo correlações lineares entre $\log Q$ e $\log \delta$, estes coeficientes de correlação R são elevados ao quadrado obtendo $\mathrm{R}^{2}$. A partir das correlações lineares entre Log Q e Log $\delta$ é definida a equação a partir do ponto de regressão. 
A carga limite considerando ruptura convencional é estimada como a carga correspondente a um recalque de $10 \%$ do diâmetro. Na Fig. 4.9 é apresentada a equação para calcular $\mathrm{R}_{\mathrm{uc}}$.

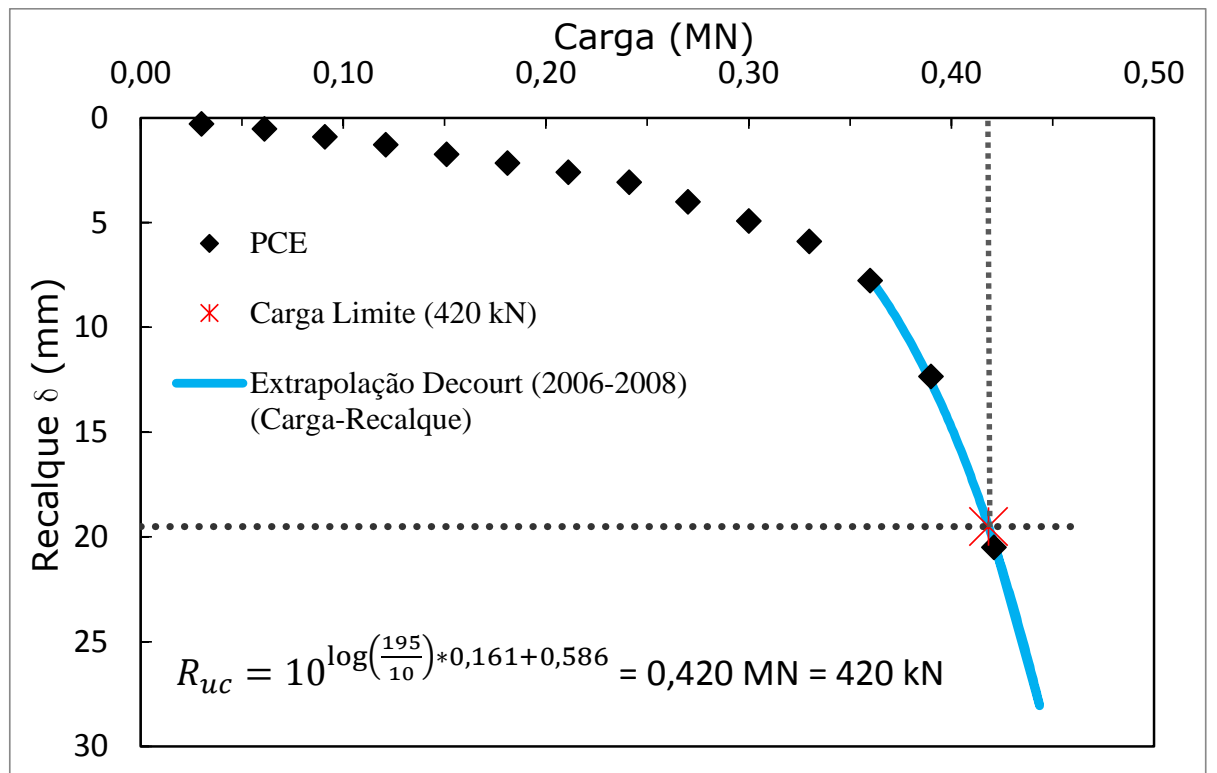

Figura 4.9. Curva carga-recalque método conceito de rigidez de Decourt (2006-2008)

O método de rigidez de Décourt (1996) conduz a resultados da carga limite através do gráfico rigidez vs carga aplicada obtido na prova de carga estática. O gráfico deverá ser do tipo Log Q-Log rigidez em estacas escavadas, para se conseguir um melhor ajuste da parte final reta da curva, como é mostrado na Fig. 4.10, já que as estacas escavadas submetidas ao ensaio de carregamento estático não atingem a ruptura física.

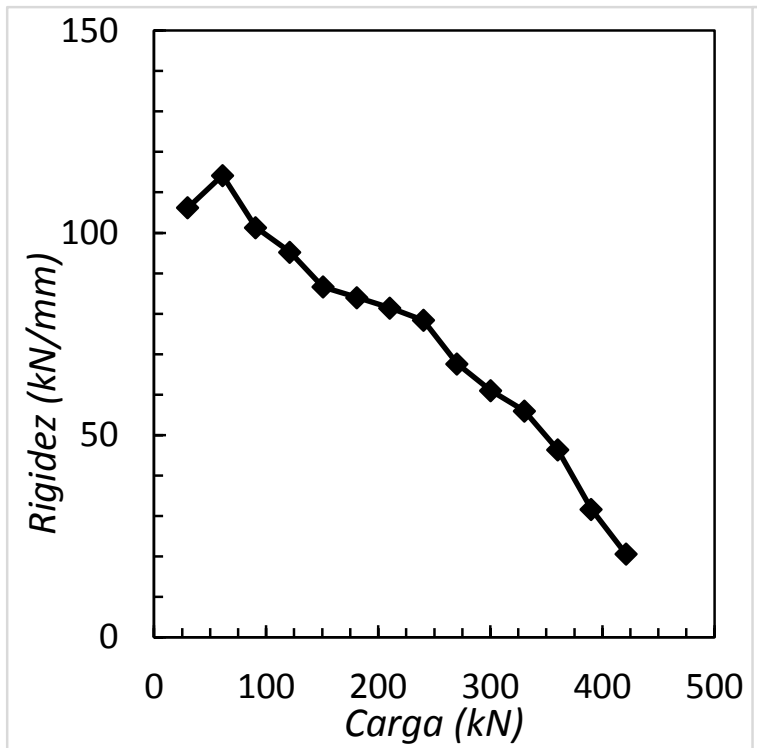

(a) Gráfico rigidez vs carga

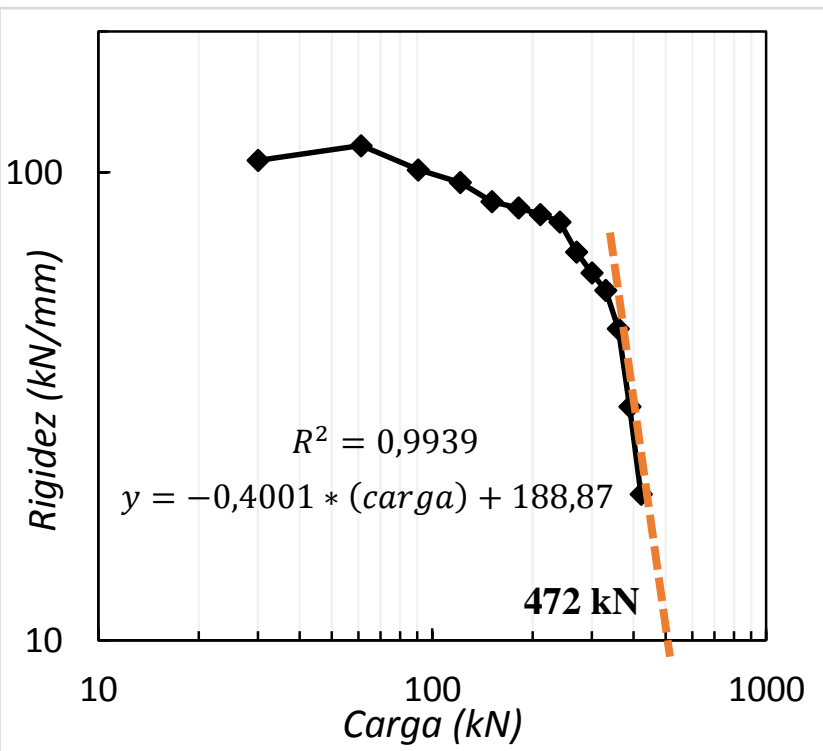

(b) Gráfico Log rigidez vs Log carga

Figura 4.10. Gráficos obtidos no método de rigidez de Decourt (1996) 
A metodologia proposta por Van der Veen (1953) tem sido amplamente utilizada pela comunidade geotécnica para extrapolar a curva obtida de um ensaio de prova de carga estática, quando o ensaio é encerrado ainda no trecho pseudo-linear da curva carga-recalque. Esta foi a metodologia recomendada por Mota (2003) para provas de carga no D.F.

O método de Van der Veen for modificado por Aoki (1976) ao adicionar à função exponencial o termo $\beta$, o que representa o ponto de intersecção com o eixo das abcissas no gráfico $\mathrm{X}$ vs recalque.

Foram inseridos valores de carga limite perto da carga última obtida na prova de carga, dado que o ensaio apresentou recalque excessivo no incremento de $421 \mathrm{kN}$ calculando-se o parâmetro $X$. Em seguida, construiu-se o gráfico $X$ vs recalque (recalque obtido na prova de carga) apresentado na Fig. 4.11, definindo como carga limite aquela que apresenta melhor ajuste linear $\left(\mathrm{R}^{2} \cong 1\right)$.

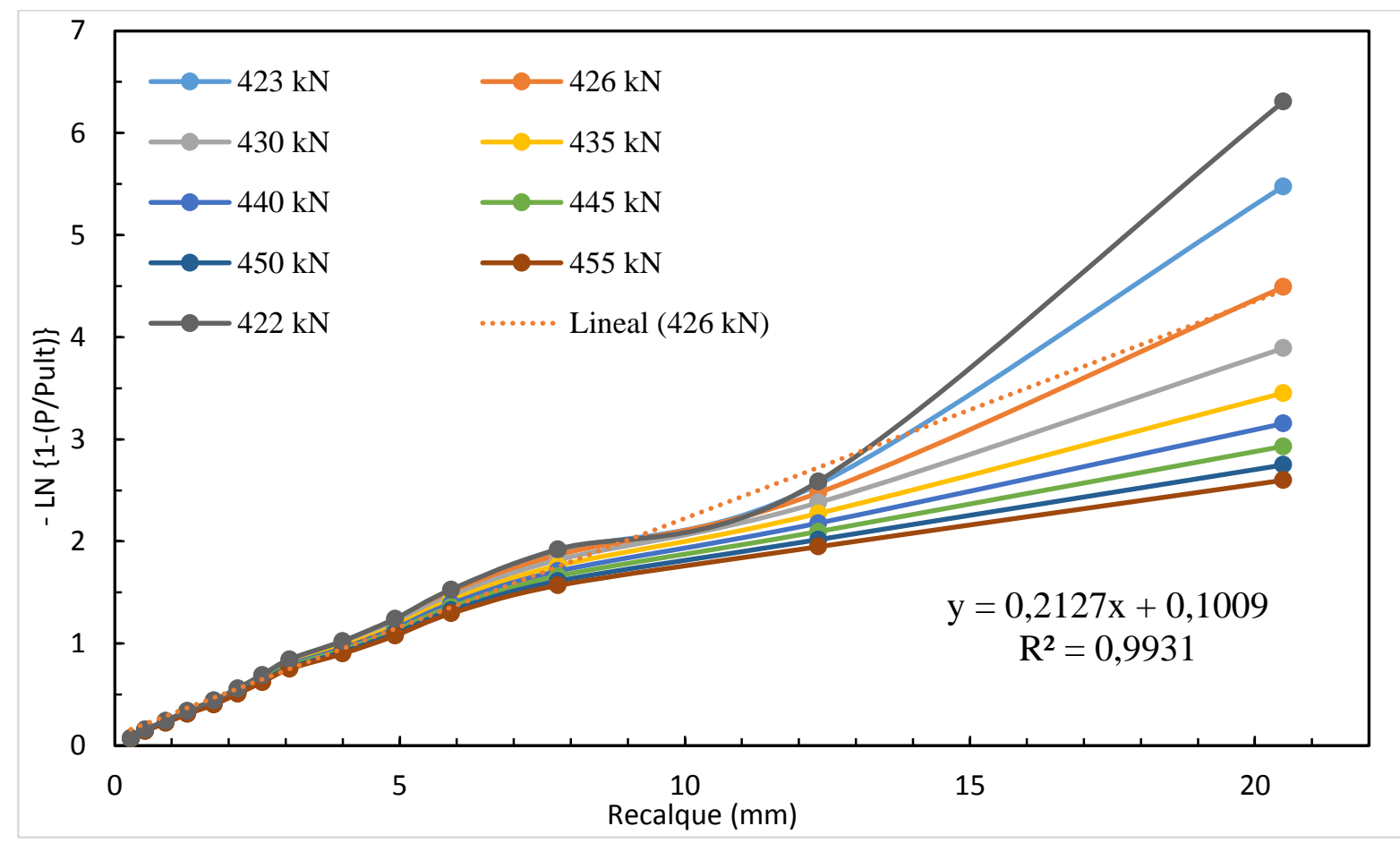

Figura 4.11. Cálculo da carga limite método de Van der Veen (1953)

A extrapolação da curva carga-recalque pelo método de Van der Veen (1953) e Van der Veen Modificado por Aoki (1976) fornecem o mesmo valor de carga limite, igual a $426 \mathrm{kN}$, dado que a prova de carga estática foi levada até a carga última experimental. Porém pode-se observar na Fig. 4.12, que o método de Van der Veen (1953) mostra um melhor ajuste no trecho inicial pseudo-elástico da curva carga-recalque. Também se pode observar que o método de Van der Veen (1953) e o Van der Veen Modificado por Aoki (1976) previu exatamente o que aconteceu em campo com a prova de carga estática na hora de manter a carga de 421 kN estável. 
E corrobora com o que foi sugerido por Décourt (2008) adotando a carga limite com o $10 \%$ do diâmetro.

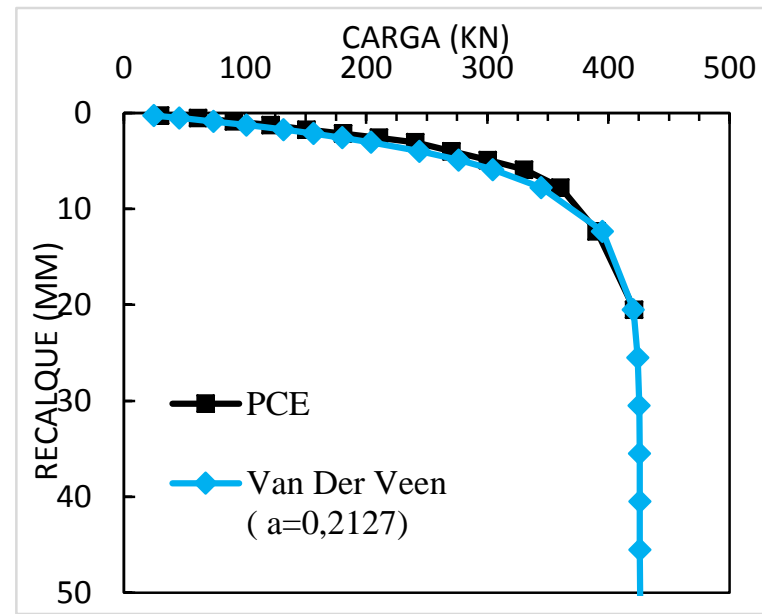

(a) Método Van der Veen (1953)

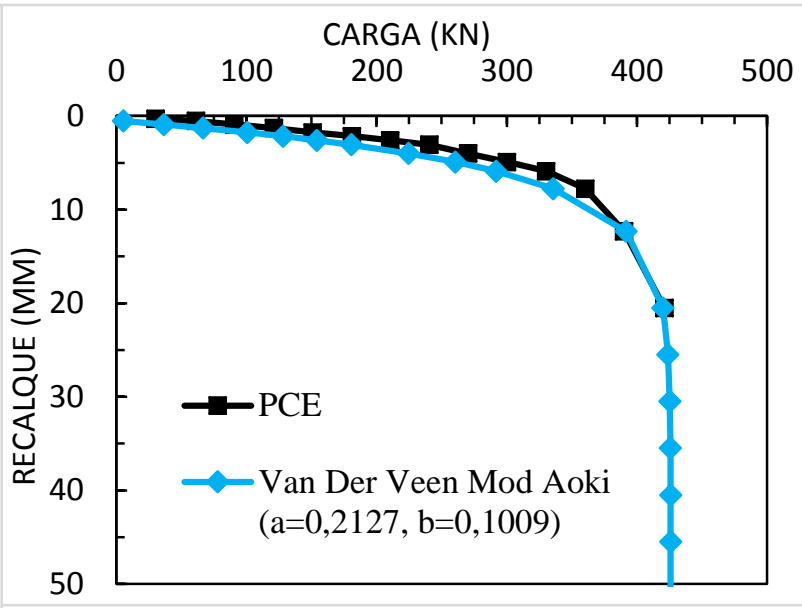

(b) Método Van der Veen Mod. (1976)

Figura 4.12. Extrapolação curva carga-recalque para estaca isolada Van der Veen $(1953,1976)$

Um outro método que utiliza a extrapolação da curva carga-recalque para obter a carga limite foi proposto por Chin (1971), plotando o inverso da rigidez vs recalque dos estágios estabilizados, e obtendo uma relação linear (reta) da qual são extraídos os coeficientes C1 e C2 (Fig. 4.13). A carga limite será o valor fornecido pelo inverso do coeficiente angular da reta C1. Segundo Fellenius (2006) se o valor da carga limite obtido fosse superior à carga máxima aplicada no topo da estaca, recomendaria-se o uso da carga máxima aplicada na estaca como a capacidade última, como foi o caso da carga limite obtida pelo método de Chin (1971), a qual apresentou o valor de $556 \mathrm{kN}$. Note novamente que a carga máxima aplicada na cabeça da estaca foi de $421 \mathrm{kN}$. O método de Chin (1971) mostra-se como um método contra a segurança pois superestima a capacidade de carga limite de um sistema solo-estaca Alluvial Anker executado no D.F.

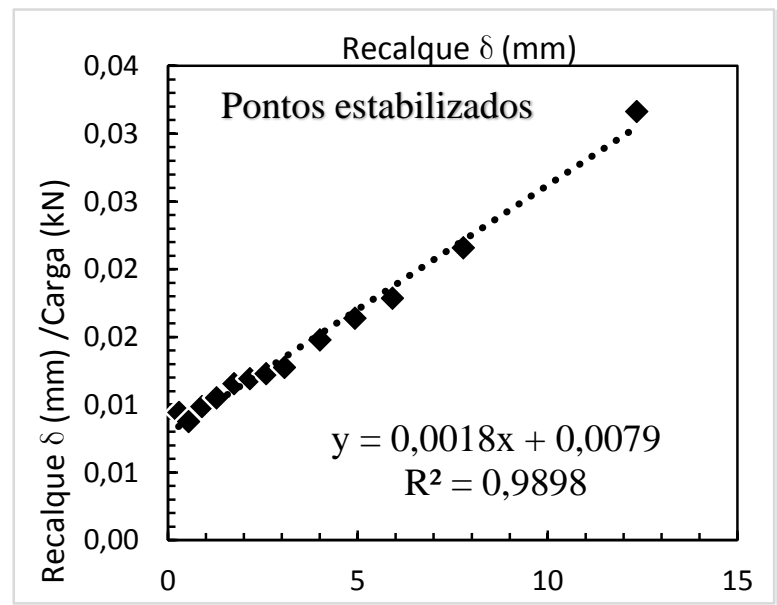

(a) Gráfico inverso rigidez vs recalque

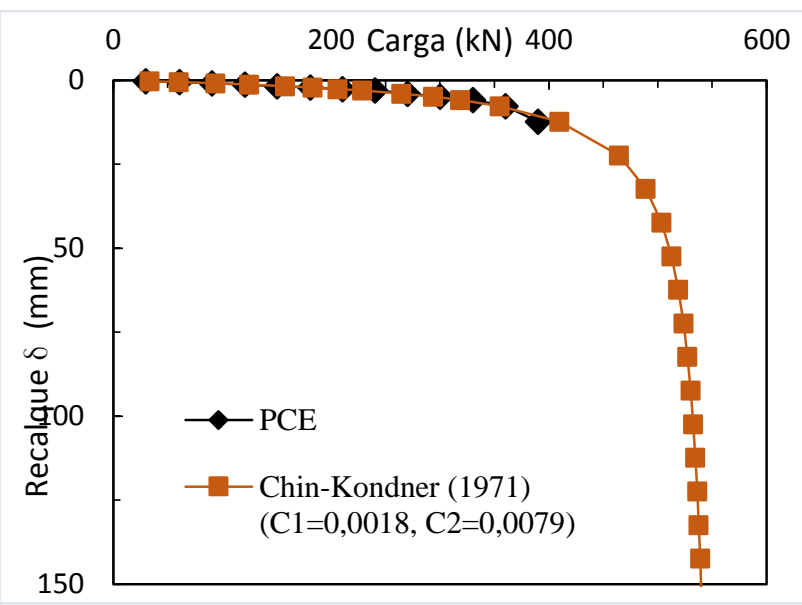

(b) Método Chin-Kondner (1971)

Figura 4.13. Extrapolação da curva carga-recalque para estaca isolada Chin-Kondner (1971) 
Na Fig. 4.14 são apresentados os resultados dos métodos da norma brasileira NBR 6122/2010 e o método de Davisson (1972), que são função do comprimento, diâmetro da estaca, módulo de elasticidade da estaca e da carga limite calculada. Na verdade, para se adotar ou escolher um critério de carga limite, é fundamental a criteriosa interpretação da curva cargarecalque obtida da prova de carga estática, além de se avaliar a necessidade da obra em termos de fator de segurança.

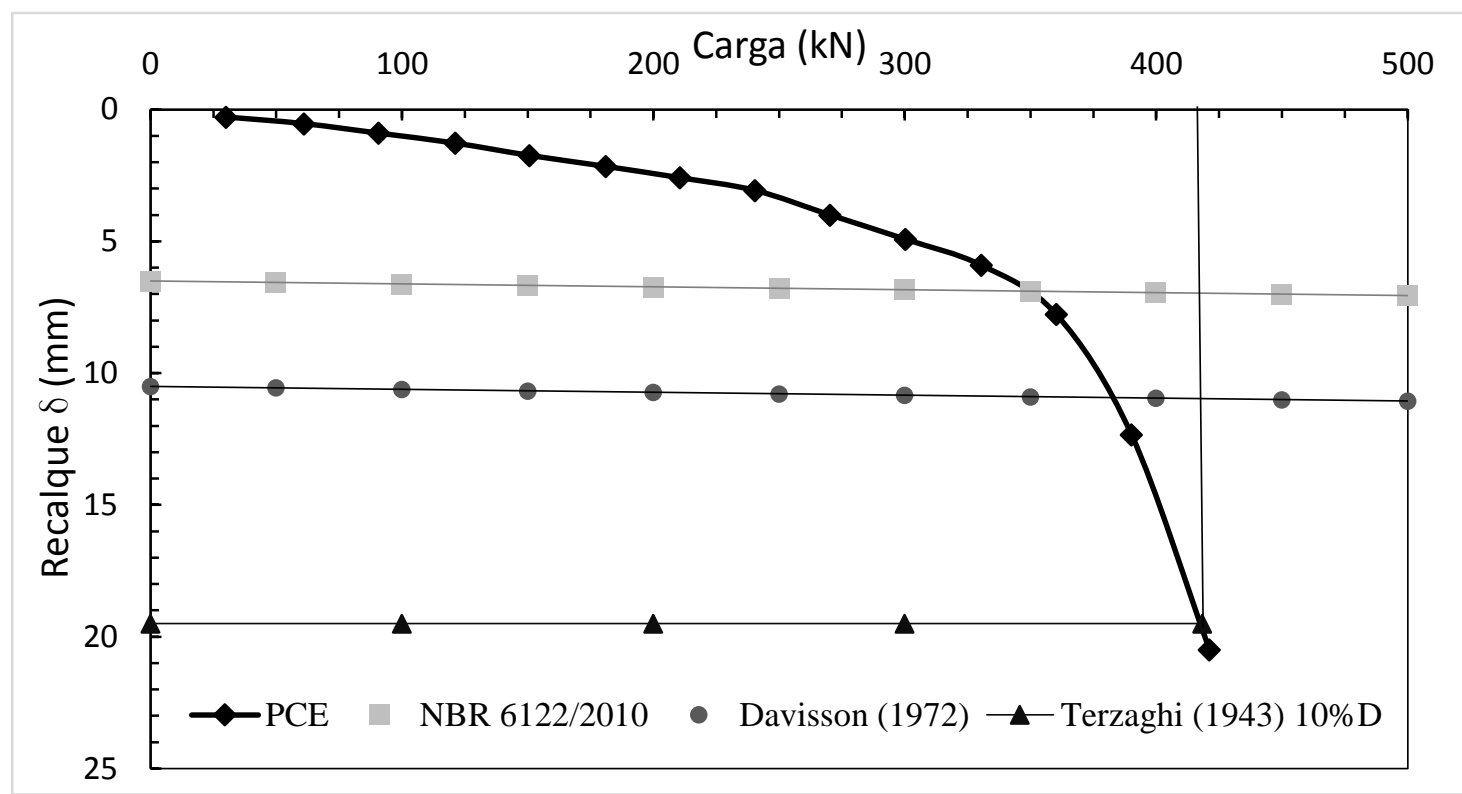

Figura 4.14. Obtenção da carga limite (Terzaghi (1943), Davisson (1972), NBR 6122/2010)

As metodologias descritas utilizadas para se estimar a carga limite do sistema soloestaca Alluvial Anker. Na Tab. 4.2 é apresentado o resumo dos resultados dos métodos e critérios utilizados, onde se adotou o valor de $424 \mathrm{kN}$ como carga limite, o qual foi obtido da média aritmética dos métodos de Van der Veen (1953), Van der Veen Modificado por Aoki (1976) e o método de conceito de rigidez de Décourt (2006-2008), porque foram os que melhor representaram o que aconteceu em campo com a prova de carga estática quando houve um aumento no recalque ao tentar se manter a carga em $421 \mathrm{kN}$. Na Tab. 4.3 são apresentados os valores obtidos dos diferentes métodos em relação ao valor da carga limite adotado, mostrando o erro em percentual (\%) na estimativa da carga limite referente ao valor experimental definido em $424 \mathrm{kN}$ para a estaca teste AA-01. 
Tabela 4.2. Valores de carga limite obtidos da análise curva carga-recalque

\begin{tabular}{|c|c|c|c|c|c|}
\hline Método & $\begin{array}{c}\text { Carga } \\
\text { Limite } \\
(\mathbf{k N})\end{array}$ & $\begin{array}{c}\text { Carga } \\
\text { Trabalho } \\
(\mathbf{k N}) *\end{array}$ & $\begin{array}{c}\boldsymbol{\delta} \mathbf{m a x} \\
(\mathbf{m m})\end{array}$ & $\begin{array}{c}\text { Tipo de } \\
\text { ruptura }\end{array}$ & $\begin{array}{c}\delta / \varnothing \mathbf{( \% )} \\
\varnothing=200 \mathbf{~ m m}\end{array}$ \\
\hline $\begin{array}{c}\text { Terzaghi (1943) Norma } \\
\text { Inglesa }\end{array}$ & 418,3 & 209 & 19,5 & Convencional & 9,75 \\
\hline Van der Veen (1953) & 426 & 213 & 25 & Convencional & 12,50 \\
\hline Davisson (1972) & 380 & 190 & 11 & Convencional & 5,50 \\
\hline Van der Veen Mod (1976) & 426 & 213 & 25 & Convencional & 12,50 \\
\hline NBR 6122 (2010) & 350 & 175 & 6,9 & Convencional & 3,45 \\
\hline Camapum (2011) & 310 & 155 & 4,2 & Convencional & 2,10 \\
\hline De Beer (1967) Norma Sueca & 340 & 170 & 4,9 & Convencional & 2,45 \\
\hline Mansur -Kaufman (1956) & 360 & 180 & 4,8 & Convencional & 2,40 \\
\hline Decourt (2006-2008) & 420 & 210 & 20 & Convencional & 10,00 \\
\hline Chin-Kondner (1971) & 556 & 278 & 200 & Física & 100,00 \\
\hline Rigidez Decourt (1996) & 472 & 236 & $\infty$ & Física & - \\
\hline * Fator de segurança $=2$ & & & & \\
\hline
\end{tabular}

Tabela 4.3. Valores de carga limite em relação ao valor da prova de carga estática

\begin{tabular}{|c|c|c|c|}
\hline Método & $\begin{array}{c}\text { Carga Limite } \\
(\mathbf{C L})(\mathbf{k N})\end{array}$ & $\mathbf{C L / P C E}$ & Erro (\%) \\
\hline Terzaghi (1943) Norma Inglesa & 418,3 & 0,99 & $-1 \%$ \\
\hline Van der Veen (1953) & 426 & 1,00 & $+0,5 \%$ \\
\hline Davisson (1972) & 380 & 0,90 & $-10 \%$ \\
\hline Van der Veen Modificado por Aoki (1976) & 426 & 1,00 & $+0,5 \%$ \\
\hline NBR 6122 (2010) & 350 & 0,83 & $-17 \%$ \\
\hline Camapum (2011) & 310 & 0,73 & $-27 \%$ \\
\hline De Beer (1967) Norma Sueca & 340 & 0,80 & $-20 \%$ \\
\hline Mansur -Kaufman (1956) & 360 & 0,85 & $-15 \%$ \\
\hline Decourt (2006-2008) & 420 & 0,99 & $-1 \%$ \\
\hline Chin-Kondner (1971) & 556 & 1,31 & $+31 \%$ \\
\hline Rigidez Decourt (1996) & 472 & 1,11 & $+11 \%$ \\
\hline
\end{tabular}

\subsection{ANÁLISE DA PROVA DE CARGA ESTÁTICA}

A análise da curva carga-recalque obtida da prova de carga estática executada na estaca Alluvial Anker AA-01 começou com a interpretação dos resultados fornecidos pelos métodos e critérios aplicados para se obter a carga limite.

No trabalho feito por Hirany e Kulhawy (1989) anteriormente citado no capitulo 2 correspondente a fundamentação cientifica, a curva carga-recalque foi dividida em três regiões claramente identificadas, como região inicial linear, região de transição e região linear final. A região linear inicial é definida pelos estágios de carregamento 1 ao 8, a região de transição vai do estágio 9 até o 13, e a região linear final começa no estágio 14, mostrando que a estaca Alluvial Anker apresenta um comportamento tensão-deformação típico de estacas escavadas, como se apresenta na Fig. 4.15. 
O resultado da carga limite obtido pelo método da norma brasileira NBR 6122/2010, Davisson (1972), e os critérios que aplicam uma regra geométrica como De Beer (1967-1968), Mansur-Kaufman (1956) e Valencia \& Camapum (2011), encontram-se na região de transição entre $\mathrm{L}_{1}$ a $\mathrm{L}_{2}$ (Fig. 4.16), onde o fuste começa a plastificar, como sugerido por (Kulhawy, 2004).

A carga limite de trabalho obtida encontra-se no limite inferior, a favor da segurança, ou seja, essas são metodologias mais conservadoras, para obtenção da carga de trabalho. O critério de Terzaghi (1943) encontra-se na região linear final, fornecendo um erro de 1\% em relação à carga limite definida. Na Fig. 4.17 foram plotadas as cargas de trabalho com FS=2, de todos os métodos e critérios usados para determinar a carga limite da curva carga-recalque, executada na estaca AA-01, onde se observa que todas as cargas de trabalho encontram-se na região linear inicial, à exceção da carga obtida pelo método de Chin (1971), que se encontra na região de transição.

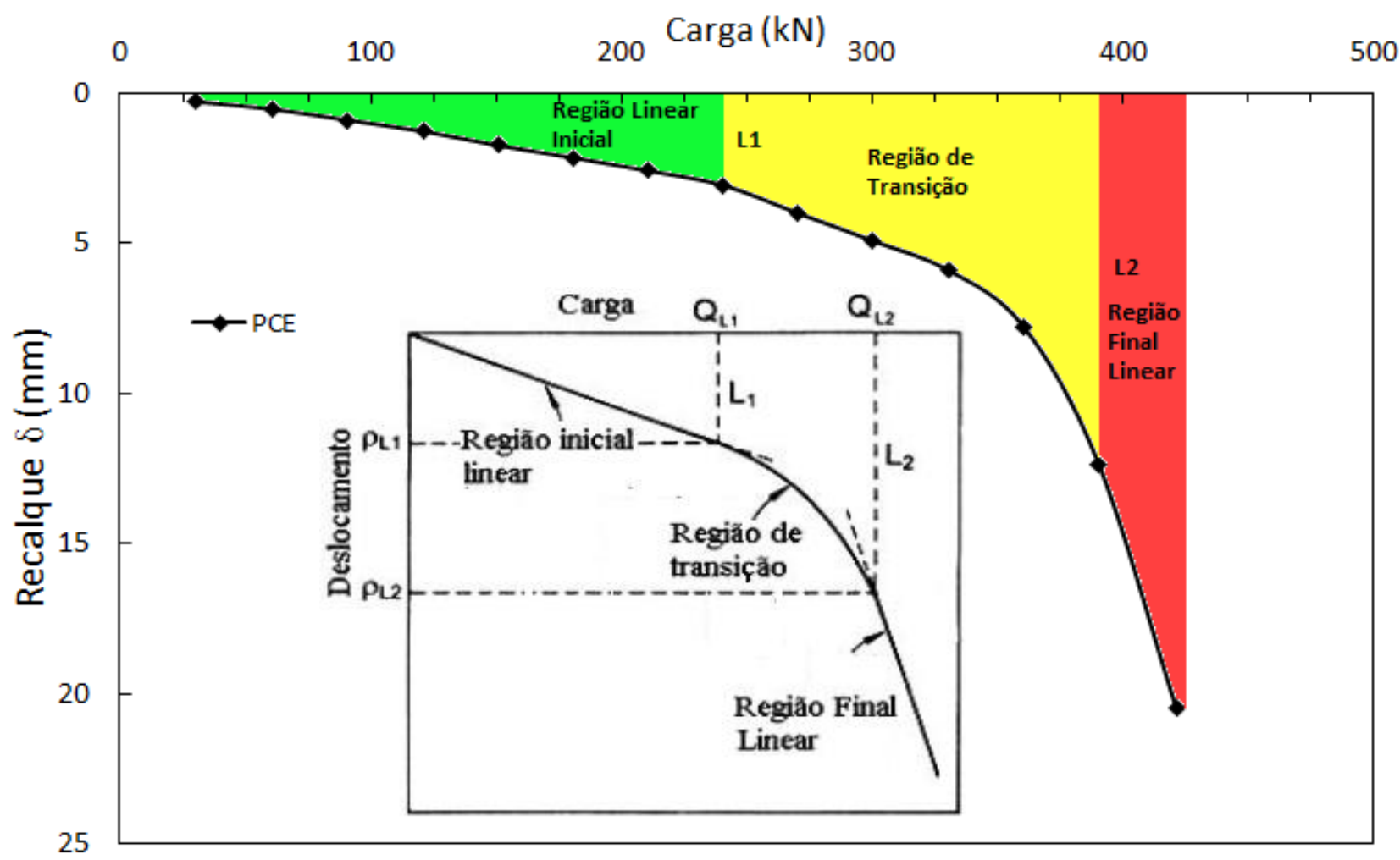

Figura 4.15 Curva carga recalque estaca escavada Alluvial Anker segundo (Hirany e Kulhawy, 1989) 


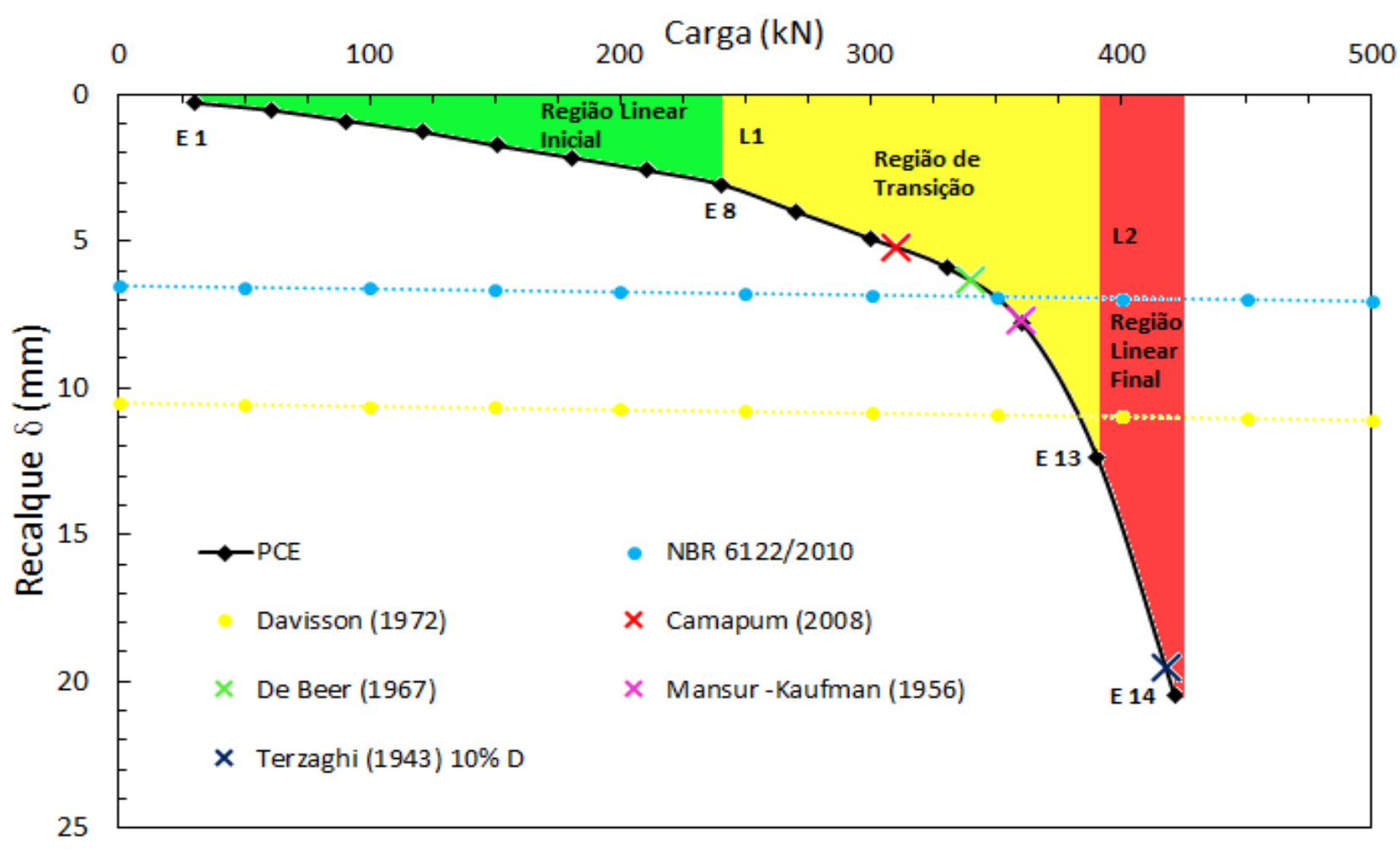

Figura 4.16 Cargas limites no gráfico de regiões da curva carga-recalque

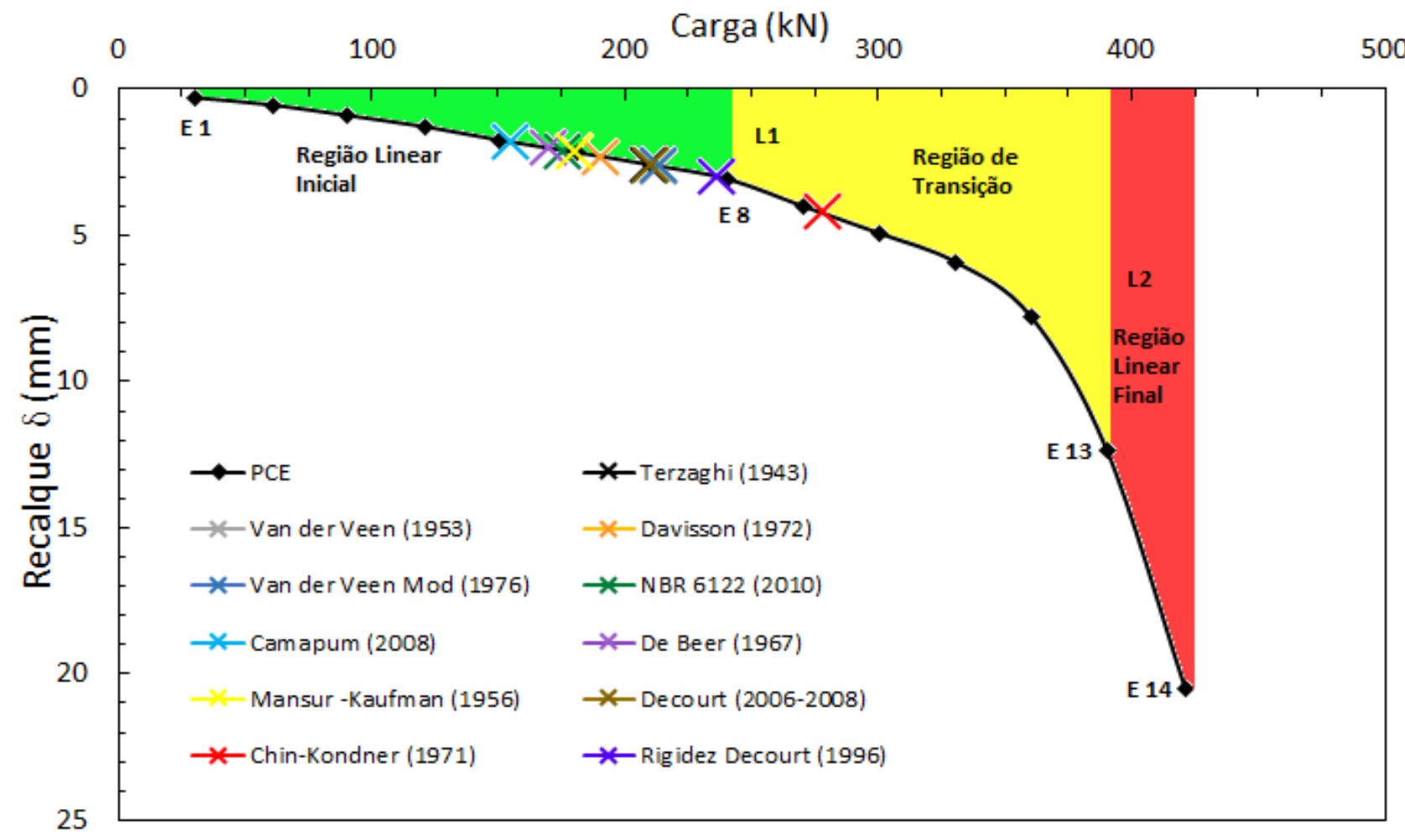

Figura 4.17 Cargas de Trabalho no gráfico de regiões da curva carga-recalque

Para a verificação da aplicabilidade do método de Van der Veen (1953) para se extrapolar a curva carga-recalque em estacas escavadas Alluvial Anker foi utilizado o procedimento segundo Valencia \& Camapum (2011), de forma a se observar o método de Van 
der Veen (1953) consegue estimar de maneira correta a carga limite, assumindo que o ensaio foi finalizado antes de atingir a carga limite.

Para observar a evolução do método de Van der Veen (1953), foram realizadas curvas individuais de extrapolação para cada ponto da curva carga-recalque escolhido. O ponto inicial foi definido de modo que a prova de carga já apresentasse uma faixa pseudo-linear definida. $\mathrm{Na}$ Tab. 4.4 são apresentados os pontos escolhidos que pertencem às regiões inicial linear, transição, linear final, como anteriormente definidas.

Tabela 4.4. Carga máxima aplicada $(\mathrm{kN})$ na estaca em cada estágio a assumindo o final do ensaio

\begin{tabular}{|c|c|c|c|c|c|c|c|c|c|c|}
\hline \multirow{2}{*}{ Estaca } & \multicolumn{10}{|c|}{ Estágio } \\
\cline { 2 - 11 } & $\mathbf{5}$ & $\mathbf{6}$ & $\mathbf{7}$ & $\mathbf{8}$ & $\mathbf{9}$ & $\mathbf{1 0}$ & $\mathbf{1 1}$ & $\mathbf{1 2}$ & $\mathbf{1 3}$ & $\mathbf{1 4}$ \\
\hline AA01 & 150,77 & 181,05 & 210,51 & 240,51 & 270,31 & 300,26 & 330,4 & 360,26 & 390,2 & 420,1 \\
\hline
\end{tabular}

A partir dessas cargas máximas aplicadas foi estimada a carga limite através da extrapolação, e como ela se afasta em relação ao valor experimental. Na Tab. 4.5 são apresentados os resultados da carga limite para cada estágio.

Tabela 4.5. Carga limite ( $\mathrm{kN})$ com o avanço da prova de carga estática

\begin{tabular}{|c|c|c|c|c|c|c|c|c|c|c|}
\hline \multirow{2}{*}{ Estaca } & \multicolumn{10}{|c|}{ Estágio } \\
\cline { 2 - 11 } & $\mathbf{5}$ & $\mathbf{6}$ & $\mathbf{7}$ & $\mathbf{8}$ & $\mathbf{9}$ & $\mathbf{1 0}$ & $\mathbf{1 1}$ & $\mathbf{1 2}$ & $\mathbf{1 3}$ & $\mathbf{1 4}$ \\
\hline AA01 & 270 & 450 & 450 & 550 & 400 & 400 & 415 & 410 & 400 & 426 \\
\hline
\end{tabular}

Foi quantificada em percentual a variação da carga limite, em relação ao estágio anterior (Tab. 4.6).

Tabela 4.6. Variação da carga limite em relação ao estágio anterior

\begin{tabular}{|c|c|c|c|c|c|c|c|c|c|c|}
\hline \multirow{2}{*}{ Estaca } & \multicolumn{10}{|c|}{ Estágio } \\
\cline { 2 - 11 } & $\mathbf{5}$ & $\mathbf{6}$ & $\mathbf{7}$ & $\mathbf{8}$ & $\mathbf{9}$ & $\mathbf{1 0}$ & $\mathbf{1 1}$ & $\mathbf{1 2}$ & $\mathbf{1 3}$ & $\mathbf{1 4}$ \\
\hline AA01 & ---- & $66 \% \uparrow$ & $0 \%$ & $22 \% \uparrow$ & $37 \% \downarrow$ & $0 \%$ & $3 \% \uparrow$ & $1 \% \downarrow$ & $2 \% \downarrow$ & $6 \% \uparrow$ \\
\hline
\end{tabular}

Calculou-se o erro da carga limite estimada por Van der Veen (1953), em relação ao valor de carga limite adotada de 424 kN, e os resultados são apresentados na Tab. 4.7.

Tabela 4.7. Erro na carga limite em cada estágio em relação ao valor de carga limite adotado

\begin{tabular}{|c|c|c|c|c|c|c|c|c|c|c|}
\hline \multirow{2}{*}{ Estaca } & \multicolumn{10}{|c|}{ Estágio } \\
\cline { 2 - 11 } & $\mathbf{5}$ & $\mathbf{6}$ & $\mathbf{7}$ & $\mathbf{8}$ & $\mathbf{9}$ & $\mathbf{1 0}$ & $\mathbf{1 1}$ & $\mathbf{1 2}$ & $\mathbf{1 3}$ & $\mathbf{1 4}$ \\
\hline AA01 & $56 \% \downarrow$ & $7 \% \uparrow$ & $7 \% \uparrow$ & $30 \% \uparrow$ & $5 \% \downarrow$ & $5 \% \downarrow$ & $1 \% \downarrow$ & $2 \% \downarrow$ & $4 \% \downarrow$ & $1 \% \uparrow$ \\
\hline
\end{tabular}

Observa-se que o erro vai diminuindo à medida que o ensaio avança. Nota-se que no começo da região de transição (estágios 9 ao 13), o erro médio da estimativa da carga limite está em cerca de 3\%, mostrando que quando a curva carga-recalque atinge a região de transição, é possível estimar de maneira muito aproximada a carga limite. O método de Van der Veen 
(1953) aplicado a estacas Alluvial Anker consegue uma boa aproximação se a prova de carga atingir a região de transição.

Na Fig. 4.18 pode-se observar a evolução da curva de extrapolação obtida pelo método de Van der Veen (1953), referente às 3 regiões que compõe a curva carga-recalque.

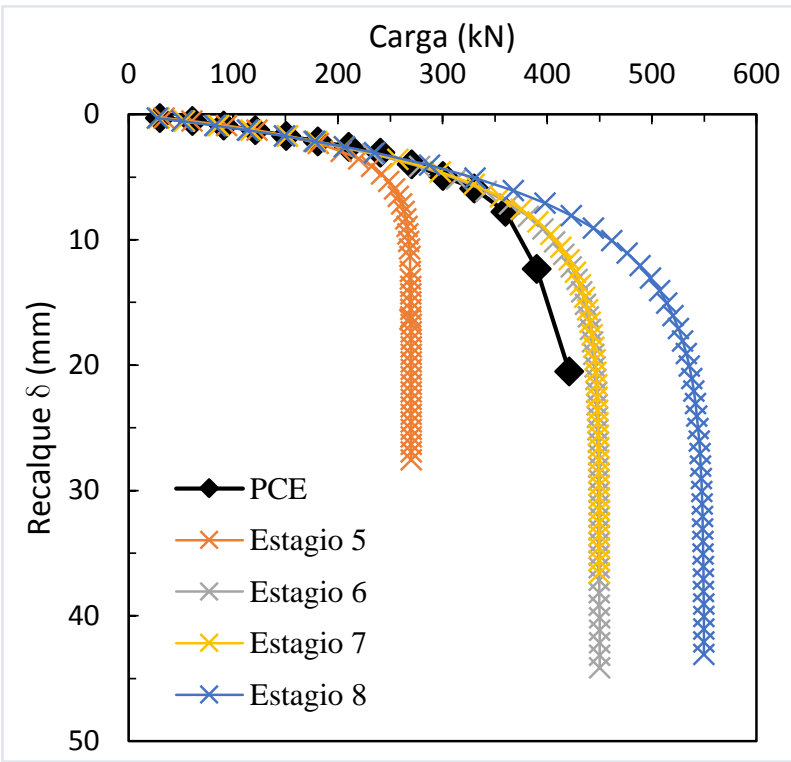

(a) Van der Veen (1953) região linear inicial

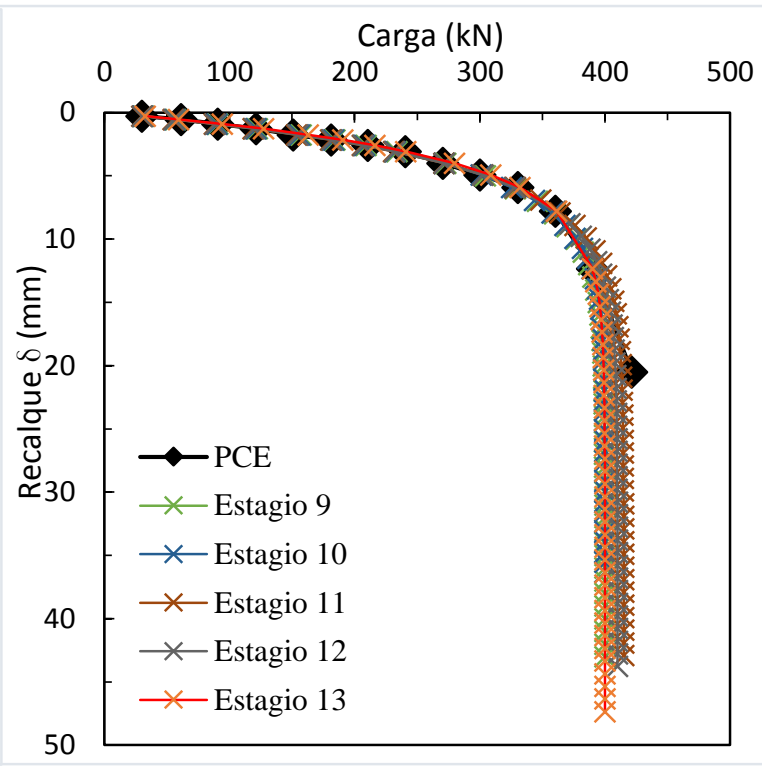

(b) Van der Veen (1953) região de Transição

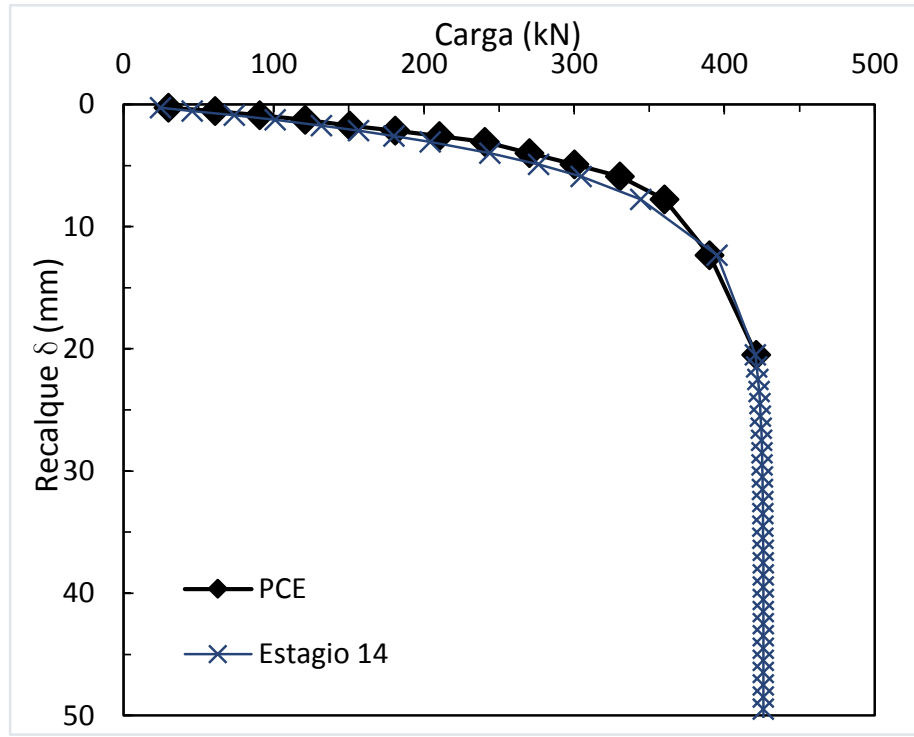

(c) Van der Veen (1953) região linear final

Figura 4.18. Evolução da curva de extrapolação nas diferentes regiões da curva carga-recalque

\subsection{DETERMINAÇÃO DA PARCELA DE ATRITO LATERAL E PONTA}

Para a análise das parcelas de atrito lateral e parcela de ponta foi utilizado o Conceito de Rigidez de Décourt (2006-2008) para a interpretação dos resultados das provas de carga. 
Esse método consiste em se estimar domínios de resistência por atrito lateral e de ponta em provas de carga sem instrumentação eletrônica.

A finalidade desta análise foi determinar a forma em que trabalha a estaca Alluvial Anker e ter a ideia de quanta carga vai para ponta e quanta é perdida ao longo do fuste como para atrito lateral.

Segundo Décourt (2006-2008) se o carregamento é levado até grandes deformações, dois domínios serão facilmente identificados: o domínio da ponta e o domínio do atrito lateral. No trecho onde a transferência por ponta é predominante, a relação entre Q e rigidez é uma curva, tornando-se linear no gráfico Log-Log. Já no trecho onde o atrito lateral é dominante, essa relação é, nitidamente, linear apresentado na Fig. 4.20(a).

São colocados os dados obtidos da prova de carga em ordem decrescente começando pelos pontos de carga mais elevados, e desta forma são estabelecidas correlações lineares entre $\log Q$ e $\log \delta$. Estes coeficientes de correlação $\mathrm{R}$ são elevados ao quadrado obtendo $\mathrm{R}^{2}$. Quando o valor de $\mathrm{R}^{2}$ começa a ser menor do que 1 , tem-se a mudança de comportamento descrita como zona de transição. Este método admite que a ponta tenha sido, pelo menos, parcialmente mobilizada. A partir do ponto $2 \mathrm{o} \mathrm{R}^{2}$ começa a diminuir, mostrando mudança de comportamento, e daí, é escolhido como o ponto de regressão (ver Tab. 4.8.).

Tabela 4.8. Determinação do ponto de regressão linear

\begin{tabular}{|c|c|c|c|c|c|c|c|c|}
\hline \multicolumn{5}{|c|}{ PCE (DADOS CAMPO) } & \multicolumn{4}{|c|}{ REGRESSÃO LINEAR } \\
\hline Estágio & Ponto & $\begin{array}{c}\text { Carga Q } \\
(\mathbf{k N})\end{array}$ & $\begin{array}{c}\text { Carga Q } \\
(\mathrm{MN})\end{array}$ & $\begin{array}{c}\delta \\
(\mathbf{m m})\end{array}$ & $\begin{array}{l}\log Q \\
(\mathbf{M N})\end{array}$ & $\begin{array}{l}\log \delta \\
(\mathbf{m m})\end{array}$ & $\mathbf{R}$ & $\mathbf{R}^{2}$ \\
\hline 14 & 1 & 421,23 & 0,421 & 20,497 & $-0,37548$ & 1,31168 & -- & -- \\
\hline 13 & $2 *$ & 390,20 & 0,390 & 12,337 & $-0,40871$ & 1,09120 & 1,00000 & 1,0000 \\
\hline 12 & 3 & 360,26 & 0,360 & 7,770 & $-0,44338$ & 0,89042 & 0,99923 & 0,9985 \\
\hline 11 & 4 & 330,40 & 0,330 & 5,903 & $-0,48096$ & 0,77104 & 0,98791 & 0,9760 \\
\hline 10 & 5 & 300,26 & 0,300 & 4,920 & $-0,52250$ & 0,69197 & 0,97087 & 0,9426 \\
\hline 9 & 6 & 270,31 & 0,270 & 3,998 & $-0,56814$ & 0,60179 & 0,96239 & 0,9262 \\
\hline 8 & 7 & 240,51 & 0,241 & 3,068 & $-0,61887$ & 0,48678 & 0,96380 & 0,9289 \\
\hline 7 & 8 & 210,51 & 0,211 & 2,585 & $-0,67673$ & 0,41246 & 0,95983 & 0,9213 \\
\hline 6 & 9 & 181,05 & 0,181 & 2,155 & $-0,74220$ & 0,33345 & 0,95544 & 0,9129 \\
\hline 5 & 10 & 150,77 & 0,151 & 1,740 & $-0,82169$ & 0,24055 & 0,95223 & 0,9067 \\
\hline 4 & 11 & 121,18 & 0,121 & 1,273 & $-0,91657$ & 0,10466 & 0,95488 & 0,9118 \\
\hline 3 & 12 & 90,68 & 0,091 & 0,895 & $-1,04249$ & $-0,04818$ & 0,95830 & 0,9183 \\
\hline 2 & 13 & 61,11 & 0,061 & 0,535 & $-1,21389$ & $-0,27165$ & 0,96444 & 0,9301 \\
\hline 1 & 14 & 30,00 & 0,030 & 0,283 & $-1,52288$ & $-0,54898$ & 0,96532 & 0,9318 \\
\hline
\end{tabular}

Sendo assim, a partir do ponto 2, a ponta deixa de preponderar, o que se pode conferir pela redução de $\mathrm{R}^{2}$. O ponto 2 é um ponto de transição entre o domínio de atrito lateral e o de 
ponta. A transição pode incluir alguns pontos até iniciar o domínio do atrito lateral (Vianna, 2000).

Com isso dito, a reta entre o ponto de regressão (ponto 2 ) e a carga limite $\left(\mathrm{R}_{\mathrm{uc}}\right)$ fornecida pelo método de Décourt (2008), fornece a informação do limite inferior do domínio do atrito lateral $\left(\mathrm{Q}_{\mathrm{sl}}=0,341 \mathrm{MN}=341 \mathrm{kN}\right)$, apresentado na Fig. 4.19.

Décourt (2006-2008) demostra que os resultados de provas de carga em estacas que trabalham predominantemente por atrito lateral apresentam, no gráfico de rigidez, relação linear entre carga e rigidez, o que pode ser observado na Fig. 4.20.

Para a estaca AA-01, conclui-se que os pontos 1 a 2 definem o domínio da ponta, sendo o ponto 2 a transição. Foram testados diferentes pares de pontos para se obter o melhor ajuste, por exemplo os pontos 4 a 6 apresentam correlação de 0,9946, mas o limite superior do atrito lateral é levado até $615 \mathrm{kN}$, o que não aconteceu na realidade. O limite superior do atrito lateral foi identificado com os pontos 2 a 5, os quais se ajustaram melhor à realidade do que a curva com um coeficiente $\mathrm{R}^{2}$ de 0,9534 .

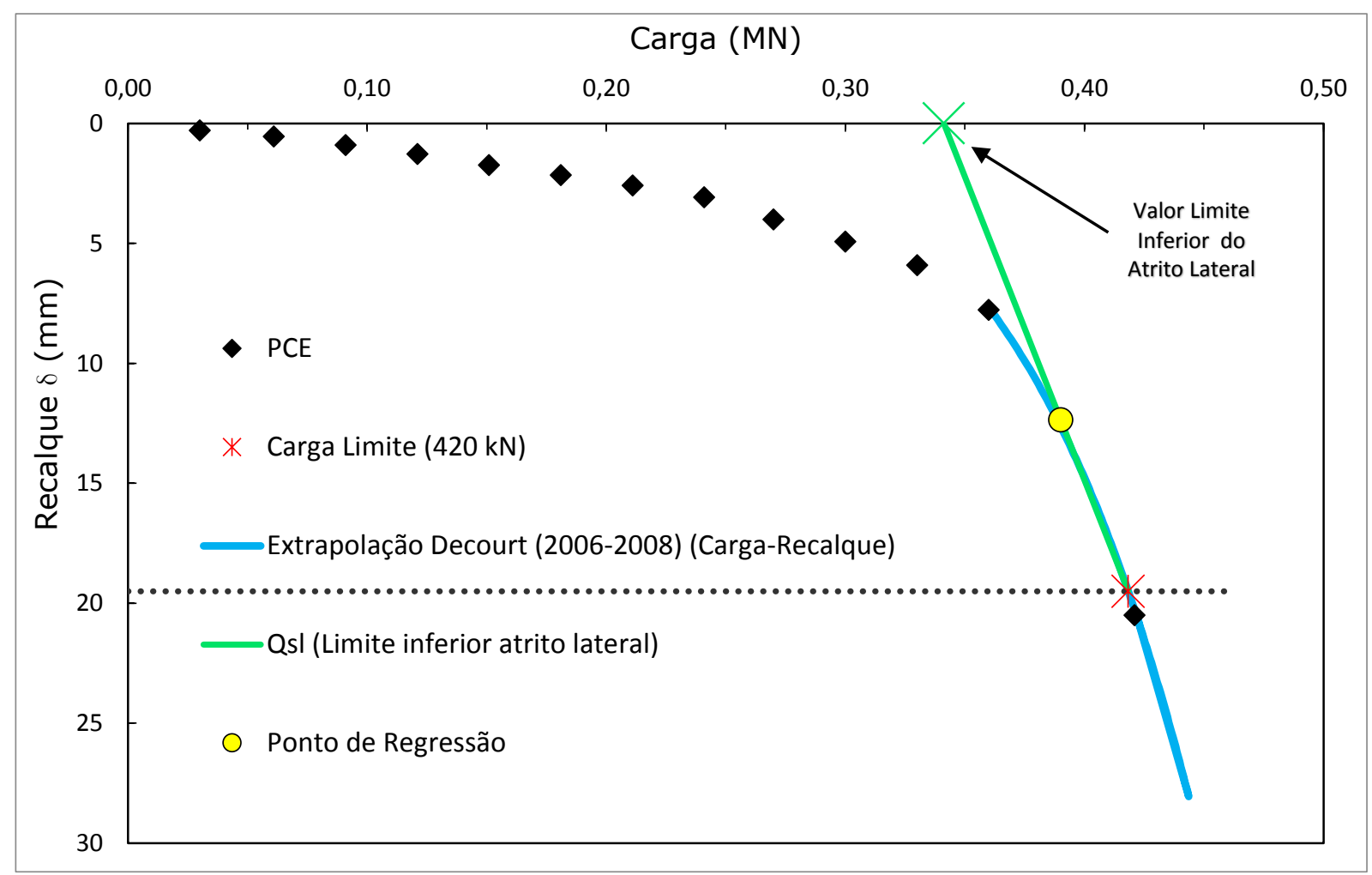

Figura 4.19 Relação carga-recalque Estaca AA-01

Segundo Décourt (2008), sem instrumentação, os valores do atrito lateral jamais serão conhecidos, porém, os mesmos terão que, obrigatoriamente, situar-se entre esses dois limites inferior $\left(\mathrm{Q}_{\mathrm{sl}}\right)$ e superior do atrito lateral $\left(\mathrm{Q}_{\mathrm{su}}\right)$. 


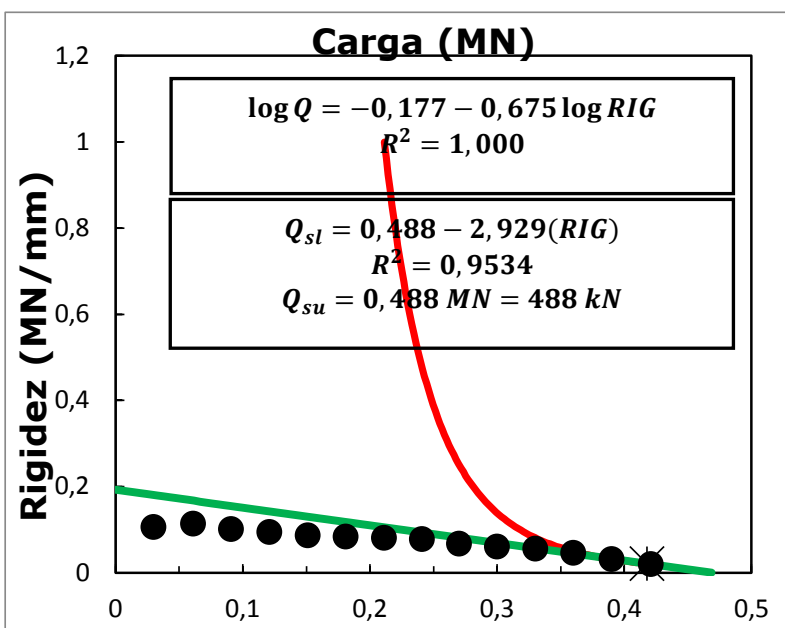

(a) Gráfico de rigidez

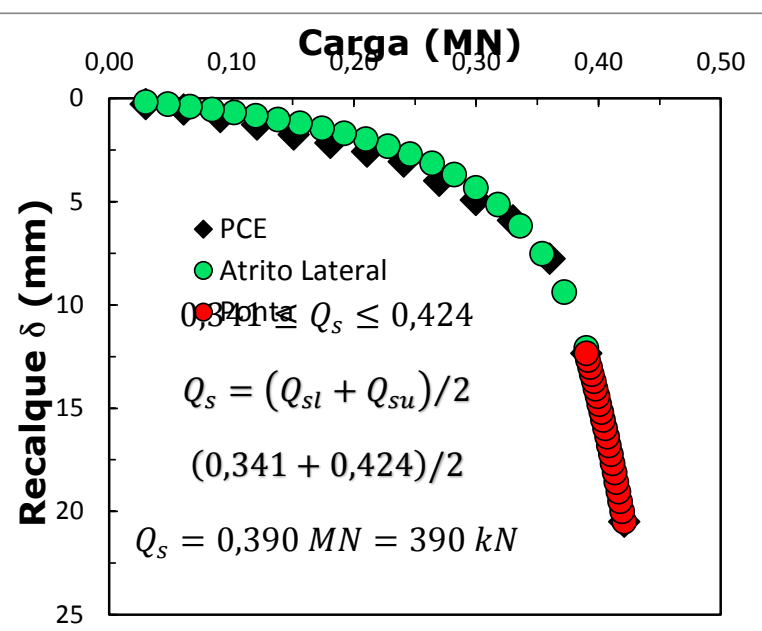

(b) Domínio do atrito lateral

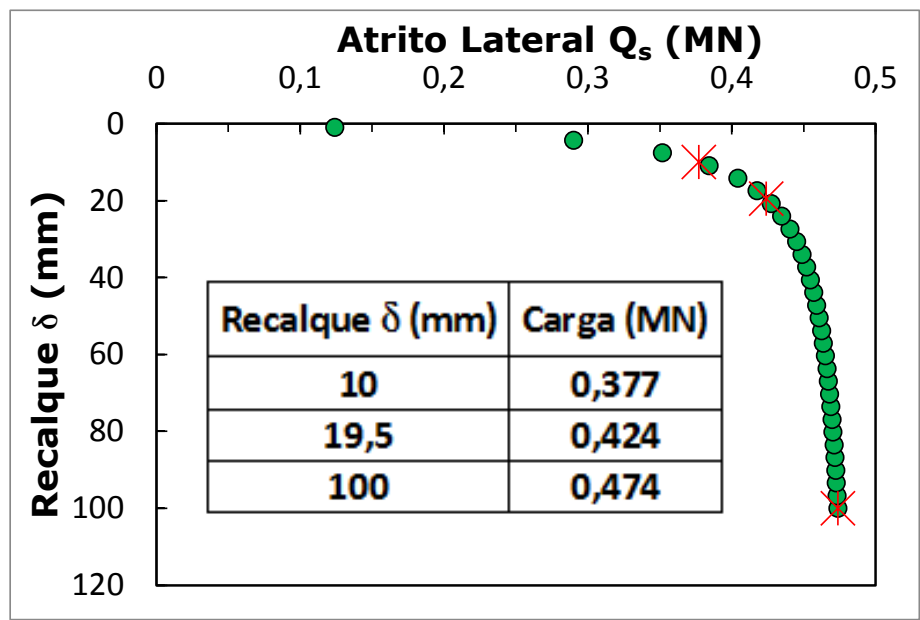

(c) Gráfico do atrito lateral

Figura 4.20 Identificação das parcelas de ponta e atrito lateral Estaca AA-01

Além do método de rigidez de Décourt (2006-2008), também se verificou no método de análise para provas de carga sem instrumentação eletrônica, proposto por Camapum de Carvalho et al, (2011), qual seria a parcela de carga atribuída ao atrito lateral e à ponta, ou pelo menos em que estágio a ponta começa a ser mobilizada.

O método descreve o comportamento de uma fundação por meio do coeficiente de recalque, que é a inclinação da parte final reta das curvas no gráfico recalque médio vs Log tempo mostrado na Fig. 4.21. Com isso é construído o gráfico de coeficiente de recalque vs carga, onde são identificados os segmentos de reta que permitem interpretar o comportamento carga-recalque de uma fundação profunda mostrado na Fig. 4.22. 
Segundo Valencia \& Camapum (2011) o ponto de encontro do primeiro segmento de reta com o segundo segmento da curva carga vs coeficiente de recalque, define o início das deformações plásticas no solo, ao fim da região pseudo-elastica do sistema solo-estaca. $\mathrm{O}$ segundo ponto de inflexão, ou seja, o encontro do segundo segmento de reta e o terceiro segmento na curva carga vs coeficiente de recalque, corresponde ao início das deformações plásticas do solo abaixo da ponta da estaca, em que a ponta está apoiada.

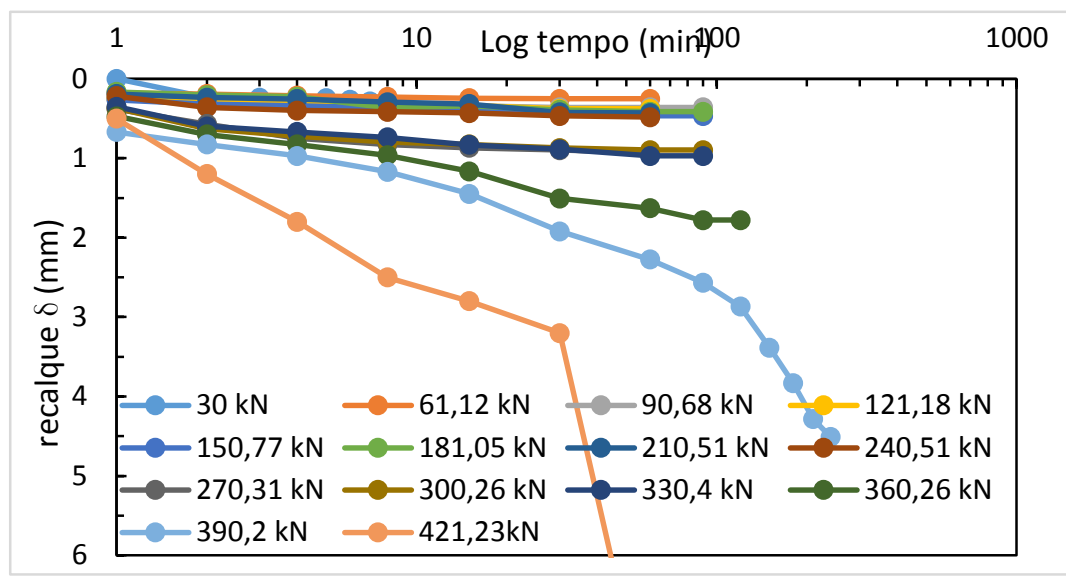

Figura 4.21 Curvas recalque médio vs log tempo

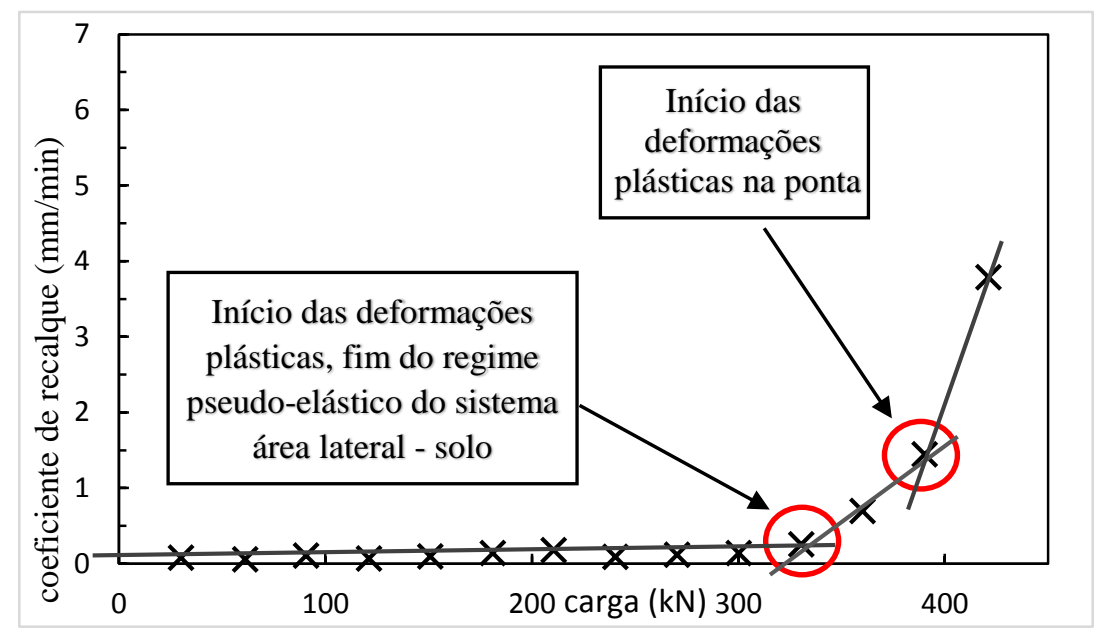

Figura 4.22 Coeficiente de recalque vs carga

Foram identificados portanto três (3) segmentos de reta, onde o primeiro segmento é identificado como a região pseudo-elástica, que foi mais extensa do que as outras regiões. A partir de $330 \mathrm{kN}$ começa a mobilização do atrito lateral identificado como o início da plastificação do atrito lateral, onde ao atingir a região de plastificação tem-se o risco de apresentar recalques importantes que deve-se ter em conta. A partir de $390 \mathrm{kN}$, a ponta começa a ser mobilizada, iniciando a plastificação nesta região.

Desta forma, utilizando metodologias como Décourt (2006-2008) e Valencia \& Camapum (2011) é possível se obter de uma prova de carga mais do que a carga limite de uma fundação. É importante ter estas ferramentas de análise que ajudam na sua interpretação, fornecendo 
informações importantes para o projeto, como a identificação das parcelas de ponta e atrito lateral, a mobilização da ponta e fuste, e a carga de trabalho mais apropriada às condições que se tenham em campo.

\subsection{PROVAS DE CARGA DE GRUPOS DE ESTACAS ALLUVIAL ANKER}

Foram executadas por Mendoza (2013) 6 provas de carga estáticas sem contato com o solo para cada configuração de estacas Alluvial Anker (2 estacas, 3 estacas, 4 estacas, 5 estacas e 6 estacas). As provas de carga realizadas mostram que com o aumento do número de estacas o trecho linear inicial proposto por Hirany e Kulhawy (1989) é identificado mais facilmente apresentando a diminuição da inclinação da região linear da curva carga-recalque.

Na Fig. 4.23 foram plotadas todas as provas de carga e observada a evolução da curva carga-recalque em sua geometria.

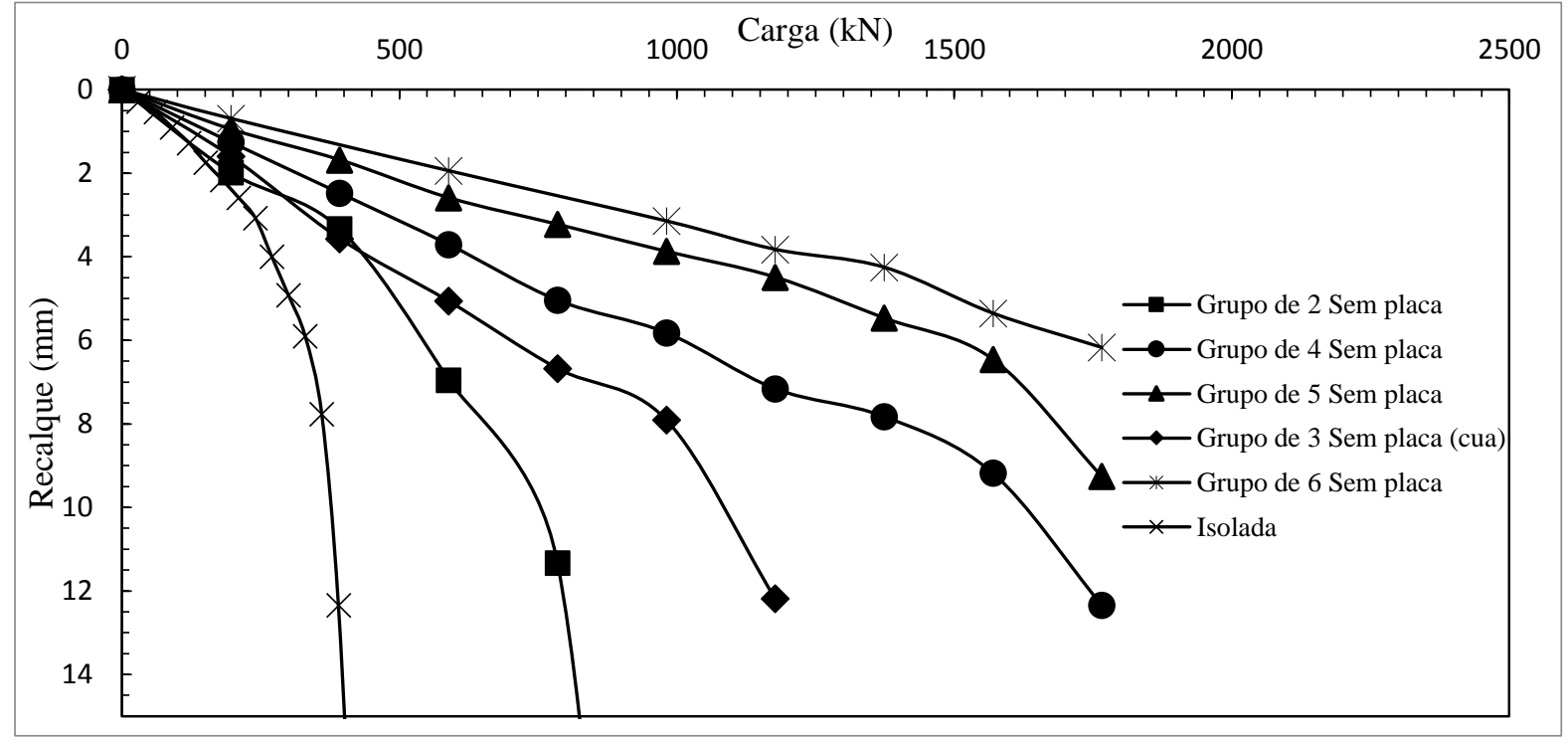

Figura 4.23 Provas de carga estática isolada e em grupos Alluvial Anker

\subsection{EFICIÊNCIA DE GRUPOS DE ESTACAS ALLUVIAL ANKER}

Já obtido o valor da prova de carga realizada na estaca isolada AA-01, e os dados das provas de carga sem contato com solo realizadas nos grupos de 2,3,4,5 e 6 estacas, passou-se a calcular a eficiência experimental dos grupos Alluvial Anker, sendo esta por sua vez comparada com métodos usuais (empíricos) de cálculo da eficiência de grupos de fundação como os métodos de Feld, 1963; Converse-Labarre e de Grupos de los Angeles. Além disso, a eficiência experimental foi comparada com a eficiência numérica calculada por Mendoza (2013). Nesse último trabalho, foi simulada uma estaca isolada Alluvial Anker no software Abaqus, com as mesmas características que a estaca testada nesta dissertação, e foi calculada a eficiência com 
os valores de carga limite fornecidos pelo programa. Dessa forma, calculou-se a eficiência com os valores experimentais das provas de carga dos grupos e o valor simulado na estaca isolada. Na Tab. 4.9 é apresentada a comparação com seus respectivos resultados para cada cálculo realizado.

A eficiência experimental foi calculada utilizando o mesmo critério para estimar a carga limite, no trabalho de Mendoza (2013) e na presente dissertação, ou seja, utilizou-se o critério da norma brasileira NBR 6122/2010 para definir a carga limite para a estaca isolada definida em $350 \mathrm{kN}$.

Tabela 4.9 Resultados das diferentes metodologias para o cálculo de eficiência

\begin{tabular}{|c|c|c|c|c|c|c|c|}
\hline \multicolumn{4}{|c|}{ Prova de Carga } & \multicolumn{5}{c|}{ Eficiência ( $\boldsymbol{\eta})$} \\
\hline $\begin{array}{c}\text { Grupo de } \\
\text { Estacas }\end{array}$ & $\mathbf{R}_{\mathbf{u}}(\mathbf{k N})^{\mathbf{1}}$ & $\mathbf{R}_{\mathbf{u}}(\mathbf{k N})^{\mathbf{2}}$ & $\mathbf{( \eta ) ^ { 1 }}$ & $(\boldsymbol{\eta})^{\mathbf{2}}$ & $\begin{array}{c}\text { Converse- } \\
\text { Labarre }\end{array}$ & $\begin{array}{c}\text { Grupo los } \\
\text { Angeles }\end{array}$ & Feld \\
\hline Estaca Isolada & 419,18 & 350 & -- & -- & -- & -- & -- \\
\hline Grupo 2 & -- & 750 & 0,89 & 1,07 & 0,93 & 0,95 & 0,94 \\
\hline Grupo 3 & -- & 1100 & 0,87 & 1,05 & 0,91 & 0,93 & 0,92 \\
\hline Grupo 4 & -- & 1780 & 1,06 & 1,27 & 0,86 & 0,86 & 0,81 \\
\hline Grupo 5 & -- & 1970 & 0,94 & 1,13 & -- & -- & 0,80 \\
\hline Grupo 6 & -- & 2520 & 1,00 & 1,20 & 0,84 & 0,83 & 0,77 \\
\hline 1 Carga de estaca isolada de 419,18 kN simulada numéricamente (Mendoza, 2013) (Abaqus) \\
2 Prova de carga estática (presente trabalho) \\
\hline
\end{tabular}

Na Fig. 4.24 pode-se observar que o gráfico de eficiência vs número de estacas não apresenta uma tendência definida sob a influência do número de estacas no aumento ou na diminuição da eficiência, mas apresenta valores de eficiência de grupo maior do que $100 \%$ independente da configuração estudada. Além disto apresenta um incremento da eficiência experimental com a mudança da configuração passando de linear à quadrada, e mantendo um valor maior com configurações quadradas. 


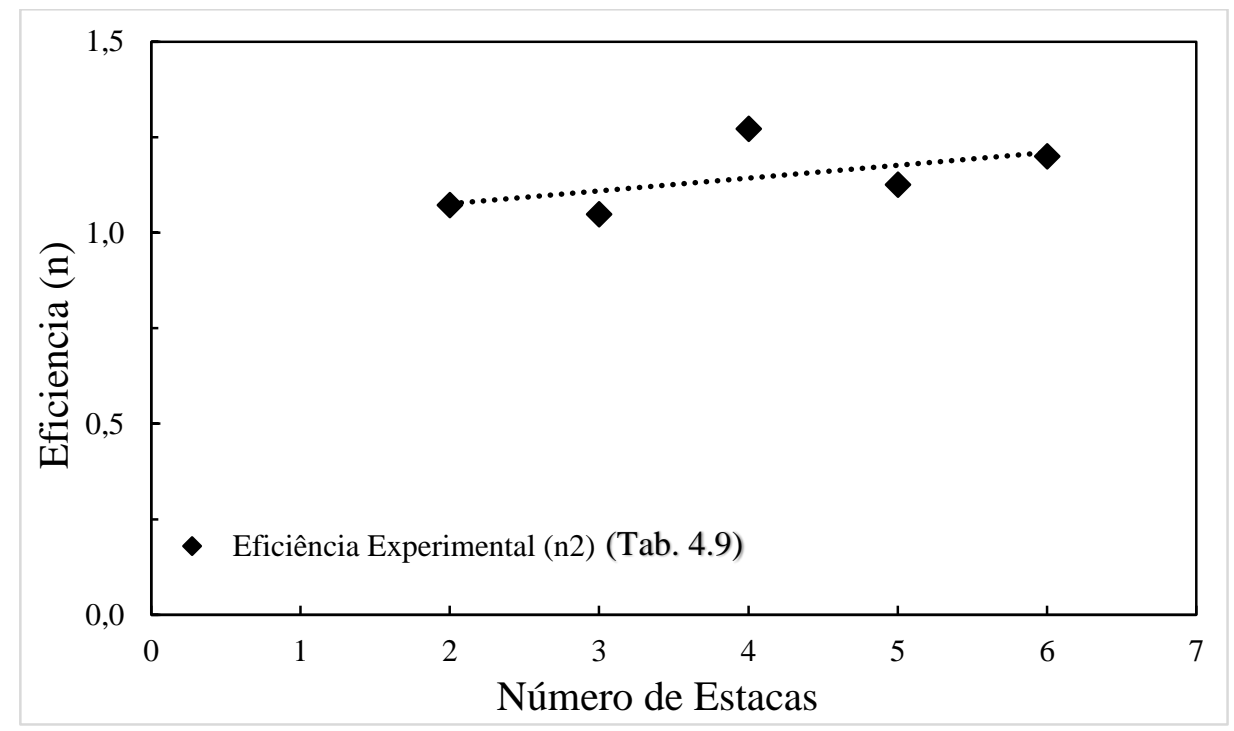

Figura 4.24 Gráfico eficiência (n) vs número de estacas

Melo (2009) calculou a eficiência em estacas escavadas do tipo "broca", realizando seis provas de carga estáticas no Campo Experimental de Fundações da USP/SC, ensaiadas

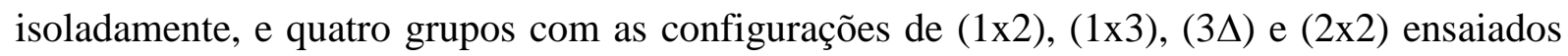
com e sem contato do bloco com o solo. O perfil geológico do Campo Experimental de Fundações da USP/SC é típico de vasta região do Estado de São Paulo. A camada superficial, de Sedimento Cenozóico com 6 m de espessura, é uma areia argilosa marrom, fina, laterizada, com SPT médio em torno de 4 golpes, com coesão drenada de $20 \mathrm{kPa}$ e ângulo de atrito igual a 30 graus (Cintra et al., 1991) citado por (Silva \& Cintra, 1996), apresentando características geotécnicas muito similares aos perfis geotécnicos do Distrito Federal.

Este autor encontrou valores de eficiência experimental em torno de 1,0, variando entre 0,90 a 1,09, mostrando que para configurações de estacas lineares a eficiência é constante com valor médio de 0,91 e para as demais configurações, ou seja, para $(3 \Delta)$ e $(2 \times 2)$ varia entre 1,09 e 0,97 respectivamente. O resultado de valores de eficiência de configurações quadradas de 0,97 no trabalho citado, contra a média de valores eficiência de 1,20 obtidos na presente dissertação em configurações quadradas, mostra uma tendência de constância em configurações deste tipo quando executadas em solos tropicais. Nota-se que a eficiência experimental das configurações $(2 \times 1)$ e $(3 \times 1)$ de Silva \& Cintra (1996) em comparação com a eficiência experimental das configurações $(2 \times 1)$ e $(3 \times 1)$ na presente dissertação apresentam também uma tendência linear nos valores $(0,90$ e 0,92 em relação a 1,07 e 1,05 respectivamente).

Vale lembrar que as estacas escavadas no trabalho de Silva \& Cintra (1996) foram igualmente do tipo broca, com 0,25 $\mathrm{m}$ de diâmetro e $6 \mathrm{~m}$ de comprimento, e as configurações estudadas apresentam espaçamento entre centros de estacas igual a 3 diâmetros. 


\subsection{SUMÁRIO DOS PRINCIPAIS RESULTADOS DA PROVA DE CARGA}

Neste capítulo apresentou-se as informações que podem ser obtidas de uma prova de carga, obtendo diferentes características do comportamento mecânico de estacas Alluvial Anker mostradas a seguir:

- A forma da curva carga-recalque fornecida da prova de carga conclui que a estaca Alluvial Anker tem comportamento de estaca do tipo escavada;

- Os critérios que aplicam uma regra geometria à curva carga-recalque como MansurKaufman (1956), De Beer (1967) e Camapum (2011) para obter a carga limite mostramse muito conservadores, apresentando recalques médios para carga limite da ordem de $3 \%$ do diâmetro da estaca;

- O critério para definir a carga limite consistiu no valor médio dos resultados fornecidos pelos seguintes métodos de extrapolação da curva carga-recalque Van Der Veen (1953), Van Der Veen Modificado por Aoki (1976) e Conceito de Rigidez de Décourt (2008), definindo-se este valor em $424 \mathrm{kN}$;

- O critério de Van Der Veen (1953) consegue fornecer uma estimativa da carga limite com bons resultados se a prova de carga é levada até que a mesma mostre a inflexão da curva denominada por Hirany e Kulhawy (1989) como o início da região de transição;

- Com metodologias como Décourt (2008) e Camapum e Valencia (2011) foi definido que, a partir de $390 \mathrm{kN}$, começa a plastificação do solo onde se encontra a ponta da estaca, ou seja, com esse nível de carga a ponta começa se movimentar. Com isto a estaca além de ter comportamento de estaca escavada, se comporta também como estaca flutuante trabalhando principalmente por atrito lateral com só aproximadamente $8 \%$ de contribuição da ponta na capacidade total limite da estaca;

- A curva carga-recalque apresenta redução na inclinação com o aumento do número de estacas, caracterizando um aumento da rigidez $(\mathrm{kN} / \mathrm{m})$;

- A eficiência experimental mostrou variação ao momento de mudar de uma configuração linear a uma quadrada, obtendo valor médio de 1,06 para configurações lineares. A configuração quadrada apresentou valores que variaram entre 1,13 e 1,25; 


\section{ESTIMATIVA DA CAPACIDADE DE CARGA E RECALQUE DE ESTACAS}

\section{ALLUVIAL ANKER}

\subsection{ESTIMATIVA DE CARGA AXIAL PARA ESTACA ISOLADA ALLUVIAL}

ANKER

Para estimar a capacidade de carga axial de estacas isoladas foram aplicadas metodologias semi-empíricas baseadas em ensaios de campo como o SPT, o SPT-T e o DMT, anteriormente descritas no item 2 da fundamentação científica. Estas metodologias estimaram a capacidade de carga em fundações do tipo Alluvial Anker, comparando-a com o valor de carga limite fornecida pela prova de carga estática de carregamento lento $\left(\mathrm{R}_{\mathrm{PCE}}=424 \mathrm{kN}\right)$. Desta forma serão apresentados a seguir os critérios e considerações adotadas.

No trabalho de Fellenius (1980) são avaliados os fatores que afetam o resultado de uma prova de carga como o tipo de carregamento, elementos de reação, macaco hidráulico, leituras de manômetros e células de carga. O erro estimado varia entre \pm 10 e $25 \%$, mas sendo a maioria entre \pm 15 e $20 \%$ como valores comumente adotados na prática da engenharia de fundações e publicações nacionais e internacionais (Schulze, 2013). Dessa forma será adotado o limite de tolerância de erro de $\pm 20 \%$ na presente dissertação.

Para escolher os coeficientes empíricos que dependem do tipo de solo, serão utilizados os resultados dos ensaios de caracterização e ensaios de campo como o SPT, o SPT-T e o DMT feitos no Campo Experimental da Solotrat Engenharia Geotécnica Ltda., fornecidos no trabalho de Mendoza (2013). A divisão geral das camadas no local são as seguintes, de acordo com as profundidades:

- 0 a 5 m: Areia siltosa laterítica avermelhada (Argila porosa de Brasília), com o lençol freático em torno de $4,5 \mathrm{~m}$.

- 5 a 8 m: Silte arenoso laterítico médio duro (Argila porosa de Brasília)

- 8 a 9 m: Silte arenoso branco duro a muito duro (camada de transição)

- 9 a 14 m: Argila siltosa dura (saprolíto de ardósia)

- Abaixo de 14 m: Silte arenoso amarelo duro (saprolíto de ardósia)

\subsubsection{CAPACIDADE DE CARGA COM METODOLOGIAS SEMI-EMPÍRICAS}

As metodologias semi-empíricas para estimar a capacidade de carga de estacas isoladas serão avaliadas considerando o processo executivo da estaca Alluvial Anker sendo um processo "misto" (escavada + injetada). Para esse fim, serão utilizados diferentes fatores empíricos de 
correlação de estaca como os de escavada sem revestimento, injetada de pequeno diâmetro e raiz.

Foram utilizados os dados das sondagens realizadas por Mendoza (2013), onde o valor de $\mathrm{N}_{\text {SPT }}$ adotado na presente dissertação foi a média entre as 5 sondagens SPT disponíveis, além disso para os dados de torque residual e pico oriundo do ensaio SPT-T foi a média entre as duas sondagens disponíveis estes dados são apresentados no Anexo I.

Apresenta-se na Tab. 5.1 como foram obtidos os valores de $\mathrm{N}_{\mathrm{p}}$ e $\mathrm{N}_{1}$ utilizados como valores de $\mathrm{N}_{\text {SPT }}$ para cada metodologia semi-empírica baseada no SPT. Dessa forma, se o método apresenta alguma modificação, seja via Alonso (1981), Laprovitera (1988), ou Rodrigues (1998), os valores de $\mathrm{N}_{\mathrm{p}}$ e $\mathrm{N}_{1}$ são mantidos constantes.

Tabela 5.1 Valores de NSPT $_{\text {considerados para cada metodologia }}$

\begin{tabular}{|c|c|c|c|}
\hline \multirow{2}{*}{ Método } & \multicolumn{3}{|c|}{ Criterios Adotados } \\
\hline & $\mathbf{N p}$ & NI & Nspt \\
\hline $\begin{array}{c}\text { Aoki-Velloso } \\
\text { (1975) }\end{array}$ & $\begin{array}{c}\text { Índice } \mathrm{N}_{\mathrm{SPT}} \text { correspondente na } \\
\text { cota de apoio da estaca }\end{array}$ & $\begin{array}{l}\text { Índice } \mathrm{N}_{\mathrm{SPT}} \text { médio na camada } \\
\text { de solo de espessura } \Delta \mathrm{L}\end{array}$ & $1>\mathrm{SPT}>50$ \\
\hline $\begin{array}{c}\text { Décourt- } \\
\text { Quaresma (1978) }\end{array}$ & $\begin{array}{l}\text { Valor médio do } \mathrm{N}_{\mathrm{SPT}} \text { na base } \\
\text { da estaca, obtido a partir de } 3 \\
\text { valores: ponta, imediatamente } \\
\text { anterior e posterior }\end{array}$ & $\begin{array}{l}\text { Valor médio do índice } \mathrm{N}_{\mathrm{SPT}} \\
\text { nas camadas identificadas } \Delta_{\mathrm{L}}\end{array}$ & $3>\mathrm{SPT}>50$ \\
\hline Teixeira (1996) & $\begin{array}{c}\text { Valor médio do } \mathrm{N}_{\mathrm{SPT}} \text { na cota } \\
\text { de apoio }+1 \mathrm{~m} \text { acima. }\end{array}$ & $\begin{array}{c}\text { Valor médio do índice } \mathrm{N}_{\mathrm{SPT}} \text { ao } \\
\text { longo do fuste da estaca }\end{array}$ & $4>\mathrm{SPT}>40$ \\
\hline Lobo (2005) & $\begin{array}{c}\text { Índice } \mathrm{N}_{\mathrm{SPT}} \text { correspondente na } \\
\text { cota de apoio da estaca }\end{array}$ & $\begin{array}{c}\text { Índice } \mathrm{N}_{\mathrm{SPT}} \text { correspondente na } \\
\text { cota de apoio da estaca }\end{array}$ & $\begin{array}{l}\mathrm{Np} \leq 40 \\
\mathrm{Nl} \leq 30\end{array}$ \\
\hline
\end{tabular}

Adotou-se o $\mathrm{N}_{\mathrm{spt}}$ da ponta como o valor obtido na camada de 8 a $9 \mathrm{~m}$ de profundidade, já que ao final da execução das estacas notou-se a presença de um silte arenoso branco duro, correspondente a esta camada. Este fato ocorreu dada a heterogeneidade do perfil estudado e ao comprimento da estaca $(8 \mathrm{~m})$ no qual poderia atingir ou não a camada de transição.

Os parâmetros utilizados em cada metodologia baseada no SPT como Aoki-Velloso (1975), Décourt-Quarema (1978), Teixeira (1996) e UFRGS (2005), para a condição (escavada), são apresentados nas Tab. 5.2, 5.3, 5.4 e 5.5 respectivamente os demais parâmetros para as condições de estaca raiz e injetada de pequeno diâmetro para cada metodologia seja baseada no SPT ou SPT-T são apresentados no Anexo II. 
Tabela 5.2 Parâmetros de estaca escavada método Aoki-Velloso (1975)

\begin{tabular}{|c|c|c|c|c|c|}
\hline Prof. $(\mathbf{m})$ & Solo & F1 & F2 & $\boldsymbol{\alpha}$ (\%) & K (kPa) \\
\hline 1 a 5 & Argila Arenosa & 3,00 & 6,00 & 2,4 & 350 \\
\hline 5 a 7 & Silte Areno argiloso & 3,00 & 6,00 & 2,8 & 450 \\
\hline 8 a 9 & Silte Arenoso & 3,00 & 6,00 & 2,2 & 550 \\
\hline 9 a 14 & Argila Siltosa & 3,00 & 6,00 & 3,0 & 330 \\
\hline
\end{tabular}

Tabela 5.3 Parâmetros de estaca escavada método Décourt-Quaresma (1978-1996)

\begin{tabular}{|c|c|c|c|c|}
\hline Prof. $(\mathbf{m})$ & Solo & $\boldsymbol{\alpha}$ & $\boldsymbol{\beta}$ & $\mathbf{C}(\mathbf{k P a})$ \\
\hline 1 a 5 & Argila Arenosa & 0,6 & 0,65 & 120 \\
\hline 5 a 7 & Silte Arenoargiloso & 0,6 & 0,65 & 250 \\
\hline 8 a 9 & Silte Arenoso & 0,6 & 0,65 & 250 \\
\hline 9 a 14 & Argila Siltosa & 0,6 & 0,65 & 200 \\
\hline
\end{tabular}

Tabela 5.4 Parâmetros de estaca escavada método Teixeira (1996)

\begin{tabular}{|c|c|c|c|}
\hline Prof. $(\mathbf{m})$ & Solo & $\boldsymbol{\beta}$ tex & $\boldsymbol{\alpha}$ tex \\
\hline 1 a 5 & Argila Arenosa & 4 & 130 \\
\hline 5 a 7 & Silte Arenoargiloso & 4 & 160 \\
\hline 8 a 9 & Silte Arenoso & 4 & 160 \\
\hline 9 a 14 & Argila Siltosa & 4 & 100 \\
\hline
\end{tabular}

Tabela 5.5 Parâmetros de estaca escavada método UFRGS (2005)

\begin{tabular}{|c|c|c|c|c|}
\hline Tipo Estaca & $\boldsymbol{\alpha}$ & $\boldsymbol{\beta}$ & $\boldsymbol{\eta} 1$ & $\boldsymbol{\eta} \mathbf{2}$ \\
\hline Escavada & 0,7 & 0,5 & 0,764 & 1 \\
\hline
\end{tabular}

Os parâmetros utilizados nas metodologias baseadas no SPT-T como, Alonso (1996), Décourt (1998), e Peixoto (2001), para a condição escavada são apresentados nas Tab. 5.6, 5.7, 5.8 .

Tabela 5.6 Parâmetros de estaca escavada método Alonso (1996)

\begin{tabular}{|c|c|c|c|}
\hline Tipo de Estaca & $\mathbf{f t}(\mathbf{k P a})$ & $\mathbf{r}$ & $\mathbf{h}_{\text {crav amostrador }}(\mathbf{c m})$ \\
\hline Escavada & $<200$ & 1,7 & 30 \\
\hline
\end{tabular}

Tabela 5.7 Parâmetros de estaca escavada método Décourt (1998)

\begin{tabular}{|c|c|c|c|c|}
\hline Prof. (m) & Solo & $\boldsymbol{\alpha}$ & $\boldsymbol{\beta}$ & $\mathbf{C}(\mathbf{k P a})$ \\
\hline 1 a 5 & Argila Arenosa & 0,6 & 0,65 & 120 \\
\hline 5 a 7 & Silte Arenoargiloso & 0,6 & 0,65 & 250 \\
\hline 8 a 9 & Silte Arenoso & 0,6 & 0,65 & 250 \\
\hline 9 a 14 & Argila Siltosa & 0,6 & 0,65 & 200 \\
\hline
\end{tabular}

Tabela 5.8 Parâmetros de estaca escavada método Peixoto (2001)

\begin{tabular}{|c|c|c|c|}
\hline \multirow{2}{*}{ Tipo de estaca } & \multirow{2}{*}{$\boldsymbol{s} \boldsymbol{| c |}$} & \multicolumn{2}{|c|}{$\mathbf{F}$} \\
\cline { 3 - 4 } & & Tmáx/ $\mathbf{N}<\mathbf{1}$ & Tmáx/N $>\mathbf{1}$ \\
\hline Escavada & 1,4 & 1,3 & 0,7 \\
\hline
\end{tabular}

Na Tab. 5.9 são apresentados os resultados do cálculo de estimativa de carga limite pelos métodos semi-empíricos baseados em ensaios SPT, SPT-T e DMT. 
Tabela 5.9 Resultados $R_{\mathrm{p}}, \mathbf{R}_{\mathrm{l}}, \mathbf{R}_{\mathrm{cal}}$ dos diferentes métodos semi empíricos

\begin{tabular}{|c|c|c|c|c|c|c|c|c|}
\hline \multicolumn{2}{|c|}{$\begin{array}{c}\text { Método de Estimativa de Capacidade de } \\
\text { Carga }\end{array}$} & \multirow{2}{*}{$\begin{array}{c}\begin{array}{c}\mathbf{R}_{\mathbf{p}} \\
(\mathbf{k N})\end{array} \\
274 \\
\end{array}$} & \multirow{2}{*}{$\begin{array}{c}\begin{array}{c}\mathbf{R}_{\mathbf{l}} \\
(\mathbf{k N})\end{array} \\
124 \\
\end{array}$} & \multirow{2}{*}{$\begin{array}{r}\mathbf{R}_{\text {cal }} \\
(\mathbf{k N})\end{array}$} & \multirow{2}{*}{\begin{tabular}{r|}
$\mathbf{R}_{\mathbf{P C E}}$ \\
$(\mathbf{k N})$
\end{tabular}} & \multirow{2}{*}{$\begin{array}{c}\mathbf{R}_{\mathbf{c a l}} / \mathbf{R}_{\mathbf{P C E}} \\
0,94 \\
\end{array}$} & \multirow{2}{*}{$\begin{array}{l}\mathbf{R}_{\mathrm{l}} / \mathbf{R}_{\mathbf{p}} \\
0,45 \\
\end{array}$} & \multirow{2}{*}{$\begin{array}{r}\mathbf{R}_{\mathbf{l} / \mathbf{R}_{\text {cal }}} \\
0,31 \\
\end{array}$} \\
\hline \multirow{12}{*}{ SPT } & Aoki-Velloso (1975) ${ }^{1}$ & & & & & & & \\
\hline & Aoki-Velloso $(1975)^{2}$ & 411 & 186 & 597 & 424 & 1,41 & 0,45 & 0,31 \\
\hline & Aoki-Velloso $(\mathbf{1 9 7 5})^{3}$ & 483 & 222 & 705 & 424 & 1,66 & 0,46 & 0,31 \\
\hline & Aoki- Velloso por Alonso $(\mathbf{1 9 8 1})^{1}$ & 274 & 104 & 378 & 424 & 0,89 & 0,38 & 0,28 \\
\hline & \begin{tabular}{|l|} 
Aoki-Velloso por Laprovitera \\
$(\mathbf{1 9 8 8})^{1}$
\end{tabular} & 159 & 186 & 345 & 424 & 0,81 & 1,17 & 0,54 \\
\hline & Decourt-Quaresma $(1978,1996)^{1}$ & 193 & 170 & 363 & 424 & 0,86 & 0,88 & 0,47 \\
\hline & Decourt-Quaresma $(1978,1996)^{2}$ & 193 & 392 & 585 & 424 & 1,37 & 2,03 & 0,67 \\
\hline & Decourt-Quaresma $(1978,1996)^{3}$ & 289 & 222 & 511 & 424 & 1,21 & 0,77 & 0,43 \\
\hline & Decourt-Quaresma $(1978,1996)^{4}$ & 321 & 784 & 1105 & 424 & 2,61 & 2,44 & 0,71 \\
\hline & Teixeira $(1996)^{1}$ & 191 & 221 & 412 & 424 & 0,97 & 1,15 & 0,54 \\
\hline & Teixeira $(1996)^{2}$ & 191 & 331 & 522 & 424 & 1,23 & 1,73 & 0,63 \\
\hline & UFRGS (2005) ${ }^{1}$ & 71 & 63 & 134 & 424 & 0,32 & 0,88 & 0,47 \\
\hline \multirow{18}{*}{ SPT-T } & Alonso $(1996 \mathrm{~b})^{1}{\text { ponta } A \& V^{1}}^{1}$ & 274 & 83 & 357 & 424 & 0,84 & 0,30 & 0,23 \\
\hline & Alonso $(1996 b){ }^{1}$ ponta $A \& V^{3}$ & 483 & 83 & 566 & 424 & 1,34 & 0,17 & 0,15 \\
\hline & Alonso $(1996 b)^{2}$ ponta $A \& V^{1}$ & 274 & 162 & 436 & 424 & 1,03 & 0,59 & 0,37 \\
\hline & Alonso $(1996 b)^{2}$ ponta $A \& V^{3}$ & 483 & 162 & 645 & 424 & 1,52 & 0,34 & 0,25 \\
\hline & Alonso $(1996 b)^{1}$ ponta $D \& Q^{1}$ & 193 & 83 & 276 & 424 & 0,65 & 0,43 & 0,30 \\
\hline & Alonso $(1996 b){ }^{1}$ ponta $D \& Q^{3}$ & 289 & 83 & 372 & 424 & 0,88 & 0,29 & 0,22 \\
\hline & Alonso $(1996 b)^{2}$ ponta $D \& Q^{1}$ & 193 & 162 & 355 & 424 & 0,84 & 0,84 & 0,46 \\
\hline & Alonso $(1996 b)^{2}$ ponta $D \& Q^{3}$ & 289 & 162 & 451 & 424 & 1,06 & 0,56 & 0,36 \\
\hline & Decourt $(1998)^{1}$ & 106 & 123 & 230 & 424 & 0,54 & 1,16 & 0,54 \\
\hline & Decourt $(1998)^{2}$ & 106 & 284 & 390 & 424 & 0,92 & 2,67 & 0,73 \\
\hline & Camapum $(1998)^{1}$ ponta $A \& V^{3}$ & 483 & 184 & 667 & 424 & 1,57 & 0,38 & 0,28 \\
\hline & Camapum $(1998)^{1}$ ponta $\mathrm{D} \& Q^{3}$ & 289 & 191 & 480 & 424 & 1,13 & 0,66 & 0,40 \\
\hline & Peixoto $(2001)^{1}$ ponta $\mathrm{D} \& Q^{1}$ & 193 & 597 & 789 & 424 & 1,86 & 3,10 & 0,76 \\
\hline & Peixoto $(2001)^{2}$ ponta $D \& Q^{1}$ & 193 & 492 & 684 & 424 & 1,61 & 2,55 & 0,72 \\
\hline & Peixoto $(2001)^{4}$ ponta $D \& Q^{1}$ & 193 & 656 & 848 & 424 & 2,00 & 3,40 & 0,77 \\
\hline & Peixoto $(2001)^{1}$ ponta $D \& Q^{3}$ & 289 & 597 & 886 & 424 & 2,09 & 2,06 & 0,67 \\
\hline & Peixoto $(2001)^{2}$ ponta $D \& Q^{3}$ & 289 & 492 & 781 & 424 & 1,84 & 1,70 & 0,63 \\
\hline & Peixoto $(2001)^{4}$ ponta $D \& Q^{3}$ & 289 & 656 & 945 & 424 & 2,23 & 2,27 & 0,69 \\
\hline \multirow{2}{*}{ DMT } & Pfeiffer \& Van Impe (1991) ${ }^{1}$ & - & 1001 & 1001 & 424 & 2,36 & 21,17 & 1,00 \\
\hline & Powell $(2001)^{1}$ & - & 725 & 725 & 424 & 1,71 & 15,32 & 1,00 \\
\hline \multicolumn{9}{|c|}{$\begin{array}{l}{ }^{1} \text { Parâmetros de estaca escavada (Anexo II) } \\
{ }^{2} \text { Parâmetros de estaca raiz (Anexo II) } \\
{ }^{3} \text { Coeficiente de Rodrigues (1998) (Anexo II) } \\
{ }^{4} \text { Parâmetros de estaca injetada (Anexo II) }\end{array}$} \\
\hline
\end{tabular}


Na prática os projetos e obras de pequeno e médio porte dificilmente possuem uma prova de carga para projetar ou verificar a capacidade de carga. Dado este limitante foi realizada uma primeira análise calculando a capacidade de carga para cada uma das metodologias anteriormente citadas, na Tab. 5.9, considerando a contribuição da resistência por ponta igual a $100 \%$.

Conforme apresentado na Fig. 5.1 as metodologias baseadas no SPT com fatores empíricos de estaca do tipo escavada apresentam valores de capacidade de carga na faixa de erro tolerável adotada de $\pm 20 \%$ proposta por Fellenius, 1980, realizando uma boa estimativa e a favor da segurança. Por outro lado, os fatores de estaca do tipo raiz, injetadas e os propostos por Rodrigues (1998) apresentam resultados mais distantes do limite superior $(+20 \%)$.

Na Fig. 5.2 pode-se apreciar separadamente os valores de resistência por ponta $\left(R_{P}\right)$ e atrito lateral $\left(\mathrm{R}_{\mathrm{L}}\right)$, observado que as metodologias baseadas no ensaio SPT e SPT-T, possuem uma contribuição de ponta maior do que a contribuição por atrito lateral, mesmo limitando o $\mathrm{N}_{\text {SPT }}$ da ponta para 50 golpes. Embora os fatores empíricos de correlação de estaca do tipo escavada possuam uma melhor estimativa de capacidade de carga, estes métodos baseados no SPT e SPT-T consideram a contribuição por ponta em cerca de $57 \%$.

Dado que a estaca não possui instrumentação eletrônica, não é apropriado considerar que a carga por ponta calculada é quase a metade da carga limite, então, para isto, foi realizado uma segunda e terceira análise diminuindo o aporte da resistência por ponta $\left(\mathrm{R}_{\mathrm{P}}\right)$ para $8 \%$, valor este aproximado e obtido das análises com as metodologias como Décourt (2008) e Valencia \& Camapum (2011) que tentam separar as resistências de ponta e atrito lateral da prova de carga. Além disto considerou-se também $0 \%$ da resistência por ponta $\left(\mathrm{R}_{\mathrm{P}}\right)$, critério este adotado neste trabalho como forma de verificação dos resultados na estaca Alluvial Anker AA-01 testada.

Schulze (2013) apresenta resultados de uma prova de carga com instrumentação numa estaca escavada de pequeno diâmetro $(0,25 \mathrm{~cm})$ e $5 \mathrm{~m}$ de comprimento executada no Campo Experimental da Universidade de Campinas, na qual é observado claramente que a contribuição da ponta na resistência última da estaca testada é nula. Este aspecto adicional corrobora a adoção de $0 \%$ da resistência de ponta $\left(\mathrm{R}_{\mathrm{P}}\right)$ como valor de análise aqui.

As análises realizadas considerando apenas $8 \%$ e $0 \%$ da resistência da ponta $\left(R_{P}\right)$, apresentaram logicamente uma redução importante na estimativa da capacidade de carga, onde as metodologias como Décourt \& Quaresma (1978), Teixeira (1996) e Peixoto (2001) com fatores empíricos de correlação de estaca do tipo raiz foram as protagonistas. Isto também se deve ao fato de que o fator de estaca do tipo raiz, comparado com do tipo escavada, é menor e 
portanto reduz menos a capacidade de carga última estimada (Rcal), colocando estas metodologias na faixa admissível de $\pm 20 \%$. Este aspecto é mostrado nas Fig. 5.3, Fig. 5.4 e Fig. 5.5, onde pode-se observar os resultados das diferentes considerações adotadas e aqui testadas.

As metodologias baseadas no ensaio SPT-T apresentam os valores mais baixos de atrito lateral entre as metodologias empregadas, apesar de que são baseadas no torque que produz a adesão que o solo tem apresentado. O método de Peixoto (2001) apresenta valores de capacidade de carga última com fatores de correlação de estaca raiz na faixa de erro admissível de $\pm 20 \%$, considerado como uma boa metodologia para levar em conta a parcela de resistência por atrito lateral. Resultados similares foram apresentados por Guimarães (2002) em estacas escavadas executadas no Campo Experimental da Universidade de Brasília.

As metodologias baseadas no ensaio DMT apresentam resistências por atrito lateral maiores do que o SPT e SPT-T, e muito elevadas em comparação ao valor experimental definido na prova de carga igual $424 \mathrm{kN}$. Os valores de capacidade de carga última estimados com o DMT apresentam valores que são o dobro do valor experimental. Dessa forma, se considerar a resistência última obtida com o DMT e um fator de segurança (FS) global igual a 2, nesse caso a estaca estaria trabalhando em sua capacidade máxima real, fato este totalmente contra a segurança.

Com isto dito, se vê a necessidade de realizar mais provas de carga estática sob fundações isoladas do tipo Alluvial Anker para se obter fatores de correlação de estaca mais apropriados para estimar a capacidade de carga última. Além disso, dependendo do tipo de estaca, de terreno e das características geométricas, o engenheiro geotécnico deve adotar critérios sob qual percentual de resistência de ponta estimar em um determinado projeto.

O método de Décourt \& Quaresma (1978) apresentou valores muito próximos dos experimentais. Este método considera a ruptura física para o sistema solo-estaca, apesar da estaca Alluvial Anker poder ser considerada como uma estaca escavada, nas quais a ruptura sempre é do tipo convencional segundo Décourt (2014). De acordo com as análises realizadas da curva carga-recalque, o melhor critério de ruptura que descreveria o comportamento da estaca Alluvial Anker seria o de ruptura física, o que também ocorreu com as estacas escavadas do tipo broca executadas no Campo Experimental da Universidade de Campinas, como citado no trabalho de Schulze (2013). 


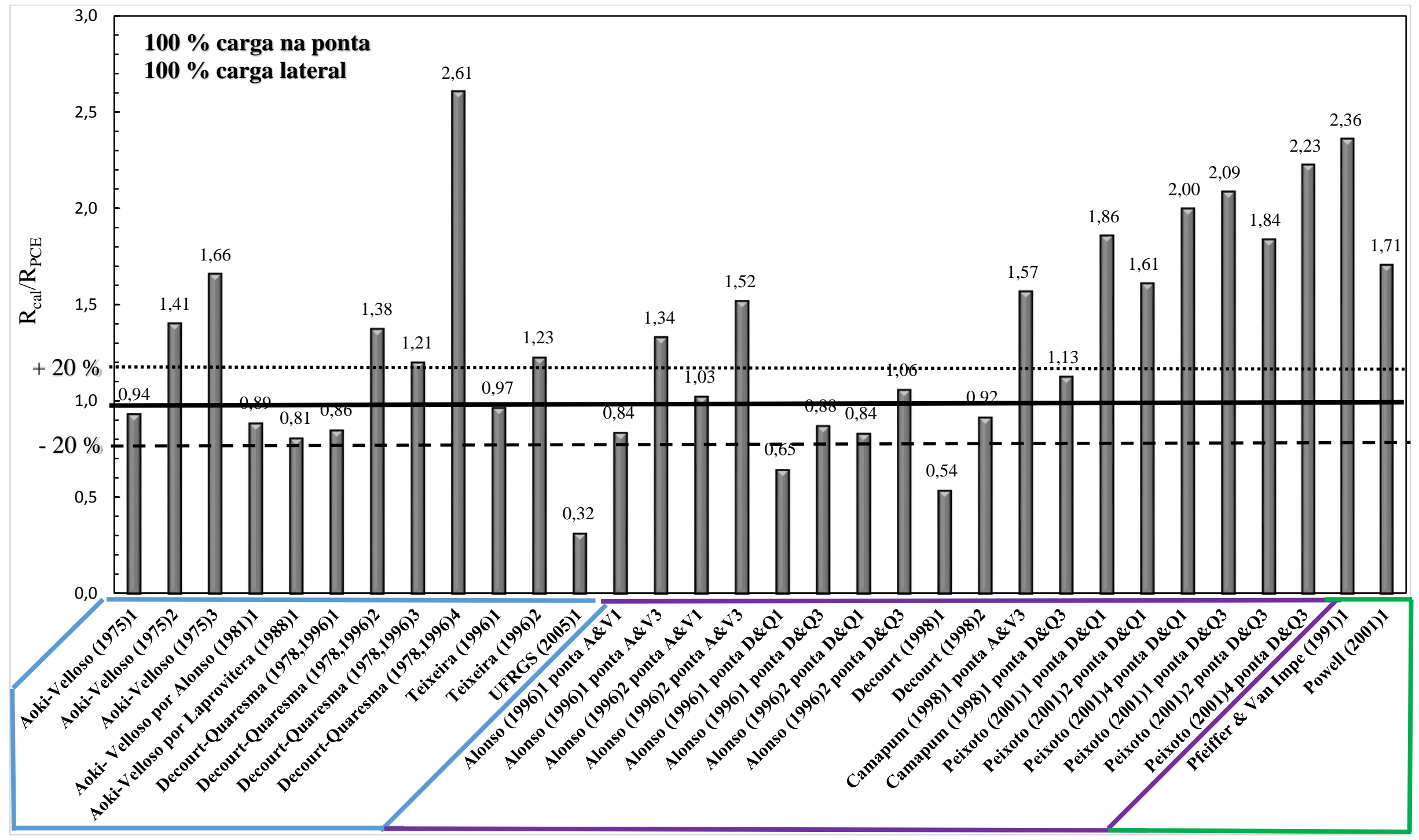

Figura 5.1 Resultado comparativo de capacidade de carga última das metodologias empregadas 


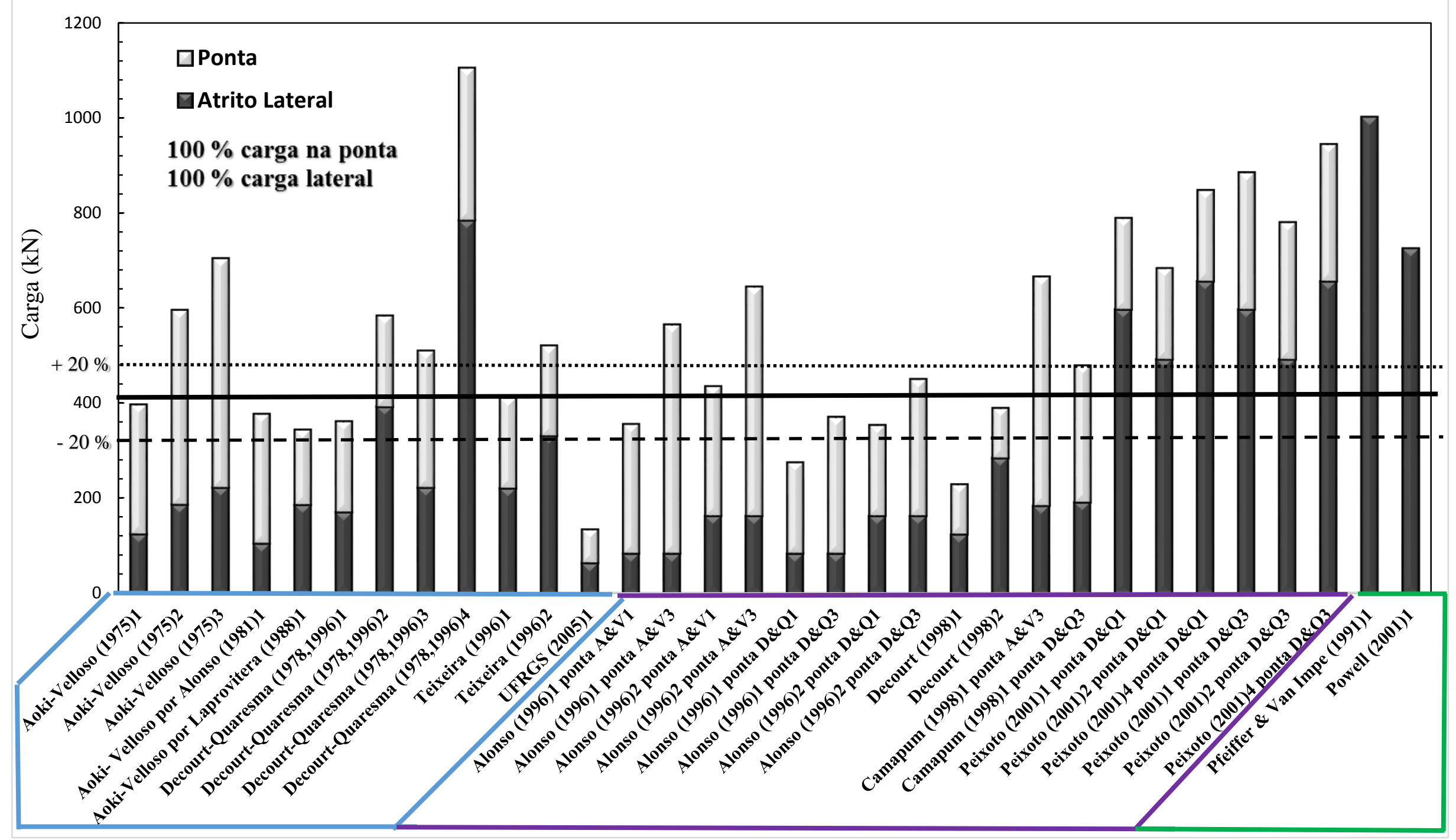

Figura 5.2 Contribuições de resistência de ponta e atrito lateral para cada metodologia 


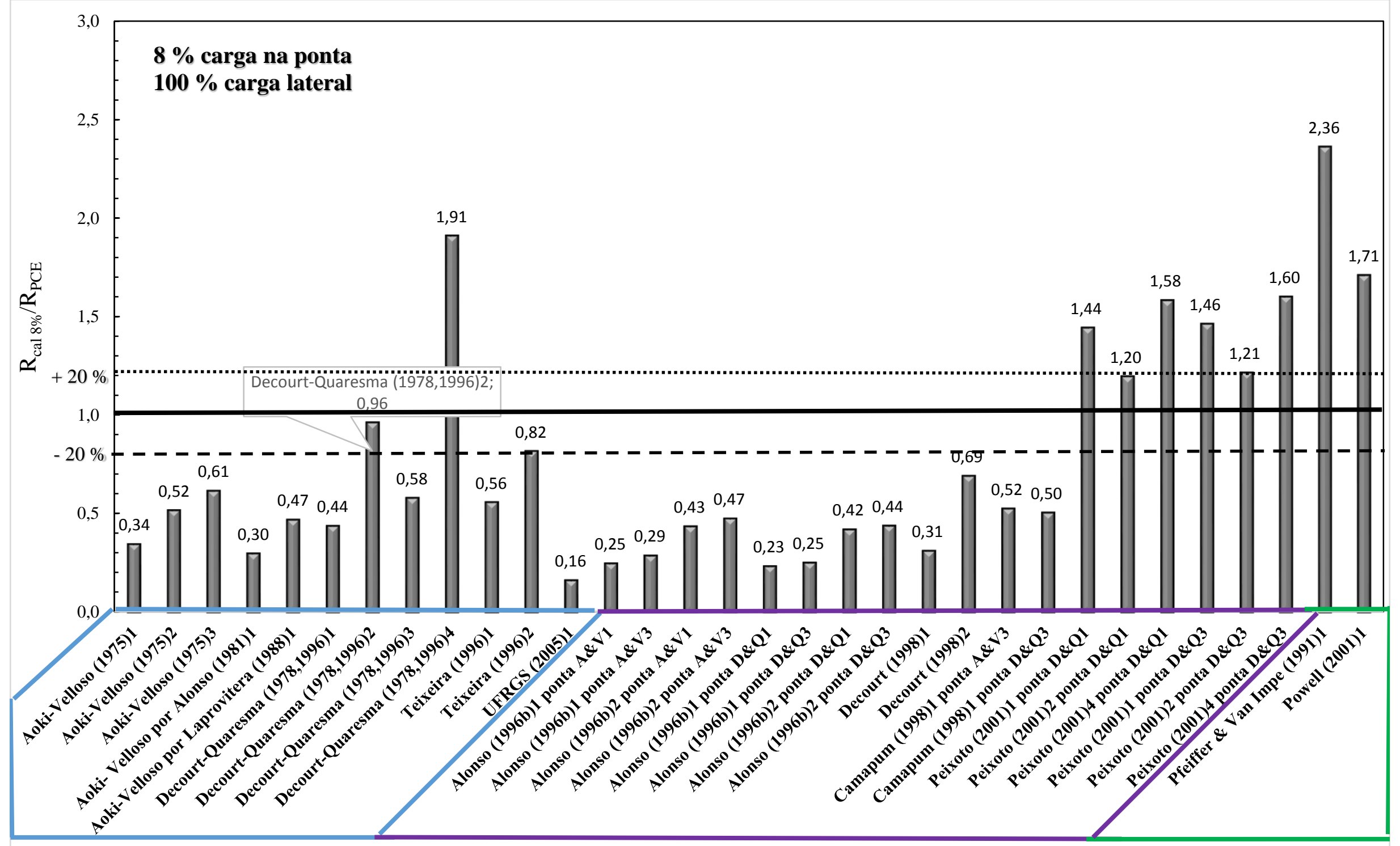

Figura 5.3 Resultado comparativo de capacidade de carga última das metodologias empregadas (8 \% RP) 


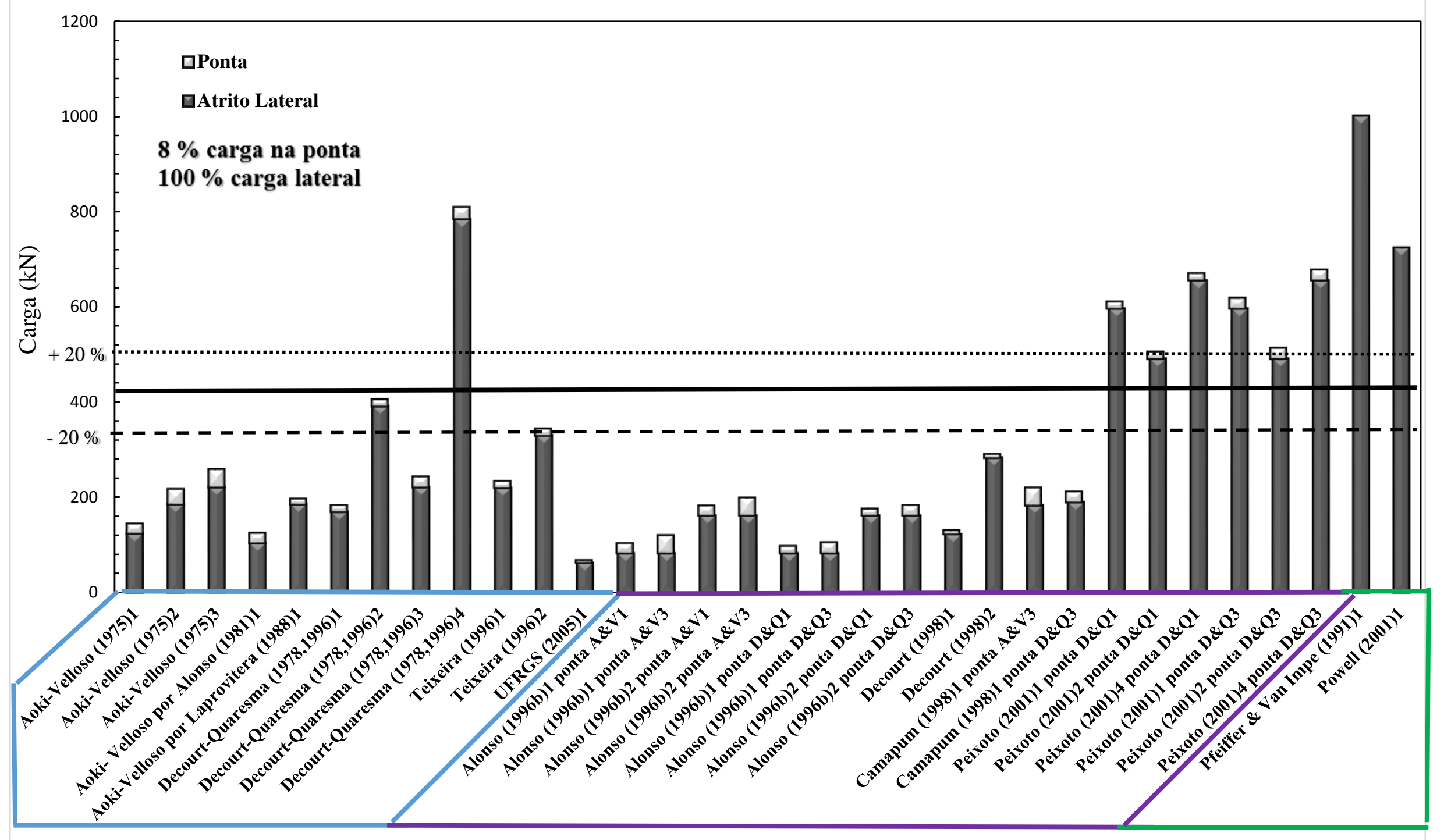

Figura 5.4 Contribuições de resistência de ponta e atrito lateral para cada metodologia $\left(8 \% \mathbf{R}_{\mathrm{p}}\right)$ 


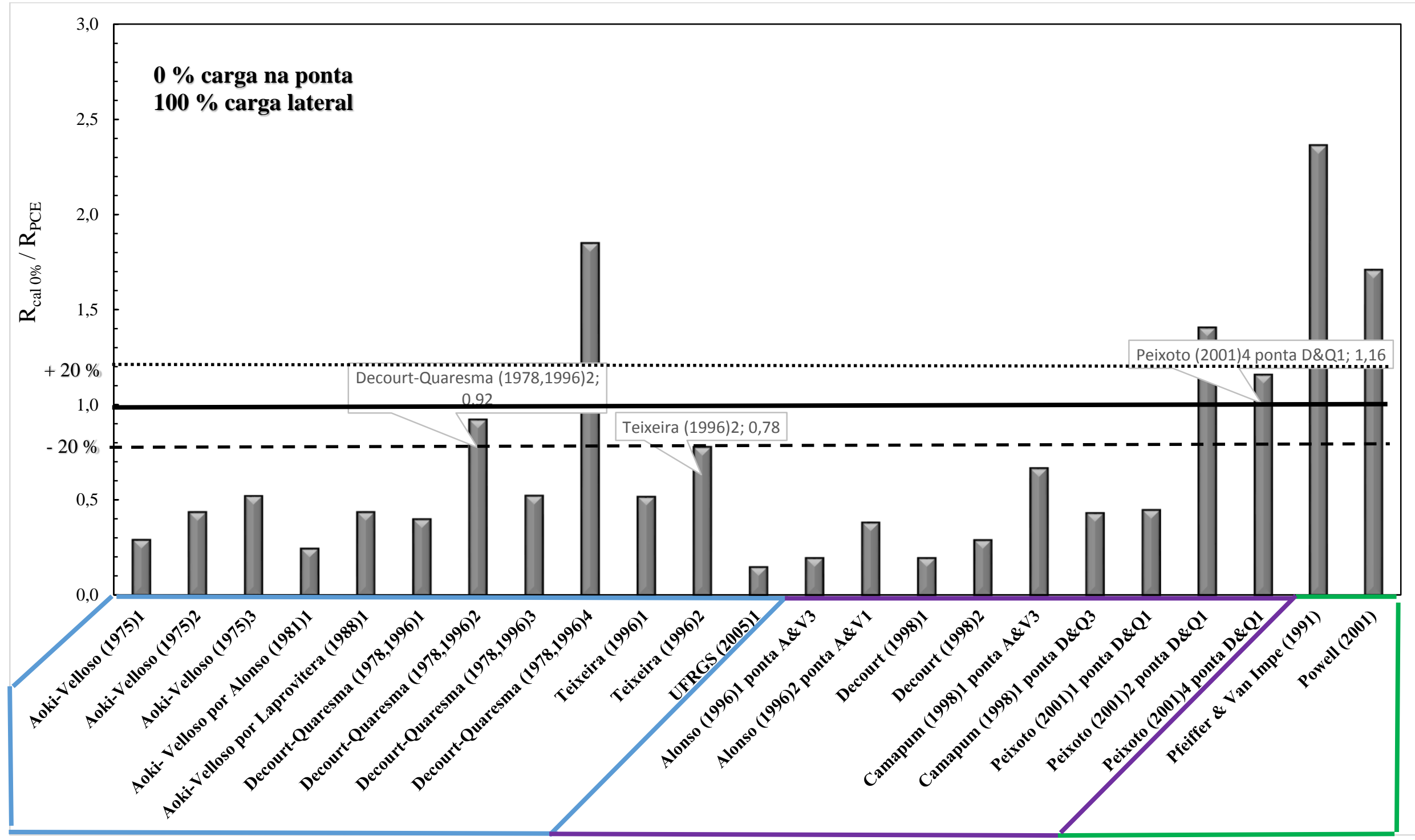

Figura 5.5 Resultado comparativo de capacidade de carga última das metodologias empregadas $\left(0 \% \mathbf{R}_{\mathrm{p}}\right)$ 


\subsubsection{CAPACIDADE DE CARGA COM MÉTODOS RACIONAIS}

As formulações teóricas clássicas encontradas na literatura são baseadas para solos puramente argilosos ou arenosos como são os clássicos métodos alfa $(\alpha)$ proposto por Tomlinson (1971) para solos coesivos, e beta $(\beta)$ proposto por Burland (1973) para solos friccionais. O perfil de solo estudado está composto nestas duas condições, e isto será considerado no cálculo somando-se as equações propostas por Tomlinson (1971) e Burland (1973) para cada camada de solo estudada. Isto foi realizado com base no exposto por Cintra e Aoki (1999) e Décourt (1996) citados por Guimarães (2002).

Para calcular a resistência por atrito lateral foi utilizada a Eq. 5.1, mostrada a seguir:

$$
f_{s}=(c * \propto)+\left(\sigma_{v}^{\prime} * k * \tan \delta^{*}\right)
$$

Onde:

c: coesão drenada

$\alpha$ : coeficiente de adesão (Fig. 5.6)

$\sigma^{\prime}$ v: tensão vertical efetiva

$\mathrm{k}$ : coeficiente de empuxo em repouso

$\delta *$ : ângulo de atrito da interface solo/estaca

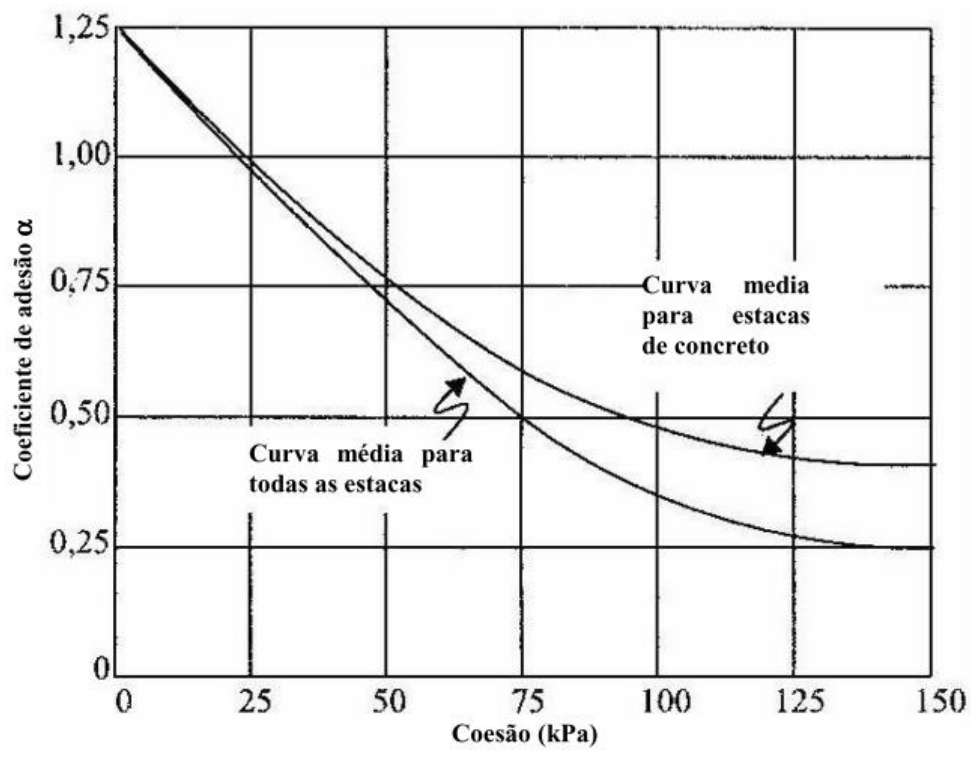

Figura 5.6 Coeficiente de adesão $\alpha$ (Tomlinson, 2008)

Os critérios adotados nos parâmetros da fração argilosa são dados da seguinte maneira e mostrado em forma de esquema na Tab. 5.10. 
Tabela 5.10 Parâmetros para metodologia analítica

\begin{tabular}{|c|c|c|c|c|c|c|c|}
\hline Prof (m) & Perfil & c (kPa) & $\alpha$ & $\phi()$ & $\sigma^{\prime}(\mathbf{k P a})$ & $k \cong k_{0}$ & $\tan \delta$ \\
\hline 1 & \multirow{4}{*}{$\mathbf{A}$} & 14 & 1,20 & \multirow{5}{*}{29} & 14,85 & 0,50 & 0,55 \\
\hline 2 & & 14 & 1,20 & & 29,7 & 0,50 & 0,55 \\
\hline 3 & & 14 & 1,20 & & 44,55 & 0,50 & 0,55 \\
\hline 4 & & 14 & 1,20 & & 59,4 & 0,50 & 0,55 \\
\hline 5 & $\overline{\text { B }}$ & 14 & 1,20 & & 74,25 & 0,50 & 0,55 \\
\hline 6 & \multirow{2}{*}{ C } & 20 & 1,18 & \multirow{2}{*}{34} & 89,1 & 0,50 & 0,67 \\
\hline 7 & & 20 & 1,18 & & 103,95 & 0,50 & 0,67 \\
\hline 8 & $\mathbf{D}$ & 50 & 0,80 & 39 & 118,8 & 0,50 & 0,81 \\
\hline
\end{tabular}

- A coesão drenada foi considerada dos ensaios triaxiais realizados por Mendoza (2013) os quais incluí os valores médios para coesão das demais camadas citados por (Araki, 1997; Guimarães, 2002; Mota, 2003), obtidos de ensaios triaxiais no Campo Experimental da Universidade de Brasília, como se vê na Tab. 3.4.

- Os coeficientes de adesão $(\alpha)$ (que se multiplica à coesão drenada) do solo ao elemento de fundação foram adotados dos gráficos apresentados por Tomlinson (1957) e citados por Cintra e Aoki (1999) e Guimarães (2002).

Os critérios adotados nos parâmetros da fração arenosa foram os seguintes:

- A tensão vertical $\left(\sigma^{\prime}\right)$ foi calculada sem levar em conta o critério de profundidade crítica medido por Vesic (1967), e Poulos \& Davis (1980), e Das (2001) onde a tensão vertical permanece constante a partir de 10 a 20 vezes o diâmetro da estaca. Isto não foi considerado dado o pequeno diâmetro da estaca, apresentando a profundidade crítica muito superficial, e perdendo ganho de resistência por atrito lateral, além disso foi considerado o lençol freático a 4,5 m como foi conferido pelas sondagens SPT.

- O coeficiente de empuxo (k) foi calculado pela fórmula de Jaky (1948) para solos normalmente adensados.

- Ângulo de atrito solo/estaca ( $\delta *)$ foi adotado como sendo o ângulo de atrito do solo $(\phi)$, segundo Potyondy (1961) citado por Cintra e Aoki (1999) e Guimarães (2002), sugerindo que para estacas de concreto rugosas (sem forma) em areias secas a relação entre o ângulo de atrito solo/estaca $(\delta *)$ e o ângulo de atrito do solo $(\phi)$ é de 0,98 .

Os valores estimados foram comparados com estacas escavadas executadas no Campo Experimental da Universidade de Brasília, com dimensões de 0,30 m de diâmetro e 7,5 m de comprimento executadas e exumadas no trabalho de Mota (2003). As 5 provas de carga realizadas no trabalho de Mota (2003) apresentam uma carga limite experimental média de 294 
$\mathrm{kN}$ e uma carga limite estimada média por metodologias analíticas de $251 \mathrm{kN}$, com uma relação média de carga calculada/carga experimental de 0,90, ou seja, apresentando bons resultados para o Campo Experimental da Universidade de Brasília. Porém no Campo Experimental da SOLOTRAT onde a prova de carga realizada na estaca Alluvial Anker AA-01 apresentou o valor de carga limite experimental de $424 \mathrm{kN}$, os resultados analíticos forneceram a estimativa de $220 \mathrm{kN}$, desta forma cerca de 50\% da carga limite experimental, ou seja mostrando-se por tanto como muito conservadores (Fig. 5.7) para uso prático.

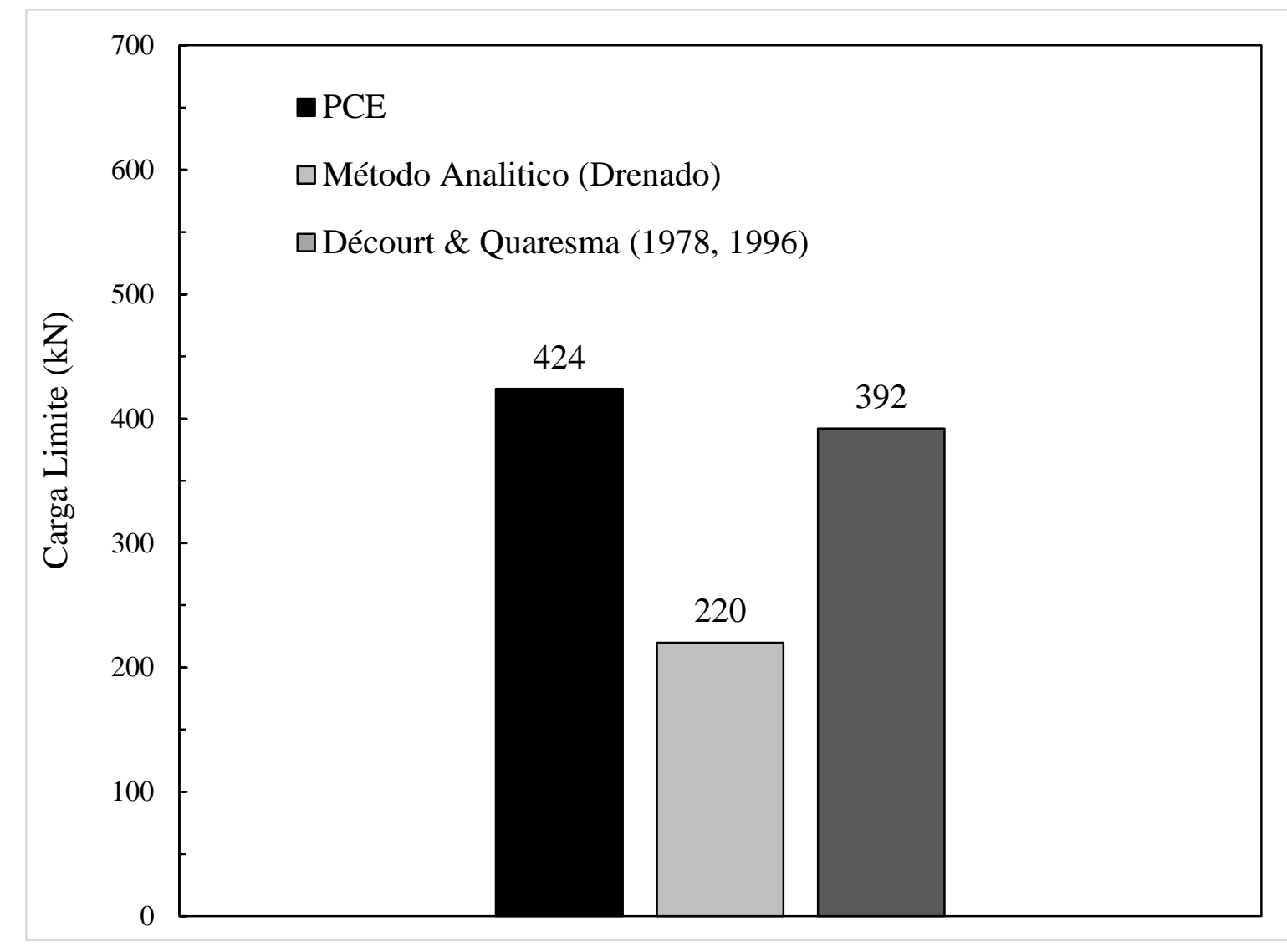

Figura 5.7 Valor estimado com metodologia analítica

\subsection{ESTIMATIVA DE CAPACIDADE DE CARGA DE GRUPOS DE ESTACAS}

\section{ALLUVIAL ANKER}

Para estimar a capacidade de carga de grupos Alluvial Anker e comparar com os resultados experimentais obtidos das provas de carga estáticas de Mendoza (2013), foram utilizadas metodologias analíticas como as de Terzaghi \& Peck (1948) e Poulos \& Davis (1980), além disso foi utilizada a formulação clássica de cálculo empírico que leva em conta a eficiência de grupo. 


\subsubsection{ESTIMATIVA DA CAPACIDADE DE CARGA COM METODOLOGIAS ANALÍTICAS}

No método de Terzaghi \& Peck (1948), os parâmetros de resistência como a coesão drenada e o ângulo de atrito do solo foram fornecidos pelos ensaios laboratoriais. A área adotada para calcular a capacidade de carga é conformada pelo contorno das estacas ( $\mathrm{Lr}$ x Br) como é mostrado na Fig. 5.8.

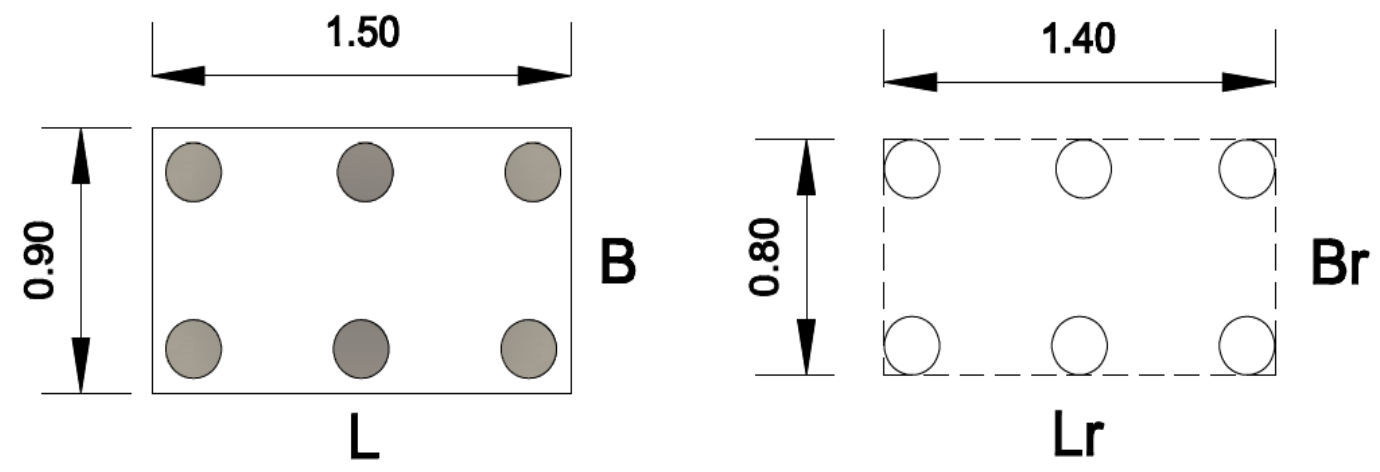

Figura 5.8 Contorno da área efetiva para cálculo de capacidade de carga

O cálculo da capacidade de carga no método de Terzaghi \& Peck (1948) é obtido pela seguinte Eq. 5.2:

$$
P_{B}=B_{r} * L_{r} * C * N_{c}+2\left(B_{r}+L_{r}\right) L * \bar{c}
$$

Onde:

$\mathrm{B}_{\mathrm{r}, \mathrm{L}}$ : contorno das estacas

$c^{\prime}$ : coesão drenada na ponta das estacas

L: comprimento da estaca

$\mathrm{N}_{\mathrm{c}}$ : fator teórico de capacidade de carga

$\bar{c}:$ média da coesão drenada entre a superfície e a ponta da estaca

Os valores adotados de fator teórico de capacidade de carga por profundidade $\left(\mathrm{N}_{c}\right)$ foram os sugeridos por Meyerhof (1951) a seguir são apresentados os parâmetros empregados no cálculo da capacidade de carga com as metodologias de Terzaghi \& Peck (1948) e Poulos \& Davis (1980). Os parâmetros adotados são apresentados na Tab. 5.11.

A capacidade de carga também foi calculada pelo método de Poulos \& Davis (1980) e foi utilizado o valor experimental de carga limite para a estaca isolada $\left(\mathrm{P}_{\mathrm{I}}\right)$, obtido da prova de carga estática, igual a 424 kN. O cálculo da capacidade de carga pelo método de Poulos \& Davis (1980) e apresentado na seguinte Eq. 5.3: 
Tabela 5.11 Parâmetros empregados na metodologia Terzaghi \& Peck (1948)

\begin{tabular}{|c|c|c|c|c|c|}
\cline { 2 - 6 } \multicolumn{1}{c|}{} & \multicolumn{5}{c|}{ Configuração } \\
\cline { 2 - 6 } \multicolumn{1}{c|}{ 2 Estacas } & 3 Estacas & 4 Estacas & 5 Estacas & 6 Estacas \\
\hline $\mathbf{B r}$ & 0,80 & 1,40 & 0,80 & 0,80 & 1,40 \\
\hline $\begin{array}{c}\text { Ratio } \\
(\mathbf{L} / \mathbf{B r})\end{array}$ & 40,00 & 40,00 & 10,00 & 10,00 & 10,00 \\
\hline $\mathbf{N}_{\mathbf{C}}$ & 68,35 & 68,35 & 68,35 & 68,35 & 68,35 \\
\hline \multicolumn{5}{|}{$\frac{1}{P_{u}^{2}}=\frac{1}{n^{2} * P_{I}^{2}}+\frac{1}{P_{B}^{2}}$}
\end{tabular}

Onde:

$\mathrm{P}_{\mathrm{u}}$ : capacidade última do grupo de estacas

PI: capacidade última da estaca isolada (obtida experimentalmente $=424 \mathrm{kN}$ )

n: número de estacas do grupo

$\mathrm{P}_{\mathrm{B}}$ : capacidade última do grupo obtido com Terzaghi \& Peck (1948)

A estimativa de capacidade de carga última $\left(\mathrm{P}_{\mathrm{u}}\right)$ para cada configuração calculada com o método de Terzaghi \& Peck (1948) apresentou resultados na média de 2,5 vezes superiores aos experimentais, mas com a modificação de Poulos \& Davis (1980), a qual é uma média ponderada, o resultado de capacidade de carga última $\left(\mathrm{P}_{\mathrm{u}}\right)$ apresentou uma aproximação satisfatória dentro, da margem de $\pm 20 \%$ do valor experimental. Isto se pode verificar nas relações dos valores de capacidade de carga calculados e os obtidos experimentalmente apresentados nas Tab. 5.12 e Tab. 5.13 respectivamente.

Tabela 5.12 Capacidade de carga método Terzaghi \& Peck (1948)

\begin{tabular}{|c|c|c|c|}
\hline Configuração & PCE $(\mathbf{k N})$ & $\mathbf{P u}_{\mathbf{u}}(\mathbf{k N})$ & PB/PCE \\
\hline 2 Estacas & 750 & 1891 & 2,52 \\
\hline 3 Estacas & 1100 & 3107 & 2,82 \\
\hline 4 Estacas & 1780 & 4338 & 2,44 \\
\hline 5 Estacas & 1970 & 4338 & 2,20 \\
\hline 6 Estacas & 2520 & 6784 & 2,69 \\
\hline
\end{tabular}

Tabela 5.13 Capacidade de carga método Poulos \& Davis (1980)

\begin{tabular}{|c|c|c|c|}
\hline Configuração & PCE $(\mathbf{k N})$ & Pu $(\mathbf{k N})$ & Pu/PCE \\
\hline 2 Estacas & 750 & 774 & 1,03 \\
\hline 3 Estacas & 1100 & 1177 & 1,07 \\
\hline 4 Estacas & 1780 & 1580 & 0,89 \\
\hline 5 Estacas & 1970 & 1905 & 0,97 \\
\hline 6 Estacas & 2520 & 2382 & 0,95 \\
\hline
\end{tabular}

Na Fig. 5.9 pode-se observar, graficamente, os resultados destas análises onde se nota um incremento linear da capacidade de carga com o aumento do número de estacas, além da 
boa aproximação entre o valor calculado com o método de Poulos \& Davis (1980) e os valores experimentais.

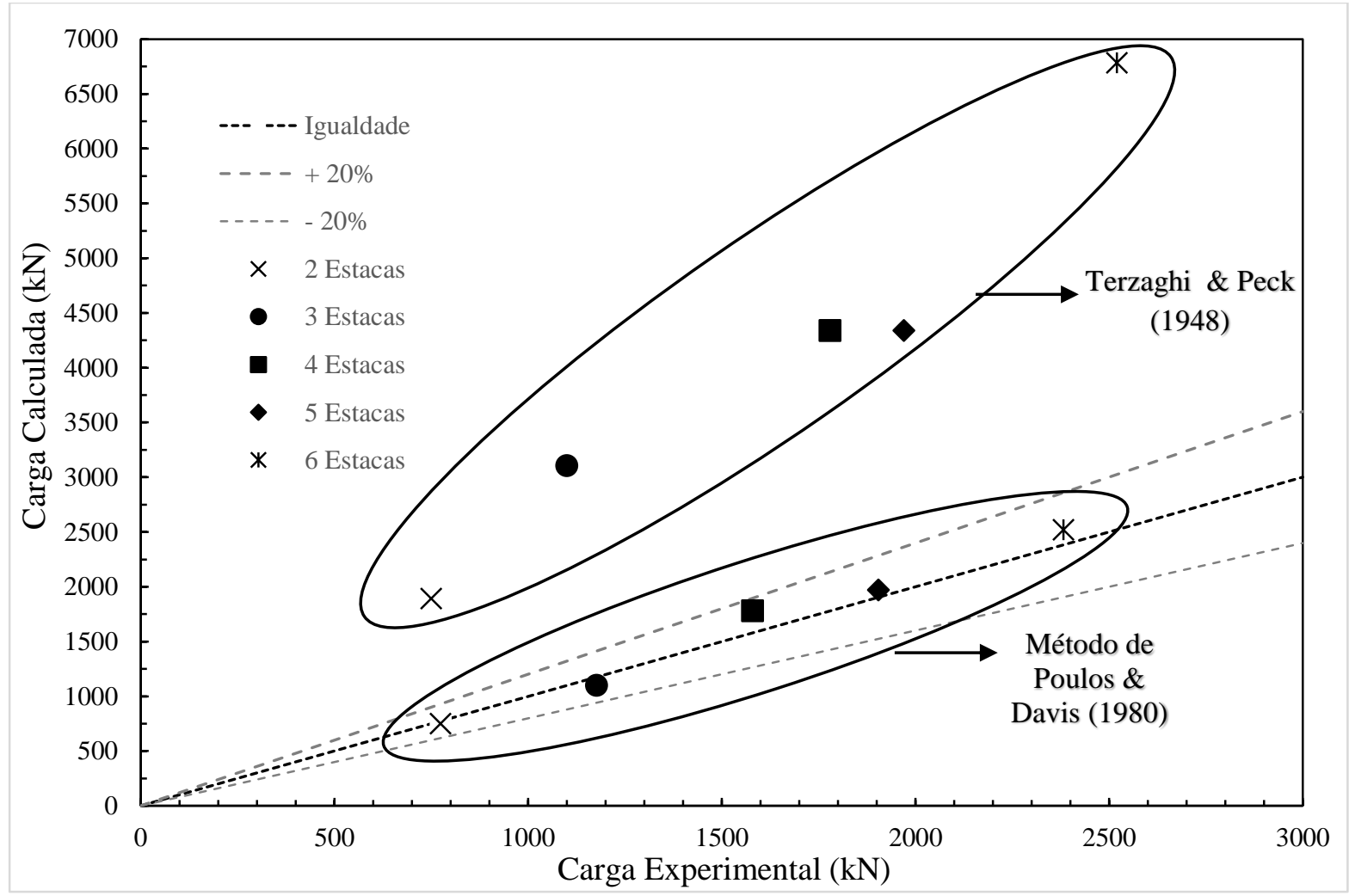

Figura 5.9. Carga calculada vs Carga experimentais para cada configuração de estacas

Diante do exposto, pode-se afirmar que além dos bons resultados na eficiência experimental, citados anteriormente no trabalho de Silva \& Cintra (1996), este trabalho também apresentou estimativas muito razoáveis de capacidade de carga para os grupos estudados, que igualmente ficaram em torno de $\pm 20 \%$ quando não se considera a contribuição do bloco de coroamento, e ao se utilizar a metodologia de Poulos \& Davis (1980).

\subsubsection{ESTIMATIVA DA CAPACIDADE DE CARGA NO MÉTODO EMPÍRICO COM EFICIÊNCIA DE GRUPO}

Para utilizar a formulação clássica de eficiência para se estimar a capacidade de carga de grupos Alluvial Anker, foram utilizados os resultados obtidos neste trabalho com o método de Décourt \& Quaresma (1978, 1996), o qual apresentou melhor desempenho na estimativa da capacidade de carga de uma estaca do tipo Alluvial Anker isolada. Chama-se a atenção que utilizou-se a eficiência experimental de 0,87 para configurações lineares e 0,99 para quadradas, via das provas de carga estáticas realizadas no presente trabalho e por Mendoza (2013).

Como valor de carga limite para uma estaca isolada foi utilizado o resultado de $392 \mathrm{kN}$ obtido pelo método de Décourt \& Quaresma $(1978$, 1996) mostrado na Fig 5.6, e devido à 
inexistência de fatores empíricos de estaca para estacas Alluvial Anker foi considerado a melhor aproximação obtida com fatores de estaca do tipo raiz sem contribuição de resistência por ponta. Esta metodologia, entre as demais, foi a que apresentou valores estimados mais próximos dos experimentais, com uma relação de 0,92 (valor calculado/valor experimental) (Ver Tab 5.9).

A eficiência experimental obtida foi avaliada com base na configuração que tinham os grupos, dado que a eficiência só apresentou variação no momento em que a configuração das estacas mudou de uma configuração linear a uma configuração quadrada. Foram separados os valores para configurações lineares e realizada uma média aritmética entre esses valores, e foi realizado o mesmo para as configurações quadradas, obtendo-se resultados médios de 0,87 para as configurações lineares e 0,99 para as quadradas.

A capacidade de carga do grupo foi calculada como eficiência da configuração vezes carga da estaca isolada fornecida pelo método de Décourt \& Quaresma $(1978,1996)$ vezes o número de estacas, conforme apresentado na Eq. 5.4:

$$
P_{G}=n * P_{I} * \eta
$$

Onde:

n: número de estacas

PI: carga última da estaca isolada Décourt \& Quaresma $(1978,1996)$

ๆ: eficiência do grupo (obtido a partir de Mendoza, 2013)

Os resultados dos cálculos são apresentados na Tab. 5.14 e plotados na Fig. 5.10, observando-se uma aproximação razoável em relação ao valor experimental, o que era de se esperar dado que se está trabalhando com os melhores valores/metodologias de interpretação para este caso, e com o valor experimental calibrado da eficiência com base em eficiência experimental.

Tabela 5.14 Resultados da capacidade de carga dos grupos com eficiência

\begin{tabular}{|c|c|c|c|c|c|}
\hline Configuração & $\begin{array}{c}\text { Eficiência } \\
\text { exp. média } \\
(\boldsymbol{\eta})\end{array}$ & $\begin{array}{c}\text { Carg. Est. Iso } \\
\mathbf{( k N )} \\
\text { Décourt \& } \\
\text { Quaresma (1978) }\end{array}$ & $\begin{array}{c}\text { Carga do } \\
\text { Grupo } \\
(\mathbf{k N})\end{array}$ & $\begin{array}{c}\text { PCE (kN) } \\
\text { Mendoza } \\
(\mathbf{2 0 1 3})\end{array}$ & $\begin{array}{c}\text { Carga } \\
\text { Grupo/PCE }\end{array}$ \\
\hline 2 Estacas & 0,87 & 392 & 682 & 750 & 0,91 \\
\hline 3 Estacas & 0,87 & 392 & 1023 & 1100 & 0,93 \\
\hline 4 Estacas & 0,99 & 392 & 1552 & 1780 & 0,87 \\
\hline 5 Estacas & 0,99 & 392 & 1940 & 1970 & 0,98 \\
\hline 6 Estacas & 0,99 & 392 & 2328 & 2520 & 0,92 \\
\hline
\end{tabular}




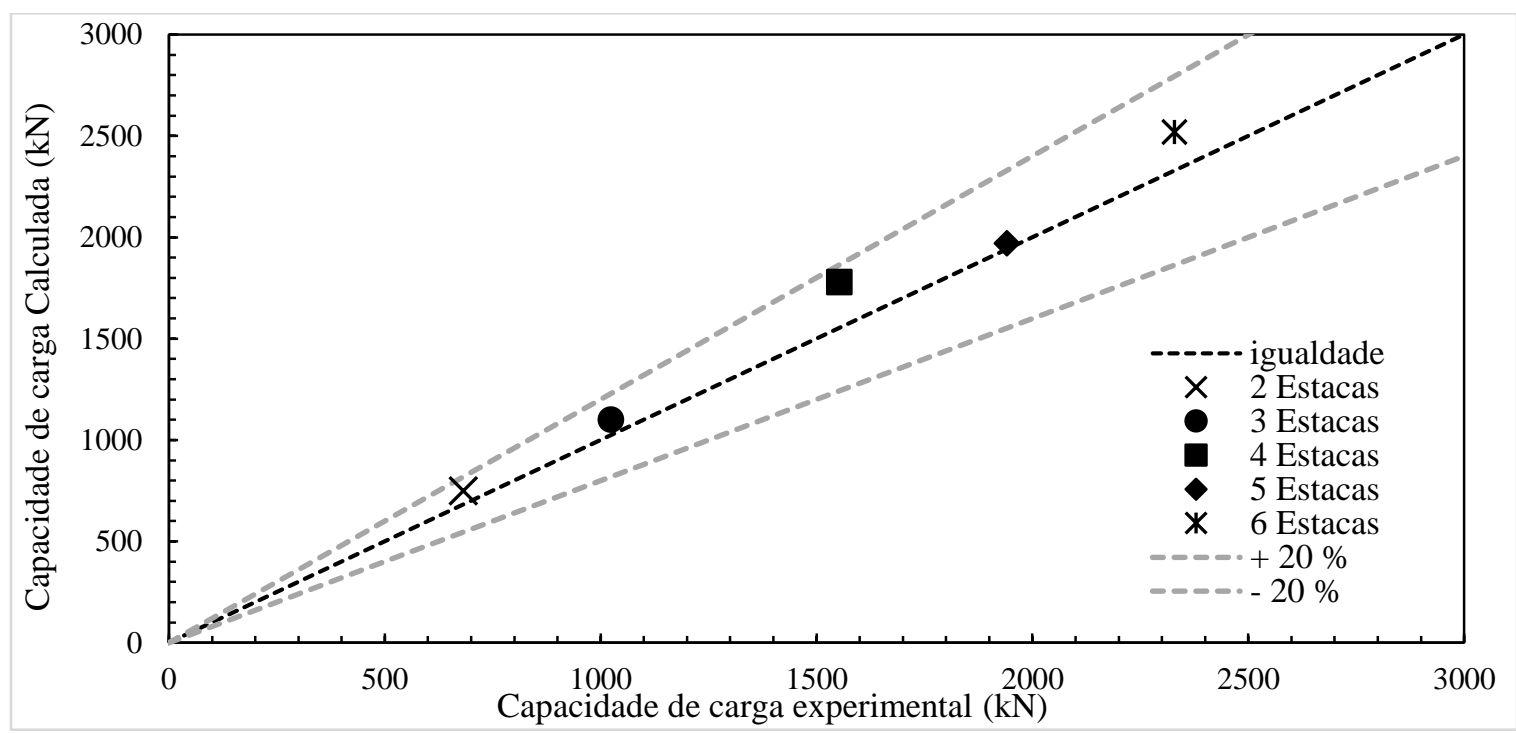

Figura 5.10 Comparação entre o valor calculado e o valor experimental contemplado a eficiência

\subsection{ANÁLISE DE DESLOCABILIDADE DE ESTACAS ISOLADAS E EM GRUPOS DE ESTACAS TIPO ALLUVIAL ANKER}

Com base nas 6 provas de carga sem contato com solo foi verificada a aplicabilidade dos métodos de deslocabilidade de fundações de Poulos \& Davis (1980), Randolph \& Wroth (1978, 1979) modificado por Randolph (1994), método empírico simplificado Randolph em Fleming (1985) e o Software numérico DEFPIG, desenvolvido por Poulos \& Davis (1980). Estes métodos foram usados para se estimar os recalques dos grupos de estacas Alluvial Anker no campo experimental da SOLOTRAT Engenharia Geotécnica Ltda.

Esta parte da dissertação consistiu em realizar uma análise de deslocabilidade comparativa dos resultados de recalque para a carga de trabalho, resultados estes obtidos das provas de carga estáticas feitas nos grupos e na estaca isolada de fundações, e na comparação aos métodos elásticos (acima relacionados) de estimativa de recalque usados normalmente na prática da engenharia de fundações. Na Tab. 5.15 são apresentados os recalques experimentais obtidos nas provas de carga estáticas, para carga de trabalho das diferentes configurações dos grupos de estacas Alluvial Anker.

Tabela 5.15 Carga e recalque de trabalho obtidos de provas de carga estáticas

\begin{tabular}{|c|c|c|c|}
\hline Origem & Configuração & Carga Trabalho (kN) & $\boldsymbol{\delta}$ PCE $(\mathbf{m m})$ \\
\hline Presente Dissertação & Isolada & 212 & 2,71 \\
\hline \multirow{4}{*}{ Mendoza (2013) } & 2 Estacas & 375 & 3,20 \\
\cline { 2 - 4 } & 3 Estacas & 550 & 4,60 \\
\cline { 2 - 4 } & 4 Estacas & 890 & 5,35 \\
\cline { 2 - 4 } & 5 Estacas & 985 & 3,80 \\
\cline { 2 - 4 } & 6 Estacas & 1260 & 4,00 \\
\hline
\end{tabular}


A primeira parte da análise começou estimando o recalque da estaca isolada utilizando a solução de Poulos \& Davis (1980) para as várias camadas (Fig. 5.11). Já para os grupos foi utilizado o método de fundação equivalente, transformado o grupo de estacas em um "estacão" equivalente, aplicando, após nele, o método de Poulos \& Davis (1980) para uma estaca isolada, metodologia esta sugerida no trabalho de Sales (2000).

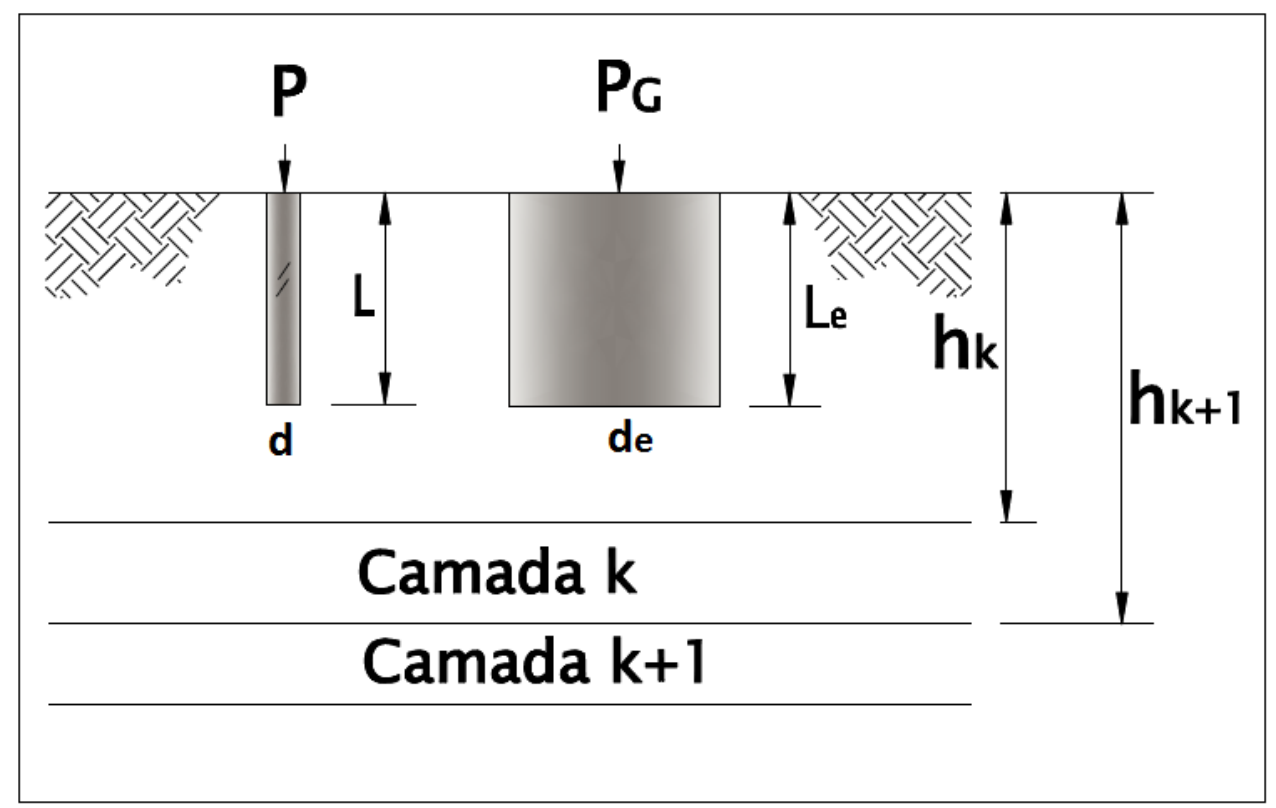

Figura 5.11 Solução de Poulos \& Davis (1980) para o módulo do solo equivalente

Como os métodos de estimativa de recalque aqui citados baseiam-se na teoria da elasticidade, foi necessário adotar valores para o módulo de elasticidade (Es) e para o coeficiente de Poisson (vs) do solo. Tais valores foram obtidos das investigações existentes de ensaios triaxiais, SPT e DMT do trabalho de Mendoza (2013) citados no capítulo 3 na Tab. 3.4 nesta dissertação.

Para o cálculo da relação "H/L" (espessura da camada de solo/comprimento da estaca) utilizado no método de Poulos \& Davis (1980), foi levado em conta um acréscimo $(\Delta \mathrm{h})$ na profundidade de parada do ensaio SPT em função do valor último $\mathrm{N}_{\text {SPT }}$ da sondagem, como

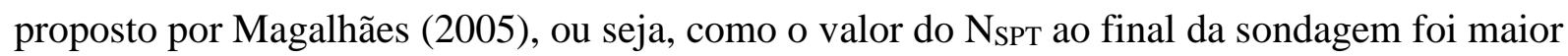
do que 35 na profundidade de $15 \mathrm{~m}$, a espessura da camada $(\mathrm{H})$ foi considerada de $20 \mathrm{~m}$. A partir desta correlação foi definida a profundidade da camada resistente. A Tab. 5.16 mostra as relações para se definir este parâmetro. 
Tabela 5.16 Relações de acréscimos $\Delta \mathrm{h}$ para definir o parâmetro $(\mathrm{H})$ de espessura total

\begin{tabular}{|c|c|}
\hline NSPT FINAL & $\Delta \mathbf{h}(\mathbf{m})$ \\
\hline $0 \leq 5$ & 35 \\
\hline$>5 \leq 10$ & 30 \\
\hline$>10 \leq 15$ & 25 \\
\hline$>15 \leq 20$ & 20 \\
\hline$>20 \leq 25$ & 15 \\
\hline$>25 \leq 35$ & 10 \\
\hline$>35$ & 5 \\
\hline
\end{tabular}

Para a solução de Poulos \& Davis (1980) para estaca isolada em várias camadas, usouse um módulo de elasticidade do solo ponderado igual a 22,62 MPa. Isto é feito quando o comprimento da estaca atravessa várias camadas com diferentes módulos de elasticidade como aconteceu no perfil estudado. Os demais parâmetros são obtidos com os ábacos propostos no livro de Poulos \& Davis (1980) já anteriormente descritos no capitulo 2.

Na Tab. 5.17 são apresentados os dados para se calcular o recalque para o método de fundação equivalente, e na Tab. 5.18 os fatores de correção para a estaca isolada, obtidos dos ábacos propostos por Poulos \& Davis (1980) como a correção por rigidez $\left(\mathrm{R}_{\mathrm{K}}\right)$, a correção para camada infinita $\left(R_{h}\right)$ e o coeficiente de Poisson $\left(R_{v}\right)$. Os resultados dos recalques estimados obtidos para cada configuração de estacas são apresentados na Tab. 5.19, incluindo os recalques estimados pelo método empírico simplificado de Randolph em Fleming et al (1985) (Ver Eq. 2.39).

Tabela 5.17 Parâmetros método Poulos \& Davis (1980)

\begin{tabular}{|c|c|c|c|c|c|c|c|}
\hline Configuração & $\operatorname{Ag}\left(\mathbf{c m}^{2}\right)$ & $\begin{array}{c}\text { deq } \\
(\mathbf{c m})\end{array}$ & $\begin{array}{c}\text { Es } \\
(\mathbf{M P a})\end{array}$ & Ep (MPa) & $\mathrm{AT}\left(\mathbf{c m}^{2}\right)$ & Eeq (MPa) & $v$ \\
\hline 2 Estacas & 3150 & 71,28 & 22,62 & 23800 & 628,32 & 4765,4 & 0,29 \\
\hline 3 Estacas & 5250 & 92,02 & 22,62 & 23800 & 942,48 & 4291,12 & 0,29 \\
\hline 4 Estacas & 8100 & 114,30 & 22,62 & 23800 & 1256,64 & 3711,45 & 0,29 \\
\hline 5 Estacas & 8100 & 114,30 & 22,62 & 23800 & 1570,8 & 4633,66 & 0,29 \\
\hline 6 Estacas & 13500 & 147,56 & 22,62 & 23800 & 1884,95 & 3342,56 & 0,29 \\
\hline \multicolumn{8}{|c|}{$\begin{array}{l}\mathrm{d}_{\mathrm{eq}}: \text { diâmetro equivalente } \\
\mathrm{E}_{\mathrm{p}}: \text { módulo de elasticidade da estaca } \\
\mathrm{A}_{\mathrm{T}} \text { : somatório das áreas das seções das estacas do grupo } \\
\mathrm{A}_{\mathrm{G}} \text { área da figura plana circunscrita ao grupo de estacas } \\
\mathrm{E}_{\mathrm{s}} \text { : módulo de elasticidade ponderado do solo } \\
\mathrm{E}_{\text {eq }} \text { : módulo equivalente do grupo de estacas } \\
\text { v: coeficiente de Poisson do solo }\end{array}$} \\
\hline
\end{tabular}


Tabela 5.18 Fatores de correção método Poulos \& Davis (1980)

\begin{tabular}{|c|c|c|c|c|c|}
\hline Configuração & Io & $\mathbf{R K}$ & $\mathbf{R h}$ & $\mathbf{R}_{v}$ & I \\
\hline Isolada & 0,055 & 1,15 & 0,4 & 0,92 & 0,02328 \\
\hline 2 Estacas & 0,14 & 1,31 & 0,84 & 0,95 & 0,14635 \\
\hline 3 Estacas & 0,15 & 1,18 & 0,83 & 0,95 & 0,13956 \\
\hline 4 Estacas & 0,17 & 1,18 & 0,82 & 0,96 & 0,15791 \\
\hline 5 Estacas & 0,17 & 1,18 & 0,8 & 0,95 & 0,15246 \\
\hline 6 Estacas & 0,198 & 1,1 & 0,78 & 0,95 & 0,16139 \\
\hline \multicolumn{6}{|c|}{$\begin{array}{l}\mathrm{I}_{0}: \text { fator de influência estaca incompressível } \\
\mathrm{R}_{\mathrm{k}} \text { : fator de correção compressibilidade da estaca } \\
\mathrm{R}_{\mathrm{h}} \text { : fator de correção para profundidade finita } \\
\mathrm{R}_{\mathrm{v}} \text { : fator de correção para o coeficiente de Poisson do solo }\end{array}$} \\
\hline
\end{tabular}

Tabela 5.19 Resultados dos recalques para cada configuração de estaca Alluvial Anker

\begin{tabular}{|c|c|c|c|}
\hline Configuração & $\begin{array}{c}\text { Estaca isolada Poulos } \\
\text { \& Davis (1980) }(\mathbf{m m})\end{array}$ & $\begin{array}{c}\text { Grupo de Fundação } \\
\text { Equivalente (mm) Poulos } \\
\text { \& Davis (1980) }\end{array}$ & $\begin{array}{c}\text { Método Empírico } \\
\text { Simplificado (mm) }\end{array}$ \\
\hline Isolada & 2,84 & -- & -- \\
\hline 2 Estacas & -- & 3,40 & 4,02 \\
\hline 3 Estacas & -- & 3,69 & 4,92 \\
\hline 4 Estacas & -- & 5,44 & 5,68 \\
\hline 5 Estacas & -- & 5,81 & 6,35 \\
\hline 6 Estacas & -- & 6,09 & 6,96 \\
\hline
\end{tabular}

Também foi realizada a estimativa de recalque para a estaca isolada pelo método de Randolph \& Wroth, 1978. Os parâmetros calculados para obter os valores de recalque para estaca isolada e para os grupos de estacas Alluvial Anker, a partir dos parâmetros elastoplásticos do solo, são apresentados nas Tab. 5.20.

Na Tab. 5.21 são apresentados os parâmetros do método de Randolph \& Wroth, 1979 modificado por Randolph (1994), para cada configuração de grupo estudada. Nesta tabela também está sinalizada a estaca que foi tomada como referência para o cálculo do fator de correção para a transferência de carga, e a interação entre as estacas vizinhas. 
Tabela 5.20 Parâmetros Método de Randolph \& Wroth (1978) para estaca isolada

\begin{tabular}{|c|c|c|}
\hline Parâmetros & Equação & Resultado \\
\hline $\begin{array}{l}\text { Módulo cisalhante do solo a } \\
\text { uma profundidade } Z=L \text { (GL) }\end{array}$ & $G_{L}=\frac{E}{2 \times(1+v)}$ & $0,877 \mathrm{kN} / \mathrm{cm}^{2}$ \\
\hline $\begin{array}{l}\text { Razão entre média do módulo } \\
\text { cisalhante do solo em que se } \\
\text { encontra a estaca e o módulo } \\
\text { cisalhante do solo na } \\
\text { profundidade } Z=L(\rho)\end{array}$ & $\rho=\bar{G} / G L$ & 1 \\
\hline $\begin{array}{l}\text { Parâmetro de rigidez da estaca } \\
\qquad(\xi)\end{array}$ & $\xi=\mathrm{GL} / \mathrm{Gb}$ & 1 \\
\hline Raio máximo de influência (rm) & $r_{m}=L\{0,25+\xi[2,5 \rho(1-v)-0,25]\}$ & $1420 \mathrm{~mm}$ \\
\hline 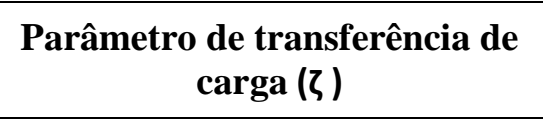 & $\zeta=\ln \left(\frac{r_{m}}{r_{0}}\right)$ & 4,955 \\
\hline $\begin{array}{c}\text { Relação entre o raio da ponta e } \\
\text { o raio da estaca }(\eta)\end{array}$ & $n=\frac{r_{b}}{r_{0}}$ & 1 \\
\hline $\begin{array}{c}\text { Relação entre o módulo de } \\
\text { elasticidade da estaca e o } \\
\text { módulo cisalhante do solo a uma } \\
\text { profundidade } Z=L(\lambda)\end{array}$ & $\lambda=E_{P} / G_{L}, E_{P}$ & 2714,59 \\
\hline $\begin{array}{l}\text { Parâmetro da equação de } \\
\text { Randolph \& Wroth }(\mu \mathrm{L})\end{array}$ & $\mu L=\frac{L}{r_{0}} \sqrt{\frac{2}{\zeta \lambda}}$ & 0,975 \\
\hline
\end{tabular}

Tabela 5.21 Parâmetros Método Randolph \& Wroth (1979-1994) para grupos de estacas

\begin{tabular}{|c|c|c|c|c|c|c|}
\hline & & 2 Estacas & 3 Estacas & 4 Estacas & 5 Estacas & 6 Estacas \\
\hline Parâmetros & Equação & $0 \quad 0$ & 00 & $\begin{array}{ll}0 & 0 \\
0 & 0\end{array}$ & $\begin{array}{ll}0 & 0 \\
& 0 \\
0 & 0\end{array}$ & $\begin{array}{lll}0 & 0 & 0 \\
0 & 0 & 0 \\
\end{array}$ \\
\hline $\begin{array}{l}\text { Correção do parâmetro de } \\
\text { transferência de carga ( })\end{array}$ & $\zeta=n \times \zeta-\sum_{i=2}^{n} \ln \left(\frac{S_{i}}{r_{0}}\right)$ & 8,154 & 11,352 & 14,203 & 19,135 & 20,253 \\
\hline 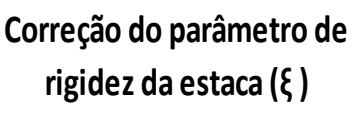 & $\xi=\xi \times\left[1+\frac{2}{\pi} \sum_{i=2} \frac{r_{b}}{S_{i}}\right.$ & 1,110 & 1,220 & 1,297 & 1,621 & 1,484 \\
\hline $\begin{array}{l}\text { Parâmetro da ecuação de } \\
\text { Randolph \& Wroth }(\mu \mathrm{L})\end{array}$ & $\mu L=\frac{L}{r_{o}} \sqrt{\frac{2}{\zeta \lambda}}$ & 0,760 & 0,644 & 0,576 & 0,496 & 0,482 \\
\hline
\end{tabular}

Os resultados dos recalques estimados como a metodologia de Randolph \& Wroth (1978 e 1979) para estaca isolada e para grupos de estacas respectivamente são apresentados na Tab. 5.22 . 
Tabela 5.22 Resultado de recalque pelo método Randolph \& Wroth

\begin{tabular}{|c|c|c|}
\hline Configuração & $\begin{array}{c}\text { Randolph \& Wroth } \\
(\mathbf{1 9 7 8}) \mathbf{( m m ) *}\end{array}$ & $\begin{array}{c}\text { Randolph \& Wroth } \\
(\mathbf{1 9 7 9 - 1 9 9 4 )} \mathbf{( m m}) * *\end{array}$ \\
\hline Isolada & 3,04 & -- \\
\hline 2 Estacas & -- & 4,41 \\
\hline 3 Estacas & -- & 5,75 \\
\hline 4 Estacas & -- & 6,91 \\
\hline 5 Estacas & -- & 8,97 \\
\hline 6 Estacas & -- & 9,30 \\
\hline $\begin{array}{l}\text { *Cálculo com valores da Tabela 5.20 } \\
\text { **Cálculo com valores da Tabela 5.21 }\end{array}$ \\
\hline
\end{tabular}

Plotou-se na Fig. 5.12 os resultados de recalque calculados com as metodologias propostas comparadas com os valores experimentais obtidos das provas de carga estáticas, tanto dos grupos como da estaca isolada. Os recalques fornecidos pelas provas de carga são os correspondentes às cargas de trabalho de cada configuração de estaqueamento testado.

O recalque calculado está acima dos valores experimentais, o que denota tais metodologias como a favor da segurança para se estimar recalques para estacas do tipo Alluvial Anker.

A exceção se dá no caso da configuração de três (3) estacas, em que o método de Fundação Equivalente proposto por Poulos \& Davis (1980) está 25\% está abaixo dos valores experimentais.

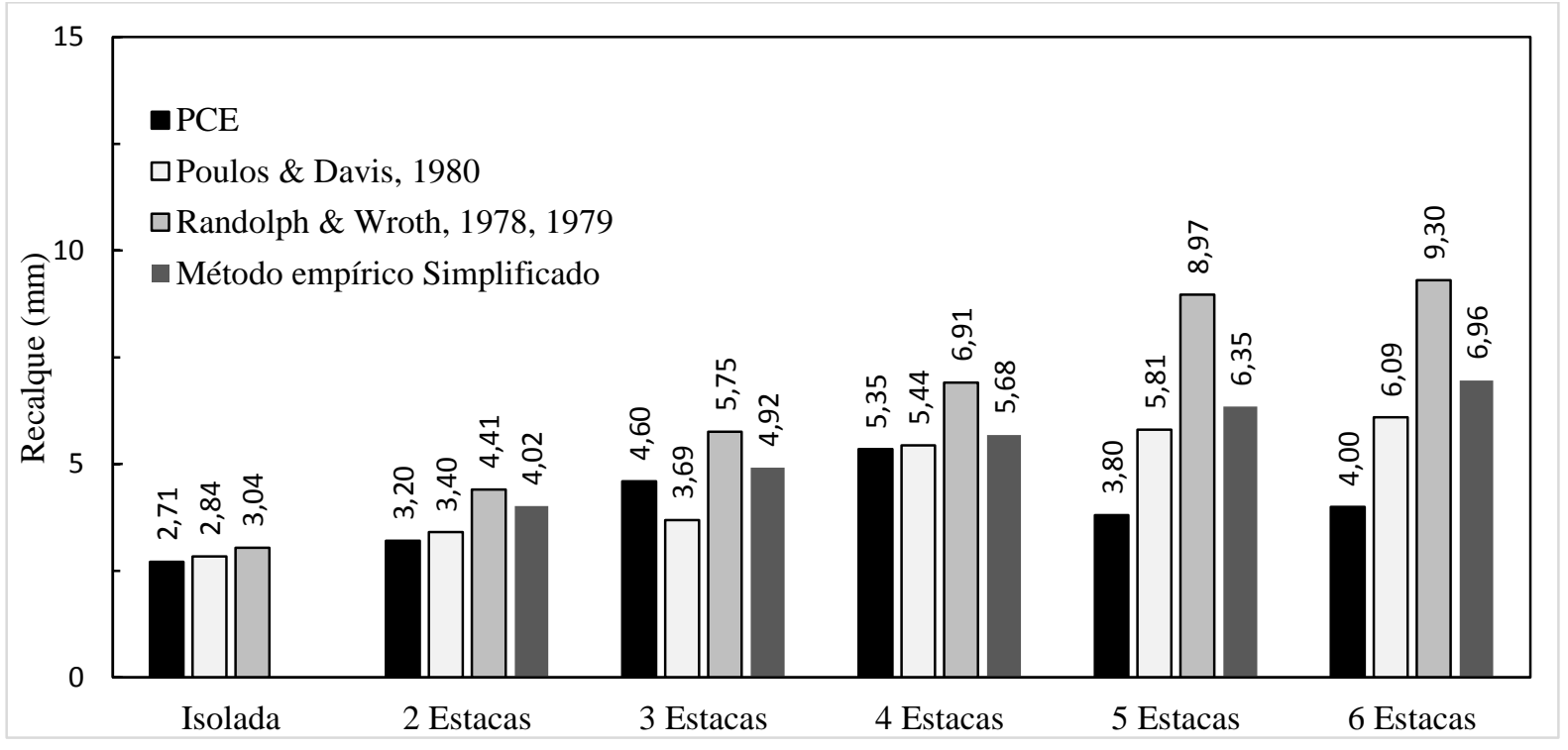

Figura 5.12 Resultados de recalque por metodologias baseadas na teoria da elasticidade

Adotou-se uma faixa de erro admissível igual a $\pm 20 \%$ na Fig. 5.13, novamente considerada como uma faixa aceitável na estimativa de recalques. Nota-se que a estimativa de recalque para a estaca isolada pelas metodologias baseadas na teoria da elasticidade apresentou bons resultados na aproximação dos resultados experimentais, para as configurações de 2, 3 e 
4 estacas. Já para as configurações com mais estacas (5 e 6 estacas), as três metodologias saíram da faixa proposta como sendo a de erro admissível.

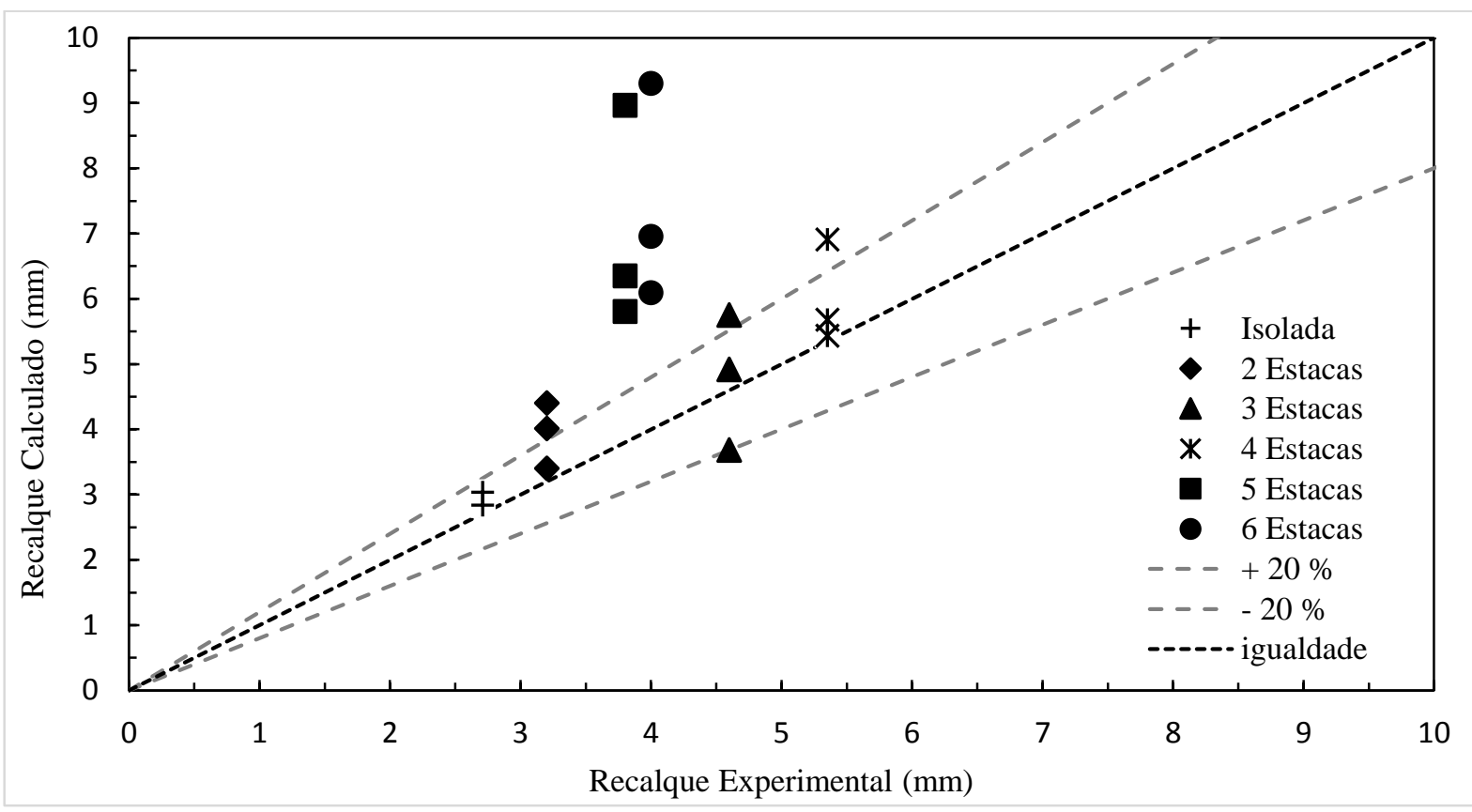

Figura 5.13 Comparação dos métodos elásticos de recalque para cada configuração de estacas Alluvial

\section{Anker}

\subsection{ANÁLISE DE DESLOCABILIDADE COM DEFPIG}

Nesta seção são apresentadas as descrições mais detalhadas dos procedimentos e da ferramenta utilizada para a realização da análise de deslocabilidade com o software numérico DEFPIG “Deformation Analysis of Piles Groups” desenvolvido por Poulos (1980).

\subsubsection{DEFINIÇÃO DOS PRINCIPAIS PARÂMETROS}

O software DEFPIG só foi utilizado só para obter o recalque produzido pela carga de trabalho de cada configuração de grupo de fundação Alluvial Anker.

Diversos aspectos condicionantes da análise podem ser facilmente considerados na entrada de dados do programa, tais como a carga de trabalho aplicada; os parâmetros geométricos (diâmetro, comprimento das estacas; espaçamento entre estacas; relação entre o diâmetro do fuste e da ponta; inércia da seção transversal da estaca), e os parâmetros mecânicos da fundação e das camadas de solo (módulo de elasticidade e coeficiente de Poisson).

O perfil estudado consistiu de várias camadas consideradas para a análise como de comportamento elástico linear, e heterogêneas de espessura H (20 m.), conforme a Fig. 5.14. Os parâmetros elásticos como o módulo de elasticidade $\left(E_{S}\right)$ e o coeficiente de Poisson $(v)$ foram considerados constantes para cada camada de solo. 


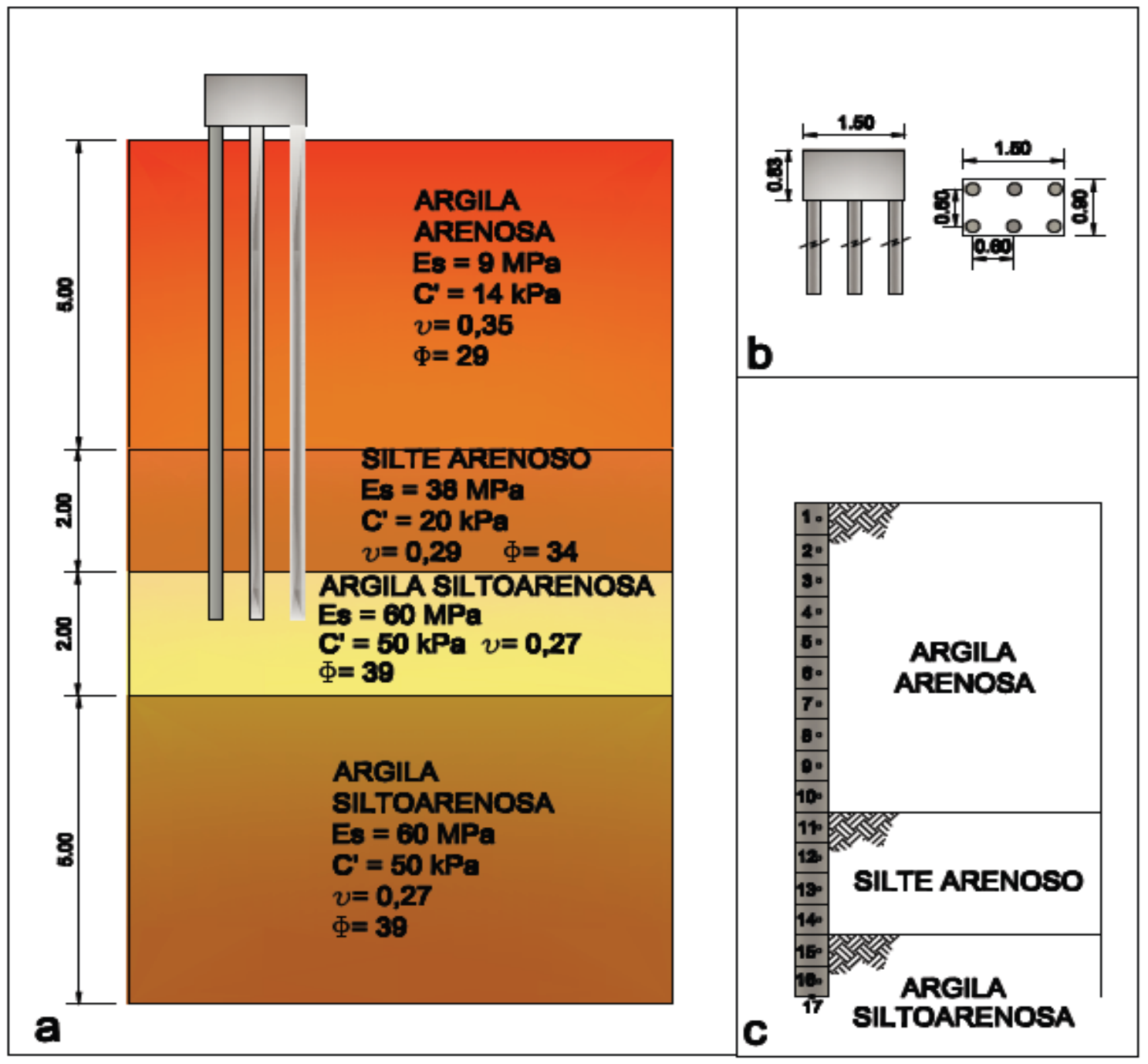

Figura 5.14 Parâmetros de entrada para o software DEFPIG

Foram realizadas quatro (4) diferentes análises de deslocabilidade, variando o módulo de elasticidade do solo $\left(\mathrm{E}_{\mathrm{s}}\right)$ de cada camada, tais valores foram obtidos das investigações existentes de ensaios triaxiais, SPT e DMT do trabalho de Mendoza (2013). Foram ainda adotados dados e correlações empíricas desenvolvidas com o N seguir como apoio da Tab. 5.22:

- Análise 1: Cálculo do recalque dos grupos de fundação Alluvial Anker, utilizando o valor médio do módulo de elasticidade do solo $\left(\mathrm{E}_{\mathrm{s}}\right)$ das camada identificadas com o SPT.

- Análise 2: Utilizando a correlação empírica do SPT com o modulo de elasticidade $\left(\mathrm{E}_{\mathrm{s}}\right)$ proposta por Clayton (1993) metro a metro, mostrada na Eq. 5.5.

$$
E_{S}=1 * N_{S P T}
$$


- Análise 3: Utilizando a correlação empírica do SPT com o modulo de elasticidade $\left(\mathrm{E}_{\mathrm{s}}\right)$ proposta por Poulos (1998) metro a metro, mostrada na Eq. 5.6.

$$
E_{S}=3 * N_{S P T}
$$

- Análise 4: Utilizando a correlação do ensaio DMT com o módulo de elasticidade $\left(\mathrm{E}_{\mathrm{s}}\right)$ proposta por Marchetti (2001) metro a metro, mostrada na Eq. 5.7.

$$
E_{S}=0,8 * M_{E D O}
$$

No cálculo para o módulo de elasticidade com o SPT, com valores de $\mathrm{N}_{\mathrm{SPT}}$ superiores a 50 golpes, foi adotado um valor limite de 50 .

No ensaio de DMT não foi possível obter medidas de pressão $\mathrm{P}_{0}$ e $\mathrm{P}_{1}$ ao começo do ensaio, e só foi possível obter dados até $8 \mathrm{~m}$ porque a haste apresentou inclinação excessiva como relatado por Mendoza (2013). Em função disto foi adotado para os primeiros dois metros do comprimento da estaca um módulo de elasticidade de $1 \mathrm{MPa}$. Na Tab. 5.23 são apresentados as diferentes correlações (SPT e DMT) dos módulos de elasticidade do solo $\left(\mathrm{E}_{\mathrm{s}}\right)$ utilizados na análise de recalque com o software DEFPIG.

Tabela 5.23 Módulos de elasticidade empregados nas análise de recalque com DEFPIG

\begin{tabular}{|c|c|c|c|c|}
\hline Prof. (m) & $\begin{array}{c}\text { Valor médio } \\
\mathbf{E}_{\mathbf{s}}(\mathbf{M P a})\end{array}$ & $\begin{array}{c}\text { Clayton } \\
\mathbf{E}_{\mathbf{s}}(\mathbf{M P a})\end{array}$ & $\begin{array}{c}\text { Poulos } \\
\mathbf{E}_{\mathbf{s}}(\mathbf{M P a})\end{array}$ & $\begin{array}{c}\text { Marchetti } \\
\mathbf{E}_{\mathbf{s}} \text { (MPa) }\end{array}$ \\
\hline 1 & 9 & 1 & 3 & 1 \\
\hline 2 & 9 & 2 & 6 & 1 \\
\hline 3 & 9 & 2 & 6 & 5,5 \\
\hline 4 & 9 & 3 & 9 & 10 \\
\hline 5 & 38 & 5 & 15 & 29 \\
\hline 6 & 38 & 9 & 27 & 55 \\
\hline 7 & 38 & 29 & 87 & 107 \\
\hline 8 & 60 & 50 & 150 & 132 \\
\hline
\end{tabular}

Os parâmetros utilizados para o perfil de solo como o coeficiente de Poisson (v), módulo de elasticidade $\left(E_{s}\right)$, ângulo de atrito $(\phi)$ são apresentados na Tab. 5.24.

Os parâmetros elasto-plásticos da estaca e o bloco de coroamento como os módulos de elasticidade (E) e coeficiente de Poisson (v), foram admitidos como de origem elástico-linear com valores reportados no trabalho de Pando et al (2002). Além disso, o bloco foi considerado como infinitamente rígido, e o solo heterogêneo conforme ao perfil estudado. 
Tabela 5.24 Parâmetros inseridos no DEFPIG para o cálculo de recalque

\begin{tabular}{|c|c|c|c|c|c|c|c|c|}
\hline Prof (m) & Perfil & Nó & Es (Mpa) & $\nu$ & $\phi(\mathbf{9})$ & $\sigma^{\prime}(\mathbf{k P a})$ & $\mathbf{k} \cong \mathbf{k} \mathbf{0}$ & $\sigma^{\prime} k \tan \delta$ \\
\hline 1 & \multirow{4}{*}{$\mathbf{A}$} & \multirow{4}{*}{1 ao 8} & \multirow{8}{*}{$\begin{array}{c}\text { Mudando } \\
\text { dependendo } \\
\text { da correlação } \\
\text { utilizada }\end{array}$} & \multirow{8}{*}{0,30} & \multirow{5}{*}{29} & \multirow{4}{*}{34} & \multirow{8}{*}{0.5} & \multirow{4}{*}{9,5} \\
\hline 2 & & & & & & & & \\
\hline 3 & & & & & & & & \\
\hline 4 & & & & & & & & \\
\hline 5 & B & 9 ao 10 & & & & 62 & & 17,2 \\
\hline 6 & \multirow{2}{*}{ C } & \multirow{2}{*}{11 ao 14} & & & \multirow{2}{*}{34} & \multirow{2}{*}{69} & & \multirow{2}{*}{23,3} \\
\hline 7 & & & & & & & & \\
\hline 8 & D & 15 ao 16 & & & 39 & 77 & & 31,2 \\
\hline
\end{tabular}

\subsubsection{CONDIÇÕES DE CONTORNO}

As diferentes configurações de grupos Alluvial Anker seguiram as seguintes condições de fronteira:

- O topo da estaca foi considerado engastado ao bloco infinitamente rígido sem permitir rotações.

- O bloco não apresenta contato com o solo.

- Foi considerada a estaca como flutuante (trabalhando por atrito lateral principalmente)

- A ponta da estaca foi considerada livre e a estaca considerou-se como flutuante

Estes aspectos são apresentados na Fig. 5.15.

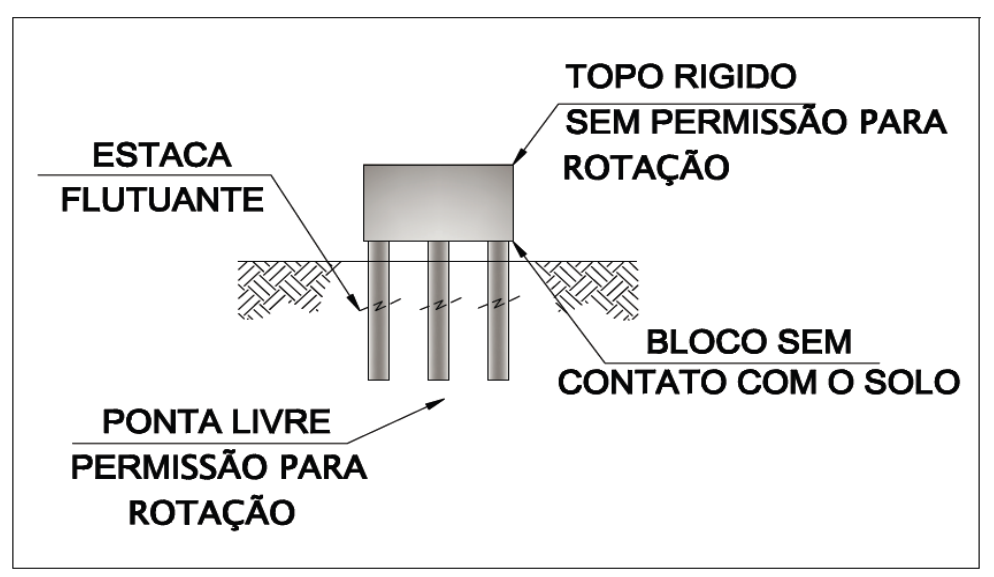

Figura 5.15 Condições do bloco adotadas no software DEFPIG

O comprimento das estacas igual a $8,0 \mathrm{~m}$ foi divido em 16 elementos com 17 nós para se obter informações cada $0,50 \mathrm{~m}$. A estaca apresentou 16 nós para considerar a resposta axial distribuída igualmente em todo o fuste. A ponta apresentou um só nó dado seu pequeno diâmetro de 0,20m. Na Fig. 5.16 é apresentado um exemplo de como o software DEFPIG considera os parâmetros em cada nó, e entre os nós. O exemplo realizado é para o recalque do grupo de 6 estacas com módulo de elasticidade do solo obtido com a correlação do SPT de Poulos (1998), da Tab. 5,22. 
Como o objetivo desta Dissertação foi só a verificação do recalque quando a estaca é solicitada axialmente, os casos de estudo não apresentaram carga lateral.

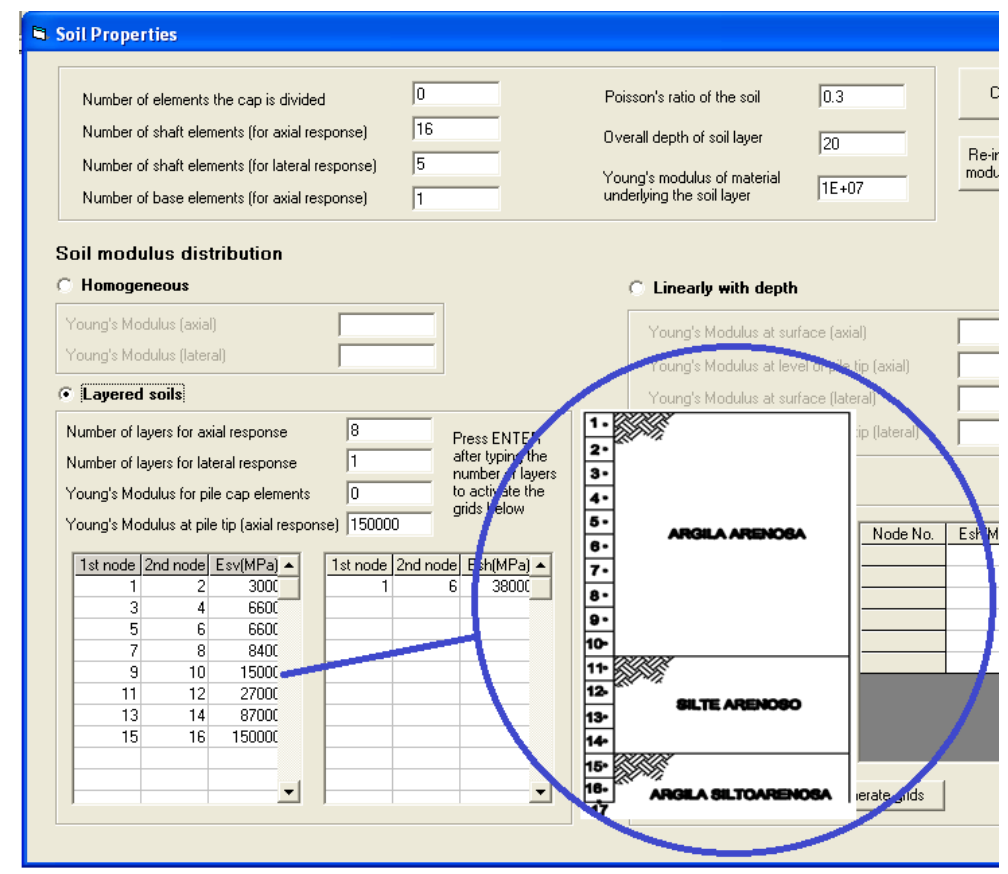

Figura 5.16 Interface de entrada de dados software DEFPIG

\subsubsection{METODOLOGIA USADA NO DEFPIG}

Foi calculado o recalque para cada configuração de estacas Alluvial Anker, só variando o módulo de elasticidade do solo. Em seguida foi calculado o recalque para o módulo obtido via ensaio DMT (Marchetti, 2001), além disso foram utilizadas duas correlações para o ensaio SPT (Clayton, 1993, Poulos, 1998 e o valor médio). No cálculo para o módulo de elasticidade com SPT, com valores de $\mathrm{N}_{\mathrm{SPT}}$ superiores a 50 golpes, foi adotado um valor limite de 50 .

Na Tab. 5.25 são apresentados os resultados dos valores de recalque obtidos com a ferramenta numérica DEFPIG para cada correlação empregada no cálculo do módulo de elasticidade do solo $\left(\mathrm{E}_{\mathrm{S}}\right)$.

\begin{tabular}{|c|c|c|c|c|c|}
\multicolumn{1}{c|}{} & \multicolumn{2}{c|}{ Tabela 5.25 Resultados de recalque obtidos com DEFPIG } \\
\cline { 2 - 6 } \multicolumn{1}{c|}{ Provas de Carga } & $\begin{array}{c}\text { Marchetti } \\
\mathbf{( 2 0 0 1 )}\end{array}$ & $\begin{array}{c}\text { Clayton } \\
(\mathbf{1 9 9 3})\end{array}$ & $\begin{array}{c}\text { Poulos } \\
(\mathbf{1 9 9 8})\end{array}$ \\
\hline \multirow{2}{*}{ Configuração } & Carg. Trab (kN)* & $\delta$ trab (mm) & $\boldsymbol{\delta}(\mathbf{m m})$ & $\boldsymbol{\delta}(\mathbf{m m})$ & $\boldsymbol{\delta}(\mathbf{m m})$ \\
\hline 1 & 212 & 2,71 & 7,314 & 14,643 & 6,226 \\
\hline 2 & 375 & 3,20 & 7,122 & 15,000 & 6,017 \\
\hline 3 & 550 & 4,60 & 7,610 & 16,491 & 6,412 \\
\hline 4 & 890 & 5,35 & 11,064 & 25,480 & 9,375 \\
\hline 5 & 985 & 3,80 & 10,900 & 27,524 & 9,600 \\
\hline 6 & 1260 & 4,00 & 12,101 & 28,790 & 10,245 \\
\hline$*$ FS =2
\end{tabular}


O recalque obtido pela correlação de proposta por Clayton em 1993 forneceu recalques muito conservadores e excessivamente distantes da realidade, ou seja, na média 5,5 vezes acima do valor experimental. Os módulos de elasticidade do solo calculados com correlações dos ensaios DMT propostos por Marchetti (2001) e do SPT proposto por Poulos (1998), forneceram valores de recalque mais "aceitáveis" para configurações com menos estacas de 2, 3 e 4 estacas, mostrando uma tendência de distanciamento do cálculo do recalque do valor experimental com o aumento do número de estacas. Estas observações se notam na Fig. 5.17.

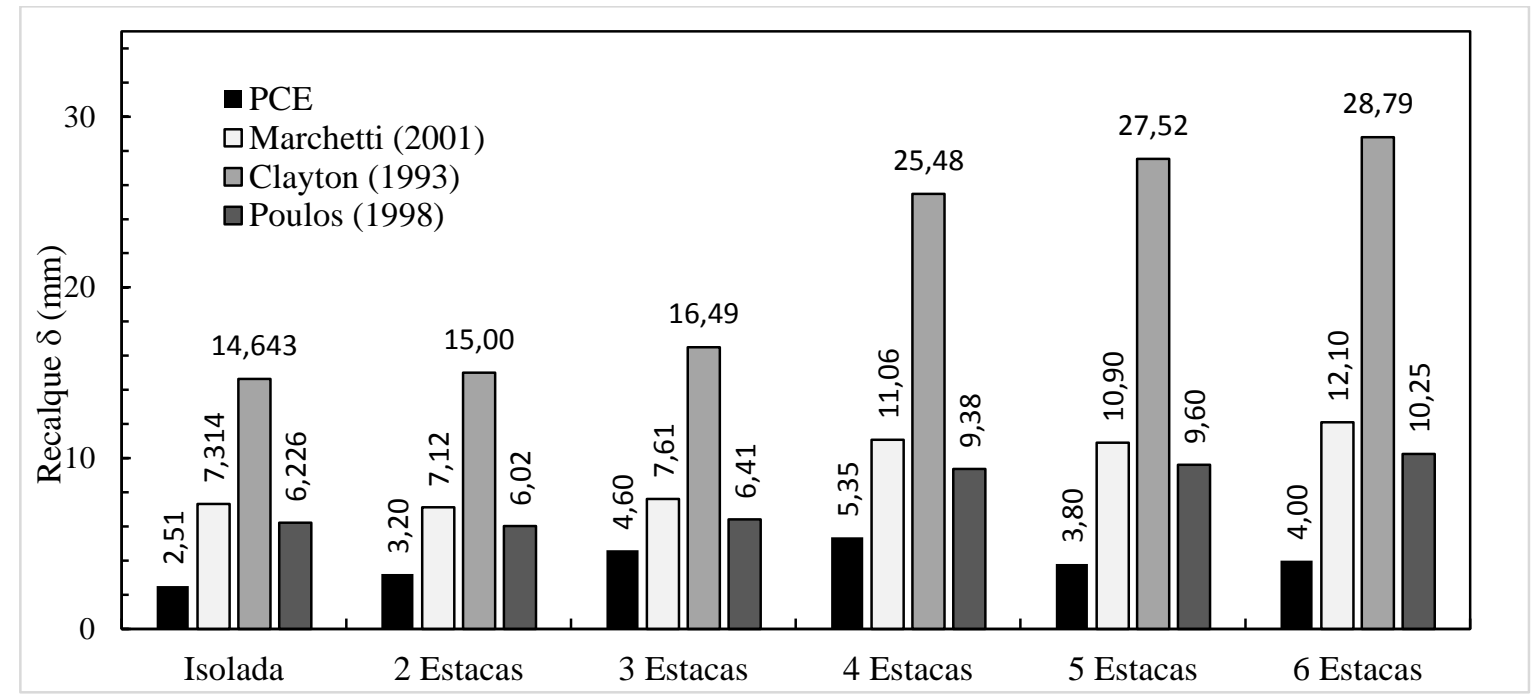

Figura 5.17 Comparação dos resultados de recalques calculados com DEFPIG

\subsection{SUMÁRIO DOS PRINCIPAIS RESULTADOS}

- As metodologias semi-empíricas baseadas no SPT e o SPT-T, apresentam valores muito altos de resistência por ponta, mesmo limitando o $\mathrm{N}_{\mathrm{SPT}}$ desta para 50 golpes. Dado o comportamento da estaca Alluvial Anker citado anteriormente no capitulo 4, deve-se desprezar a parcela de resistência por ponta, levando com que a capacidade de carga última seja reduzida em média em 50\%;

- As metodologias baseadas no SPT-T, à exceção de Peixoto (2001), forneceram valores de resistência por atrito lateral da ordem de $35 \%$ em média do valor experimental lateral obtido da prova de carga. Estas se mostram como metodologias a favor da segurança e anti-econômicas.

- Para grupos o método analíticos clássicos de Terzaghi \& Peck (1948) apresentou resultados 2,5 vezes superiores aos experimentais, possivelmente dado que o fator de carga $\mathrm{N}_{\mathrm{c}}$ não tenha sido desenvolvido para solos que contam com parcela argilosa e friccional. 
- A modificação proposta por Poulos \& Davis (1980) realizada ao método de Terzaghi \& Peck (1948) melhorou a estimativa na capacidade de carga dos grupos estudados, fornecendo valores muito próximos e em torno de $\pm 20 \%$ dos valores experimentais, sem considerar contato do bloco com o solo.

- A eficiência de grupo apresentou variação nos resultados influenciado principalmente pela mudança na configuração das estacas, já que o espaçamento entre estas ficou constante (3 diâmetros) independente da configuração, apresentado resultados médios de 0,87 para as configurações lineares e 0,99 para as quadradas.

- Observando-se que os recalques previstos e os recalques medidos nos grupos apresentaram uma grande dispersão nos valores, só as metodologias clássicas conseguem-se manter na faixa adotada de $\pm 20 \%$, os recalques estimados com o software DEFPIG utilizando a correlação de Clayton (1993) apresentaram valores variando entre 4 a 7 vezes o valor experimental, entanto os recalque estimados utilizando a correlação de Poulos (1998) apresentou o valores mais "aceitáveis" utilizando a ferramenta numérica, isto pode ser observado na Fig. 5.18. Isso pode ter ocorrido pela grande variabilidade dos parâmetros geotécnicos aqui adotados.

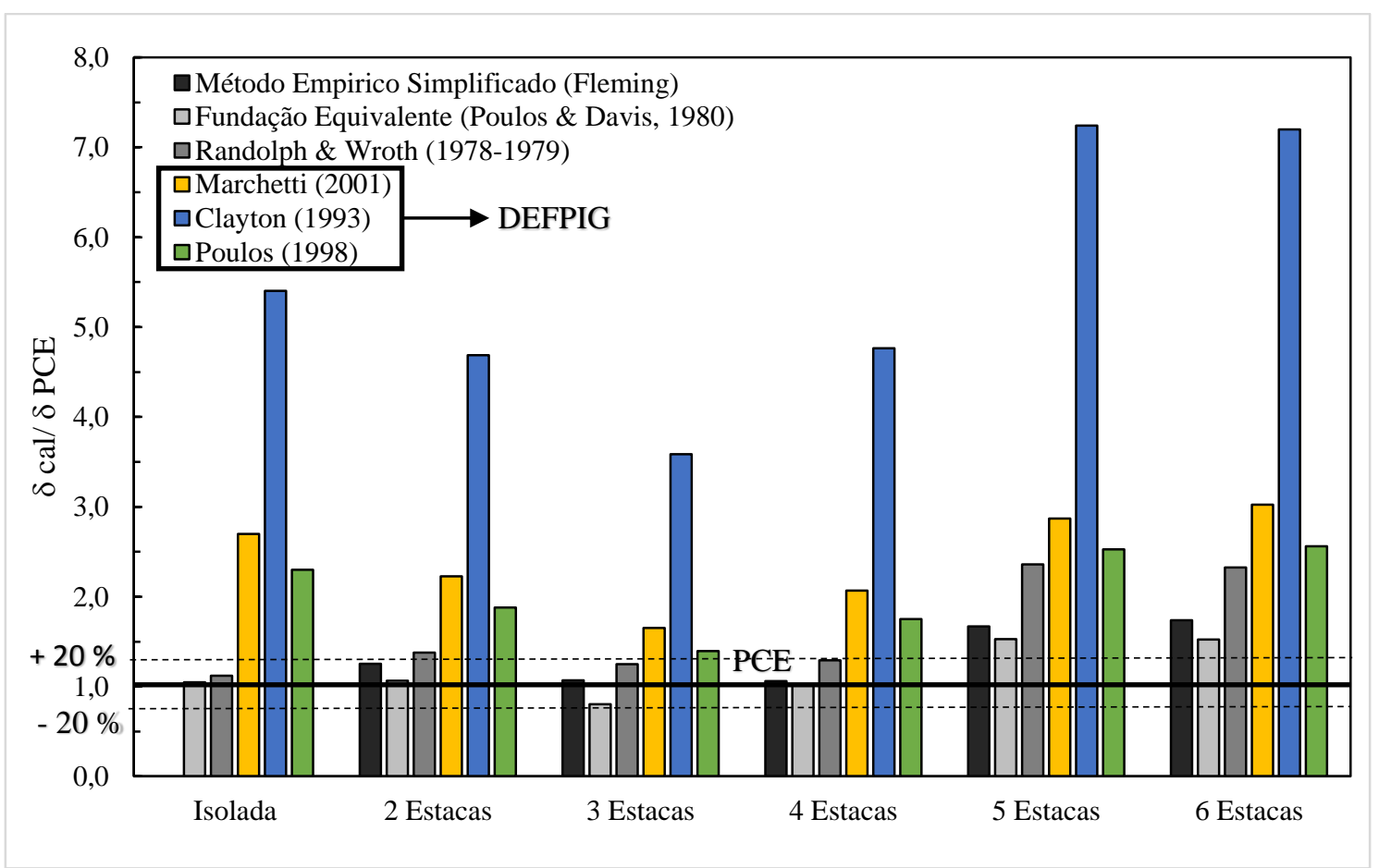

Figura 5.18 Resultado comparativo da estimativa de recalque 


\section{CONCLUSÕES E SUGESTÕES}

Este trabalho teve como finalidade avaliar o comportamento carga-recalque de estacas Alluvial Anker e sua interação quando são executadas na "Argila porosa de Brasília". A seguir serão apresentadas os principais conclusões obtidas na avaliação realizada com recomendações importantes para se levar em conta na prática da engenharia local. Para esse fim foi dado ênfase a métodos de estimativa de carga e recalque para fundações escavadas, injetada e do tipo raiz.

\subsection{CONCLUSÕES}

A partir do resultado da prova de carga estática foram estabelecidas as principais conclusões dessa dissertação.

1. A prova de carga executada na estaca Alluvial Anker AA-01 foi a melhor forma de interpretar o comportamento real do sistema solo/estaca dado que foi levada até a "ruptura" física;

2. O valor da carga limite adotada foi o valor médio dos valores fornecidos pelas metodologias de extrapolação da curva carga-recalque de Van der Veen (1953), Van der Veen Modificado por Aoki (1976) e Conceito de Rigidez de Décourt (2008) que consideram ruptura convencional;

3. A curva carga-recalque obtida na prova de carga pode ser descrita com gráficos compostos por dois segmentos retilíneos unidos por um trecho curvo (trecho de transição). O primeiro trecho (linear inicial) corresponde à mobilização da resistência por atrito lateral, com recalque inferior a $5 \mathrm{~mm}$. O segundo segmento, devido à mobilização da resistência por ponta, mostra um acréscimo dos recalque linear até grandes deslocamentos. $\mathrm{O}$ trecho de transição que une os segmentos apresenta recalques da ordem de $24 \%$ até $60 \%$ do recalque total medido e em torno de $2,5 \%$ até $6,4 \%$ em relação ao diâmetro da estaca, além disso a curva carga-recalque mostra que a estaca AA-01 apresenta comportamento de estaca escavada, com forma e resultados satisfatórios e coerentes, resolvendo a dúvida da hipótese adotada acerca do comportamento da estaca (injetada ou tipo escavada).

4. Como a estaca testada AA-01 não apresentou instrumentação eletrônica, se estimaram as contribuições de ponta e atrito lateral como respectivamente tendo valores de $8 \%$ e 92\%. Desta forma se parece que para o solo local e dependendo do tipo de uso de estacas Alluvial Anker, a parcela de ponta deve ser desprezada. Portanto deve-se desprezar a 
contribuição da parcela de ponta no cálculo da capacidade de carga axial quando as estacas Alluvial Anker sejam executadas em perfis com estas caraterísticas geotécnicas;

5. Os métodos baseados no SPT subdimensionam a parcela de atrito lateral, embora apresentam uma melhora ao usar os fatores empíricos regionais propostos por Rodrigues et al. (1998). Os métodos que apresentaram melhor aproximação para a carga limite sem a contribuição da ponta foram:

- Décourt \& Quaresma $(1978,1996)$ considerando fator empírico de estaca tipo raiz;

- Teixeira (1996) considerando fator empírico de estaca tipo raiz;

- Peixoto (2001) considerando fator empírico de estaca tipo raiz;

6. Os fatores de estaca do tipo escavada disponíveis nas diferentes metodologias forneceram valores de carga de trabalho cerca de 50\% do valor de trabalho experimental, ou seja se a fundação é projetada com estas metodologias, sem ajuste, o projeto será conservador e o fator de segurança "real" à ruptura será de 4 e não de 2 como convencionalmente preconizado por norma;

7. Os métodos baseados no SPT-T superestimam a carga limite quando se considera a parcela de ponta, porém o método de Peixoto (2001), utilizando fator empírico de estaca raiz e descontando a parcela de ponta apresenta bons resultados para estimativa de capacidade de carga oferecendo resultados cerca de $\pm 20 \%$ dos valores experimentais;

8. Os métodos baseados no DMT superestimam a capacidade de carga, mesmo quando a parcela de ponta é desprezada, fornecendo valores de atrito lateral de até 2,5 vezes o valor da carga limite obtida da prova de carga estática;

9. As metodologias analíticas (racionais) acopladas (método alpha e o método beta) forneceram resultados muito conservadores para se estimar a capacidade de carga da estaca isolada, porem na estimativa de carga dos grupos de fundação estas apresentaram valores muito mais precisos com a modificação de Poulos \& Davis (1980), embora para sua aplicação na prática seja preciso conhecer parâmetros obtidos em laboratório;

10. A eficiência de grupo para capacidade de carga experimental das diferentes configurações analisadas mostram diferenças com a variação da configuração, obtendo valores médios de 1,06, ou seja praticamente constantes para configurações lineares. Para as configurações quadradas esta eficiência variou entre 1,13 e 1,27.

11. Na análise comparativa dos resultados de recalque para a carga de trabalho na estaca isolada AA-01, pode-se observar que os métodos baseados na teoria da elasticidade (Randolph \& Wroth, 1978 e Poulos \& Davis, 1980) apresentaram resultados muito próximos ao experimentais obtidos na prova de carga estática; 
12. Os recalques estimados com as metodologias baseadas na teoria da elasticidade Randolph \& Wroth (1978, 1979 e 1994) e Poulos \& Davis (1980), apresentaram melhor aproximação com grupos de até quatro (4) estacas na faixa admissível de erro de $\pm 20 \%$. Porém com o aumento de estacas o resultado começou a se distanciar desta faixa adotada e este fato talvez seja resultado da redução da inclinação do trecho pseudo-linear da prova de carga com o aumento do tamanho do grupo de fundação, portanto com o aumento na rigidez do sistema;

13. A estimativa de recalque com o software DEFPIG apresentou resultados mais próximos dos experimentais ao se usar o módulo de elasticidade do solo (ES) com a correlação proposta por Poulos (1998), mantendo os resultados sempre a favor da segurança. Caso contrário ocorreu com a correlação proposta por Clayton (1993) que levou a valores muito conservadores, da ordem de 6 vezes o valor experimental.

14. A estaca Alluvial Anker mostra-se como uma solução prática e tecnicamente competente para ser usada na engenharia de fundações, seja como sistema de fundação ou reforço, desde que calculada com base, em parte, nos princípios estudados e recomendados na presente dissertação. Entre tanto mais estudos são necessários para validar de forma categórica as afirmativas ora apresentadas.

15. A execução da estaca Alluvial Anker não é limitada pela presença do lençol freático no terreno, pois pode ser executada abaixo do nível d'água, além disso, considerando seu pequeno diâmetro $(0,20 \mathrm{~cm})$ possui uma elevada capacidade de carga, em torno dos 400 $\mathrm{kN}$ (testada) para as condições aqui empregadas (solo, geometria, execução).

\subsection{SUGESTÕES PARA PESQUISAS FUTURAS}

- Completar a descrição geotécnica do Campo Experimental da SOLOTRAT Ltda., com ensaios do tipo pressiômetro de Ménard, e se possível com uso do DPL ou cone tipo CPT;

- Realizar mais provas de carga em estacas Alluvial Anker com o fim de se obter fatores de correlação de estaca mais confiáveis para recalque e carga limite, que representem com mais confiabilidade. Se possível, instrumentar as estacas dos futuros ensaios no sentido de se verificar se as hipóteses adotadas na presente dissertação, em relação ao comportamento das parcelas de atrito lateral e ponta, não confirmadas. 


\section{REFERÊNCIAS BIBLIOGRAFICAS}

ABNT-12131 (2006). Estacas - prova de carga estática-método de ensaio, associação brasileira de normas técnicas.

ABNT-6122 (2010). Projeto e execução de fundações, associação brasileira de normas técnicas.

Albuquerque, P. J. R. (1996). Análise do Comportamento de Estaca Pré-Moldada de pequeno diâmetro, Instrumentada em Solo Residual de Diabáso da região de Campinas. Dissertação de Mestrado. Universidade Estadual de Campinas, Campinas.

Albuquerque, P. J. R. (2001). Estacas escavadas, Hélice Contínua e Ômega: Estudo do Comportamento à Compressão em solo Residual de Diabásio, através de Provas de carga Instrumentadas em Profundidade. Tese de Doutorado. Escola Politécnica, Universidade de São Paulo, São Paulo.

Alonso, U. R. (1981). Estimativa da curva carga-recalque de estacas a partir dos resultados de sondagens à percussão. Revista Solos e Rochas, São Paulo, v.4, p. 19-32.

Alonso, U. R. (1996). Estacas Hélice Contínua com Monitoração Eletrônica - Previsão da Capacidade de Carga através do Ensaio SPT-T. Seminário de Engenharia de Fundações Especiais e Geotecnia, SEFE III, São Paulo, v.2, p 141-151.

Anjos, G.J. (2006). Estudo do Comportamento de Fundações Escavadas em Solos Tropicais. Tese de Doutorado, Universidade de Brasília, 341 p.

Aoki, N., \& Velloso, D. A. (1975). An Aproximate Method to Estimate the Bearing Capacity of Piles. Congreso Panamericano de Mecánica de Suelos y Cimentaciones PASSMFE, Buenos Aires, Argentina, p. 367-376.

Aoki, N. (1976). Considerações sobre a capacidade de carga de estacas isoladas. Curso de Extensão Universitaria em Engenharia de Fundações, Universidade Gama Filho, Rio de Janeiro, $44 \mathrm{p}$.

Aoki, N; Cintra, J. C. A. (2000). Carga Admissível e Carga Característica de Fundações por Estacas. Revista Solos e Rochas, São Paulo, v. 23, p. 137-142.

Araki, M.S. (1997). Aspectos relativos às propriedades dos solos porosos colapsíveis do distrito federal. Dissertação de Mestrado, Universidade de Brasília, 121 p.

Barbosa, M. (2009). Alluvial Anker como alternativa para fundações em argila mole. Tech. rep., Solotrat Engenharia Geotécnica Ltda., Brasília, Brazil.

Bessa, A. O. (2005). Avaliação da Resistência Lateral em Estacas Escavadas com Trado Submetidas à Tração. Dissertação de Mestrado, Universidade Federal de Viçosa, Viçosa.

Blanco, S. (1995). Aspectos de Geologia de engenharia da escavação do metrô de brasília Trecho Asa Sul. Universidade de Brasília, 95 p. 
Bowles, J.E. (1997). Foundation Analysis and Design. 1207 p. 101104

Braja, D. (2001). Principios de Ingenieria de Cimentaciones. 880 p.

Brinch Hansen, J. (1967). Hiperbolic stress strain response, cohesive soils. Journal of the Soil Mechanics Foundation Division, ASCE, 89, 241-242.

Cardoso, F. (1995). Análise Química, Mineralógica e Micromorfológica de Solos Tropicais Colapsíveis e o Estudo da Dinámica do Colapso. Dissertação de Mestrado, Universidade de Brasília, 139 p.

Cardoso, F. (2002). Propriedades e Comportamento Mecânico de Solos do Planalto Central Brasileiro. Tese de doutorado em geotecnia, Univeresidade de Brasília, Brasília, DF, Brasil.

Camapum de Carvalho (1998). Utilização do Ensaio SPT-T no dimensionamento de estacas. Congresso Brasileiro de Mecânica dos SOlos e Engenharia Geotecnica, COBRAMSEG, Brasília. CD-ROM.

Camapum de Carvalho (2013). Solos Tropicais. Notas de aulas da assinatura. Prof. José Camapum de Carvalho. Programa de Pós-graduação em Geotecnia. Faculdade de Tecnologia. Universidade de Brasilia.

Cartaxo, W. (2011). Radier Estaqueados com estaca hollow auger em solo arenoso. Tese de doutorado em geotecnia, Universidade Federal de Pernambuco, Recife, Brasil.

Chin, K. (1970). Estimation of the ultimate load of piles from test not carriad to failure. II south East Conference on Soil Engineering, 1, 81-90.

Clayton, C. (1993). The standard penetration test (SPT) - methods and use. Tech. Rep. Funder Report/CP/7, pp. 129, Construction Industry Research and Information Association (CIRIA), London, England.

Cunha (2013). Fundações. Apostila do curso de Pós-graduação em Geotecnia. Prof. Renato Pinto da Cunha. Programa de Pós-graduação em Geotecnia. Faculdade de Tecnologia. Universidade de Brasilia, $477 \mathrm{p}$.

Davisson, M. T. (1972). High Capacity Piles. Innovations in Foundation Construction, ASCE, Chicago, p. 81-112.

De Beer, E. E.; Walays, M. (1972) Franki Piles with Overexpanded Bases. La Technique des Travaux, Liege, Belgium, n. 333, p. 48.

Décourt, L., \& Quaresma, A. R. (1978). Capacidade de Carga de Estacas a partir de Valores de SPT. Congresso Brasileiro de Mecânica dos Solos e Fundações. COBRAMSEG, São Paulo. p. 215-224.

Décourt, L., \& Filho (1994). Practical Applications of the Standard Penetration Test Complemented by Torque Measurements, SPT-T. Proceedings of the 13 international conference on soil mechanics and foundations engineering. 102105 
Décourt, L. (1996). A Ruptura de Fundações Avaliada com Base no Conceito de Rigidez, Seminario de Engenharia de Fundações Especiais, SEFE III, São Paulo, p. 215-224.

Décourt, L. (2008). Fundações profundas 1. Provas de Carga em Estacas podem dizer muito mais do que têm dito, Seminario de Engenharia de Fundações Especiais, SEFE VI, São Paulo, p. 20.

Dourado, K. C. A. (2005). Utilização do pressiômetro de Ménard na identificação e previsão de recalques em um solo colapsível. Dissertaçao de Mestrado. Universidade Federal de Pernambuco. Recife. 203p.

Feld, J. (1943). Discussion on frictional pile foundation. Trans., ASCE, 108, pp. 143-144.

Fellenius, B.H. (1980). The analysis of results from routine pile load tests. Gr. Eng. London, 13(6): 19-31.

Fleming, K.; Weltman, A.; Randoloh, M. F., \& Elson, K. (2009). Pilinh Enginnering (Third., p.407). Taylor \& Francis.

González, J. de la R. (2014). Estudo Numérico do Comportamento de Estacas Carregadas Lateralmente. Universidade de Brasília, 118 p.

Guimarães, R. (2002). Análise das propriedades e comportamento de um perfil de solo laterítico aplicada ao estudo do desempenho de estacas escavas. Universidade de Brasília, 180 p.

Hachich, W., \& Falconi, F. F. (2002). Fundações: Teoria e Pratica. Brasil: Pini, 2 ed.

Hortegal, M. (2011). Avaliação do Comportamento de Estacas Hélice Contínua a Partir de Resultados de Laboratório e de Campo. Dissertação de Mestrado, Universidade de Brasilia, 173 p.

Hirany, A., \& Kulhawy, F.H. (1989). Interpretation of load test on drilled shafts part 2: Axial uplift. Foundation engineering: Current principles and practice. ASCE, v.2. p.1150-1159.

Kulhawy, F. H. (2004). On the Axial Behavior of Drilled Foundations. Geosupport: Drilled Shaft, Micropiling, Deep Mixing, Remedial Methods and Speciality Foundation Systems, Orlando. p. 34-51.

Lambe, W., \& Whitman, R. (1996). Mecánica de Suelos. Mexico: Limusa Noriega Editores, 2 th ed.

Laprovitera, H. (1988). Reavaliação do Método Semi-empírico de Previsão de Capacidade de Carga de Estacas a partir de Banco de Dados. Dissertação de Mestrado, Universidade Federal do Rio de Janeiro, Rio de Janeiro. 
Lobo, B. O. (2005). Método de Previsão de Capacidade de Carga de estacas: Aplicação dos Conceitos de Energia do Ensaio SPT. Dissertação de Mestrado, Universidade Federal do Rio Grande do Sul, Porto Alegre.

Magalhães, P.H. (2005). Avaliação dos métodos de capacidade de carga e recalque de estacas hélice contínua via provas de carga. Dissertação de Mestrado, Universidade de Brasília, $243 \mathrm{p}$.

Mandolini, A., Russo, G., \& Viggiani, C. (2003). Pile foundations: experimental investigations, analysis and design. Cell (p. 37). Napoli.

Mansur, C.L. \& Kaufman, J.M. (1956). Pile Tests, Low-Sill Structure, Old River, Louisiana. Jornal of Soil Mechanics and Foundation Division, ASCE. v. 82, pp. 1-33.

Marchetti, S., Monaco, P., Totani, G., \& Calabrese, M. (2001). The Flat Dilatometer Test (DMT) in Soil Investigations. Conference on in situ Measurement of Soil Properties., A Report by the ISSMGE Cmmitte TC 16, p. 41. 103-106.

Marchezini, S. (2013). Comparação entre Métodos Estáticos e Dinâmicos de Previsão da Capacidade de Carga em Estacas Assentes Em Solo Tropical. Dissertação de Mestrado, Universidade de Brasília, $171 \mathrm{p}$.

Mascarenha, M.M. (2003). Influência do recarregamento e da sucção na capacidade de carga de estacas escavadas em solos porosos colapsíveis. Dissertação de Mestrado, Universidade de Brasília, $141 \mathrm{p}$.

Melo, B. (2009). Análise de Provas de Carga à Compressão à Luz do Conceito de Rigidez Análise de Provas de Carga à Compressão à Luz do Conceito de Rigidez. Dissertação de Mestrado, Universidade Estadual De Campinas, 219 p.

Ménard, L. (1975). The Ménard pressuremeter, interpretation and application of pressuremeter test results to foundation design. General memorandum, Sols soils, no 26.

Mendoza, C.C. (2013). Estudo do comportamento mecânico e numérico de grupo de estacas do tipo alluvial anker em solo poroso do distrito federal. Tese de Doutorado, Universidade de Brasília, $234 \mathrm{p}$.

Meyerhof, G. G. (1956). Penetration Test and Bearing Capacity of Cohesionless Soils. Journal of the Soil Mechanics Foundation Division, ASCE, p. 1-19.

Mindlin, R. D. (1936). Force at a POint in the Interior of a Semi-infinite Solid. Journal of Applied Physics, p. 195-202.

Miguel, M.G. \& Carvalho, David, Albuquerque, P.J. (2006). Avaliação de um solo laterítico coluvionar de campinas/sp, por diferentes procedimentos de determinação de índices físicos. XVIII Congresso Argentino de Mecânica dos Solos e Engenharia Geotecnica, San Juan, 10 p. 
Mota, N. (2003). Ensaios avançados de campo na Argila Porosa não Saturada de Brasília: interpretação e Aplicação em Projetos de Fundação. Tese de Doutorado, Universidade de Brasília, 335 p.

NBR 6484. (1997). Abnt-6484 solo - sondagens de simples reconhecimento com spt - método de ensaio.

Nienov, F.A. (2006). Comportamento à compressão de estacas escavadas de pequeno diâmetro em solo sedimentar na região de santa maria. Dissertação de Mestrado, Universidade Federal de Santa Maria, 151 p.

Nogami, J.S. \& Villibor, D.F. (1995). Pavimentação de Baixo Custo em Solos Lateríticos. Villibor. São Paulo, 213 p.

Oliva, R. R. R. de (2009). Caracterização do Comportamento de Materiais a partir do Ensaio Pressiométrico. Dissertação para obtenção do Grau de Mestre em Engenharia Civil. Instituto Superior Técnico. Universidade Técnica de Lisboa. 125p.

Pando, M., Lesko, J., Fam, A., \& Rizkalla, S. (2002). Durability of Concrete Filled Tubular FRP Piles. Proceedings of the thrid International Conference on Composite Infrastructure, Art. 80.

Pfeiffer, H., Van Impe, W. F. (1991). Analyses of CFA- Pile Behaviour with DMT Results at Geel Test side, DFI International COnference on Pilling and Deep Foundations. p. 101105. 104107.

Peixoto, A.S. (2001). Estudo do Ensaio SPT-T E sua Aplicação na Prática de Engenharia de Fundações. Tese de Doutorado, Universidade Estadual de Campinas, 468 p.

Poulos \& Davis. (1980). Pile Foundation Analysis and Design. 397 p.

Poulos, H.G. \& Davis, E.H. (1980). Pile Foundation Analysis and Design. Rainbow-Bridge Book Co., 410 p.

Poulos, H. G. (1990). DEFPIG. Users' Guide. Centre Geotechnical Researches. University of Sidney, Australia.

Powell, J.J.M. (2001). Semi empirical design procedures for axial pile capacity in clays. International Conference on Soil Mechanics and Geotechnical Engineering., Istabul. CDROM.

Randolph, M. F., \& Wroth, C. P. (1979). An Analysis of the Vertical Deformation of Pile Groups. Geotechnique, 29, p. 423-439.

Randolph, M. (1994). Design Methods for Pile Groups and Piled Raft. Proceedings or the Thirteenth International Conference on Soil Mechanics and Foundations Engineering, XIII ICSMFE, 1, p. 62-82.

Ranzini, S. M. T. (1988). Revista Solos e Rochas, São Paulo, v. 11, p. 29-30. 
Ranzini, S. M. T. (1994). Revista Solos e Rochas, São Paulo, v. 17, p. 189-190.

Ranzini, S. M. T. (2000). Capacidade de Carga de Estacas a partir da Medida do Atrito Lateral no Ensaio SPT-T. Revista Engenharia. São Paulo.

Rodrigues, A.A., Camapum de Carvalho, J., Cortopassi, R.S. \& Silva, C.M. (1998). Avaliação da Adaptabilidade de Métodos de Previsão de Capacidade de Carga a Diferentes Tipos de Estcas. XI Congresso Brasileiro de Mecânica dos Solos e Engenharia Geotécnica, ABMS, Brasilia, DF, 3: 1591-1598.

Rodriguez, T. G. (2013). Caracterização Geotécnica de um Solo de Diabásio por Meio de Ensaio SPT e CPT. Dissertação de Mestrado, Universidade Estadual de Campinal, Campinas.

Sales, M. (2000). Análise do Comportamento de Sapatas Estaqueadas. Tese de Doutorado, Universidade de Brasília, 229 p.

Schulze, T. (2013). Análise da Capacidade de Carga de Estaca Escavada Instrumentada de Pequeno Diâmetro por meio de Métodos Semi- empíricos. Dissertação de Mestrado, Universidade Estadual de Campinas, 168 p.

Silva, A. \& Cintra, C.A. (1996). Capacidade de carga de grupos de estacas escavadas de pequeno diâmetro. SEFE “Seminario Eng. Fundações Especiais e Geotécnia,” (1993): 19.

Skempton, A. W. (1951). The Bearing Capacity of Clays. Building Research Congress, v. 1. p. $180-189.105108$

Teixeira, A. H. (1996). Projeto e Execução de Fundações. Seminario de Engenharia de Fundações Especiais e Geotecnia, SEFE III, São Paulo, p. 33-50.

Terzaghi, K. (1943). Theoretical Soil Mechanics.. 1ed. New York, John Willey \& Sons.

Terzaghi, K., \& Peck, R. B. (1948). Soil Mechanics in Engineering Practice. New York: John Wiley, 1 st ed.

Tomlinson, M. \& Woodward, J. (2008). Pile design and construction practice. 551 p.

Valencia, Y. \& Camapum, J. (2011). Other uses of static load test in the geotechnical design of foundations : $182-190$.

Van Der Veen (1953). The Bearing Capacity of Pile. Third International Conference on Soil Mechanics and Foundations Engeneering, p. 84-90.

Vargas, M. (1985). The Concept of Tropical Soils. International Conference on Geomechanics in Tropical Lateritic and Saprolitic Soils. p. 101-134.

Velloso, D. A., \& Lopes, F. D. R. (2010). Fundações Profundas, Vol 2. Brasil: Oficina de Textos, 1 Ed. 
Vesic, A. S. (1977). Design of Pile Foundations. Washington: Transportation Research Board, National Research Council, synthesis of highway practice, 42 ed.

Vianna, A., \& Cintra, J. C. A. (2000). Aplicabilidade do Método de Van Der Veen para Extrapolação da Curva carga Recalque. Seminario de Engenharia de Fundações Especiais e Geotecnia, SEFE IV, p. 85-92.

Vianna, A. (2000). Análise de Provas de Carga Estática em Estacas Pré-Moldadas Cravadas na Cidade de Curitiba e Região Metropolitana. Dissertação de Mestrado, Universidade de São Paulo, 112 p. 
ANEXOS 
I. DADOS DE ENSAIOS SPT, SPT-T E DMT

Tabela I.1 Sondagens SPT e SPT-T N 1 (Mendoza, 2013)

\begin{tabular}{|c|c|c|c|}
\hline \multicolumn{4}{|c|}{ SONDAGEM \#1 (SPT E SPT-T) } \\
\hline $\begin{array}{c}\text { Prof. } \\
(\mathbf{m})\end{array}$ & $\begin{array}{c}\text { SPT } \\
(\text { Golpes })\end{array}$ & $\begin{array}{c}\text { Torque Pico } \\
(\mathbf{k g f})\end{array}$ & $\begin{array}{c}\text { Torque Residual } \\
(\mathbf{k g f})\end{array}$ \\
\hline 0 & 0 & 0 & 0 \\
\hline 1 & 3 & 8 & 6 \\
\hline 2 & 2 & 10 & 10 \\
\hline 3 & 2 & 10 & 8 \\
\hline 4 & 4 & 12 & 7 \\
\hline 5 & 7 & 13 & 40 \\
\hline 6 & 20 & 40 & 40 \\
\hline 7 & 30 & 43 & 30 \\
\hline 8 & 200 & 30 & 10 \\
\hline 9 & 17 & 13 & 11 \\
\hline 10 & 22 & 20 & 18 \\
\hline 11 & 16 & 29 & 13 \\
\hline 12 & 20 & 31 & 20 \\
\hline 13 & 59 & 34 & 100 \\
\hline 14 & 26 & 24 & \\
\hline 15 & 143 & 100 & \\
\hline
\end{tabular}

Tabela I.2 Sondagens SPT e SPT-T N² (Mendoza, 2013)

\begin{tabular}{|c|c|c|c|}
\hline \multicolumn{4}{|c|}{ SONDAGEM \#2 (SPT E SPT-T) } \\
\hline $\begin{array}{c}\text { Prof. } \\
(\mathbf{m})\end{array}$ & $\begin{array}{c}\text { SPT } \\
\text { (Golpes) }\end{array}$ & $\begin{array}{c}\text { Torque Pico } \\
\text { (kgf) }\end{array}$ & $\begin{array}{c}\text { Torque Residual } \\
(\mathbf{k g f})\end{array}$ \\
\hline 0 & 0 & 0 & 0 \\
\hline 1 & 2 & 6 & 2 \\
\hline 2 & 2 & 8 & 2 \\
\hline 3 & 2 & 8 & 2 \\
\hline 4 & 4 & 9 & 3 \\
\hline 5 & 7 & 13 & 7 \\
\hline 6 & 13 & 29 & 13 \\
\hline 7 & 31 & 33 & 17 \\
\hline 8 & 42 & 39 & 22 \\
\hline 9 & 135 & 40 & 12 \\
\hline 10 & 34 & 20 & 8 \\
\hline 11 & 17 & 12 & 35 \\
\hline 12 & 48 & 42 & 40 \\
\hline 13 & 45 & 47 & 100 \\
\hline 14 & 57 & 100 & \\
\hline 15 & 200 & 100 & \\
\hline
\end{tabular}


Tabela I.3 Sondagens SPT N ${ }^{\circ} 3, N^{\circ} 4$ e $N^{\circ} 5$ (Mendoza, 2013)

\begin{tabular}{|c|c|c|c|c|c|}
\hline \multicolumn{2}{|c|}{ SONDAGEM \#3 } & \multicolumn{2}{c|}{ SONDAGEM \#4 } & \multicolumn{2}{c|}{ SONDAGEM \#5 } \\
\hline $\begin{array}{c}\text { Prof. } \\
(\mathbf{m})\end{array}$ & $\begin{array}{c}\text { SPT } \\
(\text { Golpes })\end{array}$ & $\begin{array}{c}\text { Prof. } \\
(\mathbf{m})\end{array}$ & $\begin{array}{c}\text { SPT } \\
(\text { Golpes })\end{array}$ & $\begin{array}{c}\text { Prof. } \\
(\mathbf{m})\end{array}$ & $\begin{array}{c}\text { SPT } \\
(\text { Golpes })\end{array}$ \\
\hline 0 & 0 & 0 & 0 & 0 & 0 \\
\hline 1 & 2 & 1 & 2 & 1 & 2 \\
\hline 2 & 2 & 2 & 2 & 2 & 3 \\
\hline 3 & 2 & 3 & 4 & 3 & 4 \\
\hline 4 & 7 & 4 & 5 & 4 & 5 \\
\hline 5 & 11 & 5 & 9 & 5 & 11 \\
\hline 6 & 21 & 6 & 28 & 6 & 19 \\
\hline 7 & 32 & 7 & 26 & 7 & 28 \\
\hline 8 & 44 & 8 & 43 & 8 & 32 \\
\hline 9 & 27 & 9 & 58 & 9 & 63 \\
\hline 10 & 22 & 10 & 19 & 10 & 23 \\
\hline 11 & 18 & 11 & 31 & 11 & 36 \\
\hline 12 & 35 & 12 & 30 & 12 & 53 \\
\hline 13,28 & 100 & 13,3 & 100 & 13,4 & 100 \\
\hline
\end{tabular}

Tabela I.4 Dados do ensaio DMT (Mendoza, 2013)

\begin{tabular}{|c|c|c|c|c|c|c|c|c|c|c|c|}
\hline \multirow{3}{*}{$\begin{array}{c}\text { Prof } \\
\cdot \\
(\mathrm{m})\end{array}$} & \multicolumn{2}{|c|}{ Leituras } & \multicolumn{2}{|c|}{ Leituras Corrigidas } & \multicolumn{3}{|c|}{ Parâmetros Adotados } & \multicolumn{4}{|c|}{ Índices do DMT } \\
\hline & $\mathbf{A}$ & B & p0 & p1 & $\gamma$ & \multirow{2}{*}{ uo } & $\sigma^{\prime} \mathbf{v 0}$ & Ed & Ed & \multirow[t]{2}{*}{ Id } & \multirow[t]{2}{*}{ Kd } \\
\hline & (bars) & (bars) & $(\mathrm{kN} / \mathrm{m} 2)$ & $(\mathrm{kN} / \mathbf{m} 2)$ & $(\mathrm{kN} / \mathrm{m} 3)$ & & $(\mathrm{kN} / \mathrm{m} 2)$ & $(\mathrm{kN} / \mathrm{m} 2)$ & (MPa) & & \\
\hline 0,0 & -- & -- & -- & -- & -- & -- & -- & -- & -- & -- & -- \\
\hline 0,2 & -- & -- & -- & -- & -- & -- & -- & -- & -- & -- & -- \\
\hline 0,4 & -- & -- & -- & -- & -- & -- & -- & -- & -- & -- & -- \\
\hline 0,6 & 3,500 & 9,000 & 340,50 & 855,00 & 15,41 & 0,00 & 9,25 & 17863,4 & 17,9 & 1,511 & 36,827 \\
\hline 0,8 & 3,000 & 8,500 & 290,50 & 805,00 & 15,41 & 0,00 & 12,33 & 17863,4 & 17,9 & 1,771 & 23,564 \\
\hline 2,20 & 0,700 & 1,400 & 84,50 & 95,00 & 15,41 & 0,00 & 33,90 & 364,6 & 0,4 & 0,124 & 2,492 \\
\hline 2,70 & 1,200 & 4,100 & 123,50 & 365,00 & 15,41 & 0,00 & 41,61 & 8384,9 & 8,4 & 1,955 & 2,968 \\
\hline 2,80 & 0,800 & 3,600 & 84,00 & 315,00 & 15,41 & 0,00 & 43,15 & 8020,3 & 8,0 & 2,750 & 1,947 \\
\hline 3,00 & 1,200 & 3,800 & 125,00 & 335,00 & 15,41 & 0,00 & 46,23 & 7291,2 & 7,3 & 1,680 & 2,704 \\
\hline 3,20 & 1,500 & 3,800 & 156,50 & 335,00 & 15,41 & 0,00 & 49,31 & 6197,5 & 6,2 & 1,141 & 3,174 \\
\hline 3,60 & 1,400 & 7,100 & 129,50 & 665,00 & 15,41 & 0,00 & 55,48 & 18592,6 & 18,6 & 4,135 & 2,334 \\
\hline 3,80 & 1,600 & 4,100 & 165,50 & 365,00 & 15,41 & 0,00 & 58,56 & 6926,6 & 6,9 & 1,205 & 2,826 \\
\hline 4,00 & 1,400 & 6,400 & 133,00 & 595,00 & 16,32 & 0,00 & 65,28 & 16040,6 & 16,0 & 3,474 & 2,037 \\
\hline 4,20 & 1,800 & 8,100 & 166,50 & 765,00 & 16,32 & 0,00 & 68,54 & 20779,9 & 20,8 & 3,595 & 2,429 \\
\hline 4,40 & 1,800 & 11,000 & 152,00 & 1055,00 & 16,32 & 0,00 & 71,81 & 31352,2 & 31,4 & 5,941 & 2,117 \\
\hline 4,60 & 3,800 & 12,000 & 357,00 & 1155,00 & 16,32 & 1,50 & 73,57 & 27706,6 & 27,7 & 2,245 & 4,832 \\
\hline 4,80 & 3,800 & 12,000 & 357,00 & 1155,00 & 16,32 & 3,50 & 74,84 & 27706,6 & 27,7 & 2,257 & 4,724 \\
\hline 5,00 & 3,900 & 15,000 & 352,50 & 1455,00 & 16,32 & 5,50 & 76,10 & 38278,8 & 38,3 & 3,177 & 4,560 \\
\hline 5,20 & 3,400 & 12,000 & 315,00 & 1155,00 & 16,32 & 7,50 & 77,36 & 29164,8 & 29,2 & 2,732 & 3,975 \\
\hline 5,40 & 1,800 & 11,000 & 152,00 & 1055,00 & 16,32 & 9,50 & 78,63 & 31352,2 & 31,4 & 6,337 & 1,812 \\
\hline
\end{tabular}




\begin{tabular}{|c|c|c|c|c|c|c|c|c|c|c|c|}
5,60 & 7,000 & 16,000 & 673,00 & 1555,00 & 16,32 & 11,50 & 79,89 & 30623,0 & 30,6 & 1,333 & 8,280 \\
\hline 5,80 & 8,200 & 22,000 & 769,00 & 2155,00 & 16,32 & 13,50 & 81,16 & 48121,9 & 48,1 & 1,835 & 9,309 \\
\hline 6,00 & 11,000 & 23,500 & 1055,50 & 2305,00 & 16,32 & 15,50 & 82,42 & 43382,6 & 43,4 & 1,201 & 12,618 \\
\hline 6,20 & 9,500 & 23,500 & 898,00 & 2305,00 & 16,32 & 17,50 & 83,68 & 48851,0 & 48,9 & 1,598 & 10,522 \\
\hline 6,40 & 9,500 & 23,000 & 900,50 & 2255,00 & 17,92 & 19,50 & 95,19 & 47028,2 & 47,0 & 1,537 & 9,255 \\
\hline 6,60 & 13,000 & 28,500 & 1240,50 & 2805,00 & 17,92 & 21,50 & 96,77 & 54319,4 & 54,3 & 1,283 & 12,597 \\
\hline 6,80 & 14,500 & 31,000 & 1385,50 & 3055,00 & 17,92 & 23,50 & 98,36 & 57965,0 & 58,0 & 1,226 & 13,848 \\
\hline 7,00 & 9,500 & 25,500 & 888,00 & 2505,00 & 17,92 & 25,50 & 99,94 & 56142,2 & 56,1 & 1,875 & 8,630 \\
\hline 7,20 & 13,000 & 29,500 & 1235,50 & 2905,00 & 17,92 & 27,50 & 101,52 & 57965,0 & 58,0 & 1,382 & 11,899 \\
\hline 7,40 & 14,500 & 32,000 & 1380,50 & 3155,00 & 18,92 & 29,50 & 110,51 & 61610,6 & 61,6 & 1,313 & 12,225 \\
\hline 7,60 & 14,500 & 35,000 & 1365,50 & 3455,00 & 19,92 & 31,50 & 119,89 & 72547,4 & 72,5 & 1,566 & 11,127 \\
\hline 7,80 & 14,500 & 35,000 & 1365,50 & 3455,00 & 20,92 & 33,50 & 129,68 & 72547,4 & 72,5 & 1,569 & 10,272 \\
\hline
\end{tabular}




\section{PARÂMETROS PARA METODOGIAS SEMI-EMPÍRICAS DE \\ CAPACIDADE DE CARGA}

\section{PARÂMETROS PARA MÉTODOLOGIAS SEMI-EMPÍRICAS BASEADAS NO ENSAIO SPT PARA ESTACA TIPO ESCAVADA}

Tabela II.1 Parâmetros Aoki \&Velloso Modificado Laprovitera (1988)

\begin{tabular}{|c|c|c|c|c|c|}
\hline Prof. (m) & Solo & F1 & F2 & $\boldsymbol{\alpha}(\boldsymbol{\%})$ & K (kPa) \\
\hline 1 a 5 & Argila Arenosa & 4,50 & 4,50 & 4,0 & 480 \\
\hline 5 a 7 & Silte Arenoargiloso & 4,50 & 4,50 & 3,0 & 380 \\
\hline 8 a 9 & Silte Arenoso & 4,50 & 4,50 & 3,0 & 480 \\
\hline 9 a 14 & Argila Siltosa & 4,50 & 4,50 & 5,5 & 250 \\
\hline
\end{tabular}

Tabela II.2 Parâmetros Aoki \& Velloso Modificado Alonso (1981)

\begin{tabular}{|c|c|c|c|c|c|}
\hline Prof. (m) & Solo & F1 & $\mathbf{F 2}$ & $\boldsymbol{\alpha}(\boldsymbol{\%})$ & K (kPa) \\
\hline 1 a 5 & Argila Arenosa & 3,00 & 6,00 & 2,9 & 350 \\
\hline 5 a 7 & Silte Arenoargiloso & 3,00 & 6,00 & 3,0 & 450 \\
\hline 8 a 9 & Silte Arenoso & 3,00 & 6,00 & 1,3 & 550 \\
\hline 9 a 14 & Argila Siltosa & 3,00 & 6,00 & 2,3 & 330 \\
\hline
\end{tabular}

Tabela II.3 Parâmetros Aoki \& Velloso (1975) com coeficientes empíricos de estaca escavada de Rodrigues (1998)

\begin{tabular}{|c|c|c|c|c|c|}
\hline Prof. $(\mathbf{m})$ & Solo & F1 & $\mathbf{F 2}$ & $\boldsymbol{\alpha}$ (\%) & K (kPa) \\
\hline 1 a 5 & Argila Arenosa & 1,70 & 3,35 & 2,4 & 350 \\
\hline 5 a 7 & Silte Areno argiloso & 1,70 & 3,35 & 2,8 & 450 \\
\hline 8 a 9 & Silte Arenoso & 1,70 & 3,35 & 2,2 & 550 \\
\hline 9 a 14 & Argila Siltosa & 1,70 & 3,35 & 3,0 & 330 \\
\hline
\end{tabular}

Tabela II.4 Parâmetros Décourt \& Quaresma (1978) com coeficientes empíricos de estaca escavada de Rodrigues (1998)

\begin{tabular}{|c|c|c|c|c|}
\hline Prof. (m) & Solo & $\boldsymbol{\alpha}$ & $\boldsymbol{\beta}$ & $\mathbf{C ~ ( k P a )}$ \\
\hline 1 a 5 & Argila Arenosa & 0,90 & 0,85 & 120 \\
\hline 5 a 7 & Silte Arenoargiloso & 0,90 & 0,85 & 250 \\
\hline 8 a 9 & Silte Arenoso & 0,90 & 0,85 & 250 \\
\hline 9 a 14 & Argila Siltosa & 0,90 & 0,85 & 200 \\
\hline
\end{tabular}

\section{PARÂMETROS PARA MÉTODOLOGIAS SEMI-EMPÍRICAS BASEADAS NO ENSAIO SPT PARA ESTACA TIPO RAÍZ}

Tabela II.5 Parâmetros Aoki \& Velloso (1975) com fator empírico de estaca raíz

\begin{tabular}{|c|c|c|c|c|c|}
\hline Prof. $(\mathbf{m})$ & Solo & F1 & $\mathbf{F 2}$ & $\boldsymbol{\alpha} \mathbf{( \% )}$ & $\mathbf{K}(\mathbf{k P a})$ \\
\hline 1 a 5 & Argila Arenosa & 2,00 & 4,00 & 2,4 & 350 \\
\hline 5 a 7 & Silte Areno argiloso & 2,00 & 4,00 & 2,8 & 450 \\
\hline 8 a 9 & Silte Arenoso & 2,00 & 4,00 & 2,2 & 550 \\
\hline 9 a 14 & Argila Siltosa & 2,00 & 4,00 & 3,0 & 330 \\
\hline
\end{tabular}


Tabela II.6 Parâmetros Aoki \& Velloso (1975) com fator de estaca Raiz e coeficientes para o solo de Alonso (1981)

\begin{tabular}{|c|c|c|c|c|c|}
\hline Prof. (m) & Solo & F1 & F2 & $\boldsymbol{\alpha} \mathbf{( \% )}$ & K (kPa) \\
\hline 1 a 5 & Argila Arenosa & 2,00 & 4,00 & 2,9 & 350 \\
\hline 5 a 7 & Silte Areno argiloso & 2,00 & 4,00 & 3,0 & 450 \\
\hline 8 a 9 & Silte Arenoso & 2,00 & 4,00 & 1,3 & 550 \\
\hline 9 a 14 & Argila Siltosa & 2,00 & 4,00 & 2,3 & 330 \\
\hline
\end{tabular}

Tabela II.7 Parâmetros Décourt \& Quaresma (1978) com fator empírico de estaca raiz

\begin{tabular}{|c|c|c|c|c|}
\hline Prof. $(\mathbf{m})$ & Solo & $\boldsymbol{\alpha}$ & $\boldsymbol{\beta}$ & $\mathbf{C}(\mathbf{k P a})$ \\
\hline 1 a 5 & Argila Arenosa & 0,6 & 1,50 & 120 \\
\hline 5 a 7 & Silte Arenoargiloso & 0,6 & 1,50 & 250 \\
\hline 8 a 9 & Silte Arenoso & 0,6 & 1,50 & 250 \\
\hline 9 a 14 & Argila Siltosa & 0,6 & 1,50 & 200 \\
\hline
\end{tabular}

Tabela II.8 Parâmetros Teixeira (1996) com fator empírico de estaca raiz

\begin{tabular}{|c|c|c|c|}
\hline Prof. $(\mathbf{m})$ & Solo & $\boldsymbol{\beta}$ tex & $\boldsymbol{\alpha}$ tex \\
\hline 1 a 5 & Argila Arenosa & 6 & 140 \\
\hline 5 a 7 & Silte Arenoso & 6 & 160 \\
\hline 8 a 9 & Silte Arenoso & 6 & 160 \\
\hline 9 a 14 & Argila Siltosa & 6 & 100 \\
\hline
\end{tabular}

PARÂMETROS PARA MÉTODOLOGIAS SEMI-EMPÍRICAS BASEADAS NO ENSAIO SPT-T PARA ESTACA TIPO RAÍZ

Tabela II.9 Parâmetros para Décourt (1998) para estaca raiz

\begin{tabular}{|c|c|c|c|c|}
\hline Prof. $(\mathbf{m})$ & Solo & $\boldsymbol{\alpha}$ & $\boldsymbol{\beta}$ & $\mathbf{C}(\mathbf{k P a})$ \\
\hline 1 a 5 & Argila Arenosa & 0,6 & 1,50 & 120 \\
\hline 5 a 7 & Silte Arenoargiloso & 0,6 & 1,50 & 250 \\
\hline 8 a 9 & Silte Arenoso & 0,6 & 1,50 & 250 \\
\hline 9 a 14 & Argila Siltosa & 0,6 & 1,50 & 200 \\
\hline
\end{tabular}

Tabela II.10 Parâmetros Alonso (1996) para estaca raiz

\begin{tabular}{|c|c|c|}
\hline Tipo de Estaca & $\mathbf{r} \boldsymbol{\lambda}$ & $\mathbf{h}_{\text {crav amostrador }(\mathbf{c m})}$ \\
\hline raíz & 1,15 & 30 \\
\hline
\end{tabular}

Tabela II.11 Parâmetros Peixoto (2001) para estaca raiz

\begin{tabular}{|c|c|c|c|}
\hline \multirow{2}{*}{$\begin{array}{l}\text { Tipo de } \\
\text { estaca }\end{array}$} & \multirow{2}{*}{$s \lambda$} & \multicolumn{2}{|c|}{$\mathbf{F} \lambda$} \\
\hline & & Tmáx/N<1 & Tmáx/N>1 \\
\hline raíz & 1,5 & 1,0 & 1,0 \\
\hline
\end{tabular}


PARÂMETROS PARA MÉTODOLOGIAS SEMI-EMPÍRICAS BASEADAS NO ENSAIO SPT-T PARA ESTACA TIPO ESCAVADA

Tabela II.12 Parâmetros Camapum (1998) para estaca escavada

\begin{tabular}{|c|c|}
\hline Tipo de Estaca & $\boldsymbol{\alpha}_{\text {camapum }}$ \\
\hline $\begin{array}{c}\text { Escavada para Aoki } \\
\& \text { Velloso }\end{array}$ & 1,30 \\
\hline $\begin{array}{c}\text { Escavada para } \\
\text { Décourt \& Quaresma }\end{array}$ & 1,35 \\
\hline
\end{tabular}

\section{PARÂMETROS PARA MÉTODOLOGIAS SEMI-EMPÍRICAS BASEADAS NO ENSAIO SPT-T PARA ESTACA INJETADA}

Tabela II.13Parâmetros Peixoto (2001) para estaca injetada

\begin{tabular}{|c|c|c|c|}
\hline \multirow{2}{*}{$\begin{array}{c}\text { Tipo de } \\
\text { estaca }\end{array}$} & \multirow{2}{*}{$\boldsymbol{\lambda}$} & \multicolumn{2}{|c|}{$\mathbf{F} \boldsymbol{}$} \\
\cline { 3 - 4 } & Tmáx/ $\mathbf{N}<\mathbf{1}$ & Tmáx/N $>\mathbf{1}$ \\
\hline $\begin{array}{c}\text { Injetada de } \\
\text { pequeño } \\
\text { diâmetro }\end{array}$ & 2,0 & 1,0 & 1,0 \\
\hline
\end{tabular}

